\title{
MICROBIAL CYCLING OF MARINE HIGH MOLECULAR WEIGHT DISSOLVED ORGANIC MATTER
}

By

\section{Oscar Abraham Sosa}

B.S., University of Texas at Brownsville and Texas Southmost College, 2010

Submitted in partial fulfillment of the requirements for the degree of

Doctor of Philosophy

at the

\section{MASSACHUSETTS INSTITUTE OF TECHNOLOGY \\ and the \\ WOODS HOLE OCEANOGRAPHIC INSTITUTION}

June 2016

(C) 2016 Oscar A. Sosa

All rights reserved.

The author hereby grants to MIT and WHOI permission to reproduce and to distribute publicly paper and electronic copies of this thesis document in whole or in part in any medium now known or hereafter created.

Signature of Author

Joint Program in Oceanography/Applied Ocean Sciences and Engineering Massachusetts Institute of Technology and Woods Hole Oceanographic Institution February 11, 2016

Certified by

Dr. Edward F. DeLong Thesis Supervisor

Accepted by

Dr. Ann M. Tarrant Chair, Joint Committee for Biological Oceanography

Woods Hole Oceanographic Institution

Dr. Heidi Nepf Donald and Martha Harleman Professor of Civil and Environmental Engineering Chair, Graudate Program Committee 


\title{
MICROBIAL CYCLING OF MARINE HIGH MOLECULAR WEIGHT DISSOLVED ORGANIC MATTER
}

\author{
By Oscar Abraham Sosa \\ Submitted to the MIT-WHOI Joint Program in Oceanography / Applied Ocean Science and Engineering \\ on February 11, 2016 in partial fulfillment of the requirements \\ for the degree of Doctor of Philosophy in Biological Oceanography
}

\begin{abstract}
Microorganisms play a central role mediating biogeochemical cycles in the ocean. Marine dissolved organic matter (DOM) - a reservoir of organic solutes and colloids derived from plankton is a major source of carbon, nutrients, and energy to microbial communities. The biological transformation and remineralization of DOM sustains marine productivity by linking the microbial food web to higher trophic levels (the microbial loop) and exerts important controls over the cycles of carbon and bioessential elements, such as nitrogen and phosphorus, in the sea. Yet insight into the underlying metabolism and reactions driving the degradation of DOM is limited partly because its exact molecular composition is difficult to constrain and appropriate microbial model systems known to decompose marine DOM are lacking. This thesis identifies marine microorganisms that can serve as model systems to study the metabolic pathways and biochemical reactions that control an important ecosystem function, DOM turnover. To accomplish this goal, bacterial isolates were obtained by enriching seawater in dilution-to-extinction culturing experiments with a natural source of DOM, specifically, the high molecular weight (HMW) fraction ( $>1 \mathrm{kDa}$ nominal molecular weight) obtained by ultrafiltration. Because it is relatively easy to concentrate and it is fairly uniform in its chemical composition across the global ocean and other aquatic environments, HMW DOM has the potential to serve as a model growth substrate to study the biological breakdown of DOM. The phylogeny, genomes, and growth characteristics of the organisms identified through this work indicate that HMW DOM contains bioavailable substrates that may support widespread microbial populations in coastal and open-ocean environments. The availability of ecologically relevant isolates in culture can now serve to test hypothesis emerging from cultivation-independent studies pertaining the potential role of microbial groups in the decomposition of organic matter in the sea. Detailed studies of the biochemical changes exerted on DOM by selected bacterial strains will provide new insight into the processes driving the aerobic microbial food chain in the upper ocean.
\end{abstract}

Thesis Supervisor:

Dr. Edward F. DeLong, Professor

Department of Civil and Environmental Engineering and Biological Engineering, MIT 


\section{Acknowledgments}

I owe my deepest gratitude to those who mentored me in the lab. My advisers Ed DeLong and Dan Repeta really changed my life and career trajectory in a way I never imagined bringing me on as a JP student, giving me the opportunity to take part in research at sea and an important collaborative project as part of my dissertation. Thank you to my thesis committee members Martin Polz and Tracy Mincer who always provided constructive discussion and advice that helped me progress. Thank you to my friend and collegue Jamie Becker, my reference in the JP, who convinced my advisers Ed and Dan I should help him out with his research in Hawaii as he was finishing up his thesis, an experience that would be invaluable down the road as a continued my work there when our lab moved to C-MORE at the University of Hawaii. A big mahalo also to Scott Gifford; I was very fortunate to work with Scott, at the time a postdoc in the DeLong lab, a very skilled and thoughtful scientist with whom I learned and collaborated extensively. I also want to thank Asuncion "Chon" Martinez for offering a great deal of advice (almost on a daily basis) on science but also on the realm of academia and research. Having the guidance of these mentors was really important for my preparation and success in graduate school. Thanks to all. A special thanks to my lab mates at MIT and in Hawaii, Tsultrim Palden, Anna Romano, John Eppley, Mike Valliere, Jess Bryant, Daniel Mende, Frank Aylward, Torsten Nielsen and many others who were always willing to help me in lab simply by listening to my ideas and suggesting solutions to my day to day work.

There are many other people who I met over the years, like WHOI professors, administrators, and graduate students from the JP, EAPS, and CEE, that made my experience and academic formation invaluable. Special thanks to my JP professors Sam Laney and Lauren Mullineaux who introduced me to BioOce, and my JP peers Rene Boiteau, Jesse McNichol, Winn Johnson, Alexis Fischer, Jordon Hemingway, Emily Estes, Emily Brownlee, Esther Shiu, Harriet Alexander, Katie Pitz, Nick McFarlane, Jannette Wheeler, and many, many others whose friendship was as important to my experience in the JP as the help of my mentors. I owe a big mahalo also to the C-MORE community, PIs, students, postdocs, and staff, for hosting me when my work moved over to Hawaii and showing me an enourmous deal of support.

In Hawaii I found many new friendships but little did I know there awaited me the greatest discovery of all, my partner Maia. Meeting her and her family has been a wave of support and motivation to finish this work with much gratification. I dedicate this work to my family, especially to my parents Oscar and Mine, for whom I feel an enormous debt of gratitude for their relentless support towards my formation and education, and my brother and sister, Alex and Maria Jose, for their warmth every time I vistited home. They've truly been an inspiration

and never cease to support with much enthusiasm my journey studying the natural world and the sea. 
Financial support for this work was provided by the National Science Foundation Center for Microbial Oceanography: Research and Education (award \#EF0424599) and the Gordon and Betty Moore Foundation (grant \#492.01, \#3777, and \#3298). 
WHEN YOU LOOK INTO THE ABYSS, THE ABYSS ALSO LOOKS INTO YOU.

Friedrich Nietzsche 
NVLLIAS IN VERBA

“SEE FOR YOURSELF” (OR QUESTION AUTHORITY)

Royal Society of London 


\section{TABLE OF CONTENTS}

Abstract.......................................................................

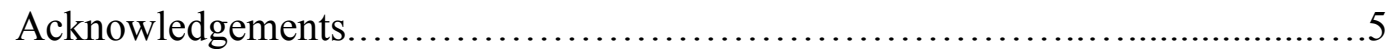

Financial support......................................................6

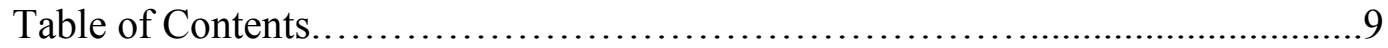

List of Tables......................................................... 12

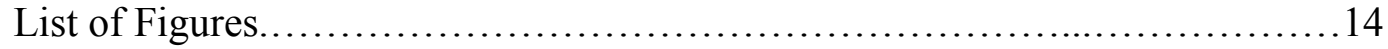

Chapter 1. Introduction.................................................17

The biogeochemical nature of DOM............................ 18

The role of bacterioplankton in the cycling of DOM in the sea..........22

Microbial model systems relevant to semi-labile DOM cycling..........27

Thesis goal and working hypotheses..............................29



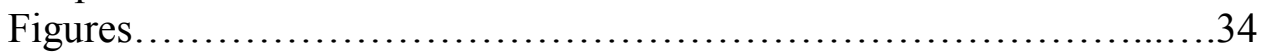

References........................................................

Chapter 2. High-molecular-weight dissolved organic matter enrichment selects for methylotrophs in dilution-to-extinction cultures..............47

Abstract.........................................................48

Introduction....................................................... 49

Materials and methods............................................52

Concentration of HMW DOM from seawater...................52

Molecular characterization of HMW DOM....................52

DOC measurements......................................53

Preparation of seawater media...............................53

Extinction culturing with HMW DOM additions................54

Detection of culture growth.................................54

HMW-DOM dose response screen of the culture collection.......55

SSU rRNA sequencing...................................55

Whole genome sequencing..............................56

Bioinformatic and phylogenetic analysis.....................57

Results and discussion.............................................58

Molecular characterization of HMW DOM.....................58

Experimental overview...................................59

Growth screen...........................................60

HMW DOM dose response..............................60

Identification and purity screen..........................661

Isolate phylogeny........................................6 63

Growth responses to differing media and $\mathrm{C}$ substrates...........63

Conclusion......................................................65

Acknowledgements............................................ 73

Tables........................................................ 74

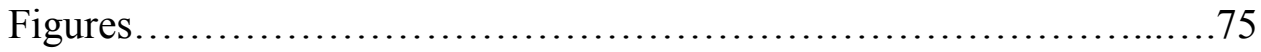

References................................................... 80 
Chapter 3. Assessment of the degradation capabilities of open-ocean bacterial isolates enriched with marine high-molecular-weight dissolved organic

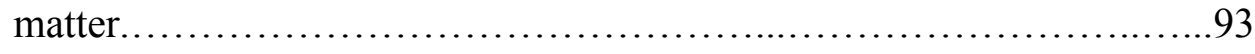

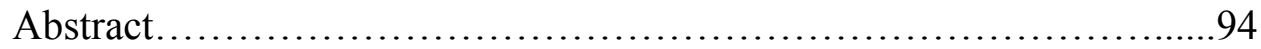

Introduction.................................................... 95

Materials and methods............................................. 98

Collection of HMW DOM and isolation of neutral

polysaccharides...........................................98

Ultrafiltration.....................................98

Isolation of HMW DOM neutral polysaccharides.........98

Overview of dilution-to-extinction experiments at Station

ALOHA................................................100

Experiment I.....................................101

Experiment II..................................102

Identification of cultures by whole genome shotgun

sequencing........................................... 103

DNA purification and genome sequencing..............103

Phylogenetic identification of cultures.................103

Assessment of the effect of HMW DOM treatments on the phylogeny of isolates recovered..............................104

DOM-dose response tests............................... 105

Carbon substrate utilization and growth analysis..............106

Functional genomics and metabolic analysis...................107

Genome draft assemblies and functional annotation......107

Functional and metabolic analysis of DOM degradation

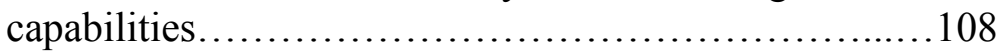

Results and discussion........................................109

Effect of HMW DOM additions on the recovery and cell

yields of dilution-to-extinction cultures...................... 110

Experiment I...................................... 110

Experiment II.......................................112

Phylogenetic placement of cultures and patterns of bacterial groups enriched in HMW DOM treatments..............113

DOM dose-response of selected Hawaii isolates................114

Experiment I isolates.................................114

Experiment II isolates...............................115

Carbon substrate utilization profiles of representative Hawaii

isolates................................................... 116

Genome draft assemblies..................................119

Genome functional and metabolic analysis...................119

Enrichment of KEGG pathways......................120

Carbohydrate degradation...........................123

Phosphonate degradation pathway.......................126

Conclusion. 
Acknowledgements........................................... 135



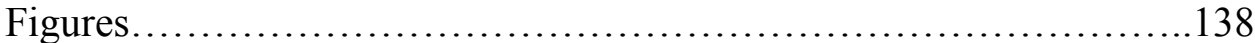

References.........................................................

Chapter 4. Production of hydrocarbon gases during bacterial degradation of covalently-bound phosphonates associated with marine highmolecular-weight dissolved organic matter...........................157

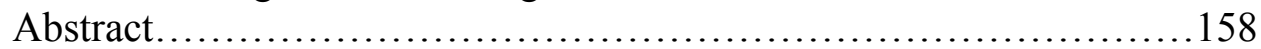

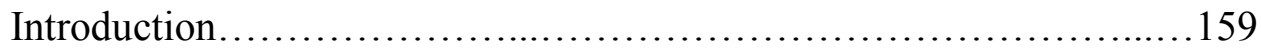

Materials and methods...........................................162

Collection of HMW DOM and isolation of neutral

polysaccharides........................................162

Culture purity of Pseudomonas and Sulfitobacter isolates........162

Growth of P. stutzeri strain HI00D01 on marine HMW DOM

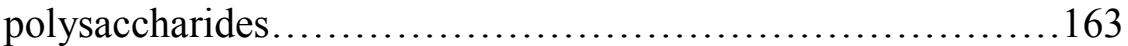

Transposon mutagenesis of $P$. stutzeri H00D01 and

identification of strains unable to metabolize phosphonate......164

Transposon mutagenesis and library preparation.........164

Screening mutants for strains deficient in metabolizing phosphonates..................................... 164

Candidate mutants deficient in phosphonate degradation...................................... 165

Evaluation of $P$. stutzeri HI00D01 growth on alkylphosphonates as a source of phosphorus.................................... 166

Detection of hydrocarbon gases in batch cultures amended with phosphonates or HMW DOM polysaccharides.................. 166

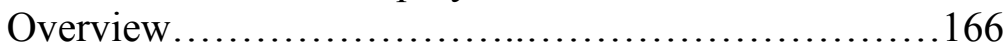

Initial screen..................................... 167

Inhibition of hydrocarbon production from phosphonates by inorganic phosphate additions in batch cultures of $P$. stutzeri strain



Degradation of two representative HMW DOM phosphonates (methyl phosphonate and 2-hydroxyethyl phosphonate) by $P$. stutzeri HI00D01.......................................171

Test for production of hydrocarbon gases using batch cultures of Sulfitobacter strain HI0054 amended with phosphonates and HMW DOM polysaccharides..............................171

Metagenomic screening of the C-P lyase pathway genes........171

Results and discussion............................................172

Introduction of Pseudomonas stutzeri HI00D01 and

Sulfitobacter HI0054 bacteria as suitable model systems to study the degradation of HMW DOM phosphonates.............172 Growth of $P$. stutzeri HI00D01 on HMW DOM polysaccharides 
Growth of P. stutzeri strain HI00D01 on alkylphosphonates asphosphorus source..........................................175

Identification of $P$. stutzeri HI00D01 transposon mutants deficient in phosphonate utilization...........................176

Screening for production of hydrocarbon gases from bacterial phosphonate degradation............................177

Inhibition of phosphonate degradation in P. stutzeri HI00D01 with inorganic phosphate....................................178

Methane and ethylene accumulation if $P$. stutzeri HI00D01 cultures amended with methyl phosphonate, 2-hydroxyethyl phosphonate, and HMW DOM polysaccharides................183 Degradation of HMW DOM phosphonates by Sulfitobacter strain HI0054....................................................184

Distribution of the C-P lyase pathway in the global ocean........185



Acknowledgements..................................................

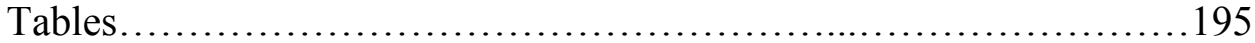



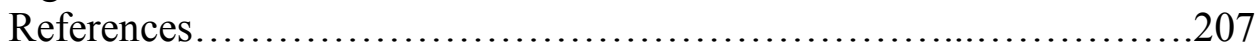

Chapter 5. Summary and future directions............................................. 211

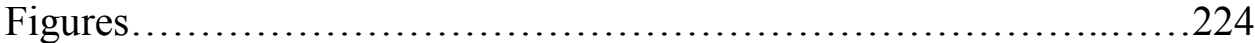

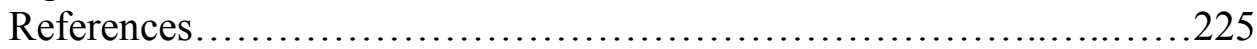

Appendices

Appendix I. Chapter 3 supplemental material ..........................229

Appendix II. Chapter 4 supplemental material.........................246

\section{List of Tables}

Chapter 2

Table 2.1: HMW DOM-enriched dilution-to-extinction cultivation experimental design and growth screen results................................................... 77

Table S1: Cell counts of dilution to extinction wells after growth screen....86

Chapter 3

Table 3.1: $\quad$ DOC treatments and incubation conditions of HMW DOMenriched dilution-to-extinction culturing open-ocean experiments............................................136

Table 3.2: $\quad$ Phylogenetic identification of Hawaii isolates via assembled SSU rRNA genes........................................ 137

Chapter 4 
Table 4.1: $\quad$ Screening of $P$. stutzeri HI00D01 phosphonate-amended culturesfor accumulation of hydrocarbon gases

Table 4.2: $\quad$ Production of hydrocarbon gases by P. stutzeri HI00D01 wildtype and mutant cultures amended with methyl phosphonate, ethyl phosphonate, and HMW DOM polysaccharides.

Table 4.3: $\quad$ Oxygen consumption in phosphonate-amended cultures of $P$. stutzeri HI00D01 wildtype and phn ${ }^{-14-E 11 ~ m u t a n t ~ s t r a i n s ~}$

Table 4.4: $\quad$ Growth of phosphonate-amended cultures of P. stutzeri HI00D01 wildtype and phn ${ }^{-}$mutant strains. 198

Table 4.5: P. stutzeri HI00D01 methane and ethylene yields from HMW DOM phosphonate degradation.

Table 4.6: Hydrocarbon gas production from the degradation of HMW DOM phosphonates by Sulfitobacter strain HI0054.

Table 4.7: Bio-availability of HMW DOM methyl phosphonate and methane source strength in the upper ocean.

Appendix I

Table A1:

Experiment I flow cytometry growth screen and recovery of cultures from control and HMW DOM-amended samples.

Table A2: Experiment II flow cytometry growth screen and recovery of cultures from control and HMW DOM-amended samples

Table A3: Vitamin and trace metal supplements for Hawaii seawater cultivation media. 232

Table A4: Genome draft assembly summary of 59 representative open-ocean isolates of cultivation Experiments I and II, as well as of the coastal SAR92 clade isolate NB0015.

Table A5: $\quad$ PROKKA annotation summary of the draft genomes of 59 representative open-ocean isolates and the SAR92 clade isolate NB0015.................................................235

Table A6: One-way ANOVA comparisons of the mean number of CAZypredicted genes for each CAZy class (AA, CBM, CE, GH, GT, and PL).............................................. 236

Table A7: The three C-P lyase gene clusters identified by Martinez et al., 2013 in microcosm experiments amended with methyl phosphonate

Table A8: The predicted C-P lyase genes in Hawaii isolate genomes and their PROKKA CDS identification number.................238

Table A9: $\quad$ SSU rRNA genes of 59 Hawaii isolates and coastal isolate NB0015 identitied in PROKKA draft genome assemblies....

Appendix II 
Table A1: $\quad$ MOPS minimal formulations (http://www.teknova.com/categorys/519.htm) used for the growth of $P$. stutzeri strain H00D01 246

\section{List of Figures}

Chapter 1

Figure 1.1: $\quad$ Size distribution and abundance depth profile of total organic carbon (TOC) characteristic of open ocean regions. ................34

Figure 1.2: Elemental stoichiometry of marine organic matter. ...............35

Figure 1.3: Tangential flow filtration (TFF) methodology for the sterilization of natural seawater media used in dilution-toextinction experiments and culturing...........................36

Figure 1.4: Enrichment of dilution-to-extinction cultures with high-molecular-weight (HMW) dissolved organic matter (DOM)

Chapter 2

Figure 2.1: $\quad$ Procedure for the setup, incubation, screening and downstream analysis of dilution to extinction cultures enriched with high molecular weight dissolved organic matter (HMW DOM), including purity screening and phylogenetic identification via whole-genome sequencing. TFF, tangential-flow filtered..........75

Figure 2.2: $\quad$ Effect of HMW DOM enrichment on dilution to extinction cultures' final cell density. Only wells that scored positive for growth $(\geqslant 105$ cells per $\mathrm{ml})$ are included........................76

Figure 2.3: Taxonomic binning of unassembled reads based on the top hit of a LAST sequence similarity search against NCBI's REFSeq database.

Figure 2.4: Phylogenetic relationships based on the SSU rRNA gene extracted from the whole-genome sequences of Nahant Bay isolates (NB00\#) belonging to the OM43 clade of Betaproteobacteria.

Figure 2.5: Growth profiles of select cultures amended with HMW

DOM

Figure S1: Growth yields of the entire HMW DOM-enriched culture collection under different HMW DOM concentrations (100x: $6930 \mu \mathrm{M}$ DOC, 20x: $1330 \mu \mathrm{M}$ DOC, 4x: $210 \mu \mathrm{M}$ DOC, and no DOM amendment) in TFF UV oxidized seawater.

Figure S2: Distribution of the cultures' unassembled SSU rRNA reads' percent identity to the assembled SSU rRNA sequence.............89

Figure S3: Distribution of unassembled SSU rRNA reads at less than $90 \%$ identity to the assembled SSU rRNA gene sequence. 
Figure S4: Phylogenetic relationships based on the SSU rRNA gene extracted from Nahant Bay (NB00\#\#) gammaproteobacteria isolates....

Figure S5: Growth profiles of SAR92 clade isolate NB0015 in defined media...................................................92

Chapter 3

Figure 3.1: HMW DOM enrichments of dilution-to-extinction cultures from Hawaii....................................................139

Figure 3.2: The effect of HMW DOM on growth and recovery of dilution-to-extinction cultures prepared in Experiment I.........140

Figure 3.3: The effect of HMW DOM on growth and recovery of DCM dilution-to-extinction cultures after an extended incubation period.

Figure 3.4: Bacterial phylogenetic groups identified in Experiment II........ 142

Figure 3.5: The growth response of Experiment I Hawaii Pseudomonas and Erythrobacter isolates to HMW DOM additions

Figure 3.6: The growth response of Experiment I Hawaii Halioglobus and Vibrio isolates to HMW DOM additions.

Figure 3.7: The growth response of Experiment II Hawaii isolates to increasing concentrations of HMW DOM...................145

Figure 3.8: Carbon substrate utilization profiles of open-ocean putative hydrocarbon degraders. 146

Figure 3.9: Carbon substrate utilization profiles of Hawaii Rhodobacteraceae isolates

Figure 3.10: The occurrence of predicted CAZy genes in the genomes of Hawaii isolates.

Chapter 4

Figure 4.1: Depth profiles of methane $(\mathrm{CH} 4)$ and ethylene $(\mathrm{C} 2 \mathrm{H} 4)$ gas concentrations characteristic of the oligotrophic ocean...........202

Figure 4.2: $\quad$ Growth of P. stutzeri strain HI00D01 on HMW DOM F1 polysaccharides. .203

Figure 4.3: Growth of a P. stutzeri HI00D01 wildetype strain (WT, left) and phn- mutant strain 14-E11 (MUT, right) on phosphonateamended agarose media. .204

Figure 4.4: Global ocean distribution of bacterial C-P lyase genes and dissolved inorganic phosphate. .206

Chapter 5

Figure 5.1: Putative model of the microbial decomposition of highmolecular-weight (HMW) marine dissolved organic matter (DOM). .224

Appendix I Figure A1:

SSU rRNA gene phylogeny of Hawaii open-ocean isolates belonging to the Gammaproteobacteria orders 
Oceanospirillales and Cellvibrionales.......................243

Figure A2: The SSU rRNA gene phylogeny of Hawaii open-ocean isolates belonging to the Alphaproteobacteria orders Rhodobacterales and Sphingomonadales..................................245 


\section{CHAPTER ONE}

\section{Introduction}

The oceans harbor one of the largest reservoirs of organic carbon on the planet (660 Pg; Hansell, Carlson, Repeta, \& Schlitzer, 2009; Hansell \& Carlson, 1998; Williams \& Druffel, 1987) comparable in magnitude to the organic carbon stored in upper bioturbated surface layer (10-20 cm) of marine sediments ( 150 Pg; Emerson \& Hedges, 1988), terrestrial soils (1576 Pg ; Eswaran, Van Den Berg, \& Reich, 1993), and carbon dioxide content in our atmosphere [850 Pg (400 ppm); (Keeling, 2015)]. The majority of the organic carbon in the ocean $(>97 \%)$ is in the form of dissolved organic matter (DOM), an operationally-defined term typically used to describe colloids and organic solutes in water that pass freely through a filter with pores measuring around $200 \mathrm{~nm}$ in diameter (Benner, 2002). Marine DOM is thought to be the result of an assortment of food web processes that produce and consume organic matter originally derived from photosynthesis and the progressive concentration of organic compounds particularly resistant to degradation (Carlson, 2002). Early studies comparing the respiratory activity of different size classes of marine biota pointed out that heterotrophic microorganisms such as bacteria, rather than zooplankton - as was originally suspected - were the primary sink of the ocean's photosynthetically-derived organic matter (Pomeroy, 1974) and estimated that as much as $60 \%$ of primary production cycles through these microorganisms (Williams, 1981) most of which is converted into DOM. Bacteria are in fact the dominant chemoorganoheterotrophic microorganisms in the sunlit regions of the ocean (Baumann, Baumann, Mandel, \& Allen, 1972; Ducklow \& Hill, 1985; Fuhrman, Sleeter, Carlson, \& Proctor, 1989) fueling their metabolism with carbon and energy obtained from oxidation-reduction reactions of organic compounds, though it is now known that many marine heterotrophic bacteria can also harvest light - and 
abundant energy source in clear surface waters - to complement their metabolism (Béjà, Spudich, Spudich, Leclerc, \& DeLong, 2001). The ecological role of bacterioplankton in aquatic ecosystems is central in the "microbial loop" as summarized by Azam et al. (1983). In this trophic cascade, energy and nutrients stored in DOM are shunted back to the food web via DOM-consuming bacteria which are preyed upon by protozoans and other bacterivores, which are in turn eaten by zooplankton and higher trophic levels. Additionally, the microbial decomposition of DOM contributes significantly to the regeneration of inorganic forms of nitrogen and phosphorus that ultimately support marine productivity (Karl, 2002). These properties make the link between DOM and microorganisms a central component of Earth's carbon cycle (Hansell \& Carlson, 2001).

\section{The biogeochemical nature of DOM}

Even though DOM is fundamental to multiple ecological processes in the ocean, its molecular composition and biogeochemistry remain poorly characterized (Benner, 2002) making it difficult to investigate the underlying biological processes that contribute to its production and consumption. Depending on its characteristic residence time, DOM is typically categorized as labile, semi-labile, or refractory. Labile DOM cycles in timescales less than one day, and thus represents a very small fraction of bulk DOM at any given time (Carlson \& Ducklow, 1996; Cherrier, Bauer, \& Druffel, 1996; Ducklow \& Carlson, 1992; Fuhrman et al., 1986). Bacterial

production assays based on ${ }^{3} \mathrm{H}$-thymidine or ${ }^{3} \mathrm{H}$-leucine incorporation typically span a few hours and thus are thought to reflect the microbial cycling of labile DOM (Fuhrman \& Azam, 1980, 1982; Kirchman, K'nees, \& Hodson, 1985). Most DOM however, is thought to be either refractory or semi-labile. Refractory organic matter is thought to have a residence time of 
thousands of years as suggested by the depletion of radiocarbon in the DOC pool in the deep ocean. Williams \& Druffel (1987) found that open-ocean surface waters accumulate DOC enriched in radiocarbon $\left(\Delta^{14} \mathrm{C}\right.$ of $\left.-146 \%\right)$ relative to deep waters $\left(\Delta{ }^{14} \mathrm{C}-540 \%\right)$ reflective of the active cycling of newly fixed bomb radiocarbon but also indicative of the existence of a major old and refractory organic carbon reservoir that cycles through the ocean's conveyor over the course of thousands of years (Druffel, Williams, \& Suzuki, 1989). In turn, the timescales associated with the turnover of semi-labile DOM - weeks, months or a few years - are derived from models that use labile and refractory DOM residence times as end members to constrain the turnover time of the remaining DOM inventory (Carlson \& Ducklow, 1995; Davis \& Benner, 2007; Druffel, Williams, Bauer, \& Ertel, 1992; Luo, Friedrichs, Doney, Church, \& Ducklow, 2010; Ogawa \& Tanoue, 2003). These results warranted the need to chemically characterize DOM in detail to understand why it accumulated in the ocean and explain the predicted residence times of the different pools of DOM.

Considerable progress has been made in the last decades to dissect and describe the chemical and molecular nature of DOM (Nebbioso \& Piccolo, 2013) although most marine organic matter cannot be easily characterized due to its small molecular size, the difficulty to isolate polar organic material from dilute saline solutions, or because of its chemical and physical state (Hedges, 1992; Benner, 2002). Considerable efforts aimed at describing DOM have focused on characterizing the high-molecular-weight (HMW) fraction - typically made up of compounds with a nominal molecular weight $>1 \mathrm{kDa}$ and less than 30-100 $\mathrm{kDa}$ (Benner, 2002). Tangential flow ultrafiltration is a chemically-unbiased technique used to concentrate HMW DOM from thousands of liters of seawater to obtain sufficient quantities for analysis (Aluwihare, Repeta, \& Chen, 1997; McCarthy, Hedges, \& Benner, 1993; Mccarthy, Hedges, \& 
Benner, 1996). About $30 \%$ of the DOM standing stock in open-ocean surface waters can be concentrated by ultrafiltration while the rest is too small to be sampled by this method and is thus defined as low-molecular-weight (LMW) DOM (Fig. 1.1). However, it is unclear if this material is representative of the bulk DOM pool (Benner, Biddanda, Black, \& McCarthy, 1997; Carlson, Brann, Mague, \& Mayer, 1985). Nonetheless, the isolation of HMW DOM from seawater has enabled molecular characterization studies which in trun have begun to shed light on the properties that may be implicated in its lability and biogeochemistry as well as its ecological role in the microbial loop.

Radiocarbon measurements of HMW DOM have provided direct evidence supporting semi-labile turnover times predicted by lability models. For example, HMW DOM from openocean surface waters and its constituting neutral sugars are highly enriched in bomb radiocarbon ( $\Delta^{14} \mathrm{C}$ of $10 \%$ and a $\Delta{ }^{14} \mathrm{C} 47-67 \%$, respectively) relative to the bulk DOC pool $\left(\Delta^{14} \mathrm{C}\right.$ of $-146 \%$ ). These values are similar to the radiocarbon content of dissolved inorganic carbon (DIC) in surface waters $\left(\Delta^{14} \mathrm{C} 72 \pm 7 \%\right.$; Repeta \& Aluwihare, 2006) and are thus indicative of recent production. These observations suggests that subcomponents of marine DOM such as HMW polysaccharides cycle faster (1-25 years) than its mean residence time consistent with the hypothesis that DOM is composed of several carbon reservoirs that turnover at different rates. Investigating the biological and chemical basis of DOM lability is critical to our understanding of the impact of this global reservoir of exchangeable carbon on Earth's carbon cycle and climate.

Atomic ratio analysis of the principal bio-elements of organic matter can be used as an indicator of its degradation state in the environment. For example, marine planktonic biomass has a an average carbon, nitrogen, and phosphorus stoichiometry (C:N:P) of 106:16:1 (Redfield, 
Ketchum, \& Richards, 1963; Redfield, 1934). In contrast, HMW DOM is depleted in nitrogen and phosphorus relative to carbon (C:N:P=298:18:1; Fig. 1.2; Benner, 2002) regardless of the depth at which it is sampled (Benner, Pakulski, McCarthy, Hedges, \& Hatcher, 1992; Mccarthy et al., 1996). The major organic nitrogen and phosphorus constituents of HMW DOM are also different than from plankton biomass or particulate organic matter. Nuclear magnetic resonance analysis has revealed the major organic constituents of organic matter. HMW DOM from openocean surface waters contains on average $40-60 \mathrm{nmol} \mathrm{N}$ per $\mu \mathrm{mol} \mathrm{C}$ primarily in the form amino polysaccharides (Aluwihare, Repeta, Pantoja, \& Johnson, 2005; Mccarthy et al., 1996) and only 3-4 nmol P per $\mu \mathrm{mol} \mathrm{C}$ as part of phosphate esters and phosphonate molecules (Clark \& Ingall, 1998; Kolowith, Ingall, \& Benner, 2001) wherase newly produced biomass is dominated by nitrogen in the form of amino acids (Cowie \& Hedges, 1992) and phosphorus in the form of phosphate esters (Kolowith, Ingall, \& Benner, 2001). These observations suggest that selective microbial decomposition processes, particularly regenerating labile forms of organic nitrogen and phosphorus, contribute to the accumulation of carbon-rich HMW DOM in the water column. However, without direct evidence constraining the source of HMW DOM alternative hypothesis explaining the observed elemental stoichiometry must be considered.

The ${ }^{13} \mathrm{C}$-NMR spectrum of HMW DOM from marine surface waters indicates it is largely composed of carbohydrates (50\%), humic substances (25\%), and a lesser amount of lipids and proteins (Aluwihare et al., 1997; Benner et al., 1992). Remarkably, the carbohydrate NMR-based molecular signature of HMW DOM is highly conserved across the global ocean and is even similar to HMW DOM in some freshwater environments (Aluwihare \& Repeta, 1999; Aluwihare et al., 1997; Mccarthy et al., 1996). In fact, HMW DOM largely consists of a conserved family of closely related heteropolysaccharides with a predictable monosaccharide composition 
including arabinose, rhamnose, fucose, xylose, mannose, galactose, and glucose (Aluwihare et al., 1997) which suggests that widespread food web processes, if not the same organisms, produce this material. In addition to its complex sugar composition, HMW DOM polysaccharides are substituted with acetyl (Aluwihare et al., 1997), amino (Aluwihare et al., 2005), deoxy, methyl (Panagiotopoulos, Repeta, \& Johnson, 2007; Quan \& Repeta, 2007), and

phosphono sugars (Daniel Repeta, personal communication) with moderate branching indicating these polysaccharides serve a very different function than, for example, cellular glucose polysaccharides used as carbon and energy reserve like glycogen and starch. It is possible that such chemical moieties, like the acetyl and amino functional groups, represent available substrates for heterotrophic bacteria. However, the chemical substitutions may render HMW DOM polysaccharides recalcitrant, for example, by impeding binding by carbohydrate-degrading enzymes. This would explain in part the semi-labile nature of HMW DOM. Identifying bacterioplankton groups that breakdown and metabolize HMW DOM is expected to enable testing this hypothesis and to shed light on the biochemical processes underlying DOM cycling.

\section{The role of bacterioplankton in the cycling of DOM in the sea}

The emergent role of bacterioplankton as a main player in the ocean's carbon cycle and novel insights on the bulk composition of organic matter set the stage to investigate in more detail individual components and processes of DOM cycling. The microbial decomposition of marine DOM in some ways resembles the gradual decomposition of organic carbon in terrestrial soils, which consists of the stepwise breakdown of a easily degradable, intermediate, and resistant fractions of material (Wolf \& Wagner, 2005). Decomposition of soil organic matter is driven primarily by the activities of bacteria and fungi (Hopkins \& Gregorich, 2005) albeit fungi 
are not prevalent in the open-ocean. Heterotrophic soil microorganisms fall under two main groups; those that respond primarily to the addition of fresh carbon substrates (zymogenous or r-selected biomass) and those that derive their energy mainly from the decomposition of older, more recalcitrant forms of organic carbon (autochthonous or K-selected biomass) (Hopkins \& Gregorich, 2005). Similar ecological divisions related to substrate lability and resource availability are often used to describe marine bacterioplankton. Copiotrophic bacteria, often considered r-strategists, are better adapted to nutrient-rich environments and display boomand-bust population dynamics, while oligotrophic bacteria, or K-strategists, are associated with dilute and stable environments and steady growth (Koch, 2001). Moreover, genome properties of cultured bacteria, such as the number of regulatory networks and substrate transporters, seem to be consistent with these microbial life-styles (Lauro et al., 2009; Singer et al., 2011). Despite having this ecological information, it remains difficult to associate specific microbial groups with the decomposition of the different pools of marine DOM, particularly in the slow cycling of the less labile reservoirs.

Seawater incubation experiments, often referred to as microcosms, have been practical for studying short term responses of microbial communities to organic matter perturbations. Carlson et al. (2004) performed field studies in the Sargasso Sea consisting of microcosm incubations combining filtered seawater and microbial inocula from different depths to show that the DOM that accumulates periodically in surface waters becomes bioavailable in the presence of mesopelagic microbial communities whereas it appears to be refractory to surface microbial communities. The consumption of surface DOC exported to mesopelagic depths has also been observed with the use of biogeochemical tracers such as chlorofluorocarbon-based estimates of water mass ventilation age (Carlson et al., 2010), oxygen mass balance (Emerson, Quay, Stump, 
Wilbur, \& Schudlich, 1995), and DOC concentration gradients in the North Atlantic (Carlson, Ducklow, \& Michaels, 1994; Hansell \& Carlson, 2001). These field observations illustrate the semi-labile nature of DOM and the highlight the importance of the composition of microbial heterotrophic communities in the cycling of organic carbon. However, it remains to be described which microbial groups are the most metabolically active and relevant to the degradation of this carbon reservoir.

The application of cultivation-independent techniques has been useful to identify bacterioplankton groups relevant to the degradation of operationally-defined fractions of organic matter. One approach has been to obtain profiles of the SSU rRNA gene pool from a microbial sample in situ or in controlled experiments. For example, 16S rRNA gene clone libraries obtained from environmental samples indicate that a large proportion of bacterial communities associated to particulate organic matter (POM) are closely related to the Cytophaga-Flavobacter and Planctomycetes taxa (Delong, Franks, \& Alldredge, 1993; Fontanez, Eppley, Samo, Karl, \& DeLong, 2015). These microbial assemblages are thought to be responsible for the remineralization of sinking particles (Cho \& Azam, 1988; Smith, Simon, Alldredge, \& Azam, 1992) and play a central role in regulating the efficiency of the biological pump. Cottrell \& Kirchman (2000) used microautoradiography combined with fluorescence in situ hybridization techniques (based on 16S rRNA gene) to investigate which microorganisms became enriched in seawater treatments with HMW or LMW substrates. The Cytophaga-Flavobacter group appeared to be associated with consumption of relevant marine HMW substrates like chitin and N-acetyl glucosamine while Alphaproteobacteria were more successful in competing for amino acids. Covert \& Moran (2001) also observed considerable differences in the composition of bacterial 
communities that developed in HMW or LMW DOM treatments in estuaries using terminal restriction fragment length polymorphism analysis of 16S rRNA gene sequences.

Most recently, more powerful cultivation-independent approaches like metagenomics and community gene expression analysis, or metatranscriptomics, have been employed to reveal the DOM degradation activities of microbes in situ or in microcosm experiments. In addition to surveying the SSU rRNA composition of microbial samples in response to experimental treatments or environmental stimuli, these techniques capture the metabolic potential of microbial communities which is particularly useful to infer transformations of matter. For example, McCarren et al. (2010) applied a metatranscriptomic analysis to an experimental microcosm of Hawaii surface water supplemented with natural HMW DOM. The data revealed an apparent succession of bacterial taxa including Alteromonadales and methylotrophic bacteria that were hypothesized to operate in syntrophy whereby the first group produced or released onecarbon compounds that supported the metabolism of the latter. In another cultivationindependent study, Teeling et al. (2012) employed metagenomics and proteomics to resolve microbial processes over the course of a bacterioplankton bloom in the North Sea. Similar to the McCarren et al. (2010) study, Teeling et al. (2012) observed a succession of taxa thought to be associated with changes in the organic matter field as the bloom progressed including an overrepresentation of Bacteroidetes populations encoding carbohydrate-active enzymes involved in the degradation of polysaccharides at the end of the bloom. These results are consistent with genomic studies of other cultured and non-cultured Bacteroidetes which predict these microorganisms are adapted to degrade biopolymers, including polysaccharides and proteins (González et al., 2008; Woyke et al., 2009). 
Recent field studies investigating the activity of specific members of bacterioplankton in response to carbon amendments indicate that many taxonomic groups are more specialized than previously thought leading to the emerging hypothesis that the organic matter field may be responsible for structuring microbial communities (Dinasquet, Kragh, Schrøter, Søndergaard, \& Riemann, 2013; Dixon, Sargeant, Nightingale, \& Colin Murrell, 2013; Gifford, Sharma, Booth, \& Moran, 2012; Gómez-Consarnau, Lindh, Gasol, \& Pinhassi, 2012; Nelson \& Carlson, 2012; Sarmento \& Gasol, 2012). The widespread occurrence of genome streamlining (Dupont et al., 2012; Giovannoni, Cameron Thrash, \& Temperton, 2014; Grote et al., 2012; Woyke et al., 2009) also indicates that marine microbes occupy narrow ecological niches that originate in stable environments though small-genome size is not the only strategy to succeed in a specialized niche. For example, recently, single-cell genomics have revealed uncultured marine bacterioplankton from the phylum Verrucomicrobia with an estimated genome size of 3.2 to 5.7 $\mathrm{Mb}$ that may be key players in the degradation of polysaccharides due to the high content of carbohydrate-degrading enzymes (Martinez-Garcia et al., 2012). Nevertheless, even if compositional changes in the DOM pool result in alterations of the bacterioplankton community structure, the transformative potential of organic carbon may remain the same given the functional redundancy between taxa (Allison \& Martiny, 2008). Moreover, trophic factors and physical conditions are thought to be more important drivers of community structure than resource availability such as the quality or quantity of DOM (Mou, Sun, Edwards, Hodson, \& Moran, 2008). Hypothetically though, a highly stable environment like the North Pacific Subtropical Gyre, where bacterioplankton communities have evolved continuously exposed to a predominantly local source of organic matter, may exhibit a naturally orchestrated aerobic microbial decomposition chain wherein different bacterioplankton populations participate in the 
slow decomposition of less labile DOM. This mechanism may be similar to the open-ocean bacterioplankton transcriptional cascades observed by Ottesen et al. (2014) associated with the tight coupling between primary producers and heterotrophic consumption processes, though these processes may be more representative of the cycling of labile substrates.

Even though the majority of microcosm experiments investigating the heterotrophic activities of bacterioplankton have only resolved broader group responses and employed model organic carbon substrates or operationally-defined size fractions of organic matter, their results indicate that many marine microbes may occupy specialized niches carved in adaptation to different sources of organic matter in the environment and the types and quantities of substrates available for growth. Cultivation-independent techniques like genomics - despite known methodological biases - have also provided numerous observations consistent with this hypothesis. However, more appropriate microbial model systems, i.e., cultivable and ecologically relevant microorganisms, are necessary to corroborate these findings.

\section{Microbial model systems relevant to semi-labile DOM cycling}

One of the main challenges in marine microbial ecology is the ability to cultivate marine microorganisms to study them in detail in pure culture. In contrast to traditional cultivation methods which employ pre-defined media enriched with organic and inorganic nutrients, the dilution-culturing approach (Button, Schut, Quang, Martin, \& Robertson, 1993) makes an effort to simulate the environmental conditions of the microbial inocula by using a sterile form of natural, minimally altered water as growth medium to isolate strains from a highly dilute sample (Fig. 1.3). Modifications of the dilution-to-extinction method (Connon \& Giovannoni, 2002) made it possible to cultivate diverse marine microorganisms including some of the most 
abundant heterotrophic bacterioplankton clades like SAR11 (Rappé, Connon, Vergin, \& Giovannoni, 2002) and Oligotrophic Marine Bacteria (OMG) (Cho \& Giovannoni, 2004). Representative cultured members of the SAR11 clade have been explored to investigate the role of this bacterioplankton clade in the marine environment. Field studies, genome analysis and pure culture experiments indicate that this diverse marine clade is best suited to metabolize simple carbon compounds - e.g., acetate, one-carbon compounds, and amino acids - and are thought to play a major role in carbon cycling (Grote et al., 2012; Malmstrom, Kiene, Cottrell, \& Kirchman, 2004; Schwalbach, Tripp, Steindler, Smith, \& Giovannoni, 2010; Sun et al., 2011a). However, other abundant groups within the Proteobacteria such as the SAR86 clade remain uncultured (Dupont et al., 2012) reflecting our lack of understanding of the ecology and physiology of marine microbes.

Even though traditional and new cultivation techniques have generated large and diverse culture collections, most culture studies typically determine the carbon and energy requirements of new marine isolates by testing simple model substrates such as LMW organic acids and simple sugars (e.g., Baumann et al., 1972; Sun et al., 2011). For the purposes of investigating the implication of microbial heterotrophic processes in the marine carbon cycle, such an approach is incomplete because it ignores the gradual decomposition of heterogeneous organic matter components derived from particulates (e.g., sinking phytoplankton and marine snow) to HMW polymers, and ultimately to LMW oligomers and monomers amenable for cell uptake and growth. Though this linear representation of organic matter degradation oversimplifies the process it highlights the need for more ecologically-relevant microbial model systems and experimentation with naturally-occurring growth substrates to study in detail the cycling of DOM. 


\section{Thesis goal and working hypotheses}

One of the primary objectives of this thesis is to develop a screening system to identify and cultivate ecologically-relevant marine microorganisms that are centrally involved in DOM decomposition in the sea. The central focus in this project is on marine HMW DOM, an abundant source of carbon that is relatively easy to concentrate from seawater without chemical biases. Because its molecular composition and spectroscopic properties are well conserved across the global ocean, HMW DOM is predicted to support widespread heterotrophic microbial populations. The second component is a robust microbiological screening and cultivation method aimed at isolating microorganisms with the phenotype of interest. The dilution-to-extinction technique has proven successful in cultivating previously uncultured bacterioplankton groups. In this thesis, a modification of this technique consisting of amending dilution-to-extinction cultures with HMW DOM is predicted to select for microorganisms adapted to degrade this naturallyoccurring substrate to obtain carbon and energy for growth (Fig. 1.4). Having such microbial systems available in the laboratory is expected to enable the use of physiological, genomic, and genetic experimentation to test hypotheses similar to those generated by cultivation-independent studies and to reveal details about the microbial processes that contribute to HMW DOM turnover including:

1. The identity of microorganisms actively involved in HMW DOM turnover.

2. The types of HMW DOM carbon constituents available for bacterial growth.

3. The genes and enzymes catalyzing the degradation of identifiable HMW DOM constituents.

4. The exact biochemical transformations of these substrates. 
The information contained in microbial genomes can be used to infer enzymatic capabilities and metabolic properties enabling HMW DOM degradation. Simple growth assays can help determine the extent to which different microorganisms degrade HMW DOM and the types of organic constituents they can metabolize. Additionally, knowledge of the chemical constitution of HMW DOM can help select appropriate analytical techniques to detect the expected biochemical transformations of HMW DOM substrates. For example, biotransformation assays consisting of batch microbial cultures enriched with HMW DOM can be used to identify decomposition byproducts or alterations in HMW DOM using analytical instruments such as high-performance liquid chromatography, gas chromatography, nuclear magnetic resonance, or mass spectrometry, or simply thin-layer chromatography. Moreover, the combination of genomic and physiological information can help design genetic tests to pin point the genes and biochemical pathways that encode the ability to decompose HMW DOM. Microbiological assays may thus provide a powerful framework to elucidate the decomposition reactions underlying DOM turnover, information that can help answer longstanding questions in biological and chemical oceanography.

One observation that has puzzled scientists studying marine DOM for over a decade, is its significant enrichment in carbohydrates, materials typically thought of as quite bioavailable. Paradoxically, microorganisms are well known to degrade complex carbohydrates such as the cellulose and pectin that provide plants structure and rigidity, and the chitin that makes up the exoskeletons of crustaceans. Another intriguing and important question is whether marine DOM will act as a sink or source of carbon during global environmental change (Jiao et al., 2014). Carbon locked away in the ocean by living organisms in marine sediments and in the water column represents a considerable and climate-sensitive, sink of anthropogenic $\mathrm{CO}_{2}($ Nellemann 
et al., 2009). In the open ocean, the microbial carbon pump (MCP), a process by which Bacteria and Archaea produce refractory DOC, is thought to sequester atmospheric $\mathrm{CO}_{2}$ for geological timescales (Jiao et al., 2014, 2010) and its magnitude may be responsive to changes in seasurface temperature, water column stratification, and production of particulate organic carbon (Legendre et al., 2015). However, we still lack a mechanistic understanding of the biological processes that drive the opposite direction of carbon flow, the aerobic microbial remineralization of DOC to carbon dioxide in marine surface waters, including the physical and environmental parameters that influence these processes. The longstanding debate of whether the ocean is net autotrophic or net heterotrophic (Duarte, Regaudie-de-Gioux, Arrieta, Delgado-Huertas, \& Agustí, 2013; Ducklow \& Doney, 2013; Williams, Quay, Westberry, \& Behrenfeld, 2013) clearly illustrates the difficulty in constraining the implication of microbial DOM cycling in the planet's carbon budget.

The goal of this thesis is to use cultivation-based techniques to elucidate the biochemical and genetic determinants underlying the decomposition of marine HMW DOM. Throughout this work, new and unexpected findings regarding the degradation properties of microbial isolates from coastal and open-ocean ecosystems have expanded our knowledge of how different functional bacterioplankton groups may participate in HMW DOM cycling and highlighted the potential of microbial-mediated carbon transformations to alter the environment and Earth's climate. Knowledge such as this is expected to contribute to a more mechanistic understanding of the aerobic decomposition of semi-labile DOM in the sea. The data chapters encompassing this work are outlined below. 


\section{Chapter summaries}

Chapter 2: High-molecular-weight dissolved organic matter enrichments select for methylotrophs in dilution to extinction cultures.

In this chapter, I put in practice the modified dilution-to-extinction cultivation strategy designed to isolate microbial degraders of HMW DOM. The study was conducted using the endemic microbial community from a coastal marine environment (Nahant Bay, MA) and HMW DOM collected from oligotrophic surface waters in the open-ocean near Hawaii. Even though the microbial inoculum and HMW DOM samples were obtained from different environments the strategy was successful in identifying several groups of heterotrophic bacteria that could use HMW DOM for growth supporting the hypothesis that this abundant substrate is well conserved across the global ocean and can be degraded by predictable and widespread functional groups of bacteria. The work encompassing this chapter was originally published by Sosa, Gifford, Repeta, \& DeLong (2015) and represents the foundation for the work developed in the subsequent chapters.

Chapter 3: Assessment of the degradation capabilities of open-ocean bacterial isolates enriched with marine high-molecular-weight dissolved organic matter

Because microbial heterotrophic communities may be better adapted to degrade cooccurring sources of organic matter, in Chapter 3 I re-applied the modified screening methodology to identify microbial degraders of HMW DOM from an open-ocean environment. For this purpose, a series of cultivation experiments were conducted with microbial inocula and HMW DOM samples collected in the open-ocean near Hawaii. The results of this work were similar to Chapter 2 in that several bacterial groups were stimulated by HMW DOM amendments but different in that most isolates had a reduced ability to utilize the substrate for 
growth. Nevertheless, genomic analysis revealed some clues regarding the enzymatic degradation potential of these cultures to transform HMW DOM substrates, information that is expected to guide future investigations.

\section{Chapter 4: Production of hydrocarbon gases during bacterial degradation of covalently- bound phosphonates associated with marine high-molecular-weight dissolved organic matter}

In Chapter 4, I delve deeper into the characterization of two such bacterial isolates from the open-ocean able to utilize known organic constituents of marine HMW DOM polysaccharides, namely, phosphonates - molecules with a direct carbon-phosphorus (C-P) bond rather than an oxygen ester (R-O-P) bond. In this chapter, pure culture studies in combination with analytical techniques used to detect the degradation byproducts of HMW DOM demonstrate the usefulness of the microbial model system approach to dissect the underlying biochemical transformations that drive the cycling of DOM in the ocean.

\section{Chapter 5: Summary and future directions}

Finally, chapter 5 summarizes the findings of this thesis, discusses the limitations of the microbial model system approach, and suggests ways in which the information gathered throughout this work can help guide future experiments with candidate microbial decomposers of HMW DOM identified in chapters 2 and 3. 


\section{Figures}



Figure 1.1. Size distribution and abundance depth profile of total organic carbon (TOC) characteristic of open ocean regions. Low-molecular-weight dissolved organic carbon (LMW DOC) dominates the TOC inventory (area left to the red line). In the surface regions highmolecular-weight (HMW) DOC accounts for up to $\sim 29 \%$ of TOC and diminishes to $\sim 18 \%$ at depth (area between the red and blue lines). Particulate organic carbon is approximately $\sim 1 \%$ of TOC. Profiles are based on data from Benner et al. (1997). 



Figure 1.2. Elemental stoichiometry of marine organic matter. High-molecular-weight (HMW) dissolved organic matter (DOM) has carbon to nitrogen atomic ratios (C:N) 2.5 times higher than plankton biomass, and slightly higher ratios than the total DOM pool. The carbon to phosphorus atomic ratios $(\mathrm{C}: \mathrm{P})$ are similarly $\sim 3$ times higher than for plankton. Both $\mathrm{C}: \mathrm{N}$ and $\mathrm{C}: \mathrm{P}$ of HMW DOM increase with depth. Elemntal stoichiometry is based on data summarized by Benner (2002). 


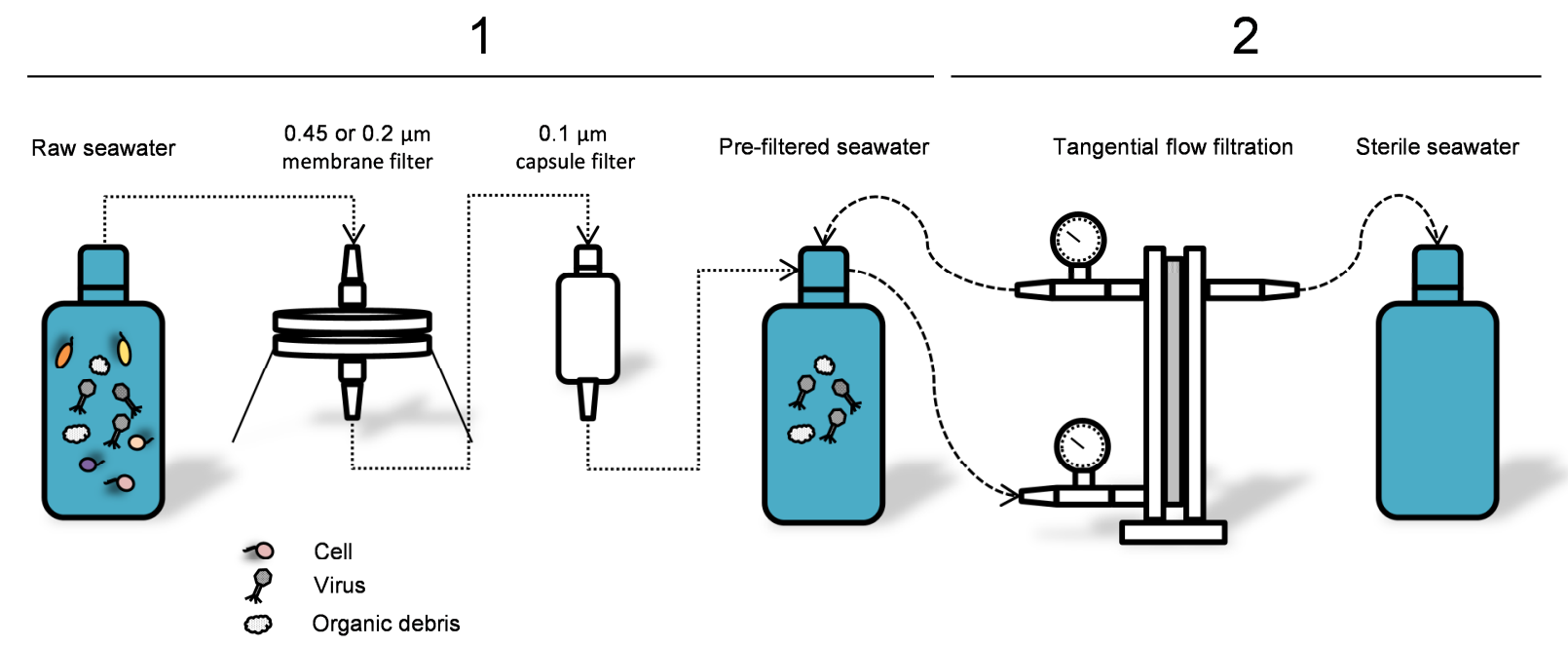

Figure 1.3. Tangential flow filtration (TFF) methodology for the sterilization of natural seawater media used in dilution-to-extinction experiments and culturing. Seawater is collected in acid-clean polycarbonate carboys and stored preferably in darkness and chilled before sterilization. The first step in the process is pre-filtration. Normally, two pre-filters are used to remove particulates and cells from seawater. The first pre-filter used for this work was a $0.22 \mu \mathrm{m}$ Supor membrane filter (PALL Corp.) to remove most cells. The second pre-filter was $0.1 \mu \mathrm{m}$ double membrane capsule filter to ensure that even small cells were removed. The second step in the protocol is to use TFF with a $30 \mathrm{kDa}$ membrane cassette to remove any remaining cells as well as viruses and a fraction of high-molecular-weight dissolved organic matter, like organic debris from cells and particulates. The permeate of the TFF membrane is collected in sterile polycarbonate bottles and stored at $4^{\circ} \mathrm{C}$ on darkness until used for cultivation. 
A

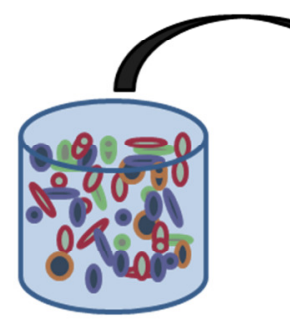

$10^{6}$ cells ml $^{-1}$

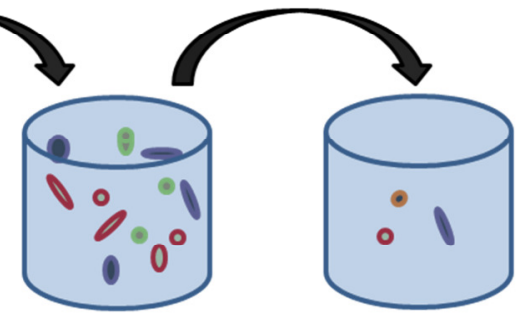

5-10 cells ml ${ }^{-1}$
B



D

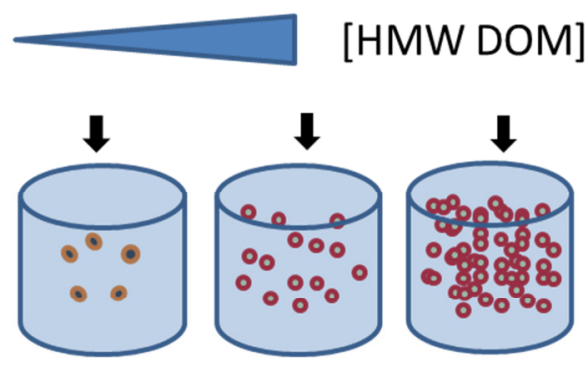

B inoculated well






\section{References}

Allison, S. D., \& Martiny, J. B. H. (2008). Resistance, resilience, and redundancy in microbial communities, Proceedings of the National Academy of Sciences of the United States of America, 105, 11512-11519.

Aluwihare, L. I., \& Repeta, D. J. (1999). A comparison of the chemical characteristics of oceanic DOM and extracellular DOM produced by marine algae. Marine Ecology Progress Series, 186, 105-117.

Aluwihare, L. I., Repeta, D. J., \& Chen, R. F. (1997). A major biopolymeric component to dissolved organic carbon in surface sea water. Nature 387, 166-169.

Aluwihare, L. I., Repeta, D. J., Pantoja, S., \& Johnson, C. G. (2005). Two chemically distinct pools of organic nitrogen accumulate in the ocean. Science, 308, 1007-1010.

Azam, F., Fenchel, T., Field, J., Gray, J., Meyer-Reil, L., \& Thingstad, F. (1983). The ecological role of water-column microbes in the sea. Marine Ecology Progress Series, 10, 257-263.

Baumann, L., Baumann, P., Mandel, M., \& Allen, R. D. (1972). Taxonomy of aerobic marine eubacteria. Journal of Bacteriology, 110(1), 402-429.

Béjà, O., Spudich, E. N., Spudich, J. L., Leclerc, M., \& DeLong, E. F. (2001). Proteorhodopsin phototrophy in the ocean. Nature, 411, 786-789.

Benner, R. (2002). Chemical Composition and Reactivity. In Hansell, D. A. and Carlson, C. A. (Eds.). Biogeochemistry of Marine Dissolved Organic Matter (pp. 59-90). Academic Press, San Diego.

Benner, R., Biddanda, B., Black, B., \& McCarthy, M. (1997). Abundance, size distribution, and stable carbon and nitrogen isotopic compositions of marine organic matter isolated by tangential-flow ultrafiltration. Marine Chemistry, 57, 243-263.

Benner, R., Pakulski, J. D., McCarthy, M., Hedges, J. I., \& Hatcher, P. G. (1992). Bulk chemical characteristics of dissolved organic matter in the ocean. Science, 255, 1561-1564.

Button, D. K., Schut, F., Quang, P., Martin, R., \& Robertson, B. R. (1993). Viability and isolation of marine bacteria by dilution culture: Theory, procedures, and initial results. Applied and Environmental Microbiology, 59(3), 881-891.

Carlson, C. A. (2002). Production and removal processes. In Hansell, D. A. and Carlson, C. A. (Eds.). Biogeochemistry of Marine Dissolved Organic Matter (pp. 139-151). Academic Press, San Diego. 
Carlson, C. A, Giovannoni, S. J., Hansell, D. A, Goldberg, S. J., Parsons, R., \& Vergin, K. (2004). Interactions among dissolved organic carbon, microbial processes, and community structure in the mesopelagic zone of the northwestern Sargasso Sea. Limnology and Oceanography, 49(4), 1073-1083.

Carlson, C. A., \& Ducklow, H. W. (1995). Dissolved organic carbon in the upper ocean of the central equatorial Pacific Ocean, 1992: Daily and finescale vertical variations. Deep Sea Research Part II: Topical Studies in Oceanography, 42(2), 639-656.

Carlson, C. A., \& Ducklow, H. W. (1996). Growth of bacterioplankton and consumption of dissolved organic carbon in the Sargasso Sea. Aquatic Microbial Ecology, 10, 69-85.

Carlson, C. A., Ducklow, H. W., \& Michaels, A. F. (1994). Annual flux of dissolved organic carbon from the euphotic zone in the northwestern Sargasso Sea. Nature, 371, 405-408.

Carlson, C. A., Hansell, D. A., Nelson, N. B., Siegel, D. a., Smethie, W. M., Khatiwala, S., ... Halewood, E. (2010). Dissolved organic carbon export and subsequent remineralization in the mesopelagic and bathypelagic realms of the North Atlantic basin. Deep-Sea Research Part II: Topical Studies in Oceanography, 57(16), 1433-1445.

Carlson, D., Brann, M., Mague, T., \& Mayer, L. (1985). Molecular weight distribution of dissolved organic materials in seawater determined by ultrafiltration: a re-examination. Marine Chemistry, 16, 155-171.

Cherrier, J., Bauer, J., \& Druffel, E. R. M. (1996). Utilization and turnover of labile dissolved organic matter by bacterial heterotrophs in eastern North Pacific surface waters. Marine Ecology Progress Series, 139, 305-307.

Cho, B. C., \& Azam, F. (1988). Major role of bacteria in biogeochemical fluxes in the ocean's interior. Nature 332, 441-443.

Cho, J. C., \& Giovannoni, S. J. (2004). Cultivation and growth characteristics of a diverse group of oligotrophic marine Gammaproteobacteria. Applied and Environmental Microbiology, $70(1), 432-440$.

Clark, L. L., \& Ingall, E. D. (1998). Marine phosphorus is selectively remineralized. Nature, $393,426$.

Connon, S. A. \& Giovannoni, S. J. (2002). High-throughput methods for culturing microorganisms in very-low-nutrient media yield diverse new marine isolates highthroughput methods for culturing microorganisms in very-low-nutrient media yield diverse new marine isolates. Applied and Environmental Microbiology, 68(8), 38783885.

Cottrell, M. T., \& Kirchman, D. L. (2000). Natural assemblages of marine Proteobacteria and members of the Cytophaga-Flavobacter clustler consuming low- and high- molecular- 
weight dissolved organic matter. Applied and Environmental Microbiology, 66(4), 16921697.

Covert, J. S., \& Moran, M. A. (2001). Molecular characterization of estuarine bacterial communities that use high- and low-molecular weight fractions of dissolved organic carbon. Aquatic Microbial Ecology, 25, 127-139.

Cowie, G. L., \& Hedges, J. I. (1992). Sources and reactivities of amino acids in a coastal marine environment. Limnology and Oceanography, 37(4), 703-724.

Davis, J., \& Benner, R. (2007). Quantitative estimates of labile and semi-labile dissolved organic carbon in the western Arctic Ocean: A molecular approach. Limnology and Oceanography, 52(6), 2434-2444.

Delong, E. F., Franks, D. G., \& Alldredge, A. L. (1993). Phylogenetic diversity of aggregateattached vs. free-living marine bacterial assemblages. Limnology and Oceanography, 38(5), 924-934.

Dinasquet, J., Kragh, T., Schrøter, M.-L., Søndergaard, M., \& Riemann, L. (2013). Functional and compositional succession of bacterioplankton in response to a gradient in bioavailable dissolved organic carbon. Environmental Microbiology, 15, 2616-2628.

Dixon, J. L., Sargeant, S., Nightingale, P. D., \& Colin Murrell, J. (2013). Gradients in microbial methanol uptake: productive coastal upwelling waters to oligotrophic gyres in the Atlantic Ocean. The ISME Journal, 7(3), 568-80.

Druffel, E. R. M., Williams, P. M., Bauer, E., \& Ertel, J. R. (1992). Cycling of dissolved and particulate organic matter in the open ocean. Journal of Geophysical Research, 97, 15639-15659.

Druffel, E. R. M., Williams, P. M., \& Suzuki, Y. (1989). Concentrations and radiocarbon signatures of dissolved organic matter in the Pacific Ocean. Geophysical Research Letters, 16(9), 991-994.

Duarte, C. M., Regaudie-de-Gioux, A., Arrieta, J. M., Delgado-Huertas, A., \& Agustí, S. (2013). The oligotrophic ocean is heterotrophic. Annual Review of Marine Science, 5, 551-569.

Ducklow, H. W., \& Carlson, C. A. (1992). Oceanic Bacterial Production. Advances in Microbial Ecology, 12(1986), 113-181.

Ducklow, H. W., \& Doney, S. C. (2013). What is the metabolic state of the oligotrophic ocean? A debate. Annual Review of Marine Science, 5, 525-533.

Ducklow, H. W., \& Hill, S. M. (1985). The growth of heterotrophic bacteria in the surface waters of warm core rings. Limnology and Oceanography, 30, 239-259. 
Dupont, C. L., Rusch, D. B., Yooseph, S., Lombardo, M.-J., Alexander Richter, R., Valas, R., ... Craig Venter, J. (2012). Genomic insights to SAR86, an abundant and uncultivated marine bacterial lineage. The ISME Journal, 6(6), 1186-1199.

Emerson, S., \& Hedges, J. I. (1988). Processes controlling the organic carbon content of open ocean sediments. Paleoceanography, 3(5), 621.

Emerson, S., Quay, P. D., Stump, C., Wilbur, D., \& Schudlich, R. (1995). Chemical tracers of productivity and respiration in the subtropical Pacific Ocean. Journal of Geophysical Research, 100, 15873-15887

Eswaran, H., Van Den Berg, E., \& Reich, P. (1993). Organic carbon in soils of the world. Soil Science Society of America Journal, 57, 192-194.

Fontanez, K. M., Eppley, J. M., Samo, T. J., Karl, D. M., \& DeLong, E. F. (2015). Microbial community structure and function on sinking particles in the North Pacific Subtropical Gyre. Frontiers in Microbiology, 6, 469.

Fuhrman, J. A, \& Azam, F. (1980). Bacterioplankton secondary production estimates for coastal waters of British-Columbia, Canada, Antarctica, and California, USA. Applied and Environmental Microbiology, 39(6), 1085-1095.

Fuhrman, J. A, \& Azam, F. (1982). Thymidine incorporation as a measure of heterotrophic bacterioplankton production in marine surface waters: Evaluation and field results. Marine Biology, 66, 109-120.

Fuhrman, J. a, Ducklow, H. W., Kirchman, D. L., Hudak, J., McManus, G. B., \& Kramer, J. (1986). Does adenine incorporation into nucleic acids measure total microbial production? Limnology and Oceanography, 31(3), 627-636.

Fuhrman, J. A., Sleeter, T. D., Carlson, C. A., \& Proctor, L. M. (1989). Dominance of bacterial biomass in the Sargasso Sea and its ecological implications. Marine Ecology Progress Series, 57, 207-217.

Gifford, S. M., Sharma, S., Booth, M., \& Moran, M. A. (2012). Expression patterns reveal niche diversification in a marine microbial assemblage, 7(2), 281-298.

Giovannoni, S. J., Cameron Thrash, J., \& Temperton, B. (2014). Implications of streamlining theory for microbial ecology. The ISME Journal, 8(8), 1553-1565.

Gómez-Consarnau, L., Lindh, M. V., Gasol, J. M., \& Pinhassi, J. (2012). Structuring of bacterioplankton communities by specific dissolved organic carbon compounds. Environmental Microbiology, 14, 2361-2378.

González, J. M., Fernández-Gómez, B., Fernàndez-Guerra, A., Gómez-Consarnau, L., Sánchez, O., Coll-Lladó, M., ... Pedrós-Alió, C. (2008). Genome analysis of the proteorhodopsin- 
containing marine bacterium Polaribacter sp. MED152 (Flavobacteria). Proceedings of the National Academy of Sciences of the USA, 105(25), 8724-8729.

Grote, J., Cameron Thrash, J., Huggett, M. J., Landry, Z. C., Carini, P., Giovannoni, S. J., \& Rappé, M. S. (2012). Streamlining and core genome conservation among highly divergent members of the SAR11 clade. mBio, 3 .

Hansell, D. A, \& Carlson, C. A. (2001). Marine Dissolved Organic Matter and the Carbon Cycle. Society, 14(4), 41-49.

Hansell, D. A., \& Carlson, C. A. (1998). Deep-ocean gradients in the concentration of dissolved organic carbon. Nature, 395, 263-266.

Hansell, D. A., Carlson, C. A., Repeta, D. J., \& Schlitzer, R. (2009). Dissolved organic matter in the ocean: A controversy stimulates new insights. Oceanography, 22(4), 202-211.

Hedges, J. I., Keil, R. G., \& Benner, R. (1997). What happens to terrestrial organic matter in the ocean? Organic Geochemistry, 27(5), 195-212.

Hopkins, D. W., \& Gregorich, E. G. (2005). Carbon as a substrate for soil organisms. In R. D. Bardgett, M. B. Usher, \& D. W. Hopkins (Eds.), Biological diversity and function in soils (pp. 57-79). Cambridge University Press.

Jiao, N., Herndl, G. J., Hansell, D. a., Benner, R., Kattner, G., Wilhelm, S. W., ... Azam, F. (2010). Microbial production of recalcitrant dissolved organic matter: long-term carbon storage in the global ocean. Nature Reviews Microbiology, 8(8), 593-599.

Jiao, N., Robinson, C., Azam, F., Thomas, H., Baltar, F., Dang, H., ... Zhang, R. (2014). Mechanisms of microbial carbon sequestration in the ocean - future research directions. Biogeosciences, 11, 5285-5306.

Karl, D. M. (2002). Nutrient dynamics in the deep blue sea. Trends in Microbiology, 10(9), 410418.

Keeling, R. (2015). Measurement Note: An Adjustment to the Record. Retrieved December 6, 2015, from https://scripps.ucsd.edu/programs/keelingcurve/

Kirchman, D., K'nees, E., \& Hodson, R. (1985). Leucine incorporation and its potential as a measure of protein synthesis by bacteria in natural aquatic systems. Applied and Environmental Microbiology, 49(3), 599-607.

Koch, A. L. (2001). Oligotrophs versus copiotrophs. BioEssays, 23, 657-661.

Kolowith, L. C., Ingall, E. D., \& Benner, R. (2001). Composition and cycling of marine organic phosphorus. Limnology and Oceanography, 46(2), 309-320. 
Lauro, F. M., McDougald, D., Thomas, T., Williams, T. J., Egan, S., Rice, S., ... Cavicchioli, R. (2009). The genomic basis of trophic strategy in marine bacteria. Proceedings of the National Academy of Sciences of the USA, 106, 15527-15533.

Legendre, L., Rivkin, R. B., Weinbauer, M. G., Guidi, L., \& Uitz, J. (2015). The microbial carbon pump concept: Potential biogeochemical significance in the globally changing ocean. Progress in Oceanography, 134, 432-450.

Luo, Y. W., Friedrichs, M. a M., Doney, S. C., Church, M. J., \& Ducklow, H. W. (2010). Oceanic heterotrophic bacterial nutrition by semilabile DOM as revealed by data assimilative modeling. Aquatic Microbial Ecology, 60, 273-287.

Malmstrom, R. R., Kiene, R. P., Cottrell, M. T., \& Kirchman, D. L. (2004). Contribution of SAR11 bacteria to dissolved dimethylsulfoniopropionate and amino acid uptake in the North Atlantic Ocean. Applied and Environmental Microbiology, 70(7), 4129-4135.

Martinez-Garcia, M., Brazel, D. M., Swan, B. K., Arnosti, C., Chain, P. S. G., Reitenga, K. G., ... Stepanauskas, R. (2012). Capturing single cell genomes of active polysaccharide degraders: An unexpected contribution of verrucomicrobia. PLoS ONE, 7(4), 1-11.

McCarren, J., Becker, J. W., Repeta, D. J., Shi, Y., Young, C. R., Malmstrom, R. R., ... DeLong, E. F. (2010). Microbial community transcriptomes reveal microbes and metabolic pathways associated with dissolved organic matter turnover in the sea. Proceedings of the National Academy of Sciences of the USA 107, 16420-16427.

McCarthy, M. D., Hedges, J. I., \& Benner, R. (1993). The chemical composition of dissolved organic matter in seawater. Chemical Geology, 107, 503-507.

McCarthy, M., Hedges, J., \& Benner, R. (1996). Major biochemical composition of dissolved high molecular weight organic matter in seawater. Marine Chemistry 55, 281-297.

Mou, X., Sun, S., Edwards, R. A., Hodson, R. E., \& Moran, M. A. (2008). Bacterial carbon processing by generalist species in the coastal ocean. Nature 451.

Nebbioso, A., \& Piccolo, A. (2013). Molecular characterization of dissolved organic matter (DOM): A critical review. Analytical and Bioanalytical Chemistry, 405, 109-124.

Nellemann, C., Corcoran, E., Duarte, C. M., Valdés, L., De Young, C., Fonseca, L., \& Grimsditch, G. (2009). Blue carbon: A Rapid Response Assessment. (p. 71 pp.). United Nations Environment Programme, GRID-Arendal. Retrieved from http://www.grida.no/files/publications/blue-carbon/BlueCarbon_screen.pdf

Nelson, C. E., \& Carlson, C. a. (2012). Tracking differential incorporation of dissolved organic carbon types among diverse lineages of Sargasso Sea bacterioplankton. Environmental Microbiology, 14, 1500-1516. 
Ogawa, H., \& Tanoue, E. (2003). Dissolved organic matter in oceanic waters. Journal of Oceanography, 59, 129-147.

Ottesen, E. A, Young, C. R., Gifford, S. M., Eppley, J. M., Marin, R., Schuster, S. C., ... DeLong, E. F. (2014). Multispecies diel transcriptional oscillations in open ocean heterotrophic bacterial assemblages. Science, 345, 207-12.

Panagiotopoulos, C., Repeta, D. J., \& Johnson, C. G. (2007). Characterization of methyl sugars, 3-deoxysugars and methyl deoxysugars in marine high molecular weight dissolved organic matter. Organic Geochemistry, 38, 884-896.

Pomeroy, L. (1974). The ocean's food web, a changing paradigm. BioScience 24, 499-504.

Quan, T. M., \& Repeta, D. J. (2007). Periodate oxidation of marine high molecular weight dissolved organic matter: Evidence for a major contribution from 6-deoxy- and methyl sugars. Marine Chemistry, 105, 183-193.

Rappé, M. S., Connon, S. a, Vergin, K. L., \& Giovannoni, S. J. (2002). Cultivation of the ubiquitous SAR11 marine bacterioplankton clade. Nature, 418(August), 630-633.

Redfield, A C., Ketchum, B. H., \& Richards, F. A. (1963). The influence of organisms on the composition of sea water. In Hill, M. N. (Ed.) The Sea, vol. 2. (pp. 26-27). Interscience Publishers, New York.

Redfield, A. C. (1934). On the proportions of organic derivatives in sea water and their relation to the composition of plankton. In James Johnstone Memorial Volume (pp. 176-192). University Press of Liverpool, Liverpool, U. K.

Repeta, D. J., \& Aluwihare, L. I. (2006). Radiocarbon analysis of neutral sugars in highmolecular-weight dissolved organic carbon: Implications for organic carbon cycling. Limnology and Oceanography, 5l(2), 1045-1053.

Repeta, D. J., Ferron, S., Sosa, O. A., DeLong, E. F., \& Karl, D. M. (2016). Title of paper. Unpublished manuscript.

Sarmento, H., \& Gasol, J. M. (2012). Use of phytoplankton-derived dissolved organic carbon by different types of bacterioplankton. Environmental Microbiology, 14, 2348-2360.

Schwalbach, M. S., Tripp, H. J., Steindler, L., Smith, D. P., \& Giovannoni, S. J. (2010). The presence of the glycolysis operon in SAR11 genomes is positively correlated with ocean productivity. Environmental Microbiology, 12, 490-500.

Singer, E., Webb, E. A., Nelson, W. C., Heidelberg, J. F., Ivanova, N., Pati, A., \& Edwards, K. J. (2011). Genomic potential of Marinobacter aquaeolei, a biogeochemical “Opportunitroph.” Applied and Environmental Microbiology, 77(8), 2763-2771. 
Smith, D. C., Simon, M., Alldredge, A. L., \& Azam, F. (1992). Nature, 359, 139-142.

Sosa, O. A, Gifford, S. M., Repeta, D. J., \& DeLong, E. F. (2015). High molecular weight dissolved organic matter enrichment selects for methylotrophs in dilution to extinction cultures. The ISME Journal, 9, 2725-2739.

Sun, J., Steindler, L., Thrash, J. C., Halsey, K. H., Smith, D. P., Carter, A. E., ,.. Giovannoni, S. J. (2011). One carbon metabolism in SAR11 pelagic marine bacteria. PLOS ONE, 6(8), e23973.

Teeling, H., Fuchs, B. M., Becher, D., Klockow, C., Gardebrecht, a., Bennke, C. M., ... Amann, R. (2012). Substrate-controlled succession of marine bacterioplankton populations induced by a phytoplankton bloom. Science, 336, 608-611.

Williams, P. J. L. B., Quay, P. D., Westberry, T. K., \& Behrenfeld, M. J. (2013). The oligotrophic ocean is autotrophic. Annual Review of Marine Science, 5, 535-549.

Williams, P. J. leB. (1981). Microbial contribution to overall marine plankton · metabolism: direct measurements of respiration. Oceanologica Acta, 4, 359-364.

Williams, P. M., \& Druffel, E. R. M. (1987). Radiocarbon in dissolved organic matter in the central North Pacific Ocean. Nature, 330, 246-248.

Wolf, D., \& Wagner, G. (2005). Carbon transformations and soil organic matter formation. In D. Sylvia, J. Fuhrmann, P. Hartel, \& D. Zuberer (Eds.), Principles and applications of soil microbiology (pp. 285-232). Pearson Prentice Hall.

Woyke, T., Xie, G., Copeland, A., González, J. M., Han, C., Kiss, H., ... Stepanauskas, R. (2009). Assembling the marine metagenome, one cell at a time. PLoS ONE, 4(4). 
WAVES ARE NOT MEASURED IN FEET AND INCHES, BUT IN INCREMENTS OF FEAR. Big-wave surfer Buzzy Trent 


\section{CHAPTER TWO}

High-molecular-weight dissolved organic matter enrichment selects for methylotrophs in dilution-to-extinction cultures 


\section{Abstract}

The role of bacterioplankton in the cycling of marine dissolved organic matter (DOM) is central to the carbon and energy balance in the ocean, yet there are few model organisms available to investigate the genes, metabolic pathways, and biochemical mechanisms involved in the degradation of this globally important carbon pool. To obtain microbial isolates capable of degrading semi-labile DOM for growth, we conducted dilution-to-extinction cultivation experiments using seawater enriched with high molecular weight (HMW) DOM. In total, 93 isolates were obtained. Amendments using HMWDOM to increase the dissolved organic carbon concentration $4 \mathrm{x}(280 \mu \mathrm{M})$ or $10 \mathrm{x}(700 \mu \mathrm{M})$ the ocean surface water concentrations yielded positive growth in $4-6 \%$ of replicate dilutions, whereas $<1 \%$ scored positive for growth in nonDOM-amended controls. The majority (71\%) of isolates displayed a distinct increase in cell yields when grown in increasing concentrations of HMW DOM. Whole-genome sequencing was used to screen the culture collection for purity and to determine the phylogenetic identity of the isolates. Eleven percent of the isolates belonged to the gammaproteobacteria including Alteromonadales, the SAR92 clade, and Vibrio. Surprisingly, $85 \%$ of isolates belonged to the methylotrophic OM43 clade of betaproteobacteria, bacteria thought to metabolically specialize in degrading $\mathrm{C} 1$ compounds. Growth of these isolates on methanol confirmed their methylotrophic phenotype. Our results indicate that dilution to extinction cultivation enriched with natural sources of organic substrates has a potential to reveal the previously unsuspected relationships between naturally occurring organic nutrients and the microorganisms that consume them. The ISME Journal advance online publication, 15 May 2015; doi:10.1038/ismej.2015.68 


\section{Introduction}

Marine dissolved organic matter (DOM) supports a considerable fraction of the carbon, energy and nutrient requirements of bacterioplankton in the ocean, yet the biological processes that control DOM turnover are poorly understood. This is due in part to the chemical complexity of naturally occurring DOM and the current level of molecular characterization, along with a lack of information on the variety of bacteria and metabolic strategies involved in DOM degradation. Marine DOM characterization has been largely limited to defining its bulk chemical properties. Marine DOM can be operationally separated into two different fractions based on size: low molecular weight $(<1 \mathrm{kDa})$ and high molecular weight (HMW: $\geqslant 1 \mathrm{kDa})$. The HMW DOM fraction is isolated from seawater by ultrafiltration and typically accounts for $25-40 \%$ of the total dissolved organic carbon (DOC) in marine waters (Benner, 2002). The elemental composition of HMW DOM (carbon:nitrogen:phosphorus=298:18:1; Benner, 2002) contrasts with marine plankton (Redfield et al., 1963) in that HMW DOM is depleted in nitrogen and phosphorus relative to carbon. HMW DOM from open ocean- surface waters contains 40-60 nmol nitrogen per $\mu \mathrm{mol}$ carbon primarily in the form of amides (Aluwihare et al., 2005; McCarthy, Pratum, Hedges, \& Benner, 1997) and only 3-4 nmol phosphorus per $\mu \mathrm{mol}$ carbon as part of phosphate esters and phosphonate molecules (Clark \& Ingall, 1998; Kolowith et al., 2001). The ${ }^{13}$ C-NMR spectrum of HMW DOM from marine surface waters indicates it is largely composed of carbohydrates (50\%), humic substances (25\%) and a lesser amount of lipids and proteins (Aluwihare et al., 1997; Benner et al., 1992; Benner, 2002). Radiocarbon analysis offers insight of the fate and reactivity of DOM. HMW DOM from the North Pacific has a $\Delta^{14} \mathrm{C}$ of $10 \%$ and its constituting neutral monosaccharides derived from acid hydrolysis have $\Delta^{14} \mathrm{C}$ values of $47-67 \%$; this is similar to the $\Delta^{14} \mathrm{C}$ of dissolved inorganic carbon in surface waters $(72 \pm 7 \%$; 
Repeta \& Aluwihare, 2006) and indicates recent production. In contrast, total DOC is radiocarbon depleted $\left(\Delta^{14} \mathrm{C}\right.$ of $-146 \%$ and $-540 \%$ in surface and deep North Pacific waters, respectively) likely owing to the presence of refractory carbon (Williams \& Druffel, 1987). This data suggests that subcomponents of HMW DOM from surface waters, including polysaccharides, cycle faster (1-25 years; Repeta \& Aluwihare, 2006) than the total pool of DOC (6000 years; Williams \& Druffel, 1987). These chemical characteristics, along with field observations of semi-labile DOM utilization in natural seawater (Carlson et al., 2004b; McCarren et al., 2010b), indicate HMW DOM can fuel microbial metabolism on ecologically relevant timescales. Difficulties in identifying the specific chemical moieties supporting such growth, however, limits current understanding of DOM transformation, remineralization and ultimate impact on the flux of carbon and nutrients through the marine food web. Bacteria and Archaea are the dominant degraders of DOM (Carlson, 2002), but the specific taxa, genes and molecular mechanisms most responsible for DOM metabolism remain relatively obscure. Recently, several culture-independent studies have begun to identify the microbial community members that respond to DOM enrichment, though the majority of these studies have focused on DOM isolated from phytoplankton cultures (Beier, Rivers, Moran, \& Obernosterer, 2014; Landa et al., 2013; Nelson \& Carlson, 2012; Poretsky, Sun, Mou, \& Moran, 2010; Sarmento \& Gasol, 2012; Sharma et al., 2014) which is presumed to be more labile than HMW DOM collected in oligotrophic environments. This is likely because of the presence of labile proteins and amino acids (Sarmento et al., 2013) and homopolysaccharides (Meon \& Kirchman, 2001) in phytoplankton DOM. Aluwihare \& Repeta (1999) and Aluwihare et al. (1997) observed rapid drawdown of phytoplankton DOM and evolution of polysaccharides from homopolysaccharides (energy storage products) to heteropolysaccharides with a composition like HMW DOM. In 
contrast, there have been fewer culture-independent studies focusing on the cycling of HMW DOM (McCarren et al., 2010b; Sharma et al., 2014). In all of these studies, DOM additions resulted in the enrichment of select members of the microbial community and in several cases a temporal succession of DOM-degrading bacteria (McCarren et al., 2010b; Sharma et al., 2014). Although these "omic"-based studies have generated hypothesis as to the functional and metabolic roles of DOM-degrading bacteria, appropriate model systems upon which to test such hypothesis and dissect the genes, metabolic pathways and chemical transformation reactions driving DOM degradation are still lacking. The goal of this study was to isolate HMW DOM metabolizing bacteria from marine environments to develop model systems for investigating the biochemical and metabolic pathways driving DOM transformations in the ocean. Dilution-toextinction cultivation has greatly expanded the collection of marine bacterial isolates (Button et al., 1993; Connon \& Giovannoni, 2002b) and has proved instrumental in isolating organisms resistant to traditional cultivation techniques, including members of the SAR11 and SAR116 clades (Rappé et al., 2002; Stingl, Desiderio, Cho, Vergin, \& Giovannoni, 2007), oligotrophic marine gammaproteobacteria (Cho \& Giovannoni, 2004), members of the SUP05 clade of gammaproteobacterial sulfur oxidizers (Marshall \& Morris, 2012) and pyschropiezophilic Alphaproteobacteria (Eloe et al., 2011). Field studies, genome analysis and pure cultures experiments enabled by the cultivation of bacterial clades like SAR11 have expanded our understanding of the ecology and physiology of marine bacteria and their role in the ocean carbon cycle (Grote et al., 2012; Malmstrom et al., 2004; Schwalbach et al., 2010; Sun et al., 2011b). In this study we expanded on the technique by enriching dilution-to-extinction cultures with HMW DOM collected directly from ocean surface waters, leveraging the high-throughput 
nature of dilution to extinction cultivation to screen a microbial assemblage for HMW DOMutilizing organisms.

\section{Materials and Methods}

\section{Concentration of HMW DOM from seawater}

DOM collection was conducted using the method described by (Quan \& Repeta, 2007). Briefly, the HMW fraction of DOM $(>1 \mathrm{kDa})$ was concentrated from $24,000 \mathrm{~L}$ of surface seawater $(15$ m) collected $2 \mathrm{~km}$ offshore of the Island of Hawaii, Hawaii at the National Energy Laboratory Hawaii Authority (NELHA) in February of 2006. The HMW DOM concentrated seawater was then filtered through a $30 \mathrm{kDa}$ ultrafiltration membrane to remove cell debris and viral particles, diafiltered to remove salts, and freeze-dried. A total of $9.5 \mathrm{~g}$ of freeze-dried HMW DOM was obtained that was $32 \% \mathrm{C}(-21.8 \%$ o), $2.7 \% \mathrm{~N}(6.5 \%$ ) with a $\mathrm{C} / \mathrm{N} 13.9$ representing $18 \%$ of the DOC in the original raw seawater.

\section{Molecular characterization of HMW DOM}

DOM was characterized by ${ }^{1} \mathrm{H}$ nuclear magnetic resonance spectroscopy to determine major constituents. Spectra were recorded on a Bruker Avance DPX $400 \mathrm{MHz}$ spectrometer fitted with an inverse broadband 5mm probe. Approximately 1-2 $\mathrm{mg}$ of sample was dissolved in 100\% $\mathrm{D}_{2} \mathrm{O}$. Chemical shifts were referenced to residual HOD at $\delta 4.80 \mathrm{ppm}$. Acid hydrolysis $(2.8 \mathrm{M}$ trifluoroacetic acid, heated at $120^{\circ} \mathrm{C}$ for four hours under nitrogen) of HMWDOM yields a suite of neutral sugars (arabinose, fucose, galactose, glucose, mannose, rhamnose, xylose) that were separated by reverse phase high pressure liquid chromatography (Ascentis C-18 column; 150x1 $\mathrm{mm}, 3 \mu \mathrm{m}$, eluted at $120 \mu 1 \mathrm{~min}^{-1}$ with $10 / 90(\mathrm{v} / \mathrm{v})$ acetonitrile/water) and quantified at $307 \mathrm{~nm}$ as the their aminobenzoate ethyl ester (ABEE) derivatives (Baik \& Cheong, 2007). Our 
chromatographic analysis does not separate xylose and arabinose which are reported as the sum xylose+arabinose. Analyses of unhyrdolyzed HMW DOM does not yield any ABEE products that interfere with our monosaccharide analyses.

\section{DOC measurements}

Samples for DOC concentration analysis were transferred into combusted glass vials and acidified with $25 \%$ phosphoric acid solution before sealing with acid-washed Teflon septa. Sample concentrations were determined using the high-temperature combustion method on a Shimadzu TOC-VCSH with platinized alumina catalyst alongside potassium hydrogen phthalate standards and consensus reference materials (CRM) provided by the DOC-CRM program.

\section{Preparation of seawater media}

The water for extinction culturing and subsequent cultivation media was collected off Bermuda $\left(33.2497^{\circ} \mathrm{N} 65.7103^{\circ} \mathrm{W}\right)$ during the KN207-01 cruise aboard the R/V Knorr on May $3^{\text {rd }}, 2012$ via the ship's flow through system with a $0.2 \mu \mathrm{m}$ filter. After collection and storage, the Sargasso seawater was sterilized by tangential flow filtration (TFF) as described by Becker, Brandon, \& Rappé (2007) with minor modifications. The seawater was pre-filtered through a $142 \mathrm{~mm}$ diameter $0.2 \mu \mathrm{m}$ pore-size Supor membrane (Pall Corp., Ann Arbor, MI, USA) and a $0.1 \mu \mathrm{m}$ pore-size Supor capsule filter (Pall Corp.), and collected in an acid-cleaned polycarbonate carboy. Pre-filtered water circulated through a Pellicon 2 Mini tangential flow ultrafiltration system (Millipore Corp., Billerica, MA, USA) consisting of a $30 \mathrm{kDa}$ cassette of regenerated cellulose (Millipore Corp.). The tangential flow filtrate was collected in autoclaved, acid-clean polycarbonate carboys and stored at $4^{\circ} \mathrm{C}$. Seawater remained sterile at room temperature after the addition of nutrients and sterile rich media. The final TFF seawater medium had a total organic carbon concentration of $70 \mu \mathrm{M}$. 


\section{Extinction culturing with HMW DOM additions}

The inoculum was collected in Nahant Bay, MA $\left(42^{\circ} 25.195 \mathrm{~N}, 70^{\circ} 54.463 \mathrm{~W}\right)$ on August $23^{\text {rd }}$, 2012. Bacterioplankton cell densities were obtained by direct cell counts of DNA-stained cells using SYBR green I (Molecular Probes, Life Technologies, Carlsbad, CA, USA) approximately 1 hour after sample collection. The inoculum was diluted into sterile seawater to an estimated cell density of 3 cells $\mathrm{mL}^{-1}$ in a final volume of $5 \mathrm{~L}$. The dilute inoculum was split into three $1 \mathrm{~L}$ aliquots, one left untreated (70 $\mu \mathrm{M}$ DOC) and two which were supplemented with HMW DOM to 210 and $630 \mu \mathrm{M}$ HMW DOC to obtain media with a final $280(4 \mathrm{x})$ and $700(10 \mathrm{x}) \mu \mathrm{M}$ DOC, respectively. One $\mathrm{mL}$ aliquots from each treatment were then distributed into non-tissue culture treated polystyrene 48-well plates (BD Biosciences, Franklin Lakes, NJ, USA). Each experimental treatment consisted of 840 potential extinction cultures in 2048 -well plates. Every plate included 6 negative controls consisting of wells filled with the corresponding treatment media made up with sterile seawater. Plates were covered in foil to reduce evaporation and incubated at $24^{\circ} \mathrm{C}$ in the dark for $4-5$ weeks. In order to ensure that potential extinction cultures remained viable and capable of growth in the corresponding cultivation media, after the 4-5 week incubation the samples were re-diluted 10,000-fold into new plates containing fresh TFF seawater and the appropriate DOM concentrations. These were then incubated for 6-7 weeks under the same conditions as before.

\section{Detection of culture growth}

Extinction cultures were detected using a guava easyCyte 8HT flow cytometry system (Millipore Corp.) by transferring $50 \mu \mathrm{L}$ from each cultivation plate well to a 96-well microtitter plate containing $10 \mu \mathrm{L}$ of 500 -fold diluted SYBR green I and $140 \mu \mathrm{L}$ of sterile seawater. Samples were stained for at least 30 minutes before flow cytometry. Each well was analyzed for $15 \mathrm{~s}$ at a 
flow rate of $0.59 \mu \mathrm{L} \mathrm{s}^{-1}$ with a blue laser (488 nm excitation) to detect green fluorescence. Wells were scored positive for cell growth when the concentration was $\geq 10^{5}$ cells $\mathrm{ml}^{-1}$.

\section{HMW-DOM dose response screen of the culture collection}

Cultures scoring positive for growth were examined for increased cell yields under different HMW DOM concentrations. To limit cell growth to consumption of HMW DOM added, background DOC in the TFF seawater was photo-oxidized via exposure to high-intensity ultraviolet light for 4 hours, reducing DOC concentrations by 30-40\%. During this process, approximately an eighth of the volume was lost due to evaporation, and this was replenished with ultrapure water. The UV oxidized TFF seawater ( $25 \mu \mathrm{M}$ DOC) was then supplemented with 210, 1330, and $6930 \mu \mathrm{M}$ DOC using HMW DOM to obtain $\sim 4 \mathrm{x}, \sim 20 \mathrm{x}$, or $\sim 100 \mathrm{x}$ DOC media respectively in similitude to media prepared for extinction culturing. Non DOM-amended UV oxidized seawater served as control. No inorganic nutrients or vitamins were added to the media. Each treatment media was distributed into 1-mL aliquots in 48-well cultivation plates. Wells were inoculated with $10-\mu \mathrm{L}$ sub-samples of the dilution to extinction cultures and incubated at $24^{\circ} \mathrm{C}$ in the dark. Subsamples were taken every 5-7 days for cell density enumeration using the SYBR green I flow cytometry assay described above.

\section{SSU rRNA sequencing}

400-800 $\mu 1$ from the 93 cultures scoring positive for growth were transferred to a $0.2 \mu \mathrm{m}$ Supormembrane 96-well filter plate (Pall Corp.) and vacuum filtered. The cells were resuspend from the filter with two separate aliquots of $125 \mu 1$ of lysis buffer (40mM EDTA, 50mM Tris at pH 8.3, $0.73 \mathrm{M}$ sucrose $1.15 \mathrm{mg} / \mathrm{ml}$ lysozyme (Sigma-Aldrich, St. Louis, MO, USA), $200 \mathrm{ug} / \mathrm{ml}$ RNase (Qiagen) and transferred to a 96 deep-well plate, which was then placed at $-80^{\circ} \mathrm{C}$. After freezing, the plate was thawed, Proteinase K and SDS were added to final concentrations of 0.65 
$\mathrm{mg} \mathrm{ml}^{-1}$ and $10 \% \mathrm{SDS}$, respectively, and allowed to incubate for $2 \mathrm{hr}$ at $55^{\circ} \mathrm{C}$. The lysate was then transferred to new $2 \mathrm{ml}$ deep well plate and DNA extracted using a DNeasy 96 well Blood and Tissue kit (Qiagen).

The SSU rRNA gene was PCR amplified using universal Eubacterial primers pA E.coli 8-28F (5'- AGA GTT TGA TCC TGG CTC AG -3') and E. coli 1510-1492R (5'- GGT TAC CTT GTT ACG ACT T -3') in $50 \mu \mathrm{l}$ reactions consisting of $1 \mu \mathrm{M}$ each forward and reverse primer, $1 \mu \mathrm{l}$ of FailSafe Enzyme Mix (Epicentre, Madison, WI, USA), $25 \mu 1$ of 2x FailSafe PCR PreMix E (Epicentre) water, and $20 \mu 1$ DNA template. After amplification, the PCR amplicons were run on $1 \%$ agarose gel and bands running at $\sim 1500-1600 \mathrm{nt}$ were excised and PCR purified with a 96 well gel extraction kit (Qiagen) followed by an additional purification using the QIAquick 96-well PCR purification kit (Qiagen) and eluted in $80 \mu$ l elution buffer. Sanger sequencing was conducted following the BigDye v3.1 sequencing protocol (Applied Biosystems, Foster City, CA, USA) on a ABI 3730 DNA analyzer (Applied Biosystems) using the SSU rRNA universal primers described above (pA E. coli 8-28, E. coli 1510-1492) and with bacterial primers 519F 5'-CAGCMGCCGCGGTAATWC-3' and 800R 5'-TACCAGGGTATCTAATCC$3 '$.

\section{Whole genome sequencing}

70 cultures were selected for whole genome sequencing based on their growth yields and response to HMW DOM substrate additions. To obtain sufficient amounts of DNA for the NexterXT library preparation, $10 \mu \mathrm{l}$ culture was inoculated into acid-clean polycarbonate bottles containing $200 \mathrm{~mL}$ TFF seawater amended with HMW DOM to 3x DOC. After incubating at $22^{\circ} \mathrm{C}$ in the dark for 4-5 weeks, the cells were harvested on $0.1 \mu \mathrm{m}$ pore-size, $25 \mathrm{~mm}$ diameter Durapore membranes (Millipore Corp.) using Swinnex filter-holders (Millipore Corp.) and 
peristaltic pumping. Filters were stored frozen $\left(-80^{\circ} \mathrm{C}\right)$ in $600 \mu \mathrm{L}$ of tissue lysis buffer (Qiagen). DNA was extracted from thawed filters using a DNeasy Blood and Tissue Kit (Qiagen) following the manufacturer instructions. DNA samples were prepared for sequencing and barcoded using the Nextera XT DNA 96-sample preparation kit (Illumina Co.), and sequenced with one 250x250 nt paired end MiSeq run (Illumina Co.). Sequences are deposited in the NCBI sequence read archive (SRA) under study SRP045600.

\section{Bioinformatic and phylogenetic analysis}

FastQ files from the MiSeq run were imported into the CLC Genomics Workbench (CLC bio, Denmark). Paired reads were joined and then assembled into contigs using CLC's De Novo assembler with automatic word and bubble sizes, a minimum contig length of 200, insertion and deletion costs set to 3 , mismatch cost set to 2 , length fraction set to 0.5 , and the similarity fraction set to 0.8 . Only contigs $\geq 1000 \mathrm{nt}$ in length were further examined. Contigs containing small and large subunit rRNA sequences were identified and annotated by a BLASTn sequence similarity search against the SILVA database (http://www.arb-silva.de, version 111).

To ensure that low abundance reads with a divergent SSU rRNA were not missed during the assembly process the unprocessed miSeq reads were trimmed and paired-end joined using trimomatic (http://www.usadellab.org/cms/?page=trimmomatic) and PandaSeq (https://github.com/neufeld/pandaseq/wiki/PANDAseq-Assembler), respectively. The trimmed and joined reads were compared to the assembled SSU rRNA for each sample via a BLASTn sequence similarity search, with hits having an e-value $<0.001$, a read length $>50 \mathrm{nt}$, and $45 \%$ identity over the BLAST alignment considered significant. The unassembled, but trimmed and joined reads, were also taxonomically binned based on a LAST (Frith, Hamada, \& Horton, 2010; Kiełbasa, Wan, Sato, Horton, \& Frith, 2011) sequence similarity search against NCBI's REfSeq 
database (version 64) with a score penalty for frameshift of 500 and an initial match multiplicity of 10 . Top hits with a score $\geq 40$ and alignment length $\geq 75$ nt were considered significant and used for the taxonomic annotation.

Partial SSU rRNA gene sequences obtained via Sanger sequencing were quality-trimmed, manually inspected, and assembled with Sequencher version 5.1 (GeneCodes, Ann Arbor, MI, USA). SSU rRNA gene sequences from Sanger or WGS were aligned using the SILVA incremental aligner online tool (Pruesse, Peplies, \& Glockner, 2012) and curated in ARB (Ludwig, 2004) using the All-Species Living Tree project release 115 (Munoz et al., 2011). Fulllength SSU rRNA gene sequences obtained from WGS were used to build phylogenetic trees and were deposited in NCBI GenBank under accession numbers KP770034 through KP770106. For the betaproteobacteria OM43 clade strains a tree was inferred from 1350 alignment positions using the RAxML maximum likelihood method (Stamatakis, 2014) and neighbor joining (Saitou \& Nei, 1987). For Gammaproteobacteria isolates, a tree was constructed using 1293 unambiguous alignment positions using RAxML. RAxML 8.0.24 was implemented on Cipres Science Gateway (Miller, Pfeiffer, \& Schwartz, 2010) and neighbor joining was implemented on MEGA5 (Tamura et al., 2011). RAxML trees were curated in EMBL's interactive Tree of Life tool (Letunic \& Bork, 2007).

\section{Results and Discussion}

\section{Molecular characterization of HMW DOM}

HMW DOM was characterized by ${ }^{1} \mathrm{H}$ nuclear magnetic resonance spectroscopy to determine major constituents. The spectrum looked similar to previously published ${ }^{1} \mathrm{H}$ NMR spectra from samples collected at the Natural Energy Laboratory study site (Repeta \& Aluwihare, 2006) with 
strong resonances at $5.5 \mathrm{ppm}$ from carbohydrate anomeric (O-CH-O), $4.0 \mathrm{ppm}$ from carbohydrate $(\mathrm{HCOH}), 2.7$ ppm from N-acetyl N-methyl aminosugar (H3C-N-C(O)CH3), 2.0 ppm from $\mathrm{N}$-acetyl aminosugars $\mathrm{N}-\mathrm{C}(\mathrm{O}) \mathrm{CH} 3)$, and $1.3 \mathrm{ppm}$ from 6-deoxysugar protons. The spectral region between 0.9-3.0 ppm also included a broad unresolved baseline attributed to cooccurring humic substances. Monosaccharide analysis of hydrolysable sugars showed the presence of similar amounts of glucose, galactose, mannose, rhamnose, fucose, and xylose+arabinose. This distribution is typical of HMW DOM hydrolysable sugars in open-ocean surface seawater (Aluwihare et al., 1997). The sum of hydrolysable neutral sugars represents $10 \%$ of total HMW DOC.

\section{Experimental overview}

The culturing method applied here is a modification of the "high-throughput" culturing (HTC) technique described by Connon \& Giovannoni (2002) to isolate marine bacteria in seawater media using dilution to extinction. Our main modification consisted of supplementing filtersterilized natural seawater with HMW DOM $(>1 \mathrm{kDa})$ isolated by ultrafiltration from oligotrophic ocean surface waters (Fig. 2.1). To limit the amount of background DOM in the natural seawater and to increase the probability of obtaining isolates responding to the HMW DOM additions we used relatively nutrient deplete, Sargasso Sea seawater sterilized by tangential flow filtration (TFF) to prepare dilution to extinction samples.

The inoculum was collected from Nahant Bay in the coastal North Atlantic and had an initial cell concentration of $1.5 \times 10^{6}\left( \pm 2.2 \times 10^{5}\right.$ s.d. $)$ cells $\mathrm{ml}^{-1}$. The inoculum was diluted into TFF seawater to a final concentration of 3 cells $\mathrm{ml}^{-1}$ and then divided into three treatments: a no DOM addition $(70 \mu \mathrm{M}$ dissolved organic carbon [DOC] background) and two HMW DOM additions (4x DOC $[280 \mu \mathrm{M}]$, and 10x DOC $[700 \mu \mathrm{M}])$. One $\mathrm{ml}$ aliquots were placed in 48 -well 
cultivation plates and incubated at $24^{\circ} \mathrm{C}$ in the dark. After 4 weeks of incubation, the cultures were diluted 10,000 fold into fresh TFF media containing the appropriate DOM concentrations to ensure viability before the screening.

\section{Growth screen}

After 6-7 weeks of incubation, the cultures were screened for growth by flow cytometry and any well with $>10^{5}$ cells ml $^{-1}$ was scored growth positive. Out of 2520 potential extinction cultures, $93(3.7 \%)$ scored positive. Only 1 of the 840 non-DOM amended inoculated wells $(0.1 \%)$ scored growth positive (Table 2.1 and Table S1). By contrast, the HMW DOM amendments had significantly more wells scoring growth positive (Table 2.1; $<<0.05$, bootstrap comparison with $10^{6}$ iterations; Table S1), increasing the percent recovery to $4.7 \%$ and $6.0 \%$ for the $4 \mathrm{x}$ and $10 \mathrm{x}$ DOC treatments, respectively. Cell concentrations also tended to increase with higher DOM

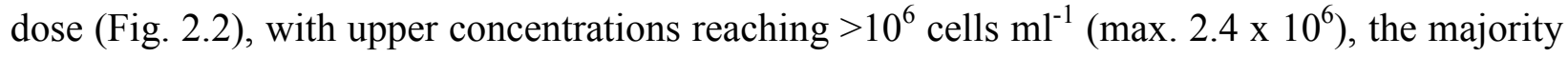
of which occurred in the 10x DOC treatment. No growth was detected in any of the noninoculated control wells (Table 2.1 and Table S1). The single culture obtained from the nonDOM amended treatment showed little sustained growth, and could not be maintained in successive transfers of the culture collection grown on $4 \mathrm{x}$ DOC.

\section{HMW DOM dose response}

To verify that the isolates had a discernible growth response to the HMW DOM, the 93 cultures were tested for increased cell yields with DOM additions. The TFF seawater was first UV oxidized to reduce background DOC concentrations from $70 \mu \mathrm{M}$ DOC to $25 \mu \mathrm{M}$ DOC. HMW DOM was then added at $4 \mathrm{x}(280 \mu \mathrm{M}), 20 \mathrm{x}(1400 \mu \mathrm{M})$, or 100x $(7000 \mu \mathrm{M})$ open-ocean DOC concentrations. Sixty six of the cultures showed an increase in cell yields with DOM addition, reaching $>5 \times 10^{5}$ cells $\mathrm{ml}^{-1}$ in the DOM amended treatments and having no growth in the non- 
DOM amended controls (Fig. S1). Furthermore, 36 cultures showed a direct proportional increase in cell yields with increasing HMW DOM concentrations $(100 x>20 x>4 x)$.

\section{Identification and purity screen}

In an initial phylogenetic screen of the isolates, 88 small subunit (SSU) rRNA gene sequences were determined via PCR amplification and subsequent Sanger sequencing. Ten of these sequences clustered within the Gammaproteobacteria Alteromonadaceae (7 cultures including three members of the SAR92 clade and one of the OM60 clade), Pseudoalteromonadaceae (1 culture), and Vibrio (2 cultures). The remaining 78 sequences all clustered within the OM43 clade of Methylophilaceae betaproteobacteria. There was no significant difference in the relative recovery of any specific taxonomic group in the $4 \mathrm{x}$ versus 10x DOC treatments.

The quality of the SSU rRNA Sanger sequencing provided an initial assessment of culture purity, with positive PCR amplifications yielding poor quality Sanger sequences being potentially indicative of mixed cultures. We applied an additional approach to assess the purity of cultures and identify their phylogenetic origins using "tagmentation" sequencing library preparation and Illumina paired-end sequencing for whole genome shotgun (WGS) sequencing (Fig 1 and see methods). Sixty-eight cultures were successfully sequenced, with an average of 120,000 paired reads (200 X 200 bases) per sample.

The purity of the cultures was assessed using the WGS data in three ways. In the first approach, the reads were de novo assembled into contigs which were then searched via BLASTn against the SILVA rRNA database to identify SSU and LSU rRNA sequences. Samples having multiple rRNA genes binning to different organisms were considered mixed. Ninety percent of the 68 cultures had a single copy small and large subunit rRNA gene binning to one organism 
with high identity (Table 2.2), either an OM43 clade betaproteobacterium (82\%) or miscellaneous Gammaproteobacteria (9\%). Five samples contained multiple rRNA genes hitting two different organisms. These were primarily an OM43 clade betaproteobacteria with a SAR92 clade Gammaproteobacteria, although one culture (NB0016) contained an OM43 clade betaproteobacteria and a flavobacterium.

To verify that rRNAs did not escape detection in the course of sequence assembly we searched for SSU rRNA sequences in the unassembled reads. The quality controlled (trimmed and paired-end joined) unassembled reads were searched against each sample's assembled SSU rRNA sequence. Samples having a large portion of reads matching at low identity were taken as an indication of a mixed culture. Four of the five same samples that yielded multiple, divergent rRNA reads after assembly (Table 2.2) had high levels of low identity rRNA matching reads (517\%; Fig. S2 and S3).

Finally, a metagenomic approach was taken, taxonomically binning the unassembled reads for each sample based on the top hit from a LAST sequence similarity search against NCBI's RefSeq database. For 54 of the 60 cultures with betaprotebacterial SSU rRNA sequences the majority of reads binned to betaproteobacterial reference genomes (Fig. 2.3). The remaining six cultures had a substantial enrichment in reads binning to non-betaprotebacterial reference genomes (17\% to $53 \%$ of total reads). Five of these cultures were also identified as mixed using the SSU rRNA analyses above but the sixth (NB0010) was only confidently detected with the metagenomic approach because the unassembled SSU rRNA analysis revealed only a marginal proportion of low identity SSU rRNA reads (1.4\%). In summary, these three screening approaches produced congruent assessments of culture identity and purity, with only six out of 68 of WGS sequenced cultures indicating the presence of mixed populations. 


\section{Isolate phylogeny}

The WGS assembled SSU rRNA sequences matched excellently with the Sanger reads and provided phylogenetic placement of the culture collection. Of the 58 WGS SSU rRNA sequences (length $=1542 \mathrm{nt}$ ) that had overlapping regions with quality Sanger sequences (489 to $1444 \mathrm{bp}$, quality $>97 \%$ ), only 5 sequences had mismatches between the Sanger and WGS data (NB0034 [10 mismatches], NB0054 [11], NB0057 [32], NB0068 [12], and NB0072 [194]), with the remaining 53 cultures matching at 100\% identity between the two sequencing methods.

The full length WGS assembled rRNA sequences were used to determine the phylogenetic placement of cultures. The OM43 clade cultures consisted of 16 unique groups of sequences that clustered with sequences obtained from coastal metagenomes and clone libraries (Fig. 2.4). The majority of methylotroph isolates were $>99 \%$ identical to one another at the SSU rRNA level with the greatest sequence divergence occurring between isolate NB0027 and NB0070 (96.6\% SSU rRNA identities, Fig. 2.4). The Gammaproteobacteria sequences were more phylogenetically diverse, spanning several Alteromonadales clades and Vibrio (Fig. S4). The SSU rRNA sequence of NB0015 clustered with the SAR92 clade isolate HTCC2207 (SSU 97\% identity). Four additional SAR92 clade SSU rRNA sequences were identified mixed with

OM43 clade cultures and were $98-100 \%$ similar to the NB0015 sequence. The remaining Alteromonadales sequences clustered with Teredinibacter turnerae (NB0011 and NB0077), Alteromonas macleodii (NB0094), and Psychrosphaera saromensis (NB0030). Vibrio sequences (NB0059, NB0072, and NB0080) were closely related to marine strains Vibrio chagasii, Vibrio lentus, and Vibrio pomeroyi (Fig. S4).

\section{Growth responses to differing media and $\mathrm{C}$ substrates}


Two isolates representative of the most commonly identified bacterial groups, OM43 clade betaproteobacterium NB0046 and SAR92 clade gammaproteobacterium NB0015, were selected for further characterization. Growth was undetectable for the OM43 betaproteobacterium NB0046 on rich media (Marine Broth 2216), methanol amended agar plates (Janvier, Frehel, Grimont, \& Gasser, 1985), or TFF seawater amended with glucose and succinate $(100 \mu \mathrm{M}$ each). In non-carbon amended TFF oligotrophic seawater, NB0046 will

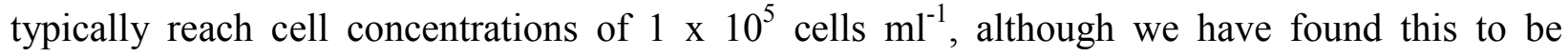
variable, with some cultures showing zero growth in the no carbon amendments, while others can reach almost $10^{6}$ cells $\mathrm{ml}^{-1}$. We also tested cultures in media prepared with UV oxidized seawater. UV oxidation lowers the total amount of naturally occurring DOM in the seawater, but the oxidation process can also produce a broad suite of low molecular weight, highly oxidized organic compounds that could serve as substrates or inhibitors to our isolates (Moran \& Zepp, 1997). However, in our experiments, UV oxidation of the seawater medium consistently reduced growth yields in non-carbon amended cultures to much lower cell concentrations $\left(\leq 10^{3}\right.$ cells $\mathrm{ml}^{-}$ $\left.{ }^{1}\right)$.

The addition of methanol to seawater media significantly increased OM43 isolate cell yields (Fig. 2.5), with maximum cell concentrations achieved between 10-100 $\mu \mathrm{M}$ methanol; higher methanol concentrations $(>1 \mathrm{mM})$ tended to inhibit, rather than increase cell yields, consistent with previous observations of OM43 clade cultures (Halsey et al., 2011). The highest cell yields were achieved with the HMW DOM additions, where isolate NB0046 reached $>5 \times 10^{6}$ cells $\mathrm{ml}^{-1}$ in HMW DOM-containing media at 50x ambient DOC concentrations ( $\sim 4 \mathrm{mM} \mathrm{DOC}$, Fig. 2.5). However, normalizing the observed cell yields to carbon added to the media indicates 
that methanol supports higher growth yields $\left(2.5 \times 10^{7}\right.$ to $2.1 \times 10^{8}$ cells $\left.\mu \mathrm{mol}^{-1} \mathrm{C}\right)$ than HMW DOC treatments $\left(1.6 \times 10^{6}\right.$ to $6.4 \times 10^{6}$ cells $\left.\mu \mathrm{mol}^{-1} \mathrm{C}\right)$.

SAR92 clade gammaproteobacterium NB0015 grew in rich media (Marine Broth 2216), although only at dilute concentrations (1:10 and 1:100 strength). No growth was detected on full strength media, marine agar, seawater amended with methanol, or seawater amended with glucose and succinate (100 $\mu \mathrm{M}$ each). In non-carbon amended TFF oligotrophic seawater, NB0015 reached $1 \times 10^{5}$ cell $\mathrm{ml}^{-1}$. Supplementing TFF oligotrophic seawater with HMW DOM (4x and 8x DOC) increased NB0015 growth to $2-5 \times 10^{5}$ cells $\mathrm{ml}^{-1}$ (Fig. 2.5). The cell yield normalized to carbon added as HMW DOC was $7.1 \times 10^{5}$ cells $\mu \mathrm{mol}^{-1} \mathrm{C}$, an order of magnitude lower than for the OM43 clade isolate NB0046. In contrast, cultures of NB0015 reached on average a maximum cell concentration of $1.5 \times 10^{6}$ cell ml $^{-1}$ when grown in an artificial seawater medium (Kester, Duedall, Connors, \& Pytkowicz, 1967) supplemented with a mix of simple carbon compounds (D-glucose [55 $\mu \mathrm{M}$ ], succinate [85 $\mu \mathrm{M}$ ], pyruvate [114 $\mu \mathrm{M}$ ], glycerol [109 $\mu \mathrm{M}$ ], N-acetyl D-glucosamine [45 $\mu \mathrm{M}$ ], and ethanol [434 $\mu \mathrm{M}$ ]; Fig. S5), consistent with the previous isolation of SAR92 clade strains (Cho \& Giovannoni, 2004).

\section{Conclusion}

Dilution to extinction cultivation has proven a useful approach for obtaining highly abundant but difficult to cultivate bacteria. It enables separation of slower growing cells from faster, more easily cultured microorganisms, and it also allows the growth of cells in media that more closely mimics the native environment. While several studies have supplemented natural seawater media with defined carbon substrates in efforts to improve cell yields (Cho \& Giovannoni, 2004) we applied the alternative approach of enriching seawater media with HMW 
DOM collected directly from the environment. We postulated that the native, complex mixture of marine HMW DOM could increase the probability of obtaining relevant DOM degrading microorganisms. Such isolates could then be used as tools to help define the chemical characteristics of marine HMW DOM and the biological processes that degrade it. A similar tactic was successfully applied by Hutalle-Schmelzer, Zwirnmann, Krüger, \& Grossart (2010) who enriched bacterioplankton dilution cultures with the humic fraction of lake-derived DOM.

In our study, dilution to extinction cultures enriched with HMW DOM increased culturing efficiency and yielded over 90 organisms with DOM degrading capabilities. Our nonDOM amended cultures had lower culturing efficiency $(0.1 \%)$ than previous dilution culturing studies, which typically range from 3 to $25 \%$ (Cho \& Giovannoni, 2004; Connon \& Giovannoni, 2002; Song, Oh, \& Cho, 2009). The reduced culturing efficiency in our experiments may be explained by the deliberate use of oligotrophic Sargasso Sea surface water to prepare the media, which likely has low levels of vitamins (e.g., $<0.1 \mathrm{pM}$ vitamin $\mathrm{B}_{12}$ [Menzel \& Spaeth, 1962], and 20-25 pM thiamin [Carini et al., 2014]), inorganic nutrients (often below detection limits, 0.05 $\mu$ mol $\mathrm{kg}^{-1}$ for nitrate + nitrite and $0.03 \mu$ mol $\mathrm{kg}^{-1}$ for phosphate; http://batsftp.bios.edu/BATS/bottle), and DOC concentrations $(70 \mu \mathrm{M}$; as measured for this study) in the basal media than are typical of coastal seawater. While this oligotrophic medium may have prohibited the enrichment of some coastal microorganisms, its low DOC and nutrient background (inorganic $\mathrm{N}$ and $\mathrm{P}$ were not added) provided greater sensitivity for detecting DOM addition effects without requiring extensive manipulation of the natural media. The fact that culturing efficiencies significantly increased in DOM amended treatments suggested that DOM addition provides, at least partially, growth factor(s) or organic sources of $\mathrm{N}$ and $\mathrm{P}$ that were missing in oligotrophic seawater. 
Establishing the purity of the culture collection is essential for linking the metabolism of DOM to specific taxa, genes and biochemical mechanisms. Determining culture purity, however, can be challenging, especially when a culture contains a secondary isolate at very low abundance (Shrestha, Nevin, Shrestha, \& Lovley, 2013). While SSU rRNA gene sequencing or screens such as restriction fragment length polymorphisms (RFLP) are most often used to identify cultures, they suffer from primer design and preferential amplification biases which can decrease sensitivity for detecting mixed cultures. The WGS screen used in this study does not suffer from oligonucleotide primer mismatch and excludes most other PCR biases thereby providing a more sensitive and universal method for determining culture purity. While PCR-based SSU rRNA gene sequencing revealed no mixed cultures in our study, WGS sequencing showed that 6 of the 68 screened cultures were mixed as congruently determined by three different bioinformatic analyses: 1) number of contigs containing SSU rRNA genes, 2) unassembled read's sequence similarity to assembled SSU rRNA sequences, and 3) unassembled read taxon binning based on sequence similarity search against NCBI's RefSeq database.

The ability of WGS sequencing to identify mixed cultures is directly dependent on the relative abundance of the secondary culture in relation to the sequencing depth, as well as on the phylogenetic relatedness of the co-isolates. In terms of resolving mixed cultures of closely related isolates, we found cultures with no other indication of being mixed had the majority of unassembled SSU rRNA reads at $\geq 98 \%$ identity to the assembled SSU rRNA sequence (Fig. A2), suggesting that two different populations with $<2 \%$ SSU rRNA divergence would be difficult to detect. We note that this would include many of the betaproteobacterial isolates obtained here. The metagenomic approach of identifying mixed cultures via taxonomic binning will be less sensitive than the SSU rRNA bioinformatic approaches to resolving closely related 
populations due to database limitations. The breadth of genes examined using the metagenomic approach, however, should provide greater sensitivity for detecting low abundance but phylogenetically diverse secondary populations. For the betaproteobacterial genomes examined here, 5 to $10 \%$ of unassembled reads had significant matches to non-betaproteobacterial genomes likely due to factors such as short reads lengths, horizontal gene transfer events, and limited reference genomes in the database. This suggests a lower bound for detecting co-isolates at around $10 \%$ total abundance, though we note differences in genome size will also affect this sensitivity. Alternative approaches to increase power for detecting closely related co-isolates at low abundance would likely require more sensitive bioinformatic analysis, such as the statistical frequency of genome single nucleotide polymorphisms (Shrestha et al., 2013) focusing on less conserved genes such as those typically used in multi-locus sequence typing.

De Novo assembly of the WGS data produced contigs containing full length SSU and LSU sequences that were as accurate, and often had 100\% identities, with overlapping Sanger reads. Phylogenetic placement of these WGS SSU rRNA sequences revealed the culture collection was dominated by members of the OM43 clade of betaproteobacteria.

The OM43 clade, initially described by Rappe, Kemp, \& Giovannoni (1997), was first isolated from the Oregon coast by Connon \& Giovannoni (2002). Their distribution is generally limited to the coastal zone, where they can compose 1 to $3 \%$ of the bacterioplankton community (Suzuki et al., 2004), though their abundance has been shown to significantly increase during phytoplankton blooms (Morris, Longnecker, \& Giovannoni, 2006; Rich, Pham, Eppley, Shi, \& DeLong, 2011). Metatranscriptomic and metaproteomic data suggest they are active components of coastal bacterioplankton communities (Gifford, Sharma, \& Moran, 2014; Sowell et al., 2011). The OM43 isolates obtained in this study were closely related to these previously characterized 
coastal strains and sequences (Fig. 2.4). The majority of our isolates clustered most closely with the Hawaiian strain HIMB624 (Huggett, Hayakawa, \& Rappé, 2012) and related SSU rRNA phylotypes identified in diverse coastal locations. Three of our isolates formed an outgroup with the Oregon coastal isolate HTCC2181 as well as sequences obtained primarily from higher latitudes. Though closely related, the presence of SSU rRNA microdiversity within our isolate collection suggests the prevalence of OM43 clade members in the dilution to extinction cultures was not due to the enrichment of a single clonal population.

Genome sequences of OM43 betaproteobacteria are missing the E1 subunit of the $\alpha$ ketoglutarate dehydrogenase complex of the TCA cycle, a trait thought to be indicative of an obligatory methylotrophic lifestyle (Halsey, Carter, \& Giovannoni, 2012; Huggett et al., 2012). A preliminary genome analysis of NB0046 shows that it is also missing the E1 $\alpha$-ketoglutarate dehydrogenase subunit. Furthermore, NB0046 shares similar characteristics with other OM43 lineage genomes(Giovannoni et al., 2008; Huggett et al., 2012), including a small genome size $(<1400$ genes), the presence of an alternative methanol dehydrogenase (XoxF) instead of the canonical Mxa or Mdh methanol dehydrogenase (Chistoserdova, 2011), genes for formaldehyde oxidation via tetrahydrofolate but not via tetrahydromethanopterin, and carbon assimilation through the RUMP cycle instead of the serine cycle. These observations suggest the methylotrophs isolated on HMW DOM have a similar 'obligate' methylotrophic lifestyle as other OM43 clade members, although a more detailed and thorough analysis of the 60 OM43 genomes sequenced here will be required to confirm this.

Given their reliance on single carbon substrates, the predominance of $\mathrm{C} 1$ compound specialists in our cultures amended with HMW DOM was unexpected. Our results, however, are predicated in a previous study by McCarren et al. (2010), who observed that HMW DOM added 
to oligotrophic ocean bacterioplankton microcosms increased the relative abundance and transcriptional activity of methylotrophs, particularly Methylophaga species belonging to the Gammaproteobacteria. McCarren et al. (2010) postulated that HMW DOM polysaccharides containing a large fraction of methylated sugars (Quan \& Repeta, 2007) were the source of single carbon compounds, including methanol, which provided the methylotrophs their growth substrate. We further propose that the prevalence of pure cultures of methylotrophs in our HMW DOM-enriched dilution-to-extinction samples is due to their ability to cleave $\mathrm{C} 1$ groups from the methylated sugars in the DOM polymer. Additionally, low levels of abiotic oxidation of the HMW DOM during collection and storage may possibly degrade the methylated sugars, releasing low molecular weight compounds that can be directly consumed by methylotrophs. In either case, the data indicated that HMW DOM can serve as a sole source of carbon and energy for these methylotrophs.

The order of magnitude difference in growth yields (cell yield normalized to C added) between methanol $\left(6.8 \times 10^{7}\right.$ to $5.3 \times 10^{8}$ cells $\left.\mu \mathrm{mol}^{-1} \mathrm{C}\right)$ and HMW DOM $\left(1.6 \times 10^{6}\right.$ to $6.4 \times 10^{6}$ cells

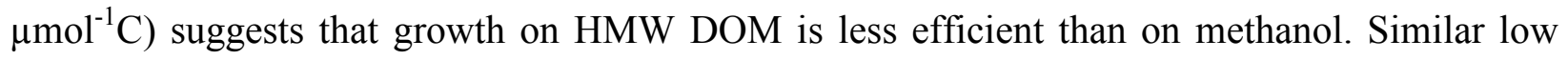
growth yields $\left(7.1 \times 10^{5}\right.$ cells $\left.\mu \mathrm{mol}^{-1} \mathrm{C}\right)$ were observed for SAR92 clade strain NB0015 in cultures amended with HMW DOM. Alternatively, the low growth yields observed may indicate that only a small fraction of HMW DOM may be available to a single organism with limited metabolic potential like isolates NB0046 and NB0015 despite the total amount of DOC added to cultures. The efficiency at which DOC is converted into biomass, typically $<20 \%$ in the openocean (Carlson \& Ducklow, 1996) has implications on the magnitude of carbon that cycles through bacterioplankton. Measurements of DOC drawdown and respiration, though not obtained in HMW DOM dose-response experiments, will be necessary to determine bacterial 
growth efficiencies on HMW DOC and to estimate the bacterial carbon demand this organic carbon pool can support.

The second major taxonomic group found in the HMW DOM enriched cultures was the Gammaproteobacteria. This included isolates belonging to the Alteromonadales and Vibrionales. The Vibrio (NB0059, NB0072, and NB0080), alteromonad (NB0094), and pseudoalteromonad (NB0030) isolates did not exhibit a proportional increase in cell yields in response to added HMW DOM in dose-response experiments even though these isolates were initially obtained from the HMW DOM enriched dilution to extinction cultures. Among the Gammaproteobacteria only strains NB0011 and NB0077 and SAR92 clade isolates increased their growth proportionally in the presence of HMW DOM. The SAR92 clade isolate NB0015 exhibited the

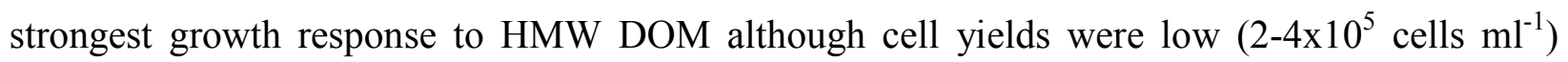
compared to the OM43 clade isolates $\left(>5 \times 10^{6}\right.$ cells $\left.\mathrm{ml}^{-1}\right)$. However, NB0015 growth yields reached $>1 \times 10^{6}$ cells $\mathrm{ml}^{-1}$ when cultured in defined media with a mixture of simple carbon substrates indicating that this isolate may require a variety of carbon compounds and nutrients not available in HMW DOM to supplement its metabolism. The SAR92 clade was the most frequently recovered Gammaproteobacteria group in the dilution to extinction cultures including four SAR92 clade-related SSU rRNA sequences found mixed with cultures of OM43 clade strains, more than any other taxa. Including these additional sequences, the SAR92 clade was the second most common group identified in our dilution to extinction cultivation experiment.

The growth of SAR92 clade strains in our HMW DOM-amended samples may partially be explained by its numerical abundance in coastal bacterioplankton assemblages (Stingl et al., 2007) and their ease of recovery by dilution to extinction cultivation (Cho \& Giovannoni, 2004). These factors alone, however, do not solely account for the prevalence of SAR92 in our cultures 
since SAR92 was only identified in the HMW DOM enriched dilution to extinction cultures and not in the non-DOM amended cultures. We postulate that the carbohydrate-rich component of HMW DOM in particular may have stimulated the growth of SAR92 bacteria. Some of the closest relatives of the SAR92 clade (90-93\% SSU rRNA identity) include cultured isolates with carbohydrate degrading capabilities. For example, Microbulbifer hydrolyticus (González, Mayer, Moran, Hodson, \& Whitman, 1997), Saccharophagus degradans 2-40 (Andrykovitch \& Marx, 1988; Weiner et al., 2008) and Simiduia agarivorans SA1 (Lin, Shieh, Chen, \& Tang, 2013; Shieh, Liu, Lin, Jean, \& Chen, 2008) can breakdown several recalcitrant polysaccharides, including agar, alginate, cellulose, or chitin. Another relative, Teredinibacter turnerae T7902, a bacterium associated with wood-boring bivalves, is capable of digesting cellulose (Distel, Morrill, MacLaren-Toussaint, Franks, \& Waterbury, 2002). It is plausible that SAR92 clade strains may directly degrade HMW DOM polysaccharides in contrast to the OM43 clade methylotrophs which may utilize $\mathrm{C} 1$ compounds that decorate the polysaccharides. The availability of model laboratory organisms able to grow on HMW DOM now allows us to test these hypotheses. Future work chemically characterizing the HMW DOM before and after microbial degradation, as well as examining the transcriptional and proteomic responses of the isolates during DOM metabolism will help determine the bonded nature of the carbon sustaining the cultures.

In summary, dilution to extinction cultures enriched with HMW DOM extended the power of the dilution cultivation technique by not only growing cells in a media closely mimicking their native environment, but also by stimulating growth using naturally derived organic substrates. This approach is critical for obtaining model DOM degrading isolates as both the carbon substrates and the organisms acting upon them are unknown. Using this technique we 
found that organisms ranging from obligate methylotrophs to less fastidious microorganisms were able to grow using oligotrophic ocean HMW DOM as a substrate, suggesting there are multiple metabolic strategies involved in the degradation of HMW DOM. We note, however, that only a fraction of the total DOM added to our cultures was remineralized, suggesting that there were other growth limiting factors, or potential requirement for syntrophic microbial partners to further degrade the DOM polymers (McCarren et al., 2010). Co-culture experiments will likely be essential to further elaborate the biological, physiological and biochemical details of consortial DOM degradation processes in the sea.

\section{Acknowledgements}

We thank Jamie Becker for DOC concentration analyses, technical assistance, and providing advice and feedback. We are also indebted to Tsultrim Palden for assistance in DNA extraction and sequencing. This research was funded by the Gordon and Betty Moore Foundation through Grant GBMF3298 to D.J. Repeta and E.F. DeLong, and NSF Science and Technology Center grant EF0424599 (EFD). 


\section{Tables}

Table 2.1. HMW DOM-enriched dilution to extinction cultivation experimental design and growth screen results. Forty-eight well plates were filled with TFF oligotrophic seawater amended with HMW DOM at 4x $(280 \mu \mathrm{M})$ DOC, 10x $(700 \mu \mathrm{M})$ DOC or non-amended and then inoculated with the diluted coastal bacterioplankton community. The 'controls' consisted of six wells on each treatment plate, as well as an entire microtiter plate, that contained the same media and DOM enrichment, but were not inoculated. Positive growth ('cultures detected') was defined as a well having a density of 105 or more cells per ml after 6-7 weeks of incubation and one round of redilution.

\begin{tabular}{r|rrrrr}
\hline & & noDOM & 4X DOM & 10X DOM & total \\
\hline \multirow{2}{*}{ wells } & innoculated & 840 & 840 & 840 & 2520 \\
& controls & 54 & 54 & 54 & 162 \\
\multirow{2}{*}{$\begin{array}{c}\text { cultures } \\
\text { detected }\end{array}$} & innoculated & 1 & 40 & 52 & 93 \\
& controls & 0 & 0 & 0 & 0 \\
\hline
\end{tabular}




\section{Figures}

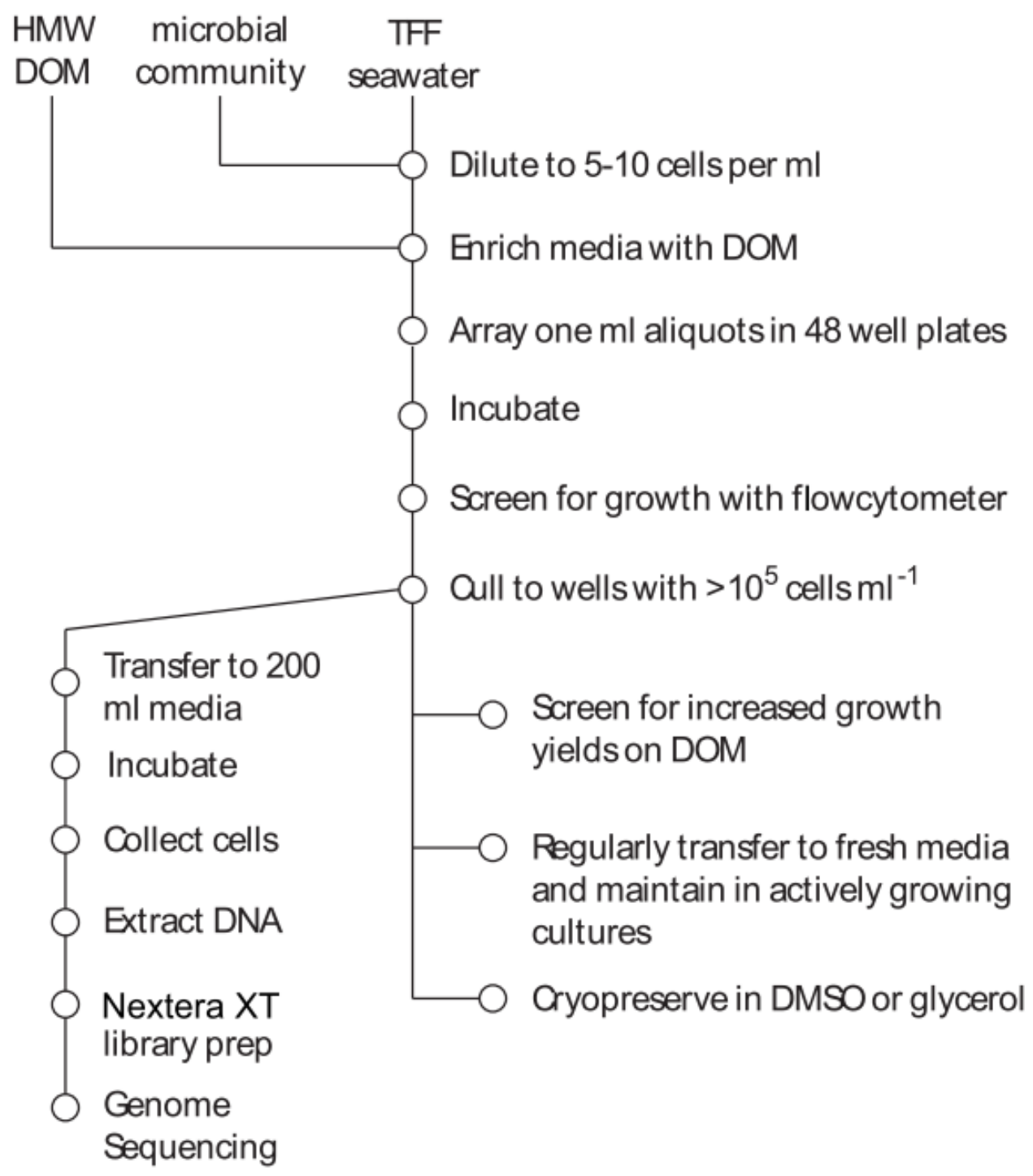

Figure 2.1. Procedure for the setup, incubation, screening and downstream analysis of dilution to extinction cultures enriched with high molecular weight dissolved organic matter (HMW DOM), including purity screening and phylogenetic identification via wholegenome sequencing. TFF, tangential-flow filtered. 




Figure 2.2. Effect of HMW DOM enrichment on dilution to extinction cultures' final cell density. Only wells that scored positive for growth ( $\geqslant 105$ cells per $\mathrm{ml})$ are included. NP, no positive cultures detected; 4x DOC, $\sim 280 \mu$ M DOC; $10 \times$ DOC, $\sim 700 \mu$ M DOC. 


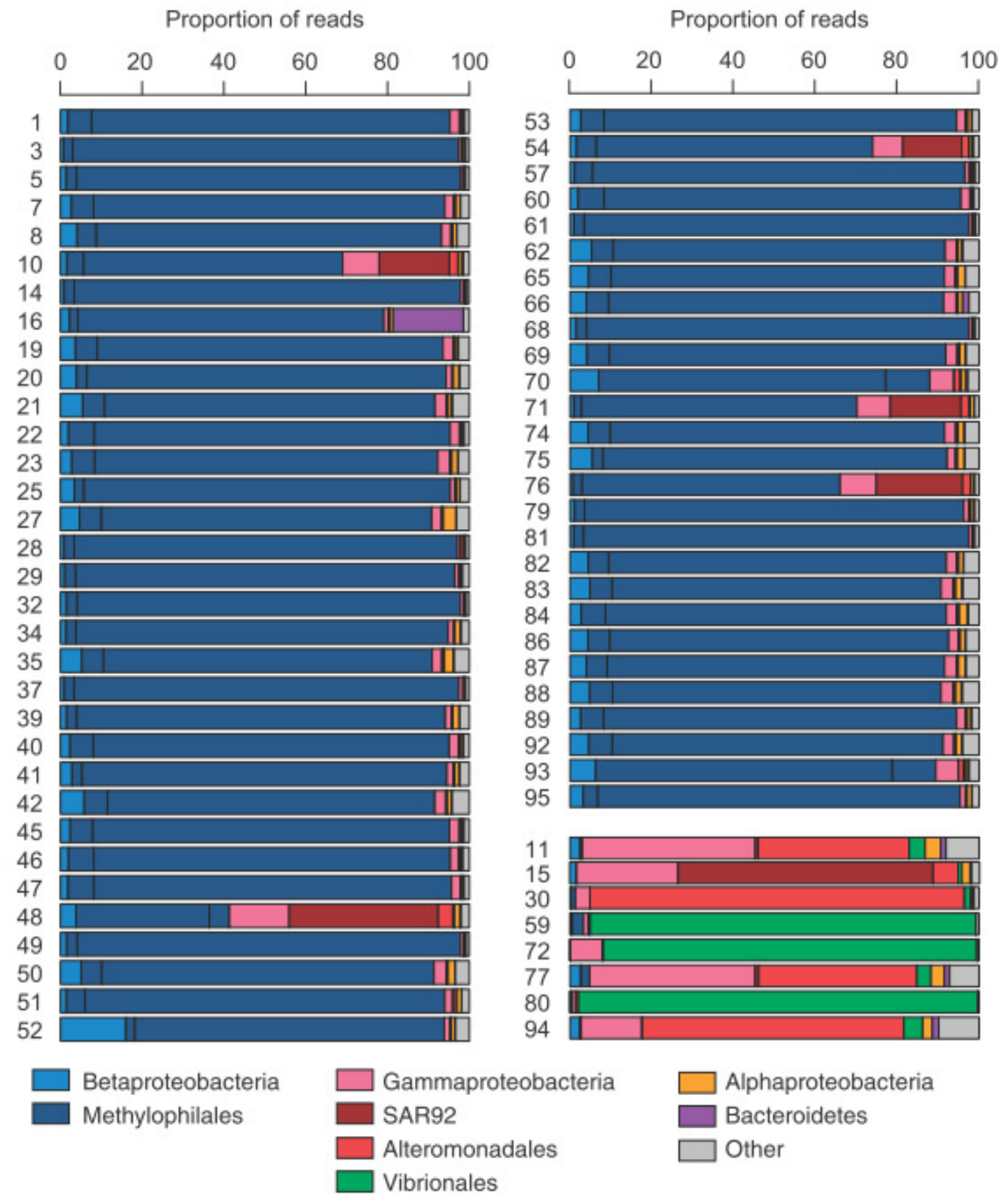

Figure 2.3. Taxonomic binning of unassembled reads based on the top hit of a LAST sequence similarity search against NCBI's REFSeq database. The culture identification number (NB00\#\#) is located on the left of the sample bar. 


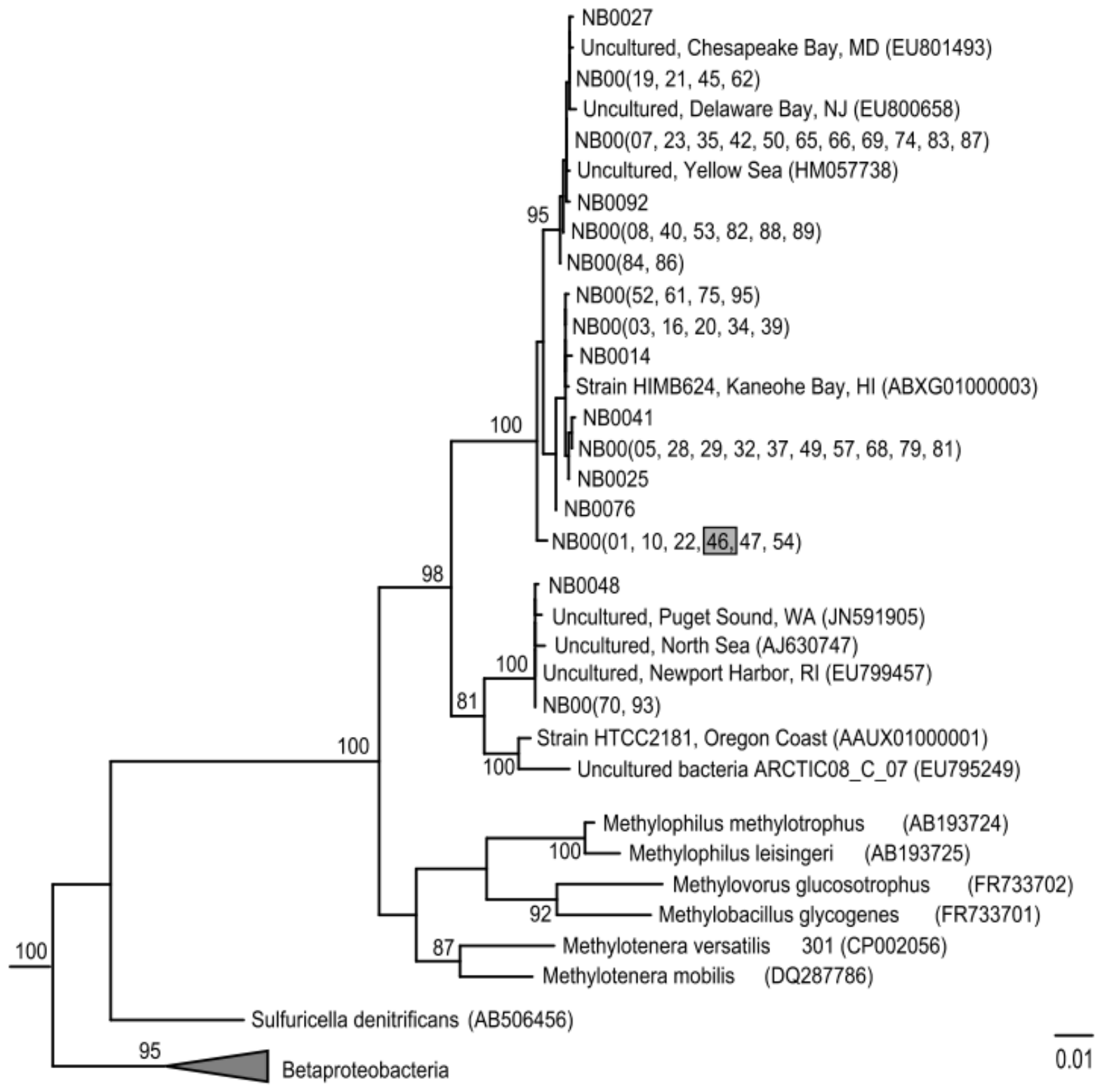

Figure 2.4. Phylogenetic relationships based on the SSU rRNA gene extracted from the whole-genome sequences of Nahant Bay isolates (NB00\#\#) belonging to the OM43 clade of Betaproteobacteria. The grey box highlights strain NB0046 used in additional growth experiments (Fig. 2.5). The tree was inferred from 1350 alignment positions from sequences curated in the ARB software using the RAxML (maximum likelihood) method. RAxML bootstrap values (1000 replicates) are shown (480\%) on nodes. Neighbor-joining inference method also produced bootstrap values $480 \%$ for these nodes. The scale bar indicates substitutions per site. Gammaproteobacteria and Alphaproteobacteria sequences (not shown) were used as outgroups. 

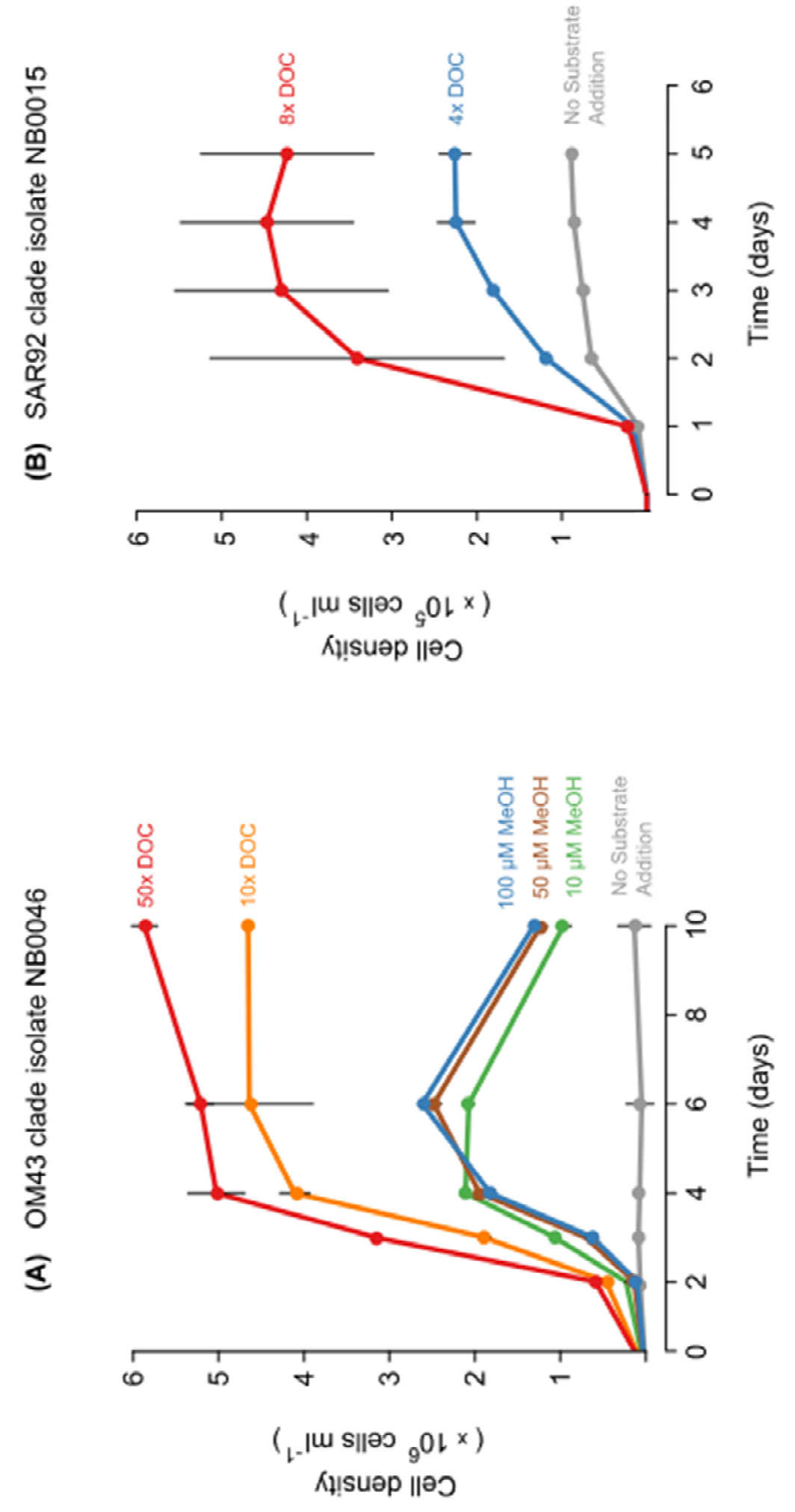

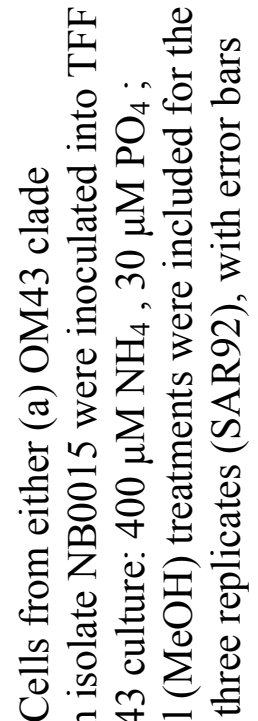

U



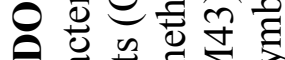

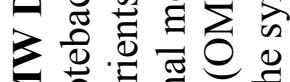

$\sum$ 을

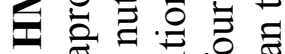

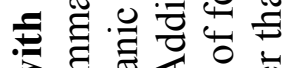

䗐

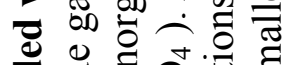

อ

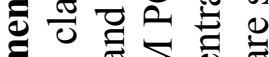
지 $\sum$ ब

ส $2 \sum^{\circ}$

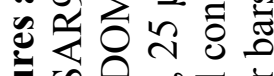

当 थ

อิํํㅇำ

它至之宓

울

\%

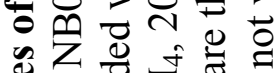

¿

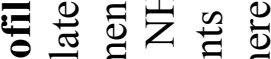

ㄴ.

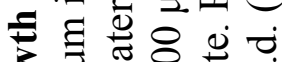

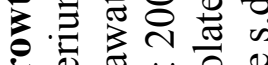

Ð

ம

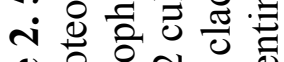

늘 을

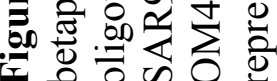




\section{References}

Aluwihare, L. I., \& Repeta, D. J. (1999). A comparison of the chemical characteristics of oceanic DOM and extracellular DOM produced by marine algae. Marine Ecology Progress Series, $186,105-117$.

Aluwihare, L. I., Repeta, D. J., \& Chen, R. F. (1997). A major biopolymeric component to dissolved organic carbon in surface sea water. Nature 387, 166-169.

Aluwihare, L. I., Repeta, D. J., Pantoja, S., \& Johnson, C. G. (2005). Two chemically distinct pools of organic nitrogen accumulate in the ocean. Science, 308, 1007-1010.

Andrykovitch, G., \& Marx, I. (1988). Isolation of a new polysaccharide-digesting bacterium from a salt marsh. Applied and Environmental Microbiology, 54(4), 1061-1062.

Baik, Y. S., \& Cheong, W. J. (2007). Development of SPE for recovery of polysaccharides and its application to the determination of monosaccharides composition of the polysaccharide sample of a lactobacillus KLB 58. Journal of Separation Science, 30, 1509-1515.

Becker, J. W., Brandon, M. L., \& Rappé, M. S. (2007). Cultivating Microorganisms from Dilute Aquatic Environments: Melding Traditional Methodology with New Cultivation Techniques and Molecular Methods. In C. J. Hurst, R. Crawford, J. Garland, D. Lipson, A. Mills, \& L. Stetzenbach (Eds.). Manual of Environmental Microbiology (3rd ed., pp. 339406). ASM Press, Washington D. C.

Beier, S., Rivers, A. R., Moran, M. A., \& Obernosterer, I. (2014). The transcriptional response of prokaryotes to phytoplankton-derived dissolved organic matter in seawater. Environmental Microbiology, 17(10), 3466-3480.

Benner, R. (2002). Chemical Composition and Reactivity. In Hansell, D. A. and Carlson, C. A. (Eds.). Biogeochemistry of Marine Dissolved Organic Matter (pp. 59-90). Academic Press, San Diego.

Benner, R., Pakulski, J. D., McCarthy, M., Hedges, J. I., \& Hatcher, P. G. (1992). Science, 255, 1561-1564.

Button, D. K., Schut, F., Quang, P., Martin, R., \& Robertson, B. R. (1993). Viability and isolation of marine bacteria by dilution culture: Theory, procedures, and initial results. Applied and Environmental Microbiology, 59(3), 881-891.

Carini, P., Campbell, E. O., Morré, J., Sañudo-Wilhelmy, S. a, Thrash, J. C., Bennett, S. E., ... Giovannoni, S. J. (2014). Discovery of a SAR11 growth requirement for thiamin's pyrimidine precursor and its distribution in the Sargasso Sea. The ISME Journal, 8, 172738. 
Carlson, C. A. (2002). Production and Removal Processes. In Hansell D. A. and Carlson, C. A. (Eds.). Biogeochemistry of Marine Dissolved Organic Matter (pp. 139-151). Academic Press, San Diego.

Carlson, C. a, Giovannoni, S. J., Hansell, D. a, Goldberg, S. J., Parsons, R., \& Vergin, K. (2004). Interactions among dissolved organic carbon, microbial processes, and community structure in the mesopelagic zone of the northwestern Sargasso Sea. Limnology and Oceanography, 49, 1073-1083.

Carlson, C. A., \& Ducklow, H. W. (1996). Growth of bacterioplankton and consumption of dissolved organic carbon in the Sargasso Sea. Aquatic Microbial Ecology, 10, 69-85.

Chistoserdova, L. (2011). Modularity of methylotrophy, revisited. Environmental Microbiology, $13,2603-2622$.

Cho, J. C., \& Giovannoni, S. J. (2004). Cultivation and growth characteristics of a diverse group of oligotrophic marine Gammaproteobacteria. Applied and Environmental Microbiology, $70(1), 432-440$.

Clark, L. L., \& Ingall, E. D. (1998). Marine phosphorus is selectively remineralized. Nature, $393,426$.

Connon, S. A, \& Giovannoni, S. J. (2002). High-throughput methods for culturing microorganisms in very-low-nutrient media yield diverse new marine isolates. Applied and Environmental Microbiology, 68(8), 3878-3885.

Distel, D. L., Morrill, W., MacLaren-Toussaint, N., Franks, D., \& Waterbury, J. (2002).

Teredinibacter turnerae gen. nov., sp. nov., a dinitrogen-fixing, cellulolytic, endosymbioticproteobacterium isolated from the gills of wood-boring molluscs (Bivalvia: Teredinidae). International Journal of Systematic and Evolutionary Microbiology, 52, 2261-2269.

Eloe, E. A, Malfatti, F., Gutierrez, J., Hardy, K., Schmidt, W. E., Pogliano, K., ... Bartlett, D. H. (2011). Isolation and characterization of a psychropiezophilic alphaproteobacterium. Applied and Environmental Microbiology, 77(22), 8145-8153.

Frith, M. C., Hamada, M., \& Horton, P. (2010). Parameters for accurate genome alignment. BMC Bioinformatics, 11, 80 .

Gifford, S. M., Sharma, S., \& Moran, M. A. (2014). Linking activity and function to ecosystem dynamics in a coastal bacterioplankton community. Frontiers in Microbiology, 5, 1-12.

Giovannoni, S. J., Hayakawa, D. H., Tripp, H. J., Stingl, U., Givan, S. a., Cho, J. C., ... Rappé, M. S. (2008). The small genome of an abundant coastal ocean methylotroph. Environmental Microbiology, 10, 1771-1782. 
González, J. M., Mayer, F., Moran, M. a, Hodson, R. E., \& Whitman, W. B. (1997).

Microbulbifer hydrolyticus gen. nov., sp. nov., and Marinobacterium georgiense gen. nov., sp. nov., two marine bacteria from a lignin-rich pulp mill waste enrichment community. International Journal of Systematic Bacteriology, 47(706), 369-376.

Grote, J., Cameron Thrash, J., Huggett, M. J., Landry, Z. C., Carini, P., Giovannoni, S. J., \& Rappé, M. S. (2012). Streamlining and core genome conservation among highly divergent members of the SAR11 clade. mBio, 3(5), e00252-12.

Halsey, K. H., Carter, A. E., \& Giovannoni, S. J. (2012). Synergistic metabolism of a broad range of $\mathrm{C} 1$ compounds in the marine methylotrophic bacterium HTCC2181. Environmental Microbiology, 14, 630-640.

Huggett, M. J., Hayakawa, D. H., \& Rappé, M. S. (2012). Genome sequence of strain HIMB624, a cultured representative from the OM43 clade of marine Betaproteobacteria. Standards in Genomic Sciences, 6, 11-20.

Hutalle-Schmelzer, K. M. L., Zwirnmann, E., Krüger, A., \& Grossart, H. P. (2010). Enrichment and cultivation of pelagic bacteria from a humic lake using phenol and humic matter additions. FEMS Microbiology Ecology, 72, 58-73.

Janvier, M., Frehel, C., Grimont, F., \& Gasser, F. (1985). Methylophaga marina gen. nov., sp. nov. and Methylophaga thalassica sp. nov., marine methylotrophs. International Journal of Systematic Bacteriology, 35(2), 131-139.

Kester, D. R., Duedall, I. W., Connors, D. N., \& Pytkowicz, R. M. (1967). Preparation of artificial seawater. Limnology and Oceanography, 12(1), 176-179.

Kiełbasa, S. M., Wan, R., Sato, K., Horton, P., \& Frith, M. C. (2011). Adaptive seeds tame genomic sequence comparison. Genome Research, 21, 487-93.

Kolowith, L. C., Ingall, E. D., \& Benner, R. (2001). Composition and cycling of marine organic phosphorus. Limnology and Oceanography, 46(2), 309-320.

Landa, M., Cottrell, M. T., Kirchman, D. L., Kaiser, K., Medeiros, P. M., Tremblay, L., ... Obernosterer, I. (2013). Phylogenetic and structural response of heterotrophic bacteria to dissolved organic matter of different chemical composition in a continuous culture study. Environmental Microbiology, 16(6):1668-1681.

Letunic, I., \& Bork, P. (2007). Interactive tree of life (iTOL): An online tool for phylogenetic tree display and annotation. Bioinformatics, 23, 127-128.

Lin, S. Y., Shieh, Y., Chen, J., \& Tang, S. (2013). Complete genome sequence of Simiduia agarivorans SA1 T, a marine bacterium able to degrade a variety of polysaccharides. Genome Announcements, 1(1), 1-2. 
Ludwig, W. (2004). ARB: a software environment for sequence data. Nucleic Acids Research, 32(4), 1363-1371.

Malmstrom, R. R., Kiene, R. P., Cottrell, M. T., \& Kirchman, D. L. (2004). Contribution of SAR11 both dissolved dimethylsulfoniopropionate and amino acid uptake in the North Atlantic Ocean contribution of SAR11 bacteria to dissolved dimethylsulfoniopropionate and amino acid uptake in the North Atlantic Ocean. Applied and Environmental Microbiology, 70(7), 4129-4135.

Marshall, K. T., \& Morris, R. M. (2012). Isolation of an aerobic sulfur oxidizer from the SUP05/Arctic96BD-19 clade. The ISME Journal, 7(2), 452-455.

McCarren, J., Becker, J. W., Repeta, D. J., Shi, Y., Young, C. R., Malmstrom, R. R., ... DeLong, E. F. (2010). Microbial community transcriptomes reveal microbes and metabolic pathways associated with dissolved organic matter turnover in the sea. Proceedings of the National Academy of Sciences of the USA, 107, 16420-7.

McCarthy, M. D., Pratum, T., Hedges, J. I., \& Benner, R. (1997). Chemical composition of dissolved organic nitrogen in the ocean. Nature, 390, 150-154.

Menzel, D. W., \& Spaeth, J. P. (1962). Occurrence of vitamin B12 in the Sargasso Sea. Limnology and Oceanography, 7, 151-154.

Meon, B., \& Kirchman, D. L. (2001). Dynamics and molecular composition of dissolved organic material during experimental phytoplankton blooms. Marine Chemistry, 75, 185-199.

Miller, M. a, Pfeiffer, W., \& Schwartz, T. (2010). Creating the CIPRES Science Gateway for inference of large phylogenetic trees. 2010 Gateway Computing Environments Workshop, GCE 2010, 1-8.

Moran, M. A., \& Zepp, R. G. (1997). Role of photoreactions in the formation of biologically labile compounds from dissolved organic matter. Limnology and Oceanography, 42(6), 1307-1316.

Morris, R. M., Longnecker, K., \& Giovannoni, S. J. (2006). Pirellula and OM43 are among the dominant lineages identified in an Oregon coast diatom bloom. Environmental Microbiology, 8, 1361-1370.

Munoz, R., Yarza, P., Ludwig, W., Euzéby, J., Amann, R., Schleifer, K.-H., ... Rosselló-Móra, R. (2011). Release LTPs 104 of the All-Species Living Tree. Systematic and Applied Microbiology, 34, 169-70.

Nelson, C. E., \& Carlson, C. A. (2012). Tracking differential incorporation of dissolved organic carbon types among diverse lineages of Sargasso Sea bacterioplankton. Environmental Microbiology, 14, 1500-1516. 
Poretsky, R. S., Sun, S., Mou, X., \& Moran, M. A. (2010). Transporter genes expressed by coastal bacterioplankton in response to dissolved organic carbon. Environmental Microbiology, 12, 616-627.

Pruesse, E., Peplies, J., \& Glockner, F. O. (2012). SINA: Accurate high-throughput multiple sequence alignment of ribosomal RNA genes. Bioinformatics, 28(14), 1823-1829.

Quan, T. M., \& Repeta, D. J. (2007). Periodate oxidation of marine high molecular weight dissolved organic matter: Evidence for a major contribution from 6-deoxy- and methyl sugars. Marine Chemistry, 105, 183-193.

Rappé, M. S., Connon, S. A, Vergin, K. L., \& Giovannoni, S. J. (2002). Cultivation of the ubiquitous SAR11 marine bacterioplankton clade. Nature, 418, 630-633.

Rappé, M. S., Kemp, P. F., \& Giovannoni, S. J. (1997). Phylogenetic diversity of marine coastal picoplankton 16S rRNA genes cloned from the continental shelf off Cape Hatteras, North Carolina. Limnology and Oceanography, 42, 811-826.

Redfield, A C., Ketchum, B. H., \& Richards, F. A. (1963). The influence of organisms on the composition of sea water. In Hill, M. N. (Ed.) The Sea, vol. 2. (pp. 26-27). Interscience Publishers, New York.

Repeta, D. J., \& Aluwihare, L. I. (2006). Radiocarbon analysis of neutral sugars in highmolecular-weight dissolved organic carbon: Implications for organic carbon cycling. Limnology and Oceanography, 51(2), 1045-1053.

Rich, V. I., Pham, V. D., Eppley, J., Shi, Y., \& DeLong, E. F. (2011). Time-series analyses of Monterey Bay coastal microbial picoplankton using a "genome proxy" microarray. Environmental Microbiology, 13, 116-134.

Saitou, N., \& Nei, M. (1987). The neighbor-joining method: A new method for reconstructing phylogenetic trees. Molecular Biology and Evolution, 4(4), 406-425.

Sarmento, H., \& Gasol, J. M. (2012). Use of phytoplankton-derived dissolved organic carbon by different types of bacterioplankton. Environmental Microbiology, 14, 2348-2360.

Sarmento, H., Romera-Castillo, C., Lindh, M., Pinhassi, J., Sala, M. M., Gasol, J. M., ... Taylor, G. T. (2013). Phytoplankton species-specific release of dissolved free amino acids and their selective consumption by bacteria. Limnology and Oceanography, 58(3), 1123-1135.

Schwalbach, M. S., Tripp, H. J., Steindler, L., Smith, D. P., \& Giovannoni, S. J. (2010). The presence of the glycolysis operon in SAR11 genomes is positively correlated with ocean productivity. Environmental Microbiology, 12, 490-500.

Sharma, A. K., Becker, J. W., Ottesen, E. a, Bryant, J. a, Duhamel, S., Karl, D. M., ... DeLong, E. F. (2014). Distinct dissolved organic matter sources induce rapid transcriptional 
responses in coexisting populations of Prochlorococcus, Pelagibacter and the OM60 clade. Environmental Microbiology, 16, 2815-30.

Shieh, W. Y., Liu, T. Y., Lin, S. Y., Jean, W. D., \& Chen, J. S. (2008). Simiduia agarivorans gen. nov., sp. nov., a marine, agarolytic bacterium isolated from shallow coastal water from Keelung, Taiwan. International Journal of Systematic and Evolutionary Microbiology, 58, 895-900.

Shrestha, P. M., Nevin, K. P., Shrestha, M., \& Lovley, D. R. (2013). When is a microbial culture "Pure"? Persistent cryptic contaminant escapes detection even with deep genome sequencing. mBio, 4(2), e00591-12.

Song, J., Oh, H. M., \& Cho, J. C. (2009). Improved culturability of SAR11 strains in dilution-toextinction culturing from the East Sea, West Pacific Ocean. FEMS Microbiology Letters, $295,141-147$

Sowell, S. M., Abraham, P. E., Shah, M., Verberkmoes, N. C., Smith, D. P., Barofsky, D. F., \& Giovannoni, S. J. (2011). Environmental proteomics of microbial plankton in a highly productive coastal upwelling system. The ISME Journal, 5(5), 856-865.

Stamatakis, A. (2014). RAxML version 8: A tool for phylogenetic analysis and post-analysis of large phylogenies. Bioinformatics, 30, 1312-1313.

Stingl, U., Desiderio, R. a., Cho, J. C., Vergin, K. L., \& Giovannoni, S. J. (2007). The SAR92 clade: An abundant coastal clade of culturable marine bacteria possessing proteorhodopsin. Applied and Environmental Microbiology, 73(7), 2290-2296.

Sun, J., Steindler, L., Thrash, J. C., Halsey, K. H., Smith, D. P., Carter, A. E., ... Giovannoni, S. J. (2011). One carbon metabolism in SAR11 pelagic marine bacteria. PLoS ONE, 6(8).

Suzuki, M. T., Preston, C. M., Béjà, O., de la Torre, J. R., Steward, G. F., \& DeLong, E. F. (2004). Phylogenetic screening of ribosomal RNA gene-containing clones in bacterial artificial chromosome (BAC) libraries from different depths in Monterey Bay. Microbial Ecology, 48, 773-775.

Tamura, K., Peterson, D., Peterson, N., Stecher, G., Nei, M., \& Kumar, S. (2011). MEGA5: Molecular evolutionary genetics analysis using maximum likelihood, evolutionary distance, and maximum parsimony methods. Molecular Biology and Evolution, 28(10), 2731-2739.

Weiner, R. M., Taylor, L. E., Henrissat, B., Hauser, L., Land, M., Coutinho, P. M., ... Hutcheson, S. (2008). Complete genome sequence of the complex carbohydrate-degrading marine bacterium, Saccharophagus degradans strain 2-40T. PLoS Genetics, 4(5), e1000087.

Williams, P. M., \& Druffel, E. R. M. (1987). Radiocarbon in dissolved organic matter in the central North Pacific Ocean. Nature, 330, 246-248. 


\section{Supplemental material}

Table S1. Cell counts of dilution to extinction wells after growth screen. Wells with $>\mathbf{1 0 0 , 0 0 0}$ cell $\mathbf{~ m l}^{-1}$ were scored positive. Sterile wells were prepared on separate plates than control wells, which were prepared on the treatment plates (6 per plate).

\begin{tabular}{cccccc}
\hline $\mathbf{1 0}^{3}$ Cells $^{-1}$ & Sterile wells & Control wells & No DOC & 4X DOC & 10X DOC \\
\hline$<\mathbf{1 0}$ & 48 & 360 & 953 & 908 & 876 \\
$\mathbf{1 0 - 5 0}$ & 0 & 0 & 4 & 11 & 30 \\
$\mathbf{5 0 - 1 0 0}$ & 0 & 0 & 2 & 1 & 2 \\
$\mathbf{1 0 0 - 5 0 0}$ & 0 & 0 & 0 & 7 & 5 \\
$\mathbf{5 0 0 - 1 0 0 0}$ & 0 & 0 & 1 & 13 & 11 \\
$>\mathbf{1 0 0 0}$ & 0 & 0 & 0 & 20 & 36 \\
Total wells & 48 & 360 & 960 & 960 & 960 \\
& & & & & \\
\hline
\end{tabular}




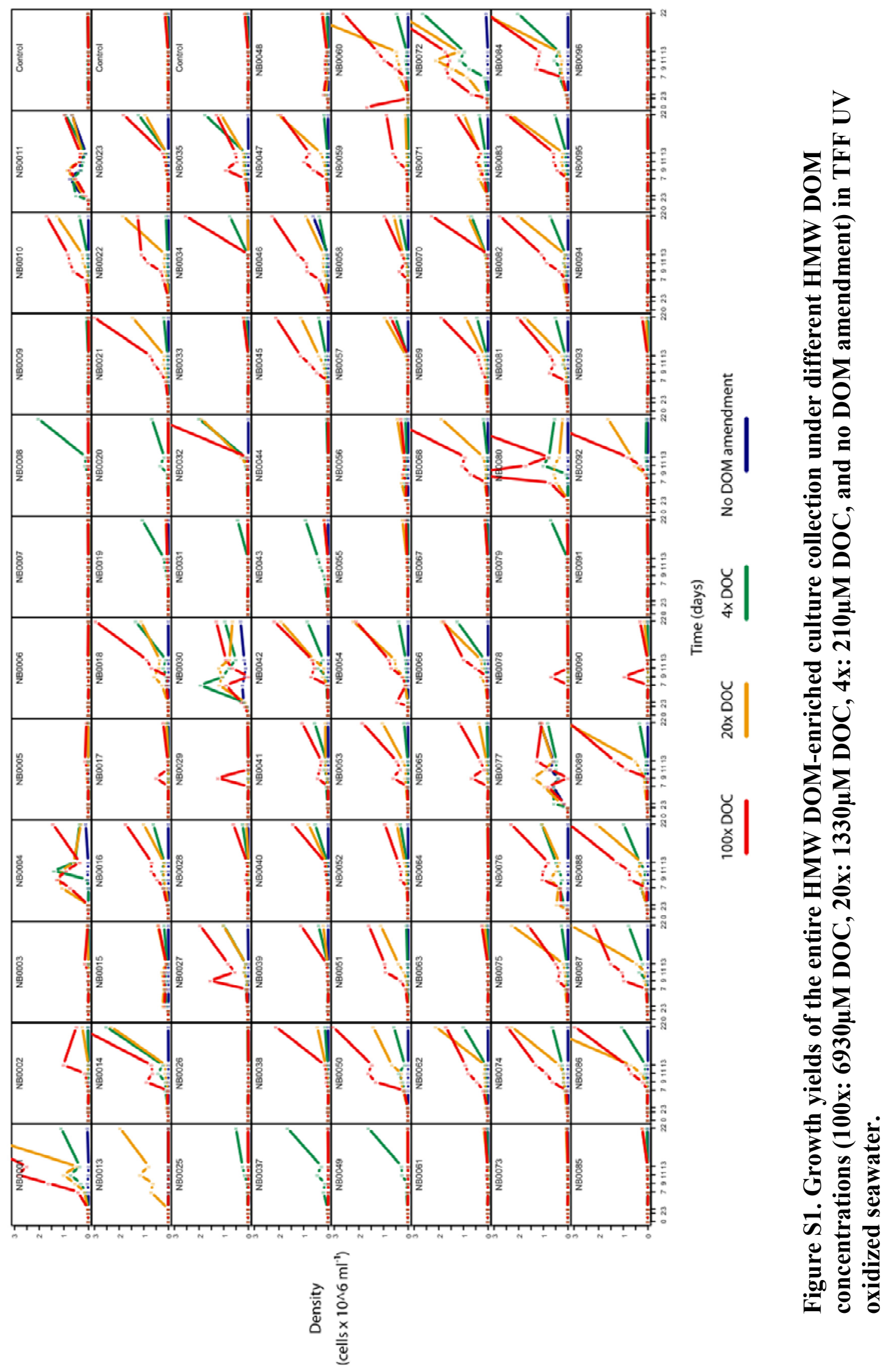




\section{(Opposite page)}

Figure S2. Distribution of the cultures' unassembled SSU rRNA reads' percent identity to the assembled SSU rRNA sequence. Quality controlled unassembled reads $>50 \mathrm{nt}$ in length were compared to the assembled SSU sequences via a BLASTn search, with reads hitting the SSU rRNA with a bit score $>50$ considered significant hits. The distribution of percent IDs from the BLASTn search is shown as a boxplot, with the bottom and top of the box representing the $1^{\text {st }}$ and $3^{\text {rd }}$ quartiles, and the inner notch marking the median. Outliers (percent IDs $>1.5$ times the interquartile range) are shown as individual points. The total reads meeting the BLASTn significance criteria, as well as the percent of those reads at less than $90 \%$ identity to the assembled sequence, are shown at the bottom. The culture identification number (NB00\#\#) is shown above its respective plot. 

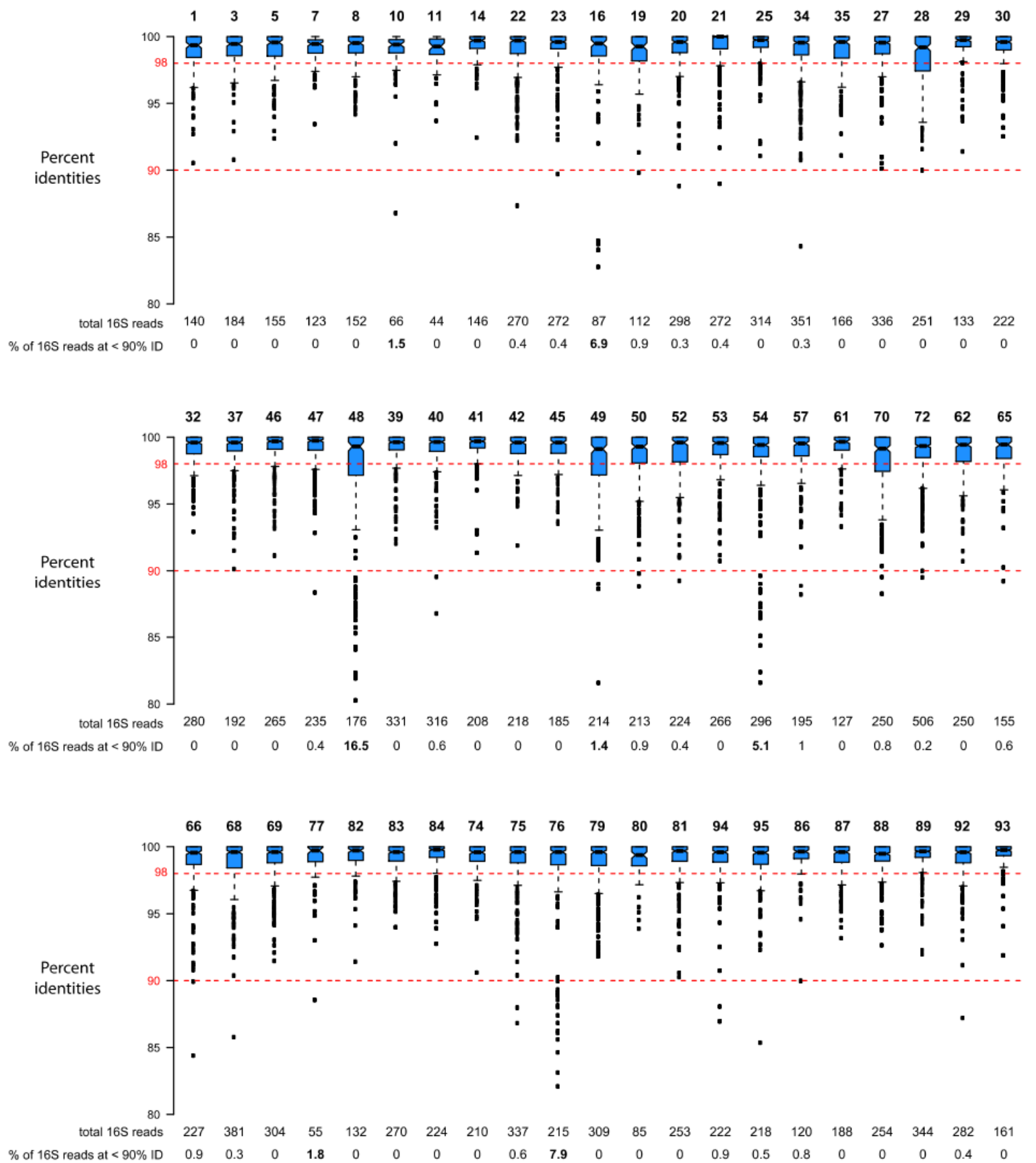


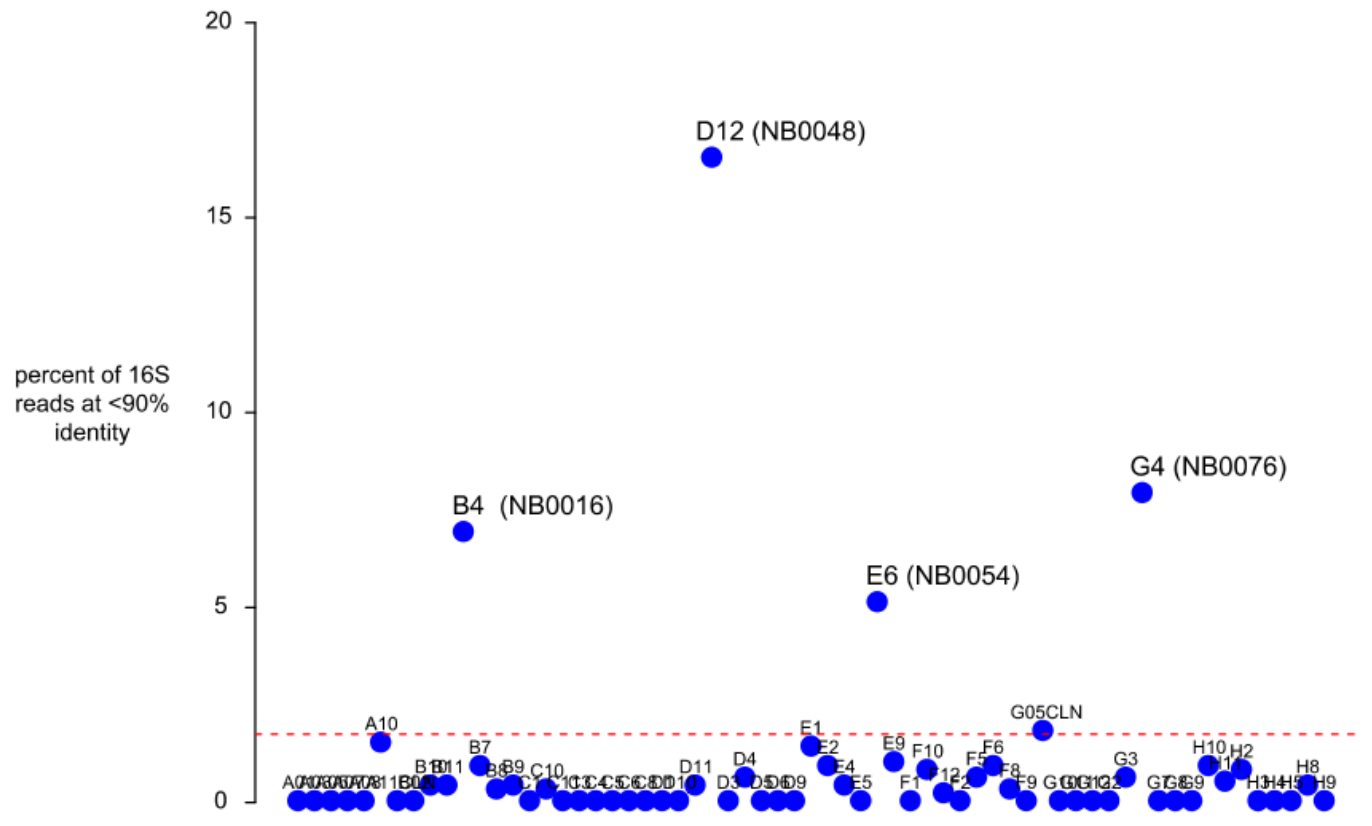

Figure S3. Distribution of unassembled SSU rRNA reads at less than $90 \%$ identity to the assembled SSU rRNA gene sequence. See Figure S2 legend for annotation criteria. 

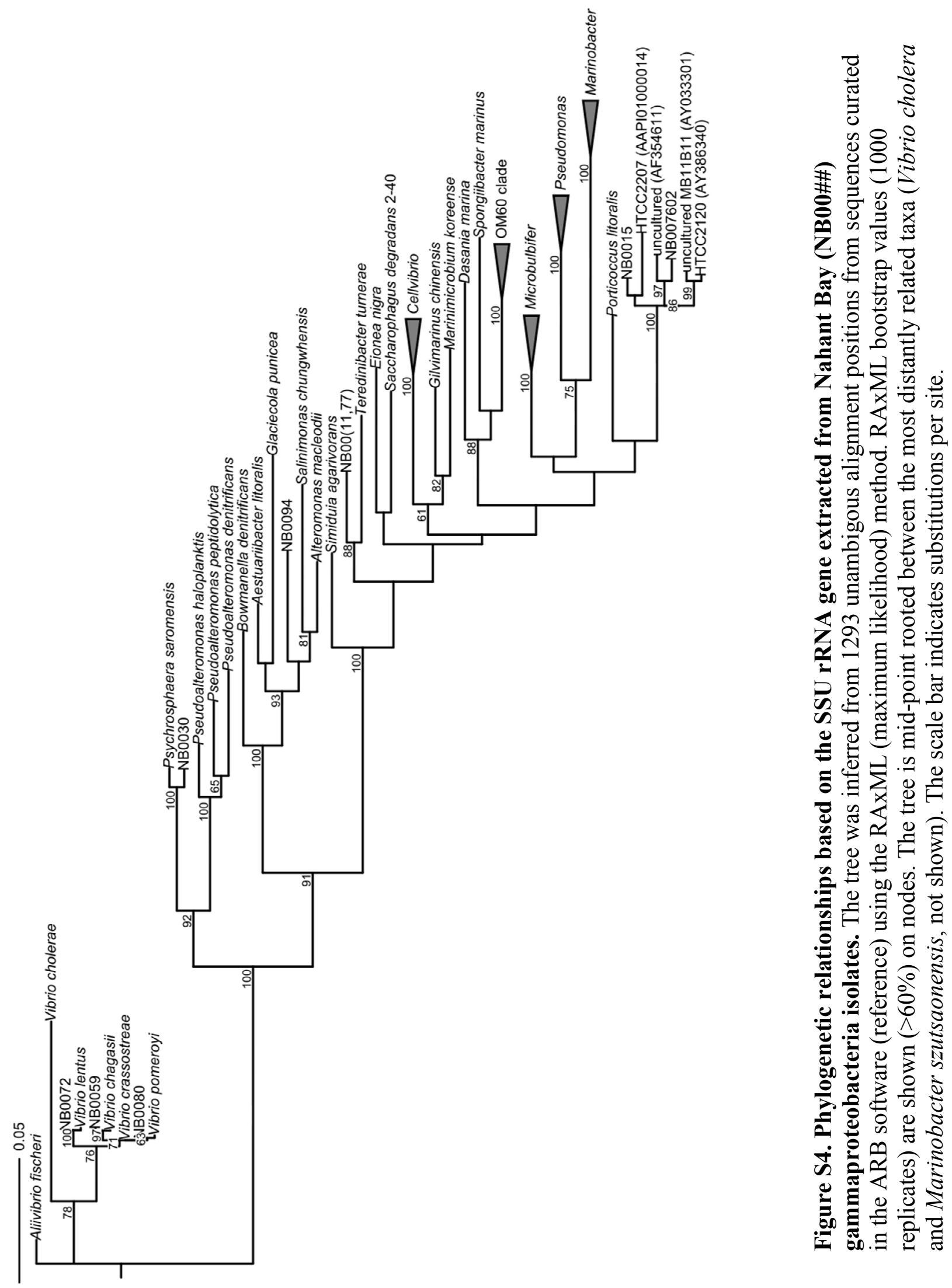




Time (days)

Figure S5. Growth profiles of SAR92 clade isolate NB0015 in defined media. Cells of NB0015 were grown in artificial seawater (ASW) with and without mixed carbons (MC) including D-glucose $(55 \mu \mathrm{M})$, succinate $(85 \mu \mathrm{M})$, pyruvate $(114 \mu \mathrm{M})$, glycerol $(109 \mu \mathrm{M}), \mathrm{N}-$ acetyl D-glucosamine $(45 \mu \mathrm{M})$, and ethanol $(434 \mu \mathrm{M})$. Points are the mean cell concentrations of three replicates, with error bars representing the standard deviation (where not visible, error bars are smaller than the symbols). 


\section{CHAPTER THREE}

Assessment of the degradation capabilities of open-ocean bacterial isolates enriched with marine high-molecular-weight dissolved organic matter 


\section{Abstract}

In the previous chapter, I described how the experimental additions of high-molecularweight (HMW) dissolved organic matter (DOM) to dilution-to-extinction cultures resulted in the enrichment of bacterial groups able to degrade this natural substrate to obtain carbon and energy for growth. In this chapter I apply the same methodology to cultivate bacterial groups from openocean planktonic communities and investigate their biochemical and metabolic potential to degrade HMW DOM through growth experiments and genome analysis. Two DOM samples, ultra-filtered HMW DOM and a purified sub-fraction (F1) enriched in HMW polysaccharides obtained by chromatography, were used to supplement dilution-to-extinction cultures with dissolved organic carbon (DOC) above ambient concentrations. The inocula consisted of seawater collected at Station ALOHA $\left(22^{\circ} 45^{\prime} \mathrm{N}, 158^{\circ} 00^{\prime} \mathrm{W}\right)$ from the deep chlorophyll maximum (DCM) and from mesopelagic depths (>200 m). The addition of HMW DOM resulted in a significantly higher number of cultures recovered from mesopelagic samples whereas DCM samples did not respond significantly to the treatments. Genomic analysis indicated that these isolates have the genetic pathways required to break down and metabolize known DOM constituents such as carbohydrates and phosphonates. However, cultures exhibited relatively small changes in cell yields in the presence of HMW DOM when DOC was increased from $\sim 80$ $\mu \mathrm{M}$ ambient concentrations to over $1200 \mu \mathrm{M}$ in treatments. Taken together these results indicate that as monocultures these isolates have limited access to HMW DOM though they seem sensitive to increases in DOC concentrations. This may indicate that in the open-ocean, the breakdown of HMW DOM is heavily dependent on microbial consortia and abiotic degradation processes. Future work employing co-cultures rather than monocultures may help to further identify important microbial interactions mediating DOM cycling. 


\section{Introduction}

The subtropical gyres of the Pacific and Atlantic Oceans represent some of the most extensive biomes on the planet, and as such have important influence on the global carbon cycle. These open-ocean regions are characteristically oligotrophic ecosystems. Their distance from large land masses, the central gyre hydrography, and strong stratification of the water column limits the availability of nutrients - compared to coastal and upwelling systems - that sustain primary production. Such conditions favor the so-called "regeneration loop" (Sarmiento \& Gruber, 2006) in which the organic matter produced in the surface is efficiently recycled to renew nutrient (inorganic nitrogen and phosphorus) supplies in great part through the "microbial loop" (Azam, 1998; Azam et al., 1983).

Microbial heterotrophic communities are thought to play a major role regulating the turnover of organ matter. In addition to establishing a link between microorganisms and higher trophic levels through the microbial loop, DOC remineralization maintains the balance between the organic carbon transported downward by the biological pump and the upward transport of dissolved inorganic carbon (Sarmiento \& Gruber, 2006). The organic matter that escapes biological remineralization in the surface is exported to the dark ocean via the biological pump by lateral and downward transport of DOM and by sinking of POM (Ducklow, Steinberg, \& Buesseler, 2001). In the North Atlantic Subtropical Gyre for example, organic matter is exported during the spring after winter convective mixing returning to regenerated production thereafter whereas in the North Pacific Subtropical Gyre the water column is permanently stratified favoring regenerated production (Brix, Gruber, Karl, \& Bates, 2006).

In addition to the strong stratification in the gyres, the accumulation of degradable DOM in the surface ocean is thought to be the result of a malfunctioning microbial loop wherein DOC 
cannot be consumed as quickly as it is produced (Thingstad, Hagström, \& Rassoulzadegan, 1997). This is because microbial heterotrophic communities in the sunlit regions of the ocean are thought to be highly dependent for their growth and metabolism on the production of organic carbon by photosynthetic organisms with which they also compete for nutrients. Accordingly, estimates of bacterial activity are usually best predicted by phytoplankton primary productivity (Cole, Findlay, \& Pace, 1988) and diel patterns are often observed in parameters like cellular volume and bacterial abundance relating to phytoplankton activity (Kuipers, Van Noort, Vosjan, $\&$ Herndl, 2000). Even at the transcriptional level diverse bacterial heterotrophic clades appear to be synchronized to autotrophic processes (Aylward et al., 2015; Ottesen et al., 2014). On the other hand, in the dark ocean, where the available light no longer supports photosynthesis, microorganisms can obtain carbon, energy, and nutrients from sinking POM (Cho \& Azam, 1988). However, the particulate organic carbon (POC) flux alone cannot explain the observed respiration rates in the dark ocean; to close the budget DOC exported to these depths ( $\sim 2.0$ mol C $\mathrm{m}^{-2} \mathrm{yr}^{-1}$ ) must be remineralized by microbial heterotrophic communities (Carlson et al., 1994; Emerson, Quay, Karl, Winn, \& Tupas, 1997). The majority ( $70 \%)$ of the respiration in the dark ocean, 3-4 mol C m${ }^{-2} \mathrm{yr}^{-1}$, is thought to occur within the mesopelagic (150-1000 m) fueled primarily by POC and of which exported DOC can contribute between 10-20\% (Arístegui, Agustí, Middelburg, \& Duarte, 2005; Carlson et al., 2010, 1994). Illustrating the significance of DOC export, open-ocean microcosm experiments in the North Atlantic Subtropical Gyre found that growth of mesopelagic microbial communities was stimulated in the presence of filtered surface water which harbors the surplus of semi-labile DOM that accumulates periodically (Carlson et al., 2004a). However, the transformation and degradation processes by which semilabile DOM supports microbial metabolism remain largely unexplored. 
Ultra-filtered marine HMW DOM may prove a useful and appropriate substrate to study microbial cycling of semi-labile DOM. HMW DOM is operationally defined as the fraction of DOM that can be typically concentrated by $1 \mathrm{kDa}$ ultrafiltration membranes and constitutes about a third of the standing stock of DOM in marine surface waters (Benner et al., 1997; Mccarthy et al., 1996). Notably, this HMW fraction is made up primarily of carbohydrates $(\sim 50 \%$ in surface waters) with a fairly homogenous monosaccharide composition across major ocean basins indicating this material has a widespread and common source throughout the global ocean (Aluwihare et al., 1997; Mccarthy et al., 1996). Radiocarbon analysis of the monosaccharides making up HMW DOM carbohydrates indicates this fraction has an estimated residence time of $<3$ years (Repeta \& Aluwihare, 2006) consistent with the residence time of semi-labile DOM (100 to 1000 days) obtained from ecosystem models (Luo et al., 2010). Interestingly, the carbohydrate content of HMW DOM has been observed to decrease with depth indicating that polysaccharides are a major bio-reactive component (Benner et al., 1992; McCarthy et al., 1993).

Despite several lines of evidence that demonstrate the importance of microorganisms in the cycling of DOM, there is limited information on what types of microbial groups and biochemical pathways mediate this basic ecological function. The work described in this chapter aims to identify microbial model systems that may serve to investigate in detail the processes that drive biological semi-labile DOM turnover. For this purpose, HMW DOM, a widespread and naturally occurring carbon-rich and nutrient-poor substrate representative of semi-labile DOM, is supplemented to dilution-to-extinction cultures to stimulate the growth of HMW DOMdegrading microorganisms. The experiments were conducted with seawater collected in the field site of the Hawaii Ocean Time series (HOT), Station ALOHA, a region representative of general conditions in the North Pacific Subtropical Gyre. The cultivation media for dilution-to extinction 
experiments consisted of natural seawater collected in Hawaii waters sterilized by tangential flow filtration as described in Chapters 1 and 2. Microbial samples for cultivation experiments were obtained from two depths, one within the euphotic zone specifically targeting the DCM $(\sim 100 \mathrm{~m})$, and one below it in the upper mesopelagic (below $200 \mathrm{~m})$. The DCM at Station ALOHA is situated below the surface mixed layer year-round and coincides roughly with the depth of $1 \%$ surface photosynthetically available radiation (Laws, Letelier, \& Karl, 2014; Letelier, Karl, Abbott, \& Bidigare, 2004). In this region, Prochloroccocus and picoeukaryotes dominate the photosynthetic biomass (Campbell, Liu, Nolla, \& Vaulot, 1997) and heterotrophic populations may rely more heavily on newly produced organic matter to obtain carbon and energy for growth. In contrast, in mesopelagic depths where light levels no longer support photosynthesis, heterotrophic bacteria may be better adapted to degrade semi-labile HMW DOM. Thus, I expected to identify a higher number of microbial degraders of HMW DOM in cultivation experiments prepared from mesopelagic samples than from DCM samples. It is possible, however, that heterotrophic microorganisms from both depths support a fraction of their carbon demand with HMW DOM.

\section{Materials and Methods}

\section{Collection of HMW DOM and isolation of neutral polysaccharides}

\section{Ultrafiltration}

Large-volume seawater samples were drawn from the $20 \mathrm{~m}$ intake pipe at the Natural Energy Laboratory in Kona, Hawaii $(19.727 \mathrm{oW}, 156.063 \mathrm{oN})$ in February 2013. The samples were filtered to remove bacteria and small particles using a cleaned $(10 \% \mathrm{HCl})$ Suporflow dual-stage (0.8 and 0.2 microns) Gelman polyether sulfone (PES) cartridge filter (Chisolm-Pall) fitted to an 
Advanta stainless-steel housing. The high molecular weight dissolved organic matter fraction (HMWDOM) was collected using two spiral wound ultrafiltration systems consisting of a stainless-steel centripetal pump and membrane housings and a fluorinated high-density polyethylene reservoir. Each system was plumbed with Teflon tubing and PVDF valves, and fitted with two ultrafiltration membranes (Osmonics GE-H4040C; Separation Engineering) that nominally retain organic matter with a relative molecular weight $>1 \mathrm{kDa}(>99 \%$ rejection of vitamin B-12 ). Membranes were cleaned using isopropanol, detergent ( $0.01 \%$ micro), $\mathrm{HCl}(0.01$ $\mathrm{M})$, and $\mathrm{NaOH}(0.01 \mathrm{M})$; stored in sodium azide $(0.55 \mathrm{mM})$; and rinsed with water immediately before use. Approximately 32,241 liters of seawater were concentrated over a period of 14 days. Each day, samples ( 1150 liter per system) were concentrated to 20 liter, filtered through a 0.2 micron PES cartridge filter (Propor demi-cap) into a fluorinated HDPE carboy and stored in a $20^{\circ} \mathrm{C}$ freezer. The sample was cooled, but did not freeze during storage. The following day, this concentrate was combined with the new day's concentrate, reduced in volume to 20 liter, and again stored at $-20^{\circ} \mathrm{C}$. This process was repeated daily. At the end of the sampling period, the pooled samples were frozen, and returned to Woods Hole for further processing. Dissolved organic carbon measurements showed $22 \%$ of TOC was recovered in the concentrate. In Woods Hole, samples were thawed, filtered through a 0.2 micron PES filter, then filtered again through a stirred cell system fitted with a $30 \mathrm{kD}$ cellulose fiber (ultracell) filter to remove viruses. Samples were desalted by a smaller ultrafiltration system fitted with Osmonics GE-E4010 filters. Twenty liters of sample was concentrated to 2 liter, to which 2 liter of ultra-pure water was added. The diluted sample was again reduced in volume to 2 liter, and the process repeated a total of 12 times, until the no visible precipitate was observed with the addition of sample to 10 $\mathrm{mg} \mathrm{ml}^{-1}$ silver nitrate. Desalted samples were lyophilized to a fluffy white powder. 


\section{Isolation of HMW DOM neutral polysaccharides}

A $2.2 \mathrm{~cm}$ i.d. x $30 \mathrm{~cm}$ glass chromatography column was slurry packed with $16 \mathrm{~g}$ of Biorex-5 (BioRad Corp.) anion exchange resin (chloride form) suspended in ultrapure water (Q-water). The water drained to the resin bed. Sodium hydroxide $(1.92 \mathrm{~g})$ was dissolved in $88 \mathrm{mls}$ of Qwater and the solution used to wash the column to convert the resin to the hydroxide form. The column was washed with $80 \mathrm{~mL}$ Q-water, and the $\mathrm{pH}$ checked to ensure the final wash was neutral. Approximately $0.5 \mathrm{~g}$ of freeze dried HMWDOM ( $\sim 36 \%$ by weight $\mathrm{C})$ was dissolved in $5 \mathrm{~mL}$ of warm Q-water, and the solution applied to the column. The column was drained to the bed. The first fraction (F1) was eluted by washing the column with $80 \mathrm{mLs}$ of Q water. The fraction was freeze dried to yield $\sim 150 \mathrm{mg}$ of a pure white, cotton-like material. ${ }^{1} \mathrm{H}$ and ${ }^{13} \mathrm{C}$

NMR of F1 showed the preparation to be carbohydrate. ${ }^{31} \mathrm{P}$ NMR showed the presence of phosphonates $(20 \%$ total $\mathrm{P})$, phosphate esters $(70 \%$ of total $\mathrm{P})$ and pyrophosphate $(10 \%$ of total P).

\section{Overview of dilution-to-extinction experiments at Station ALOHA}

Two dilution-to-extinction cultivation experiments were prepared with seawater collected in the open-ocean near Hawaii (Station ALOHA, $22^{\circ} 45^{\prime} \mathrm{N}, 158^{\circ} 00^{\prime} \mathrm{W}$ ). The experiments consisted of treatments enriched with HMW DOM and control media with no DOC added. The cultivation media consisted of natural Hawaii seawater collected offshore, sterilized by tangential flow ultrafiltration (30 kDa) as described in Chapter 2 (Sosa, Gifford, Repeta \& DeLong, 2015) and amended with inorganic nitrogen and phosphorus to alleviate nutrient limitation and promote HMW DOM carbon utilization. Trace metals and vitamins were not added to the media. Details on the preparation of each experiment including HMW DOM and nutrient amendments are summarized in Table 3.1. 


\section{Experiment I}

Seawater inoculum samples for dilution-to-extinction were collected from the DCM (110 m-depth, based on in situ fluorometry) and from the Mesopelagic (200 m-depth) during the Hawaii Ocean Time series (HOT) cruise 250 (KM 13-05) on March 9, 2013. Inoculum samples were initially diluted $\sim 1000$-fold onboard with sterile seawater prepared by tangential flow ultrafiltration (30 kDa cut-off). Total cell counts were obtained from formaldehyde-fixed samples by epi-fluorescence microscopy for the raw and diluted inoculum seawater. Samples were kept onboard at room temperature in darkness for 14 hours until arrival to port and transport to the laboratory where the dilution-to-extinction was completed. Dilution-to-extinction samples incubated for an additional 24 hours during transport from Hawaii to MIT before they were amended with HMW DOM and arrayed into 48-well cultivation $\left(1 \mathrm{ml}\right.$ well $\left.{ }^{-1}\right)$. Three DOC treatments were prepared with dilution-to-extinction samples from each depth. The DOC treatments consisted of a control with no DOC added, and two experimental treatments; the first was supplemented with $2.5 \mathrm{x}$ DOC (ca. $200 \mu \mathrm{M}$ ) and the second with 7x DOC (ca. $560 \mu \mathrm{M}$ ) using a HMW DOM concentrate (4592 $\mu \mathrm{M}$ DOC liquid sample; not freeze-dried) obtained by ultrafiltration. In addition, dilution-to-extinction samples were supplemented with $400 \mu \mathrm{M}$ nitrate and $30 \mu \mathrm{M}$ phosphate. For both the DCM and Mesopelagic dilution-to-extinction cultures, no DOC control treatments were arrayed into 15 cultivation plates ( 720 wells total) and $2.5 \mathrm{x}$ and $7 \mathrm{x}$ DOC treatments were arrayed into 30 plates each (1440 wells total). Non-inoculated media prepared with the same DOC concentrations were also arrayed into 5 plates each ( 240 well total). Plate samples were incubated for a period of $1-3$ months at $22^{\circ} \mathrm{C}$ in darkness. To assess the effect of HMW DOM treatments on cell growth, wells were subsampled to enumerate SYBR Green Istained cells on a GUAVA easyCyte 8HT (Millipore) flow cytometry system. Flow cytometry 
data analysis was performed in $\mathrm{R}$ with flowCore and prada packages. Dilution-to-extinction wells with $>10^{5}$ cells $\mathrm{ml}^{-1}$ were considered positive hits.

\section{Experiment II}

Seawater inoculum samples for dilution-to-extinction were collected from the fluorometric DCM (95 m-depth) and from the Mesopelagic (250 m-depth) during the Hawaii Ocean Experiment - Budget of Energy I research cruise (KM 14-09) on March 23, 2014 (http://hahana.soest.hawaii.edu/hoeboe/hoeboe.html). In order to calculate the dilutions necessary to yield of 1-5 cells $\mathrm{ml}^{-1}$ the inoculum samples were analyzed by flow cytometry. Briefly, triplicate $1 \mathrm{ml}$ sub-samples were fixed with $15 \mu \mathrm{l}$ of $16 \%$ PFA for 10 minutes and stained with $5 \mu \mathrm{l}$ of Sybr Green I (200-fold diluted stock) for 20 minutes in the dark. A total of $50 \mu 1$ of each replicate were analyzed through an Influx cell sorter (BD Biosciences, San Jose, CA) to determine the total number of fluorescent events. Samples incubated onboard for 14 hours before reaching the laboratory where final dilution-to-extinction samples were prepared.

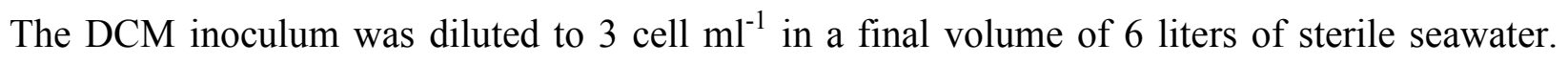
Similarly, the mesopelagic inoculum was diluted to an estimated 2 cells $\mathrm{ml}^{-1}$. Each 6-liter dilution-to-extinction sample was amended with inorganic phosphate $(7 \mu \mathrm{M})$, nitrate $(60 \mu \mathrm{M})$, and ammonium $(4 \mu \mathrm{M})$. The 6-liter dilution-to-extinction samples were split into four 1-liter aliquots to receive the HMW DOM amendments (Table 3.1). Each dilution-to-extinction treatment was arrayed into 15 cultivation plates resulting in total of 720 wells. Each control or treatment media was also arrayed into 3 plates (144 wells). DCM samples were set to incubate at $26^{\circ} \mathrm{C}$ under a diurnal cycle and mesopelagic samples incubated at $25^{\circ} \mathrm{C}$ in darkness for $10-11$ weeks. To determine the effect of HMW DOM treatments on cell growth, wells were subsampled to enumerate SYBR Green I-stained cells on a GUAVA easyCyte PLUS (Millipore) 
flow cytometry system. Flow cytometry data analysis was performed in R with flowCore and prada packages. Dilution-to-extinction wells with $>10^{4}$ cells $\mathrm{ml}^{-1}$ were considered positive hits.

\section{Identification of cultures by whole genome shotgun sequencing}

DNA purification and genome sequencing

The cultures identified in dilution-to-extinction samples were routinely maintained in the laboratory by passaging samples into sterile seawater. Sub-samples of selected cultures were transferred into 0.2 to 1.5 liters of sterile seawater to obtain sufficient genomic DNA for whole genome shotgun (WGS) sequencing. Culture growth was determined by enumerating total cells by flow cytometry. Upon reaching stationary phase cells were harvested by filtration onto 0.22 $\mu \mathrm{m}$ Supor membranes (Pall) and stored at $-80^{\circ} \mathrm{C}$ in sucrose lysis buffer. Genomic DNA was purified using Qiagen's Blood and Tissue Kit (Experiment I) or through an in-house automated protocol using Proteinase K and Lysozyme additions using an MSM robot (Experiment II). Samples expected to have low DNA yield based on total cell counts were analyzed in a Fragment Analyzer (Advanced Analytical, Heidelberg, Germany) to determine sample quality. All samples

of purified genomic DNA were quantified by the PicoGreen assay (Life Technologies). DNA concentrations were normalized before sequencing. DNA samples were prepared for sequencing using the Nextera XT 96 DNA sample preparation kit (Illumina, San Diego, CA, USA) to obtain indexed paired-end libraries. The libraries were sequenced with a 2x250 nt paired-end MiSeq run (Experiment I) and with a 2x300 nt paired-end MiSeq run (Experiment II).

\section{Phylogenetic identification of cultures}

FastQ files from the MiSeq runs were imported into the CLC Genomics Workbench (CLC bio, Aarhus, Denmark). Reads were assembled into contigs using CLC's de novo assembler with automatic word and bubble sizes, a minimum contig length of 200, insertion and 
deletion costs set to 3 , mismatch cost set to 2 , length fraction set to 0.5 and the similarity fraction set to 0.8 . Only contigs $\geqslant 1000 \mathrm{nt}$ in length were further examined. Small subunit (SSU) rRNA sequences were identified in assembled contigs and annotated by a LAST (Frith et al., 2010; Kiełbasa et al., 2011) sequence similarity search against the SILVA non-redundant SSU database (version 119). The SSU rRNA gene sequences identified were aligned using the SILVA Incremental Aligner (SINA) version 1.2.11 (http://www.arb-silva.de/aligner/; Pruesse, Peplies, \& Glockner, 2012) and imported into ARB (Ludwig et al., 2004) for alignment with the SILVA “All-Species Living Tree" (LTPs115) SSU reference tree (Munoz et al., 2011). A total of 240 sequences including closely related reference sequences from SILVA were selected for phylogenetic comparisons. The sequence alignment was filtered in ARB to exclude gaps, missing data ambiguous nucleotide positions, and lower case positions (nucleotides outside of an E. coli reference sequence). The filtered alignment contained 1172 comparable nucleotide positions across all sequences. Phylogenetic analysis was implemented using the NeighborJoining method (Saitou \& Nei, 1987) with 1000-replicate bootstrap confidence limits (Felsenstein, 1985) in MEGA6 (Tamura et al., 2013). The optimal tree sum of branch length $=$ 3.36318869. The evolutionary distances were computed using the Kimura 2-parameter method (Kimura, 1980) and are in the units of the number of base substitutions per site. The rate variation among sites was modeled with a gamma distribution (shape parameter $=2$ ). Assessment of the effect of HMW DOM treatments on the phylogeny of isolates recovered

To determine if the control and HMW DOM treatments had a notable effect on the phylogeny of isolates recovered in Experiment II, SSU rRNA genes were binned into phylotypes based on a $98 \%$ similarity threshold with BLASTClust (http://toolkit.tuebingen.mpg.de/blastclust). In addition, a chi-squared goodness of fit test was 
applied to determine if the occurrence of phylo-types (irrespective of depth) was independent from the treatments $(\mathrm{P}$-value $<0.05)$. To evaluate the correlation between the occurrence of phylotypes and HMW DOM treatments a principal component analysis was performed in R statistical software using prcomp from the package stats.

\section{DOM-dose response tests}

Isolates were examined for higher growth yields under different HMW DOM treatments (increasing DOC concentrations). The isolates from Experiment I (cruise HOT 250) were tested in four different DOC treatments. The HMW DOM sample used as DOC supplement consisted of a 1-30 kDa fraction concentrated in seawater $(4592 \mu \mathrm{M}$ DOC) by tangential flow filtration. The seawater base media and control treatment consisted of UV-oxidized seawater with DOC reduced from 80 to $25 \mu \mathrm{M}$ and amended with sodium nitrate $(400 \mu \mathrm{M})$ and phosphoric acid (30 $\mu \mathrm{M})$. Trace metals and vitamins were not added to the base media. The DOC treatments supplemented with HMW DOM concentrate were 3X DOC $(230 \mu \mathrm{M}), 15 \mathrm{X}$ DOC $(1148 \mu \mathrm{M})$, and 30X DOC $(2296 \mu \mathrm{M})$. The media was arrayed into 48-well plates and inoculated with $10 \mu \mathrm{l}$ of culture maintained in HMW DOM media. Duplicate sets of cultures were prepared for each isolate. Samples were incubated at $22^{\circ} \mathrm{C}$ in darkness. Growth was determined by flow cytometry analysis of DNA-stained cells as described previously.

Selected isolates from Experiment II (cruise HOE-BOE I) were tested with seawater media with increasing HMW DOM concentrations. The control base media consisted of Hawaii sterile seawater from $250 \mathrm{~m}$-depth amended with phosphoric acid $(7 \mu \mathrm{M})$, sodium nitrate $(60$ $\mu \mathrm{M})$, and ammonium chloride $(4 \mu \mathrm{M})$. Trace metals and vitamins were not added to the base media. Five HMW DOM treatments were prepared with the base media, the first three (4X, $8 \mathrm{X}$, 12X DOC) amended with freeze-dried HMW DOM, and two additional media (8X and 16X 
DOC) amended with the freeze-dried HMW DOM sub-fraction F1 consisting of neutral polysaccharides. The $4 \mathrm{X}, 8 \mathrm{X}, 12 \mathrm{X}$ and $16 \mathrm{X}$ DOC treatments indicate the estimated DOC concentrations above the typical concentration in open-ocean Hawaii waters $(\sim 80 \mu \mathrm{M}$ DOC) which resulted from the addition of 7.2, 14.4, 21.6, and $28.8 \mu \mathrm{g} \mathrm{ml}^{-1}$ of HMW DOM sample to seawater, respectively. Samples were inoculated with $<100 \mathrm{cells} \mathrm{m}^{-1}$ of each isolate in triplicate and incubated at $25^{\circ} \mathrm{C}$ in darkness. Growth was determined by flow cytometry analysis of DNAstained cells as described previously.

\section{Carbon substrate utilization and growth analysis}

To identify the types of carbon substrates Hawaii isolates could utilize for growth, representative isolates (HI0003, HI0035, HI0037, HI0049, HI0053, HI0054, HI0113, HI00120, and HI0133) were assayed for increases in cell yields in Biolog multi-carbon plates (PM1 and PM2A) containing a total of 190 different organic compounds. The exact formulation of the Biolog plates is proprietary but is similar to the recipes published by Bochner, Gadzinski, \& Panomitros (2001) which utilize $25 \mathrm{mM}$ carbon compound concentrations and 2 and $5 \mathrm{mM}$ inorganic phosphorus and nitrogen concentrations, respectively. Because these nutrient concentrations are orders of magnitude greater than the concentrations found in open-ocean waters the dried contents of Biolog plates were re-suspended in $100 \mu 1$ of sterile water and used a $\sim 10,000 \mathrm{X}$ stock solutions to amend seawater media. The isolates tested were pre-grown in sterile Hawaii seawater amended with $1 \mu \mathrm{M}$ phosphoric acid and ammonium chloride, as well as trace metals and vitamins (see Appendix I Table A3 for details on media supplements). Upon reaching stationary phase cultures were arrayed into plates with $1 \mathrm{X}$-concentrated Biolog substrate. Samples incubated for 3-7 days at $26^{\circ} \mathrm{C}$ under a 12 hour diurnal light cycle. Cell growth was measured by detection of DNA-stained (SYBR Green I) cells on an Attune cytometer system 
(Applied Biosystems, Foster City, CA, USA). To determine which Biolog substrates supported isolate growth, the end-point (2-4 day incubations) cell yields were analyzed using the Hampel (1974) outlier identifier method as modified by Leys, Ley, Klein, Bernard, \& Licata (2013) which relies on the Median Absolute Deviation (MAD) to determine upper (median+2 $\times$ MAD) and lower (median-2×MAD) confidence intervals of the data. MAD was implemented in $\mathrm{R}$ with function mad and default options. The Standard Boxplot Rule outlier detection method, which uses the first and third quartiles (Q1 and Q3) of the data to identify the upper $(\mathrm{Q} 3+1.5 \times \mathrm{IQD})$ and lower $(\mathrm{Q} 1-1.5 \times \mathrm{IQD})$ confidence interlvas (where IQD is the interquartile difference) was implemented for comparison. Substrates deemed to support growth had cell yields greater than the upper MAD-based thresholds. The assay was also able to detect detrimental treatments (negative growth) indicated by cell yields less than the lower MAD-based threshold. In addition, the relative growth effect of each Biolog substrate was evaluated by normalizing the cell yield to the median across all treatments (190 substrates) and $\log _{2}-$ transforming this ratio to produce a doubling scale ( $\log _{2}$ fold change). Positive growth agreed well with cell yields resulting in a $\log _{2}$ fold change $>1$ and negative growth with $\log _{2}$ fold change $<-1$. The median was selected to analyze the data and normalize cell yields because its value closely approximated the cell yields in negative controls (samples with no Biolog carbon substrate present; not used for analysis) as most treatments did not result in considerable growth.

\section{Functional genomics and metabolic analysis}

\section{Genome draft assemblies and functional annotation}

For a subset of isolates with high quality Illumina data, paired-end reads were first assembled using MIRA version 4.9.3 (Chevreux, Wetter, \& Suhai, 1999) with options for removing remaining Illumina adapters, low quality stretches, phiX174 standard, as well as 
common Illumina artifacts. This generated a very conservative assembly which was used to call genes. As part of the MIRA assembly process, a set of cleaned/clipped reads was also generated. This set of clean reads was used as input to SPAdes version 3.5 (Bankevich et al., 2012) with default parameters and explored with different k-mer settings. To annotate the assembled genomes (including rRNA and tRNA genes, and CDS), the assembled contigs were analyzed in PROKKA (Seemann, 2014) implemented through the Galaxy platform (Cuccuru et al., 2014). PROKKA-predicted CDS were further annotated by comparison to the NCBI RefSeq database (release 69) and the Kyoto Encyclopedia of Genes and Genomes (KEGG, release 67.11; Kanehisa \& Goto, 2000) using the LAST algorithm (Frith et al., 2010; Kiełbasa et al., 2011). Functional and metabolic analysis of DOM degradation capabilities

The conservative genome drafts of open-ocean isolates were examined to identify genes and biochemical pathways that have the potential to participate in the degradation of known HMW DOM constituents including carbohydrates and phosphonates. The analysis included the genome of Pseudomonas stutzeri HI00D01 isolate from Experiment I, 55 genome assemblies obtained from Experiment II isolates, and the genome of SAR92 clade coastal isolate NB0015 (described in Chapter 2), for comparison. In addition, to identify metabolic and functional differences among genomes, PROKKA-predicted protein sequences of 28 isolates including $P$. stutzeri HI00D01 and the coastal strain NB0015 were analyzed on the KEGG Automatic Annotation Server (http://www.genome.jp/tools/kaas/) using the BBH (bi-directional best hit) method to assign KEGG orthologs (KO) and generate KEGG pathways. The representation of KEGG pathways and predicted KOs were compared between closely related isolates and across all isolates tested. 
To assess the potential for the degradation of carbohydrates - a major component of HMW DOM - PROKKA-predicted protein sequences of all available genomes were compared to the Carbohydrate Active Enzyme (CAZy) database (Cantarel et al., 2009) using HMMER3.0 (Eddy, 2009) and hidden Markov models of CAZy signature domains (Yin et al., 2012). Differences in the average number of predicted CAZy family genes were assessed between DCM and Mesopelagic genomes (Mann-Whitney U test) and among phylogenetic clusters (one-way ANOVA). Post hoc analysis via Tukey's honest significance difference test was employed to identify phylogenetic groups in which the genomes contained significantly different number of predicted CAZy genes.

In addition, the C-P lyase pathway (Metcalf et al., 1993a, 1993b) was specifically targeted in the genome functional analysis because of the prevalence of phosphonates in marine HMW DOM (Kolowith et al., 2001). To determine if the C-P lyase pathway (Metcalf \& Wanner, 1993a, 1993b) was encoded in the genomes of open-ocean isolates a BLASTp analysis (Camacho et al., 2009) was implemented in Galaxy (Cock, Grüning, Paszkiewicz, \& Pritchard, 2013) using as queries the nucleotide sequences of phosphonate degradation operons identified in several uncultivated marine bacteria enriched in phosphonate addition experiments to openocean surface seawater (Martínez, Ventouras, Wilson, Karl, \& DeLong, 2013).

\section{Results and Discussion}

This chapter explores the hypothesis that, as was observed in a coastal ecosystem microbial community, the open-ocean harbors bacterial groups that contribute to the breakdown of HMW DOM. To test this hypothesis two cultivation experiments were prepared aimed to stimulate the growth of such bacterial groups by enriching seawater with HMW DOM above the 
ambient DOC concentrations ( $\sim 60-80 \mu \mathrm{M}$; Fig. 3.1). In the following section I describe the effect that HMW DOM treatments had on the growth and number of cultures recovered from dilutionto-extinction samples. Later I present the phylogenetic classification of the isolates obtained and discuss the unexpected low cell yields of isolates grown in media supplemented with HMW DOM relative to unamended controls. Finally, I present some of the isolates' physiological and metabolic characteristics identified through growth experiments and genome analysis and discuss their potential implication in degrading specific constituents of HMW DOM.

Effect of HMW DOM additions on the recovery and cell yields of dilution-to-extinction cultures

Experiment $I$

The first dilution-to-extinction experiment was prepared with seawater collected near Hawaii at Station ALOHA and transported to MIT for laboratory incubations. Because a prolonged handling time of seawater samples may alter the viability and composition of the microbial community, as a precaution the inoculum samples were diluted to extinction before transporting them to MIT. The cell concentration of inoculum seawater samples were 197,052.2

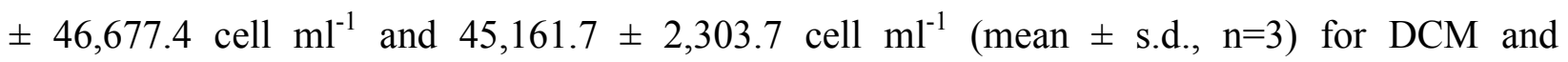
Mesopelagic samples, respectively. The estimated final cell densities for dilution-to-extinction samples were 2-4 cells $\mathrm{ml}^{-1}$. Inspection of dilution-to-extinction samples by epi-fluorescence microscopy did not reveal a drastic increase in cell numbers after transport, though small changes in cell density cannot be ruled given that such low cell numbers cannot be quantified accurately even by flow cytometry. Because the samples seemed unaltered they were deemed appropriate for cultivation. The complete flow cytometry growth screen results are presented in Appendix I Table A1. 
For Mesopelagic samples, the $7 \mathrm{X}$ DOC and No DOC treatments resulted in $>50 \%$ of

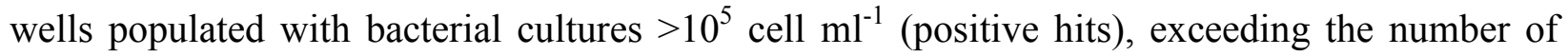
expected cultures, typically 4-5\% (Fig. 3.2). In contrast, the fraction of wells with grown cultures $(8 \%)$ in the $2.5 \mathrm{X}$ DOC treatments was closer to the expected (Fig. 3.2). Dilution-to-extinction plates prepared with seawater samples from the DCM did not have as strong a response to HMW DOM treatments as the Mesopelagic samples $(<1.2 \%$ positive hits, Fig. 3.2$)$. In addition, the flow cytometry screen revealed a small fraction of sterile media control wells with positive hits $(<1 \%)$.

In order to select for isolates with the strongest growth response to HMW DOM and to eliminate potential non-HMW DOM consuming microorganisms, a subset of five Mesopelagic plates from each treatment were serially diluted $(1: 100)$ into sterile media (final $10^{8}$-fold dilution) and incubated for 1 month (Fig. 3.1). A total of 71 of 210 wells recovered cultivars on either the last or second-to-last step of the dilution series. After passaging these cultures into sterile media, 53 (91\%) Mesopelagic isolates from the 7X DOC treatment, 6 from the $2.5 \mathrm{X}$ DOC treatment, and 7 from the No DOC treatment were recovered.

Because the DCM dilution-to-extinction samples did not show an equally robust growthresponse to HMW DOM treatments as the Mesopelagic samples did after one month of incubation, the plates were left incubating for an additional 1.5 months (Fig. 3.1). Re-screening of the DCM plates after the extended incubation period revealed wells with positive hits, cultures that reached cell densities $>10^{5} \mathrm{cell} \mathrm{ml}^{-1}$ (Fig. 3.3). Samples from the No DOC treatment produced $18(2.85 \%)$ new cultures and samples from the $2.5 \mathrm{X}$ DOC treatment resulted in 133 (10\%) positive hits, the highest number of cultures recovered (Fig. 3.3). In contrast, plates with 7X DOC treatments did not produce any positive hits (Fig.3.3). To verify their viability, cultures 
considered positive hits were serially diluted into sterile DOM media and incubated for 2 months under the same conditions (Fig. 3.1). Only 17 of 18 cultures from the No DOC treatment were recovered. Cultures from 2.5X DOC and 7X DOC treatments were not viable or recoverable. In total, 83 isolates were recovered from Experiment I: 66 from Mesopelagic samples and 17 from the DCM. These cultures were identified by whole genome shotgun sequencing (Table 3.2).

\section{Experiment II}

The cell concentrations of inoculum seawater were 498,653 $\pm 14,536 \mathrm{ml}^{-1}$ and 108,235 \pm 2,626 (mean \pm s.d., $\mathrm{n}=3$ ) for $\mathrm{DCM}$ and Mesopelagic samples, respectively. These cell concentrations fell within the typical ranges observed at Station ALOHA (Campbell et al., 1997). The complete flow cytometry growth screen results are presented in Table A2 (Appendix I). Wells with positive hits $\left(>10^{4}\right.$ cell $\left.\mathrm{ml}^{-1}\right)$ were detected across all samples including non-DOM amended controls. Flow cytometry failed to detect positive hits in sterile media preparations. Sterile controls only registered wells with $<5,000$ events $\mathrm{ml}^{-1}, 98.4 \%$ of which had $<1,000$ events $\mathrm{ml}^{-1}$. Notably, HMW DOM supplements had a significant effect in the number of positive wells detected in Mesopelagic samples relative to controls (Fig. 3.4; $\mathrm{P}<0.05$, bootstrap comparisons with $10^{4}$ iterations). The percentage of wells with positive hits in HMW DOM treated Mesopelagic samples was $1.67-5.56 \%$ compared to $0.69 \%$ in unamended controls (Appendix I Table A2). In contrast, DCM samples seemed to be unaffected by DOM additions (Fig. 3.4; P < 0.05 , bootstrap comparisons with $10^{4}$ iterations). To assess the viability of cultures identified in wells identified as positive hits, sub-samples $(\sim 0.5 \mathrm{ml})$ from each well were transferred into sterile seawater media $(5-10 \mathrm{ml})$ with HMW DOM and incubated under the same conditions. After passaging cultures twice in sterile HMW DOM seawater, 16 cultures ( $40 \%$ of positive hits) from the DCM and 58 cultures (61.7\% of positive hits) from the Mesopelagic were able to re- 
grow (Fig. 3.4). In total, 74 cultures (55.2\% of all positive hits) were deemed amenable to subculturing and were grown in large volume to obtain genomic DNA for whole genome shotgun sequencing and identification (Table 3.2).

\section{Phylogenetic placement of cultures and patterns of bacterial groups enriched in HMW DOM treatments}

WGS sequencing produced genomic data for a total of 157 cultures from which complete or partial SSU rRNA gene sequences were obtained (Table 3.2). The HMW DOM-treated openocean dilution-to-extinction samples resulted in the isolation of diverse bacterial groups within the Alphaproteobacteria and Gammaproteobacteria. The cultures were phylogenetically placed based on the SSU rRNA percent sequence similarity to closest neighbors in the SILVA database (Table 3.2; see also Fig. A1 and A2 in Appendix I). Based on the identity of the SSU rRNA gene sequences obtained from assembled Illumina reads all cultures consisted of a single isolate and there was no indication of mixed populations (Table 3.2; see also Appendix I Table A9 for a list of PROKKA gene identifications of SSU rRNA gene sequences of 60 draft genomes available under NCBI BioProject PRJNA305749). In Experiment I, single taxon was recovered from each DOC treatment. The 7X DOC treatment in Mesopelagic samples was dominated by the gammaproteobacterium Pseudomonas stutzeri while the $2.5 \mathrm{X}$ DOC treatment selected for Alphaproteobacteria of the genus Erythrobacter and the No DOC treatment produced Vibrio isolates. The No DOC treatment of DCM samples recovered Halioglobus isolates (order Cellvibrionales). Viable cultures were not recovered from the DCM 2.5X DOC and 7X DOC treatments even though the flow cytometry screen detected wells with growth in those samples. In Experiment II, the types of isolates obtained in the DCM were similar to the Mesopelagic samples and could be grouped into 12 phylo-types based on $98 \%$ rRNA gene sequence similarity 
clustering. These phylo-types corresponded well with the Neighbor-Joining phylogenetic tree branches (Appendix I Fig. A1 and A2). All Alcanivorax isolates were grouped into the phylotype (>98\% similarity) though DCM and Mesopelagic Alcanivorax isolates clustered separately in Neighbor-Joining trees due to differences in nucleotide the SSU rRNA gene sequence (Appendix I, Fig. A1). Similarly, some Erythrobacter SSU rRNA gene sequences were unique to the DCM while other sequences occurred both in DCM and Mesopelagic samples (Table 3.2). The relationship between phylo-types and DOC treatments was evaluated using principal component analysis (Fig. 3.4B). Notably, in Mesopelagic samples 64\% of isolates were close relatives of Oleiphilus messinensis (Oleiphilus 1 and 2 phylo-types, Appendix I Fig. A1) and dominated the 10X DOC and 4X DOC F1 treatments (Fig. 3.4). The Oceanibulbus/Sulfitobacter phylo-type was also strongly associated with the 10X DOC treatment and with the $4 \mathrm{X}$ DOC treatment (Fig. 3.4B). Some taxa were unique or strongly associated with a particular DOC treatment, like the Alteromonas isolates (4 total) which only occurred in the 4X DOC F1 treatments and the Erythrobacter 1 phylo-type which was associated with the 10X DOC treatment (Fig. 3.4). In contrast, the Alcanivorax phylo-type occurred across all DOC treatments, including No DOC treatments, which suggests these isolates may have grown independently of HMW DOM additions. The remaining taxa were present in at least one DOC treatment and were absent from the No DOC controls though the total number of isolates recovered was too low to infer a strong association to a particular DOC treatment (Fig. 3.4).

\section{DOM dose-response of selected Hawaii isolates}

\section{Experiment I isolates}

Among the Mesopelagic isolates, the majority of Pseudomonas stutzeri cultures obtained from 7X DOC treatments increased their cell yields correspondingly with DOC concentration 
(Fig. 3.5). The Erythrobacter cultures obtained from 2.5X DOC treatments also increased cell yields with DOC additions although not proportionally and seemed to have a maximum growth despite the higher DOC treatments (Fig. 3.5). In turn, the Vibrio isolates did not appear to be stimulated by HMW DOM additions, consistent with their isolation in No DOC controls samples (Fig. 3.6). Unexpectedly, the DCM Halioglobus cultures obtained from the No DOC treatment exhibited increased cell yields correspondingly with DOC additions (Fig. 3.6). The Halioglobus isolates were not detected by flow cytometry originally after the first month of incubation. It is possible that the prolonged incuabtion period allowed them to utilize semi-labile DOC although there growth might be induced by evaporation in the wells and the resulting concentration of salts and organic matter. Overall in this experiment, the growth profiles of closely related isolates exposed to HMW DOM was similar and consistent with the DOC treatment from which they were obtained. However, proportional increases in cell yields with DOC added were difficult to detect.

Experiment II isolates

The HMW DOM growth response of isolates HI0053 (Pseudoalteromonas), HI0054 (Sulfitobacter), HI0077 (Erythrobacter), HI0090 (Alteromonas), HI0096 (Alcanivorax), and HI0113 (Oleibacter) is presented in Fig. 3.7. These cultures did not show a significant growth response to DOC additions despite their isolation in HMW DOM treatments. For example, the Mesopelagic Alteromonas isolates (3 were tested including HI0090) obtained from the 4X DOC F1 treatment (HMW neutral polysaccharide fraction) did not to have a discernible growth response to increasing concentrations of HMW DOM despite the addition of up to $12 \mathrm{X}$ and $16 \mathrm{X}$ DOC ( $\sim 960$ and $\sim 1280 \mu \mathrm{M}$, respectively). Instead, the cell yields in unamended media (No DOC) were slightly higher than the growth in media with DOC additions suggesting that the 
addition of HMW DOM may be detrimental to cells. Similarly, the Mesopelagic Alcanivorax isolate HI0096 obtained from the 4X DOC F1 treatment observed higher growth yields in media without HMW DOM than in media with HMW DOM. On the other hand, some isolates including the HI0053, HI0063, HI0077, and HI0113 showed slightly higher cell yields in media supplemented with HMW DOM, though the growth difference with respect to control media was not statistically significant over the course of the incubation period (Fig. 3.7).

\section{Carbon substrate utilization profiles of representative Hawaii isolates}

The Biolog multi-carbon substrate assay was used to determine the growth requirements of 9 representative bacterial isolates obtained from Experiment II. The cell yields of inoculum cultures pre-grown in Hawaii seawater with inorganic nutrients, trace metals, and vitamins ranged from $1 \times 10^{4}$ to $1 \times 10^{5}$ cell $\mathrm{ml}^{-1}$. Hawaii isolates closely related to known hydrocarbon degraders were compared for differential substrate utilization (Fig. 3.8). The Alcanivorax HI0003 and HI0035 were able to grow on capric acid and caproic acid (fatty acids), and sebacic acid (dicarboxylic acid) as well as on low-molecular-weight compounds like propionate, pyruvate, and methyl pyruvate ( $\log _{2}$ fold change $>1$ ). Another isolate, Oleibacter HI0113, metabolized Tween 80 (polysorbate 80 ), capric acid, caproic acid, and the polysaccharides mannan ( $\log _{2}$ foldchange $>1$ ), laminarin and pectin ( $\log _{2}$ fold change $\sim 0.9$ ). Isolate Thalassolituus HI0120 observed similar carbon substrate preferences as HI0113. Growth was stimulated in the presence of Tween 80 , L-proline, and capric acid ( $>2 \log _{2}$ fold-change) as well as Tween 40 , itaconic acid, L-homoserine, dextrin, acetic acid $\left(>1 \log _{2}\right.$ fold-change $)$, and Tween $20\left(\log _{2}\right.$ fold change $\left.=0.9\right)$. Finally, Oleiphilus HI0133 was stimulated by Tween compounds (polysorbate 20, 40, and 80), acetic acid, and the trisaccharide D-raffinose ( $\log _{2}$ fold change $>1$; Fig. 3.8). Interestingly, the Erythrobacter isolate HI0037 was also strongly stimulated by Tween compounds ( $\log _{2}$ fold 
change $>2$ ). In addition, HI0037 degraded two polysaccharides, laminarin ( $\log _{2}$ fold change $>2$ ) and pectin, and the polymer gelatin ( $\log _{2}$ fold change $>1$ ), a derivative of collagen.

Two Rhodobacteraceae isolates, HI0049 (Roseovarius) and HI0054 (Sulfitobacter), were also tested (Fig. 3.9). HI0054 showed preferential utilization of $\alpha$-amino acids (L-leucine, Lisoleucine, L-phenylalanine, L-methionine, L-proline, L-threonine, D-alanine), nonproteinogenic amino acids ( $\gamma$-amino butyric acid, N-acetyl-L-glutamic acid, hydroxyl-L-proline, glycyl-L-proline, glycyl-L-aspartic acid, glycyl-L-glutamic acid, $\delta$-amino valeric acid), degradation products of amino acids (L-ornithine and putrescine), and other low-molecularweight compounds including $\beta$-hydroxy butyric acid, $\alpha$-keto-valeric acid, sebacic acid, thymidine, and D-lactic acid methyl ester ( $\log _{2}$ fold-change $>2$ ). Similarly, isolate HI0049 had a strong preference for amino acids including L-valine, L-ornithine, L-proline, L-leucine, Dalanine, L-lysine, $\gamma$-amino butyric acid, $\delta$-amino valeric acid, L-pyroglutamic acid, L-aspartic acid, and L-isoleucine ( $\log _{2}$ fold-change $>1$ ). Carbohydrate substrates did not stimulate the growth of these Rhodobacteraceae isolates, with the exception of $\beta$-cyclodextrin to which HI0054 was responsive.

In contrast to the seemingly specialized metabolism of the hydrocarbon degraders and the Rhodobacteraceae isolates, the Pseudoalteromonas isolate HI0053 could be described as having a generalist metabolism. In total, HI0053 was stimulated positively by 44 substrates including carbohydrates and nucleosides such as maltose, D-trehalose, D-cellobiose, sucrose, maltotriose, laminarin, $\alpha$-cyclodextrin, $\beta$-cyclodextrin, inosine, $\gamma$-cyclodextrin, adenosine, and 2-deoxy adenosine, and the amino acids L-proline and L-glutamic acid ( $\log _{2}$ fold-change $>3$ ). In addition, HI0053 could metabolize N-acetyl-D-galactosamine, methyl pyruvate, L-arginine, acetic acid, 
formic acid, D-mellobiose, propionic acid, succinic acid, citric acid, D-mannitol, uridine, and capric acid ( $\log _{2}$ fold-change $\left.>2\right)$.

In addition to detecting growth substrates, the Biolog screen was able to detect potential toxic or detrimental compounds as observed by a relative decrease in cell numbers over the incubation period relative to the median value across all treatments. The Alcanivorax HI0003 seemed to be particularly sensitive to glycyl-L-glutamic acid $\left(\log _{2}\right.$ fold change $\left.=-6\right)$ while Alcanivorax HI0035 was sensitive to a different set of compounds including D-galactose, succinic acid, D-saccharic acid, L-arabinose, N-acetyl-D-glucosamine, L-aspartic acid, Dalanine, D-mannose, D-trehalose, D-mannose, D-sorbitol, and $\alpha$-ketobutyric acid $\left(\log _{2}\right.$ fold change < -1). Thalassolituus HI0120 cell yields decreased in the presence of L-threonine and Larginine $\left(\log _{2}\right.$ fold change $\left.<-2\right)$. Oleiphilus HI0133 cells were also sensitive to amino acids including L-homoserine, L-histidine, and L-threonine ( $\log _{2}$ fold change <-3). In contrast, Oleibacter HI0113 appeared to be uninhibited by Biolog substrates. The Rhodobacteraceae isolates were sensitive to different substrates. Roseovarius HI0049 was sensitive to gelatin, itaconic acid, $\alpha$-hydroxybutyric acid, and D-tartaric acid $\left(\log _{2}\right.$ fold change $\left.<-1\right)$. Similarly, cell yields of Sulfitobacter HI0054 cultured decreased in the presence of $\alpha$-hydroxybutyric acid and 2-deoxy-D-ribose $\left(\log _{2}\right.$ fold change $\left.<-1\right)$ but these were not deemed significant by the outlier test.

It is worth noting the polarized effect of substrates like amino acids serving, on the one hand, as growth substrates for bacterial groups like the Rhodobacteraceae and on the other, being potentially detrimental compounds for cultures of hydrocarbon degraders like Oleiphilus and Thalassolituus. It is possible that in the environment the dual role of such substrates helps 
control the abundance or activity of bacterioplankton populations or that in turn, specific bacterial groups enable the growth of other taxa by clearing toxic compounds.

\section{Genome draft assemblies}

In total, 60 draft genomes were obtained from isolates, including one for the coastal isolate NB0015 ( SAR92 clade), 4 for Hawaii open-ocean isolates from Experiment I, and 55 for Hawaii open-ocean isolates from Experiment II. The results of the assemblies are summarized in Appendix I Table A4. The genome coverage for Experiment II isolates was $24 \pm 8$ (mean \pm s.d.) Four representative genome drafts were obtained from Experiment I isolates including the DCM isolate Halioglobus, and the Mesopelagic Vibrio, Erythrobacter, and Pseudomonas stutzeri isolates. The raw reads obtained from these groups were pooled for assembly to obtain better coverage. The genome coverage for these assemblies was higher, $214 \pm 102$ (mean \pm s.d.), than in Experiment II. The highest N50 value obtained was for Halioglobus isolate HI00S01 (342,731 nucleotides) and the lowest was for Oleiphilus isolate HI0085 (2,070 nucleotides). The GC content was lowest in Oleiphilus isolates, ranging from 44-48\%, and highest for the Alphaprotobacteria isolates, between 61-64\%. The combined assemblies included 54,103,639 Illumina reads. A summary of the gene annotations obtained through analysis with PROKKA as well as LAST analysis against KEGG and RefSeq are summarized in Appendix Table A5 including the number of CDSs with hypothetical functions and number of SSU and LSU genes.

The draft genome assemblies with annotations are available under NCBI BioProject PRJNA305749.

\section{Genome functional and metabolic analysis}

The analysis of draft genome assemblies of several Hawaii isolates revealed examples of HMW DOM degradation strategies consistent with several known chemical constituents of 
HMW DOM, including polysaccharides and phosphonates. This analysis also provided evidence of the chemical class of carbon substrates preferentially used for growth by the isolates that could be compared to the Biolog multi-carbon growth assays. PROKKA CDSs were assigned to KEGG pathways, compared to the carbohydrate active enzymes (CAZy) database (Cantarel et al., 2009; http://www.cazy.org/), and aligned against reference protein sequences comprising the phosphonate degradation pathway.

\section{Enrichment of KEGG pathways}

The KEGG ortholog (KO) assignments of PROKKA-predicted protein sequences served to assess the enrichment of KEGG pathways among isolates. A total of 28 isolates, 16 from the DCM, 11 from Mesopelagic depths, including P. stutzeri HI00D01, and one coastal isolate, NB0015 were compared. These isolates represented all the Hawaii phylo-types identified by clustering, except the Alteromonas for which conservative draft genomes were not obtained. Several of the isolates compared were also tested with the Biolog multi-carbon plates. The enrichment of KEGG pathways varied among different bacterial groups (KO count mean \pm s.d., $\mathrm{n}=28)$ of which $\mathrm{ABC}$ transporters $(58.5 \pm 32.0)$, two-component systems $(64.1 \pm 13.3)$, flagellar assembly (19.4 \pm 11.2$)$, and lipopolysaccharide biosynthesis $(12.8 \pm 7.7)$ were the most differentially represented. For example, the Rhodobacteracea (Roseovarius, Oceanibulbus, and Sulfitobacter isolates) had the highest number of $\mathrm{ABC}$ transporters $(107.3 \pm 4.5 ; \mathrm{n}=6)$ while the Pseudoalteromonas HI0053 and P. stutzeri HI00D01 had the most two-component system proteins (92 and 104, respectively). Two-component systems are signal transduction pathways that regulate the physiology of the cell in response to changes in the environment or within the cell. For example, the $\mathrm{PhoR} / \mathrm{PhoB}$ regulon is a two-component system protein in which $\mathrm{PhoR}$, a membrane-associated protein kinase, phosphorylates PhoB in response to changes in phosphate 
levels (McGrath, Chin, \& Quinn, 2013). This triggers a signal cascade that regulates gene expression of genes associated with phosphorus uptake and metabolism. The genome of Pelagibacter ubique, strain HTCC1062, a member of the oligotrophihc SAR11 clade, contains only 4 two-component systems three of which are predicted to help regulate nutrient and osmotic stress (Giovannoni et al., 2005) indicating of the importance of these physiological parameters for bacteria. In contrast, the so-called opportunistic bacteria like Marinobacter aquaeloei and several Pseudomonas species (Singer et al., 2011), as well as copiotrophic bacteria (Lauro et al., 2009) are enriched $(\sim 1 \%$ of the CDSs) in two-compnent regulators and signal transduction pathways reflecting the ability of these bacteria to quickly respond to environmental stimuli like pulses of nutrients. All isolates except Alcanivorax HI0003 and Roseovarius HI0049 encoded a complete flagellar apparatus (flagellar assembly KEGG pathway). On the other hand, all the Erythrobacter isolates analyzed lacked lipopolysaccharide biosynthesis genes as is expected of the Sphingomonadales which replace them with glycosphingolipids (Kawasaki et al., 1994). In some cases, the presence of genes encoding $\mathrm{ABC}$ transporters or degradation pathways associated with specific chemical classes of compounds could be compared to the Biolog carbon substrate utilization profiles of isolates. For example, The KEGG pathways of two different oildegrading isolates, Oleiphilus HI0133 and the Alcanivorax HI0003, were compared. Biolog multi-carbon assays confirmed that these isolates preferentially used lipid-containing compounds for growth (Fig. 3.8). The Alcanivorax HI0003 could only metabolize simple fatty acids like capric (decanoic) and caproic (hexanoic acid), and sebacic (decanedioic) acids while Oleiphilus HI0133 preferred Tween compounds (polysorbate 20, 40, and 80) which in addition to the hydrocarbon tail contain a hydrophilic polyoxyethylene group. Interestingly, the genome of HI0133 encoded 4 ABC transporter sub-unit homologs (mlacDEF) associated with 
phospholipids, molecules that resemble the Tween compounds, while HI0003 only contained a copy of mlaC. In addition, HI0133 contained ABC transporters for various substrates including L-amino acids, proline, putrescine, and osmoprotectants though significant growth on these substrates was not observed. Another distinguishing feature of the Oleiphilus HI0133 genome was that it encoded a complete flagellar apparatus and several bacterial chemotaxis genes, 9 more than HI0003. In comparing the KEGG pathways of four closely related Oliephilus isolates (HI0067, HI00118, HI0132, and HI0133) the most differences occurred in the number of twocomponent system proteins, $\mathrm{ABC}$ transporters, porphyrin and chlorophyll metabolism, nitrogen metabolism, and phonsphonate/phosphinate metabolism. One distinguishing feature of Oleiphilus HI0067 was that its genome encoded complete ABC transporters for alkylphosphonates (Metcalf \& Wanner, 1993a, 1993b), and several single sub-units of ABC transporters associated with oligosaccharides, and one complete ribose/D-xylose ABC transporter while the other Oleiphilus genomes did not. Oleiphilus HI0133 was able to grow on D-raffinose, a trisccharide, but no oligosaccharide or monosaccharide $\mathrm{ABC}$ transporters were detected by the KEGG analysis. On the other hand, the NarX, NarL two-component system proteins and the NarG, NarH, NarJ, NarI subunits of nitrate reductase were only present in the genome of HI0132.

Two closely related Rhodobacteraceae isolates were also compared, Roseovarius HI0049 and Sulfitobacter HI0054. These isolates showed preferential utilization of amino acids for growth. In accordance with this result, HI0049 and HI0054 had 16 and 17 predicted ABC transporters sub-unit homologs for amino acids and 5 and 10 for oligopeptides and dipeptides, respectively. For comparison, Oleiphilus HI0133 and P. stutzeri HI00D01 had 13 amino acid ABC transporters sub-units each but lacked $\mathrm{ABC}$ transporters for the oligopepetides and 
dipeptides. Differences in motility capabilities were also evident. Sulfitobacter HI0054, with 23 flagellar assembly genes, seems to be motile while Roseovarius HI0049, with only 1 predicted gene is limited in this respect, though it may use other forms of motility. In addition to the amino acid ABC transporters, Roseovarius HI0049 and HI0054 were enriched in genes involved in the degradation of aromatic compounds (25 and 10, respectively), specifically in benzoate and catechol oxidation. Isolate $P$. stutzeri HI00D01, with 14 genes, was also enriched in this KEGG pathway though the ability of these isolates to metabolize aromatic compounds remains to be tested since this chemical class was not well represented in Biolog multi-carbon plates.

\section{Carbohydrate degradation}

Significant differences in the number of predicted CAZy genes were observed between the genomes of DCM (16) and Mesopelagic (39) cultures (Mann-Whitney U test, $\mathrm{H}_{0}: \bar{X}=\bar{Y}$, Pvalue $<0.05$; Fig. 3.10). Mesopelagic genomes harbored more predicted carbohydrate-binding module genes $(\mathrm{CBM}, \mathrm{P}-\mathrm{value}=0.01998)$ and fewer auxiliary activities $(\mathrm{AA}, \mathrm{P}-\mathrm{value}=0.001129)$ genes than the DCM genomes (mean \pm s.d.; $3.1 \pm 2.1$ vs. $1.6 \pm 1.6$ CBM genes and $15.6 \pm 5.3 \mathrm{vs}$ $23.2 \pm 8.3$ AA genes, respectively). The CBM genes recognize and bind carbohydrates and require associated enzymes such as glycoside hydrolases to cleave substrates (Cantarel et al., 2009). Several CBM families were present in Mesopelagic genomes but absent in the DCM genomes. These included CBM6, CBM23, CBM35, and CBM61 which characteristically bind carbohydrates substrates such as mannan, xylan, cellulose, glucans, and galactans. Among the Mesopelagic isolates the Pseudolateromonas HI0053 had the highest number of CBM genes 8 different predicted proteins (Fig. 3.10). Close inspection of the Pseudolateromonas HI0053 CBM genes revealed some characteristic features of secreted carbohydrase systems used to degrade polysaccharides. For example, one CBM protein annotated as a beta-xylosidase/alpha-L- 
arabinfuranosidase (67.6\% identity to Cellvibrio japonicus strain Ueda107 ) was clustered with genes encoding an alpha-glucosidase and a metal-dependent hydrolase, an ABC-transporter, enzymes involved in protein secretion, namely the sec-independent Twin-Arginine Translocation (TAT) system, and two GGDEF domain-containing proteins that likely regulate cyclic diguanylate (Ausmees et al., 2001), a secondary messenger involved in signal transduction. All of these proteins likely make up a functional carbohydrase system as observed in the complex carbohydrate-degrading bacterium Saccharophagus degradans 2-40 (Weiner et al., 2008) For example, a carbohydrase system needs to be secreted to the cell wall, a function that can be mediated by the TAT system, and requires sensor proteins at the cell surface like the GGDEF domain-containing proteins to detect the presence of carbohydrate substrates and convey the information to secondary messengers like cyclic di-guanylate, which in turn help regulate the expression of the carbohydrase genes. Isolate HI0053 also contained CBM genes predicted to encode a chitinase, a glycogen branching enzyme, a collagen-lytic enzyme or a serine protease, a secreted glycosyl hydrolase, a putative hemolysin-type calcium-binding protein, and two hypothetical proteins. A one-way ANOVA was conducted to assess differences in CAZy gene class representation between phylogenetic groups (Appendix I Table A6). Significant differences in CAZy-predicted genes between phylogenetic groups were identified for all enzyme classes except for the polysaccharide lyases (Appendix I Table A6, Fig. 3.10). A Tukey's honest significance difference (HSD) post hoc test was applied to determine differences in the mean number of CAZy genes for each enzyme class among phylogenetic groups (P-value $<0.05)$. The analysis revealed that, in addition to the Pseudoalteromonad HI0053, The Oleiphilus 1 and Erythrobacter 2 clusters also had a higher number of CBM genes compared to other clusters (Fig. 3.10). In particular, two Oleiphilus strains, HI0071 and HI0118, each with 7 CBM genes were 
enriched. It was unclear though if the CBM predicted genes of Oleiphilus isolates encoded secreted carbohydrases as most hits lacked a functional annotation and adjacent genes did not fit the description of the additional proteins required for polysaccharide degradation.

CAZy Auxilary Activities (AA) class consists of genes encoding redox enzymes that act in conjunction with other CAZy enzymes and include ligninolytic enzymes and lytic polysaccharide mono-oxygenases (Cantarel et al., 2009). A one-way ANOVA was conducted to compare the number of predicted CAZy AA genes among phylo-types (Appendix I Table A6). Post hoc tests indicated that the Alcanivorax and Oceanibulbus/Sulfitobacter phylo-types harbored a significantly different number of AA genes compared to other bacterial groups (Fig. 3.10, Tukey's HSD, P-value <0.05). Of all isolates though, Roseovarius HI0049 had the highest number of AA genes (Fig. 3.10). In addition, the AA1 and AA3 families were enriched in DCM genomes (Mann-Whitney U test, P-value $<0.05$ ) compared to Mesopelagic genomes. The AA1 enzymes are multicopper oxidases that use diphenols and related substances as donors with oxygen as the acceptor while AA3 enzymes are flavoproteins that belong to the glucosemethanol-choline (GMC) oxidoreductase family. Among the DCM isolates, Erythrobacter HI0037 and HI0038 contained the highest number of AAl predicted genes ( 9 and 8, respectively) while the Alcanivorax HI0035 contained the highest number (24) of AA3 predicted genes.

No significant differences were observed on the mean number of homologs predicted as carbohydrate esterases (CE), glycoside hydrolases (GH), and glycosyl transferases (GT) or polysaccharides lyases (PL) enzyme classes between DCM and Mesopelagic genomes (MannWhitney U test, P-value $<0.05$; Fig. 3.10). However, within these CAZy enzyme classes several families were differentially enriched in DCM and Mesopelagic genomes (Mann-Whitney U test, 
P-value $<0.01$ ). For example, among GH families, GH73 (lysozymes and peptidoglycan hydrolases) homologs were enriched in Mesopelagic genomes as it was present in all Oleiphilus isolates, while GH107 (sulfated fucan endo-1,4-fucanase) and GH114 (endo- $\alpha-1,4-$ polygalactosaminidase) were only present in Alcanivorax isolates, and GH28 (galacturonase) in

DCM Erythrobacter isolates. Similarly, among the CE families CE4 (acetyl xylan esterases and chitin deacetylases) and CE16 (carbohydrate acetyl esterases) were most prevalent in Mesopelagic genomes. In particular, three Oleiphilus isolates (HI0065, HI0071, and HI0133) contained 10 predicted CE4 genes. These acetyl esterases may be involved in the degradation of acetyl ester moieties in HMW DOM polysaccharides - up to $7 \%$ of the total carbon based on ${ }^{1} \mathrm{H}$ NMR (Aluwihare et al., 1997). In contrast, the CE7 (acetyl xylan esterases and cephalosporin-C deacetylases) and CE10 (aryl and carboxyl esterases and cholinesterases) families were most prevalent in the Erythrobacter and Alcanivorax genomes isolated from the DCM. Finally, the polysaccharide lyase (PL) family PL9 comprised of pectate and thiopeptidoglycan lyases was absent from DCM genomes and only occurred in two Alcanivorax and twelve Oleiphilus Mesopelagic isolates.

\section{Phosphonate degradation pathway}

Previously, Martínez et al. (2013) identified three phosphonate degradation gene clusters expressed in open-ocean microcosms amended with free methyl phosphonate and glucose. These clusters were related to sequences found in Vibrio nigripulchritudo ATCC27043, the gammaproteobacterium IMCC1989, and a Rhodobacterales, respectively. In addition, the isolate Pseudomonas stutzeri strain HI0D01 harbors a complete phosphonate degradation pathway with a similar arrangement as the E. coli and V. nigripulchritudo operons (Appendix I Table A8). The presence of phosphonate degradation genes in other isolates obtained from HMW DOM 
enrichments may be an indication of their ability to partially degrade HMW as the phosphonates are thought to be bound to polysaccharides. Details of the P. stutzeri HI0D01 phosphonatedegrading capabilities are presented in Chapter 4.

Surveying the RefSeq functional assignments of PROKKA-predicted genes revealed an enrichment of phosphonate degradation genes in 10 isolates closely related to members of the Rhodobacteracea and Oleiphilaceae (Appendix I Table A8). With the exception of one isolate (Oleiphilus HI0009), all of these isolates were obtained from HMW DOM-treated dilution-toextinction samples (4x DOC, 10x DOC, and 4x DOC F1) from Hawaii Experiment II. To confirm this observation, the protein sequences comprising the phosphonate degradation operons B3TF_MPn_1, B3TF_MPn_2, and B3TF_MPn_8 identified by Martinez et al. (2013) were used as queries (Appendix Table A7) in a BLASTp analysis against the PROKKA-predicted protein sequences of the open-ocean isolates. The PROKKA-predicted CDSs matching C-P lyase genes of Hawaii isolates are listed in Appendix I Table A8. The Roseovarius strain HI0049 harbored all the genes present in the Rhodobacteraceae operon B3TF_MPn_2. One contig was composed of 7 genes: a tetR family transcriptional regulator, $p h n C, D, E 1$, and E2 encoding ABC-type phosphate/phosphonate transport system proteins, a putative acetyltransferase as in the B3TF_MPn2 cluster, and phnM1. A second contig CDSs for $p h n F$ (a GntR-like transcriptional regulator; Gebhard \& Cook, 2008), phnG, H, I, a short hypothetical protein, phnJ, $K$, and $L$. Finally, a third contig contained copies of $p h n N, \operatorname{rcs} F$ (a phosphoesterase perhaps analogous to phnP; Martínez et al., 2013), and phnM2]. The draft assembly of this isolate's genome could not resolve if all these genes are clustered in the region. Nevertheless, they constitute a complete set of genes required for phosphonate degradation with additional putative auxiliary functions. 
The Oceanibulbus HI0021, HI0027, HI0076, HI0082 isolates and the Sulfitobacter HI0054 also contained phosphonate degradation genes similar to Roseovarius HI0049 and the Rhodobacterales cluster B3TF_MPn_2 (Appendix I Table A8). A common difference was the absence of phnMl in the Oceanibulubs and Sulfitobacter genomes, though they carry a second copy homologous to phnM2. In the cytoplasm, PhnI catalyzes the conversion of MPn and ATP to and adenine in the presence of PhnG, H, and L. PhnM is a phosphatase that hydrolyzes $\alpha$-Dribose-1- methylphosphonate-5-triphosphate to form 5-phospho-a-D-ribosyl 1-alkylphosphonate, the substrate of the C-P bond cleavage reaction catalyzed by PhnJ (Zhang \& van der Donk, 2012). Also lacking in all but one Sulfitobacter isolate (HI0054) was a putative transferase, located between phnE2 and phnM1 in the Rhodobacterales B3TF_MPn_2 cluster, though its function in the C-P lyase pathway remains to be determined. In these isolates' genome assembly the phosphonate degradation genes were found contiguous to one another in the same contig and are thus likely to form complete and functional operons. Interestingly, the Rhodobacteraceae, CP lyase operons were accompanied by sequences encoding a blue-light activated protein, a photosensitive response regulator kinase (Swartz et al., 2005), and a bacterial SH3 domaincontaining protein, which is likely involved in intracellular and membrane-associated functions (Morton \& Campbell, 1994; Musacchio, Gibson, Lehto, \& Saraste, 1992). If these genes are associated with C-P lyase activity the first may be an additional response regulator of the pathway that acts independently of the transcriptional regulator PhnP, and the second may mediate the assembly of the C-P lyase complex or aid in signal transduction. Expression of these genes during phosphonate degradation can be explored further as they may provide alternative regulatory pathways independent from the Pho regulon (sensitive to phosphorus levels) as is charactersitc of the C-P lyase operon in E. coli (White and Metcalf, 2007). 
The remaining isolates carrying phosphonate degradation genes comprised four Gammaproteobacteria related to the genus Oleiphilus (isolates HI0009, HI0066, HI0067, and HI0125). Interestingly, these Oleiphilus strains clustered together in the SSU rRNA gene tree (Appendix I Fig. A1). The phosphonate degradation genes of these strains were most similar to the genes in the gammaproteobacterium IMCC1989 cluster B3TF_MPn_1 though the percent identity between them ranged from $29-52 \%$, a similarity perhaps too low to attribute the same function confidently. The low identity between gene clusters may be explained by the longer phylogenetic distance separating different Gammaproteobacteria lineages compared to other Proteobacteria (Williams et al., 2010). The C-P lyase gene clusters of isolates HI0009 and HI0066 were resolved on the same contig and consisted of phnFDCEGHIJKLMNP. Additionally, sequences similar to a TetR family transcriptional regulator and an integrase were found in the vicinity of these clusters. The two additional Oleiphiuls isolates (HI0067 and HI0125) had the same phosphonate degradation genes though they were split between two or three contigs.

The Pseudoalteromonas strain HI0053, did not harbor genes matching these phosphonate degradation operons. It did carry genes annotated as a 2-aminoethylphosphonate--pyruvate transaminase $(\mathrm{PhnW})$, next to a GntR family transcriptional regulator (perhaps repressing 2aminoethylphosphonate transport), and a putative phosphohydrolase that may be associated with phosphonate metabolism. Also present were a second putative transcriptional regulator of 2aminoethylphosphonate degradation and a 2-aminoethylphosphonate-pyruvate transaminase next to a predicted transcriptional regulator CysB. In addition, HI0053 contained a phosphonoacetaldehyde hydrolase $(\mathrm{PhnX})$ and three sequences similar to PhnA (putative phosphonacetate metabolism). While these sequences do not comprise the canonical alkyl- 
phosphonate degradation pathway they may encode enzymes that degrade other types of phosphonates occurring in the marine environment (Martinez, Tyson, \& Delong, 2010).

\section{Conclusion}

The cultivation experiments conducted as part of this work were motivated by several lines of evidence indicating that isolates originating from mesopelagic microbial communities are capable of degrading semi-labile DOM, and therefore appear not totally reliant on recently produced photosynthate exported from the surface. In these experiments, HMW DOM treatments did in fact recover a larger number of cultures from Mesopelagic samples than from DCM samples. This result may be biased given the dominance of Prochlorococcus in the euphotic zone (28 $\pm 6.3 \%$ of total prokaryotic cells in the upper $100 \mathrm{~m}$ at Station ALOHA) and its rapid decline below $150 \mathrm{~m}$ (Campbell et al., 1997) which may lower the chances of isolating bacterial heterotrophs from the DCM using the dilution-to-extinction method. However, considering the Experiment II dilution-to-exitnction samples' final cell concentrations $\left(3\right.$ cells $\mathrm{ml}^{-1}$ and 2 cells $\mathrm{ml}^{-1}$ for DCM and Mesopelagic experiments, respectively), even if only 2 out of every 3 cells in the DCM are heterotrophic bacteria (assuming 1 out of 3 cells are Prochlorococcus) the percent recovery of cultures in DCM samples is still 2-4 times lower than the percent recovery of Mesopelagic samples (Appendix I, Table A2). In this case it would seem that mesopelagic microbial communities harbor bacteria better adapted to degrade semi-labile HMW DOM. This result is consistent with microcosm experiments performed by Carlson et al. (2004) in which the mesopelagic bacterioplankton communities were more responsive than surface communities to the semi-labile organic matter amendments from filtered surface waters. However, since none of the Mesopelagic or DCM isolates tested observed significant increases in cell yields in response 
to HMW DOM additions (see DOM dose-response experiment results in Figures 3.3, 3.4, and 3.5) it remains unclear if HMW DOM is more readily available to heterotrophic populations from either depth. The only isolates with a significant DOM dose-response to HMW DOM were the Pseudomonads but these are not dominant members of the marine microbiota. How well the properties of the isolates identified reflect the general characteristics of the indigenous communities remains to be determined.

Even though the presence of HMW DOM did not elicit a robust growth response in the isolates tested, an undetectable fraction of HMW DOM may be bio-available. Thus, through physiological screens and genomics I investigated which types of carbon substrates and metabolisms could support the growth of these isolates. The isolation of hydrocarbon-degrading bacteria related to the genus Alcanivorax and Oleiphilus was unexpected given that HMW DOM is primarily composed of carbohydrates. The occurrence of Alcanivorax cultures in particular did not increase in HMW DOM treatments compared to control cultures as did other putative hydrocarbon degraders like Oleiphilus and Erythrobacter isolates suggesting that the former are not stimulated by HMW DOM. However, a small proportion of low-molecular-weight lipids (6\% of total carbon) has been detected in ultrafiltered HMW DOM samples (Aluwihare et al., 1997) which may be sufficient to stimulate the growth of these isolates in dilution-to-extinction cultures. It cannot be ruled out that other HMW DOM constituents like polysaccharides can supply the carbon and energy necessary for growth of such isolates. It is worth noting that many isolates, including members of the Alcanivorax and Oleiphilus, were able to support their growth with acetate as observed in Biolog multi-carbon screens. Proton NMR of HMW DOM revealed a clear signature of acetylated polysaccharides (Aluwihare et al., 1997) of which N-acetyl amino polysaccharides, for example, can contribute $\sim 26 \%$ of the total carbon in HMW DOM from 
surface waters (Aluwihare et al., 2005). Bacteria like the Oleiphilus isolates investigated may be capable of degrading the acetate moieties from these biomolecules using carbohydrate acetyl esterases as identified in the CAZy gene analysis. In addition, the prevalence of these and other hydrocarbon-degrading bacteria in dilution-to-extinction cultures and in the marine environment may be associated with the production of higher alkanes by cyanobacteria, in particular Prochlorococcus (Lea-Smith et al., 2015), the dominant autotroph in subtropical gyres. On the other hand, the Rhodobacteraceae isolates identified in DOC treatments, primarily stimulated by amino acids, may be utilizing $\mathrm{N}$ available in HMW DOM from the degradation of proteins $(21 \%$ of total $\mathrm{N}$ ) or in $\mathrm{N}$-acetyl amino polysaccharides $(43 \%$ of total $\mathrm{N}$ ) using cell surface-bound amidases (Aluwihare et al., 2005). These and similar hypotheses generated using preliminary physiological and genomic evidence can now be tested in the laboratory with the bacterial isolates and appropriate analytical techniques.

Even though HMW DOM treated samples produced a greater number of cultures, the DOM-growth response of open-ocean isolates was only discernible when UV-oxidized seawater was used as the base media. This low-DOC media was not used in DOM dose response tests with isolates from Experiment II which may explain the small increase in cell yields observed despite high DOC treatments (Fig. 3.7). Regardless, the addition of HMW DOM was expected to prompt a proportional increase in cell yields if open-ocean cultures were able to utilize organic carbon constituents for growth but this was not the case. These observations indicate that, in its native form, HMW DOM collected from the upper ocean is not easily accessible to marine microbial heterotrophic populations, at least under the timescales and incubation conditions of these experiments. Most likely, microbial partners may be required to degrade different HMW DOM 
constituents including amino acids in proteins, the acetate and amide nitrogen moieties in polysaccharides, trace lipids as well as humic acids.

Even though HMW DOM appears to be a limited source of carbon to the monocultures investigated it may contain sufficient labile carbon or nutrients to stimulate their initial growth from a single cell in dilution-to-extinction samples to measureable concentrations of $10^{5}-10^{6}$ cell $\mathrm{ml}^{-1}$. To illustrate this, bacterial cultures reaching $10^{6}$ cell ml-1 in $12 \mathrm{X}$ DOC treatments $(960$ nmols $\mathrm{C} \mathrm{ml}^{-1}$ ) only require 8.3 nmols $\mathrm{C}$ assuming a carbon content of marine bacteria of $20 \mathrm{fg}$ cell $^{-1}$ (Lee \& Fuhrman, 1987) and a growth efficiency of $<20 \%$ (Carlson \& Ducklow, 1996) which is $<1 \%$ of the total DOC that was available. On the other hand, trace metals, vitamins, or other growth requirements may be necessary for these bacterial cultures to degrade HMW DOM although the coastal isolates described in Chapter 2 did not receive such supplements and were able to increase their cell yields with respect to the control low-DOC media. It is possible that the open-ocean bacterial isolates tested may only consume nanomolar amounts of carbon from HMW DOM and that microbial partners are required to further access HMW DOM substrates.

Another possibility is that HMW DOM samples contain growth factors like vitamins that stimulated the growth of bacteria on labile DOC already present in the natural seawater media but did not further enhance their growth. Vitamin B-12, for example, is present at picomolar concentrations in seawater (Carini et al., 2014; Menzel \& Spaeth, 1962) and has a molecular wieight of $1.2 \mathrm{kDa}$ indicating it can be easily concentrated by the $1 \mathrm{kDa}$ ultrafiltration membranes used to collect HMW DOM. An alternative explanation to the observed effect that HMW DOM had on the recovery of dilution-to-extinction cultures may be that it serves as antioxidant. Natural polysaccharides including fucans (sulfated sugars) and agar are known to have antioxidant properties that protect organisms by scavenging reactive oxygen species (Kong 
et al., 2010; Wang et al., 2013). Because HMW DOM is largely composed of polysaccharides, the DOC treatments may have effectively increased the antioxidant potential of the cultivation media, especially the 10X DOC and 4X DOC F1 (HMW netural polysaccharides) treatments, increasing the viability of the few cells present in the dilution-to-extinction samples at the beginning of the incubation. However, the loss of some cultures while passaging cells into sterile DOM media and the lower cell yields of Alteromonas cultures with increased DOC indicates that some chemical constituents of HMW DOM may also be inhibitory or toxic to cells.

Investigating DOM-degrading capabilities encoded in the genomes of these isolates remains difficult because the molecular composition of HMW DOM is not well resolved. Because HMW DOM carbohydrates consist on average of five-sugar oligosaccharides with an average molecular mass of $1 \mathrm{kDa}$ (Aluwihare et al., 1997), I hypothesized that isolates enriched in the DOC-treated samples would harbor carbohydrate-degrading complexes similar to microorganisms that specialize in the breakdown of structural plant polysaccharides (e.g., lignins and cellulose) including marine bacterial isolates like Saccharophagus degradans (Weiner et al., 2008) and Cellvibrio japonicus (DeBoy et al., 2008). Nevertheless, only one clear example of a secreted carbohydrase was identified in the mesopelagic Pseudoalteromonas isolate HI0053. Even though HI0053 and other isolates were also able to metabolize simple sugars, none of these were able to clearly increase their cell yields with the HMW polysaccharides obtained from HMW DOM indicating that carbohydrates were not bio-available. Perhaps even at the mesopelagic depth of $200 \mathrm{~m}$, sinking POM is still the primary source of carbon and energy to copiotrophic heterotrophs. It may be necessary to attempt to obtain more oligotrophic isolates, or sample deeper in the water column to find more efficient HMW DOM degraders, capable of metabolizing semi-labile organic carbon constituents. 


\section{Acknowledgements}

I am indebted to several people who assisted in field work and analysis in the laboratory. Special thanks to Daniel Repeta, Scott Gifford, and Rene Boiteau who organized HMW DOM sampling in Hawaii. Thank you to Anna Romano and Tsultrim Palden for assistance DNA sequencing and John Eppley and Torben Nielsen for help with genome assemblies and annotations. Thanks to the crew of the RV Kilo Moana, the Hawaii Ocean Time (HOT) series team members and CMORE community aboard research cruises HOT 250 and HOE-BOE I for their dedication to sea operations. Financial support for this work was provided by the National Science Foundation Center for Microbial Oceanography: Research and Education (award \#EF0424599) and the Gordon and Betty Moore Foundation (grant \#492.01, \#3777, and \#3298). 


\section{Tables}

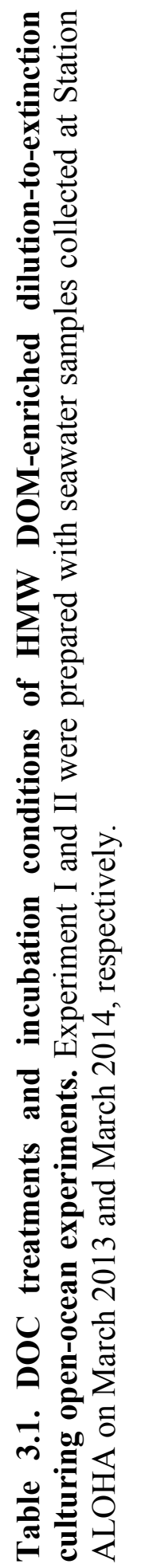

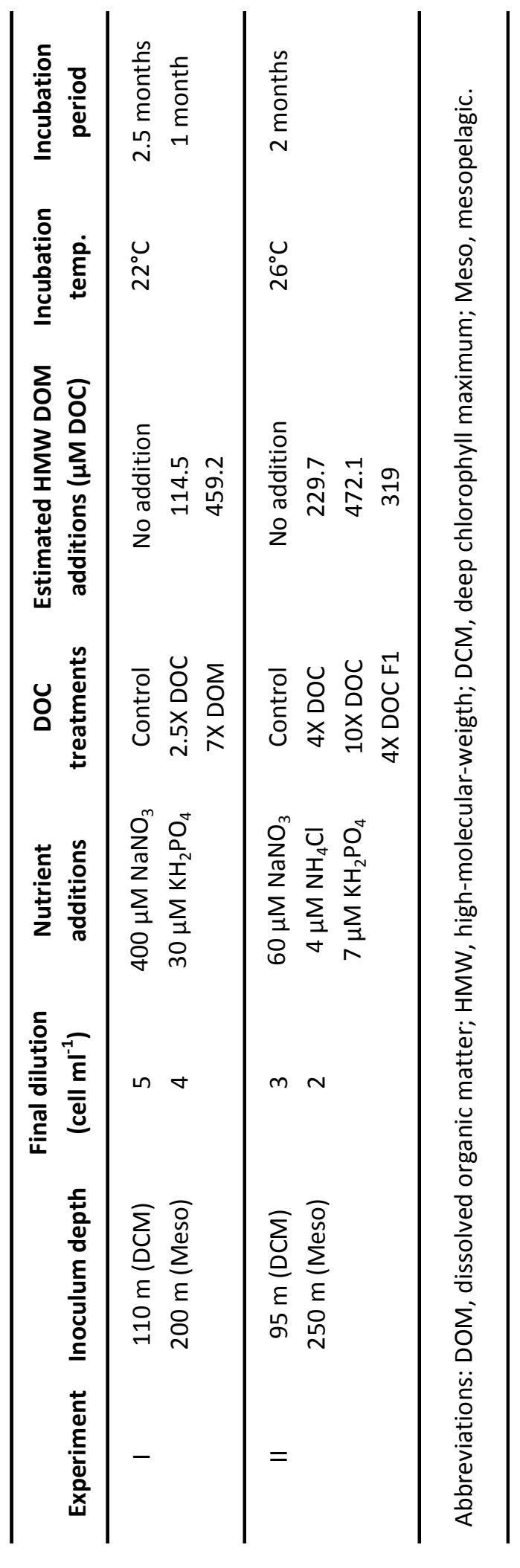


Table 3.2. Phylogenetic identification of Hawaii isolates via assembled SSU rRNA genes.

The dilution-to-extinction experiment and DOC treatment from which isolates originated are indicated as well as the number of cultures with the same SSU rRNA gene sequence similarity.

\begin{tabular}{|c|c|c|c|c|c|}
\hline Isolate ID ${ }^{\mathrm{a}}$ & Best matching described taxa via SSU rRNA ${ }^{b}$ & $\% I^{c}$ & Length $^{d}$ & No. cultures ${ }^{e}$ & DOC treatment \\
\hline \multicolumn{6}{|l|}{ Experiment I } \\
\hline \multicolumn{6}{|l|}{ DCM } \\
\hline S01 & Halioglobus;uncultured bacterium & 99.73 & 1492 & 17 & No DOC \\
\hline \multicolumn{6}{|l|}{ Mesopelagic } \\
\hline D01 & Pseudomonas stutzeri T13 & 99.93 & 1517 & 19 & $7 X$ \\
\hline D02 & Pseudomonas sp. R-25343 & 99.92 & 1312 & 11 & $7 X$ \\
\hline D04 & Pseudomonas stutzeri T13 & 99.87 & 1517 & 22 & $7 X$ \\
\hline D40 & Pseudomonas sp. R-25343 & 99.86 & 1408 & 1 & $7 X$ \\
\hline D59 & Erythrobacter;uncultured bacterium (EF659424.1.1483) & 99.86 & 1453 & 6 & $2.5 X$ \\
\hline D65 & Vibrio crassostreae $9 \mathrm{ZC} 13$ & 98.83 & 1535 & 6 & No DOC \\
\hline D71 & Vibrio; uncultured marine microorganism (EU188141.1.1516) & 99.5 & 1205 & 1 & No DOC \\
\hline \multicolumn{6}{|l|}{ Experiment II } \\
\hline \multicolumn{6}{|l|}{ DCM } \\
\hline 9 & Oleiphilus;uncultured bacterium AD12-E7 & 97.95 & 1514 & 1 & No DOC \\
\hline 21 & Oceanibulbus indolifex HEL-45 & 99.52 & 1444 & 1 & $10 \mathrm{X}$ \\
\hline 27 & Oceanibulbus indolifex HEL-45 & 99.51 & 1219 & 1 & $10 \mathrm{X}$ \\
\hline 19,28 & Erythrobacter; uncultured bacterium AD84-H10 & 99.86 & 1468 & 2 & $10 \mathrm{X}$ \\
\hline 23,40 & Oceanibulbus; marine bacterium SCRIPPS_101 & 98.05 & 1437 & 2 & $10 \mathrm{X}, 4 \mathrm{XF} 1$ \\
\hline $20,37,38$ & Erythrobacter; uncultured bacterium (EF659424.1.1483) & 99.93 & 1453 & 3 & $10 \mathrm{X}, 4 \mathrm{XF1}$ \\
\hline $3,7,11,13,33,35$ & Alcanivorax sp. Abu-1 & 99.93 & 1507 & 6 & No DOC, $4 \mathrm{X}, 4 \mathrm{X} F 1$ \\
\hline \multicolumn{6}{|l|}{ Mesopelagic } \\
\hline $43^{f}$ & Oleiphilus; uncultured gamma proteobacterium (JQ579692.1.1494) & 98.19 & 1494 & 16 & No DOC \\
\hline 49 & Roseovarius; uncultured alpha proteobacterium (HQ727624.1.1431) & 99.79 & 1431 & 1 & $4 X$ \\
\hline 53 & Pseudoalteromonas; uncultured bacterium (KF906589.1.1533) & 99.47 & 1509 & 1 & $4 X$ \\
\hline 54 & Sulfitobacter sp. CC-AMSY-48 & 99.93 & 1429 & 1 & $4 X$ \\
\hline 63 & Erythrobacter; uncultured bacterium HF0500_24B12 & 100.00 & 1469 & 1 & $4 X$ \\
\hline $65^{9}$ & Oleiphilus; uncultured bacterium AD12-E7 & 99.27 & 1514 & 15 & $10 \mathrm{X}$ \\
\hline 75 & Oleibacter; uncultured bacterium (AF382127.1.1491) & 99.73 & 1491 & 1 & $10 x$ \\
\hline 76 & Oceanibulbus indolifex HEL-45 & 99.54 & 1300 & 1 & $10 x$ \\
\hline 82 & Oceanibulbus indolifex HEL-45 & 99.45 & 1444 & 1 & $10 \mathrm{X}$ \\
\hline 90 & Alteromonas sp. KOPRI 11568 & 99.76 & 1276 & 1 & $4 \times \mathrm{F} 1$ \\
\hline 92 & Alteromonas macleodii str. 'Black Sea 11' & 98.53 & 819 & 1 & $4 \times \mathrm{F} 1$ \\
\hline 96 & Alcanivorax sp. Mho1 & 99.93 & 1435 & 1 & $4 \times \mathrm{F} 1$ \\
\hline $97^{9}$ & Oceanibulbus indolifex HEL-45 & 99.51 & 1219 & 1 & $4 \mathrm{XF} 1$ \\
\hline 107 & uncultured Psychrobacter sp. (JX530017.1.1434) & 82.57 & 1113 & 1 & $4 \mathrm{XF1}$ \\
\hline 109 & Alteromonas macleodii str. 'Black Sea 11' & 100.00 & 1187 & 1 & $4 \mathrm{XF} 1$ \\
\hline 113 & Oleibacter; uncultured bacterium (AF382127.1.1491) & 99.80 & 1491 & 1 & $4 \times \mathrm{F} 1$ \\
\hline 120 & Thalassolituus; uncultured gamma proteobacterium (FJ403082.1.1500) & 97.87 & 1500 & 1 & $4 \mathrm{XF1}$ \\
\hline 66,67 & Oleiphilus;uncultured bacterium AD12-E7 & 97.95 & 1514 & 2 & $10 \mathrm{X}$ \\
\hline 74,77 & Erythrobacter; uncultured bacterium AD84-H10 & 99.86 & 1468 & 2 & $10 \mathrm{X}$ \\
\hline 44,83 & Alcanivorax; unidentified (E31375.1.1516) & 99.54 & 1516 & 2 & No $\mathrm{DOC}, 10 \mathrm{X}$ \\
\hline 69,85 & Oleiphilus; uncultured gamma proteobacterium (JQ579692.1.1494) & 98.13 & 1494 & 2 & $10 \mathrm{X}$ \\
\hline 94,125 & Oleiphilus; uncultured bacterium AD12-E7 & 97.89 & 1514 & 2 & $4 \times \mathrm{F} 1$ \\
\hline 112,129 & Oceanibulbus; marine bacterium SCRIPPS_101 & 98.05 & 1437 & 2 & $4 \times \mathrm{F} 1$ \\
\hline
\end{tabular}

${ }^{\mathrm{a}}$ Culture identification number (HIO\#\#).

${ }^{\mathrm{b}}$ Top hit of a LAST sequence similarity search against the SILVA 119 SSU database.

${ }^{\mathrm{C}}$ Percent matching identities to SILVA reference sequence

${ }^{\mathrm{d}}$ Alignment length

${ }^{\mathrm{e}}$ Number of cultures with equal SSU rRNA gene percent matching identities

I Isolate IDs (HIO\#\#) matching HI0043: 050, 061, 068, 072, 078, 081, 086, 098, 100, 103, 111, 117, 123, 128, and 132

Isolate IDs (HIO\#\#) mathcing HI0065: 071, 073, 079, 080, 087, 088, 104, 105, 108, 114, 118, 122, 130, 133 


\section{Figures}

\section{(Opposite page)}

Figure 3.1. HMW DOM enrichments of dilution-to-extinction cultures from Hawaii. Two dilution-to-extinction cultivation experiments (I and II) were prepared with HMW DOM enrichments of seawater samples collected at Station ALOHA from the deep chlorolphyll

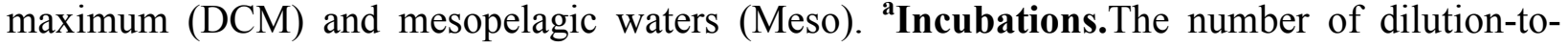
extinction wells prepared for each DOC treatment is indicated. Black circles indicated incubations in darkness. Half black/yellow circles indicate incubations under a 12-hour diurnal cycle). ${ }^{\mathbf{b}}$ Flow cytometry growth screen. The screening procedure is discussed in detail in the Materials and Methods. 'Sub-culturing. Wells considered positive hits were sub-cultured by dilution into fresh media of the corresponding DOC treatment. The number of wells sub-cultured from each DOC treatment and the incubation conditions are indicated. The isolates recovered from the sub-culturing steps are indicated in Table 3.2. 


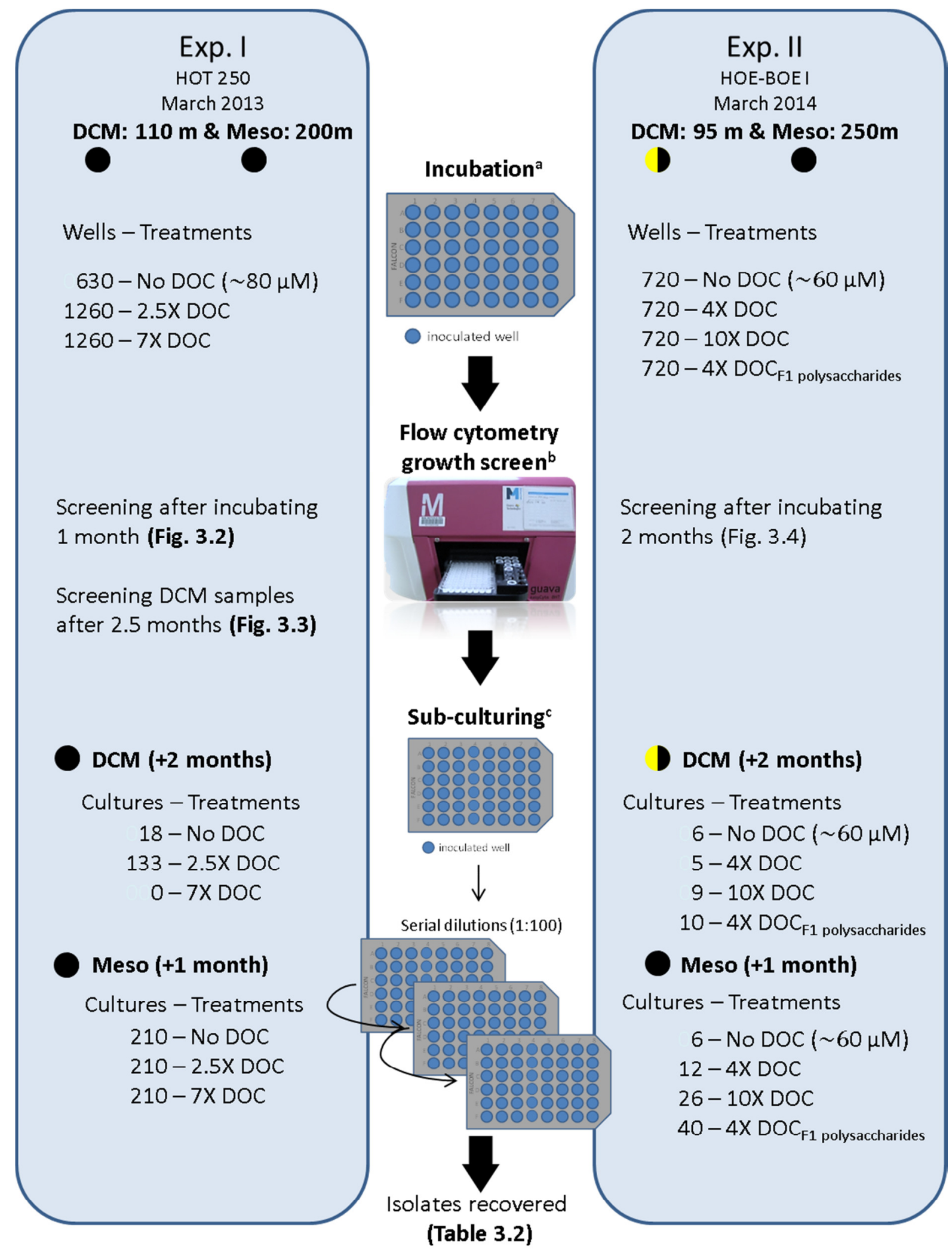


A



B



Figure 3.2. The effect of HMW DOM on growth and recovery of dilution-to-extinction cultures prepared in Experiment I. A) Percent positive wells $\left(>5 \times 10^{4}\right.$ cells $\left.\mathrm{ml}^{-1}\right)$ detected in each DOC treatment after one month of incubation. B) Mesopelagic well cell densities (cell ml ${ }^{-1}$ ) are color coded: red, $>10^{5}$ to $<5 \times 10^{5}$; yellow, $>5 \times 10^{5}$ to $<10^{6}$; green, $>10^{6}$. No DOC, non-DOM amended samples; $2.5 \mathrm{X}$ DOC, $\sim 200 \mu \mathrm{M} \mathrm{C}$; $7 \mathrm{X}$ DOC, $\sim 560 \mu \mathrm{M} \mathrm{C}$. 


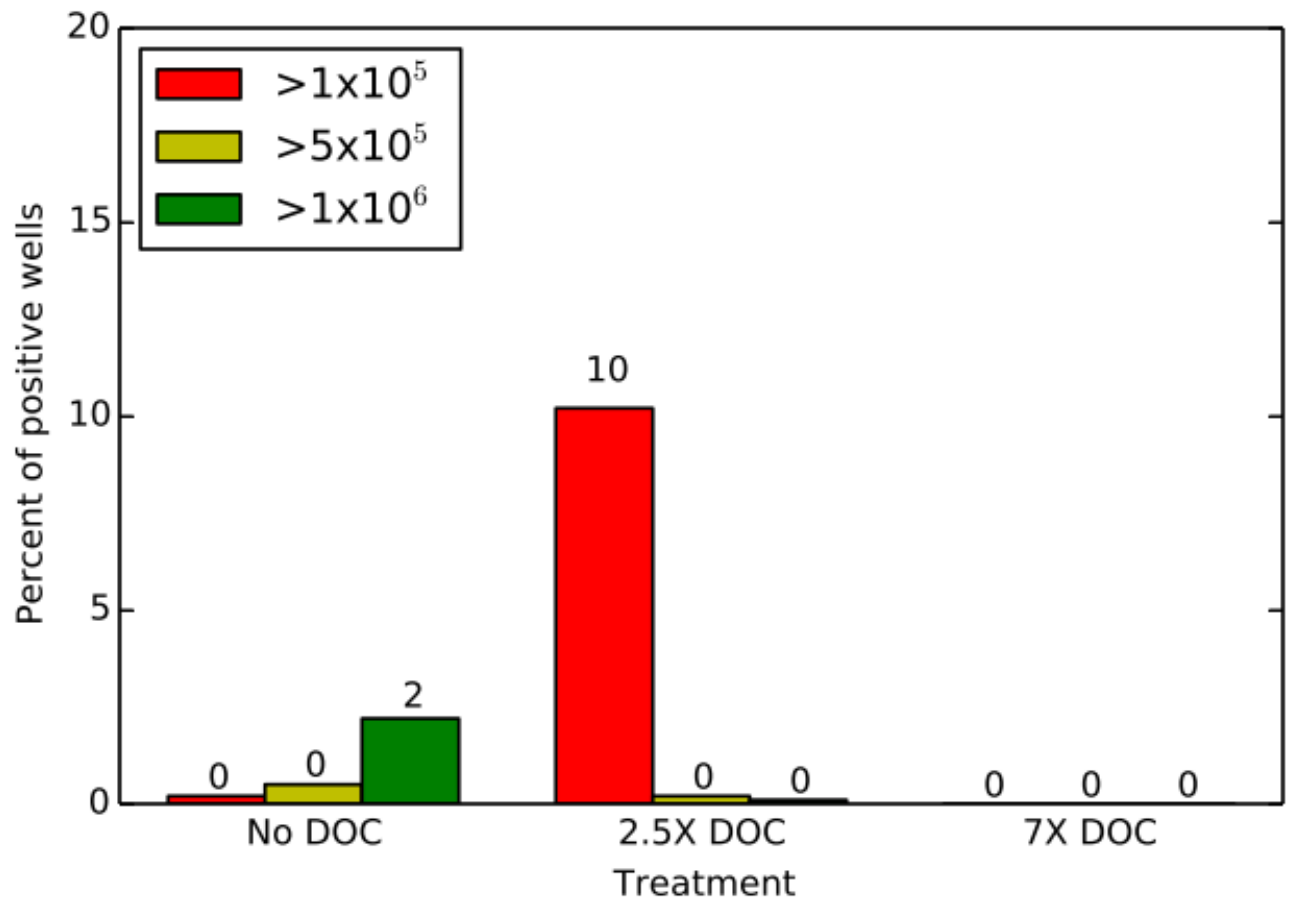

Figure 3.3. The effect of HMW DOM on growth and recovery of DCM dilution-toextinction cultures after an extended incubation period. DCM cultures incubated for an additional 1.5 months after the first screen (Fig. 3.1). Positive wells are indicated as a fraction of the total number of wells screened for each treatment. Total number of wells screened: No DOC, 630 wells; 2.5X DOC, 1260 wells; 7X DOC, 630 wells. Well cell densities (cell ml ${ }^{-1}$ ) are color coded: red, $>10^{5}$ to $<5 \times 10^{5}$; yellow, $>5 \times 10^{5}$ to $<10^{6}$; green, $>10^{6}$. DOC tretments: No DOC, nonDOM amended samples; $2.5 \mathrm{X}$ DOC, $\sim 200 \mu \mathrm{M} \mathrm{C}$; 7X DOC, $\sim 560 \mu \mathrm{M}$ C. Numbers on the top of each bar indicate the percent of positive wells $(0$ if $<1 \%)$. 
A

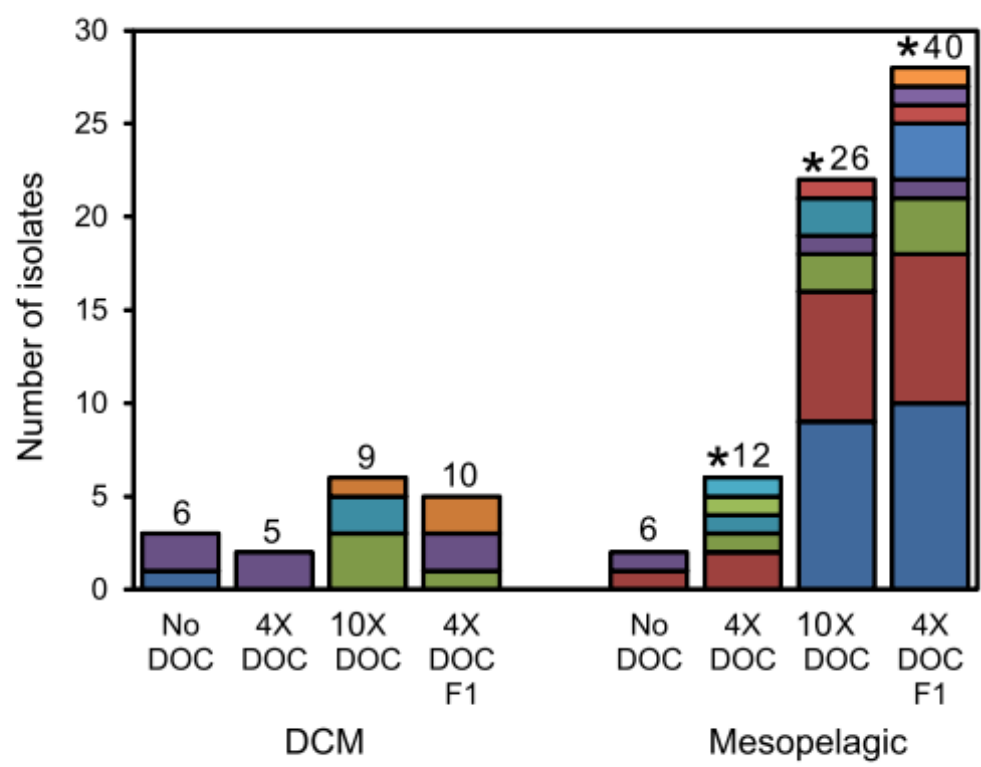

口Alteromonas 2

口Roseovarius

口Thalassolituus

口Pseudoalteromonas

口Oleibacter

口Alteromonas 1

口Erythrobacter 2

-Erythrobacter 1

-Alcanivorax

口Oceanibulbus/Sulfitobacter

-Oleiphilus 2

口Oleiphilus 1

B
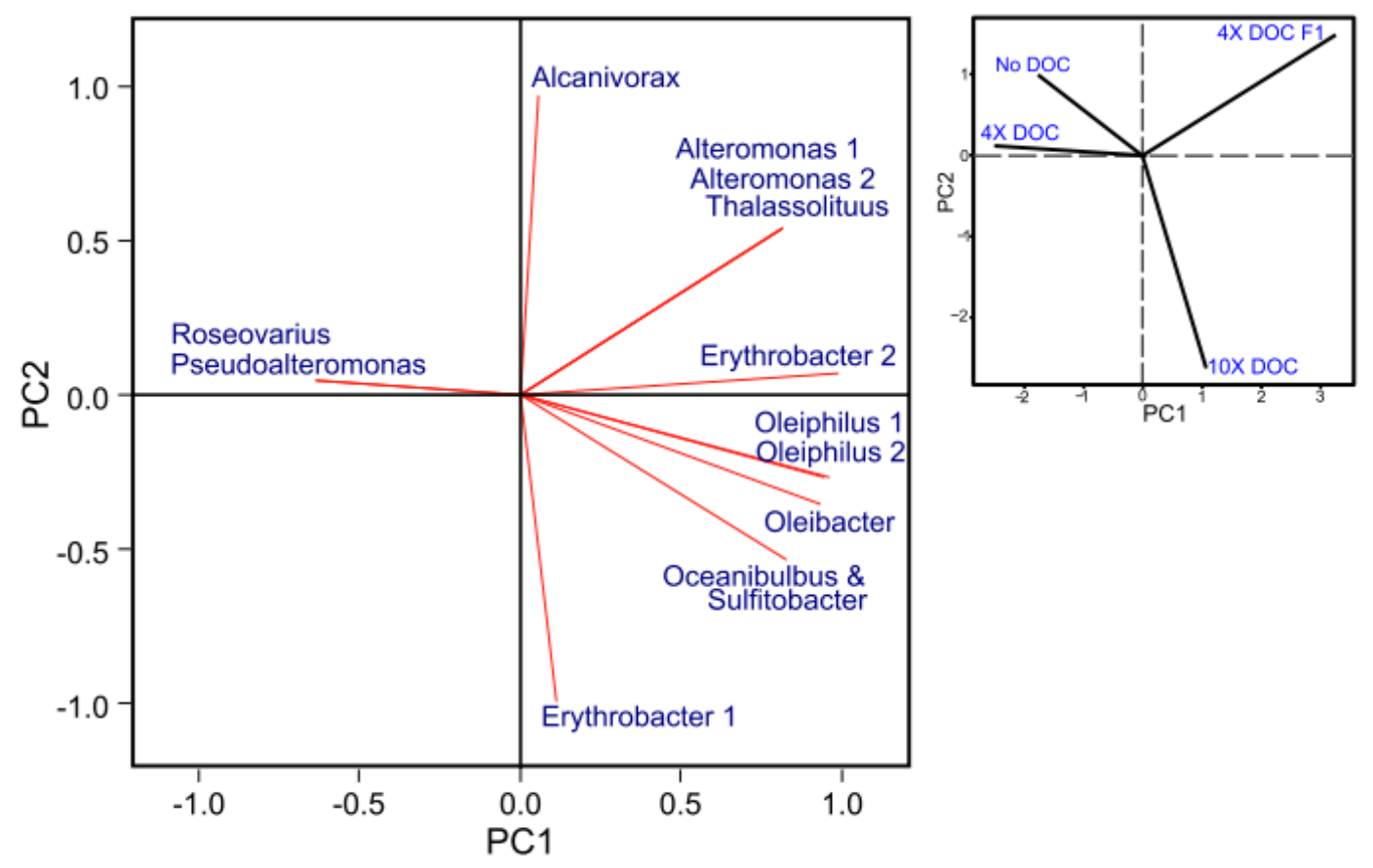

Figure 3.4. Bacterial phylogenetic groups identified in Experiment II. A) Occurrence of SSU rRNA gene clusters (98\% sequence similarity) among DOC treatments. The number on the top of each column indicates the total number of positive wells $\left(>1 \times 10^{4}\right.$ cells $\left.\mathrm{ml}^{-1}\right)$ originally detected in the flow cytometry growth screen. Treatments marked with $\left(^{*}\right)$ were significantly different from the control $\left(\mathrm{P}<0.05\right.$, bootstrap comparisons with $10^{4}$ iterations).

B) The occurrence of SSU rRNA gene clusters across treatments (independent of sample-depth) was assessed through a principal component analysis $(\mathrm{PCA}$; $\mathrm{PC} 1=59.79 \%, \mathrm{PC} 2=28.08 \%$ of variance, respectively). The inset indicates the PCA score received by each DOC treatment. 




Figure 3.5. The growth response of Experiment I Hawaii Pseudomonas and Erythrobacter isolates to HMW DOM additions. Pseudomonas and Erythrobacter isolates were obtained from 7X and 2.5X DOC treatments of Mesopelagic samples, respectively. Controls consisted of UV-oxidized seawater (25 $\mathrm{MM}$ DOC). Treatments $3 \mathrm{X}, 15 \mathrm{X}$, and 30X DOC indicate the estimated DOC concentration above natural Hawaii open-ocean waters $(\sim 80 \mu \mathrm{M}$ DOC). Error bars indicate the difference between duplicate samples. 


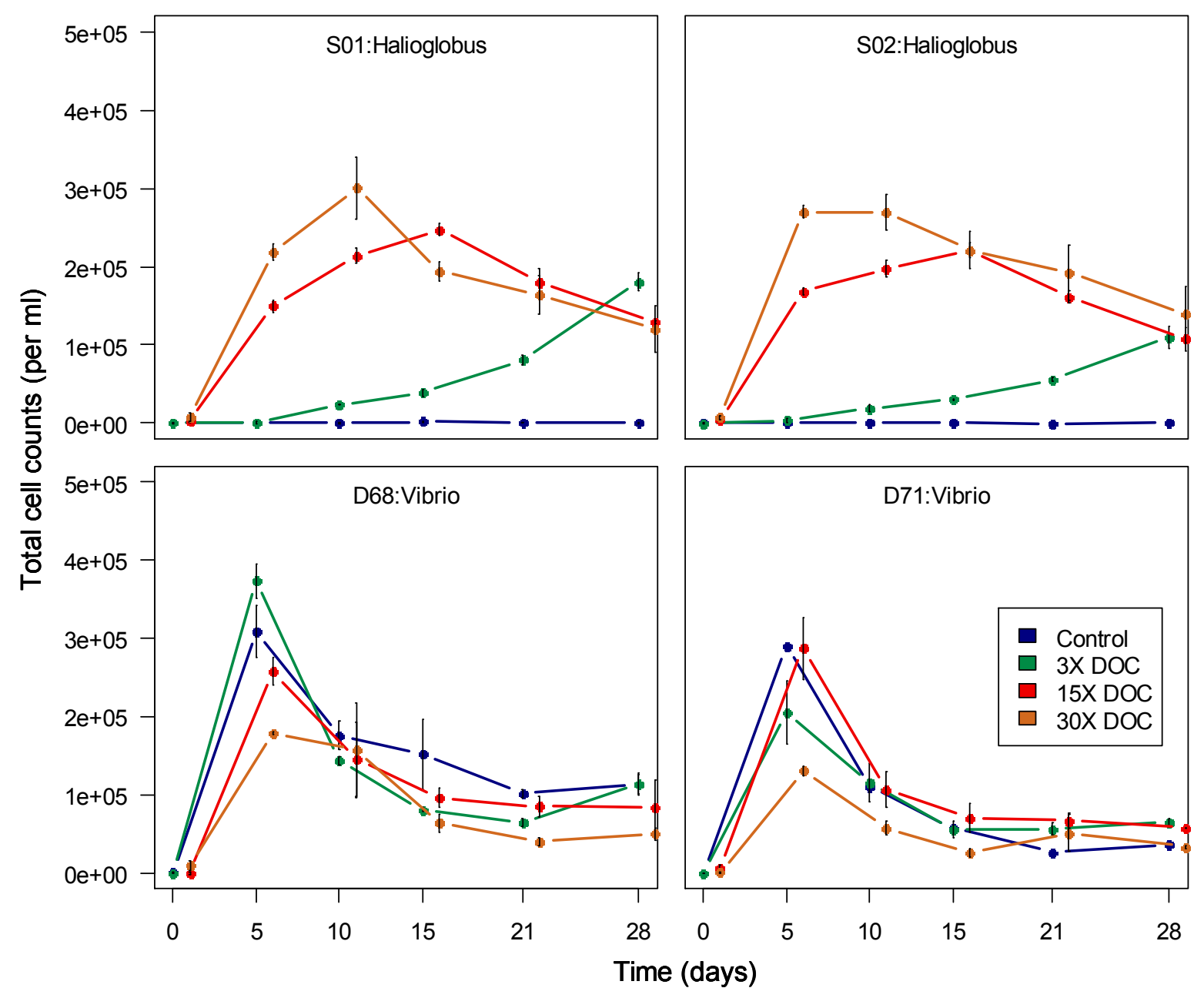

Figure 3.6. The growth response of Experiment I Hawaii Halioglobus and Vibrio isolates to HMW DOM additions. Halioglobus and Vibrio isolates were obtained from DCM and Mesopelagic No DOC treatments, respectively. Controls consisted of UV-oxidized seawater (25 $\mu \mathrm{M}$ DOC). Treatments $3 \mathrm{X}, 15 \mathrm{X}$, and $30 \mathrm{X}$ DOC indicate the estimated DOC concentration above natural Hawaii open-ocean waters $(\sim 80 \mu \mathrm{M}$ DOC). Error bars equal the difference between duplicate samples. 




Figure 3.7. The growth response of Experiment II Hawaii isolates to increasing concentrations of HMW DOM. The control treatment consisted of unamended Hawaii seawater. $4 \mathrm{X}, 8 \mathrm{X}, 12 \mathrm{X}$, and $16 \mathrm{X}$ indicate the DOC concentrations above the typical concentration in open-ocean Hawaii waters $(\sim 80 \mu \mathrm{M}$ DOC $)$. F1 refers to the neutral polysaccharide fraction of HMW DOM obtained by chromatography. Error bars equal one standard deviation. 


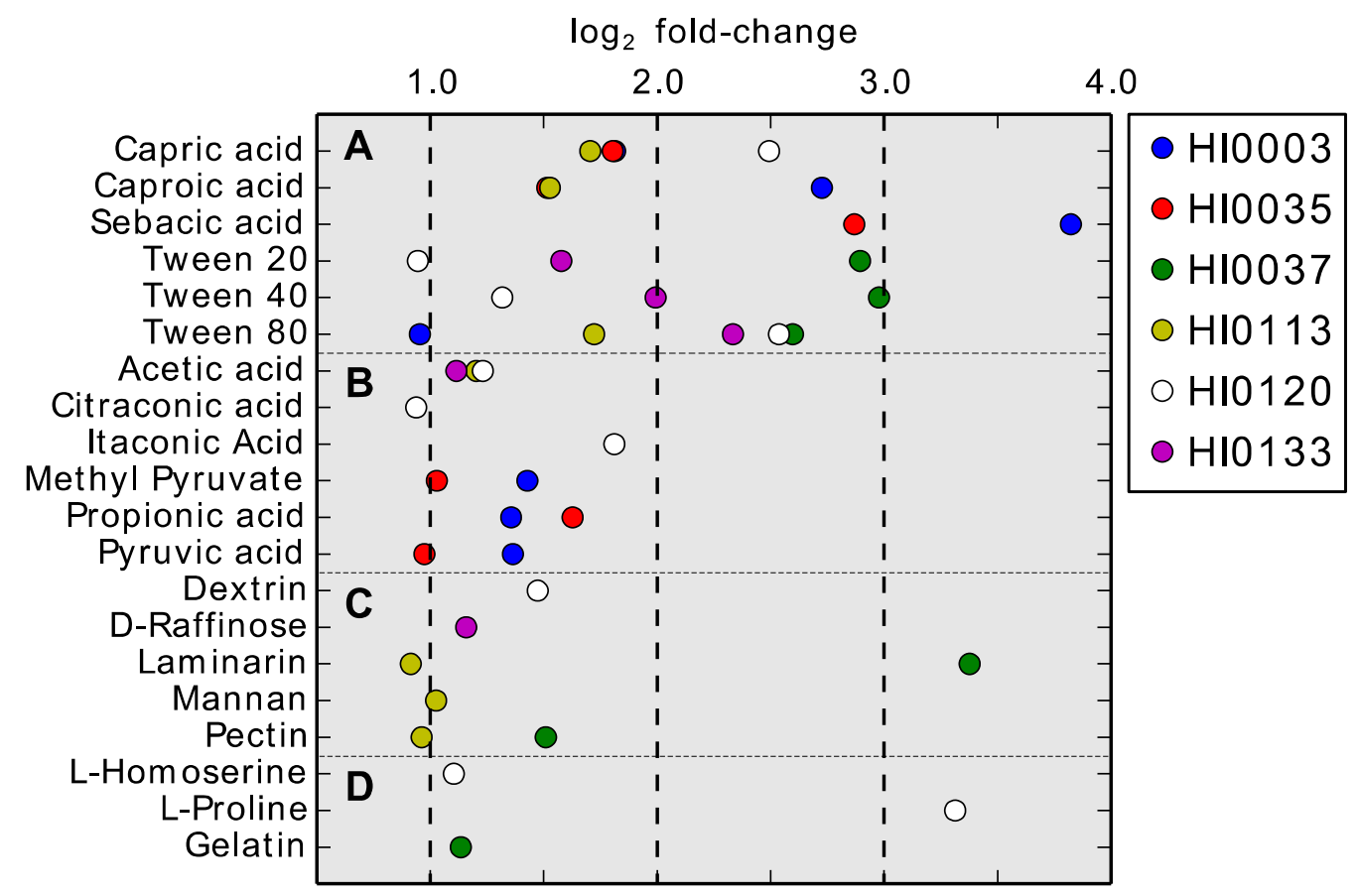

Figure 3.8. Carbon substrate utilization profiles of open-ocean putative hydrocarbon degraders. Sub-panels: (A) hydrocarbon chain-containing compounds, (B) low-molecularweight organic acids, (C) carbohydrates, (D), amino acids and nitrogen-containing compounds. Biolog substrates for which the $\log _{2}$ fold change was $>0.9$ or $<-1.0$ are shown. A $\log _{2}$ fold change $=2$ indicates cell yields $4 \times$ the median cell yield for all substrates $(\mathrm{n}=190)$. Legend: HI0003 (Alcanivorax), HI0035 (Alcanivorax), HI0037 (Erythrobacter), HI0113 (Oleibacter), HI00120 (Thalasolitus), and HI0133 (Oleiphilus).

\section{(Opposite page)}

Figure 3.9. Carbon substrate utilization profiles of Hawaii Rhodobacteraceae isolates. Subpanels: (A) amino acids and nitrogen-containing compounds, (B) low-molecular-weight organic acids, (C) hydrocarbon chain-containing compounds. Biolog substrates for which the $\log _{2}$ fold change was $>0.9$ are shown. A $\log _{2}$ fold change $=1$ indicates cell yields doubled the median cell yield for all substrates (n=190). Legend: HI0049 (Roseovarius) and HI0054 (Sulfitobacter). 


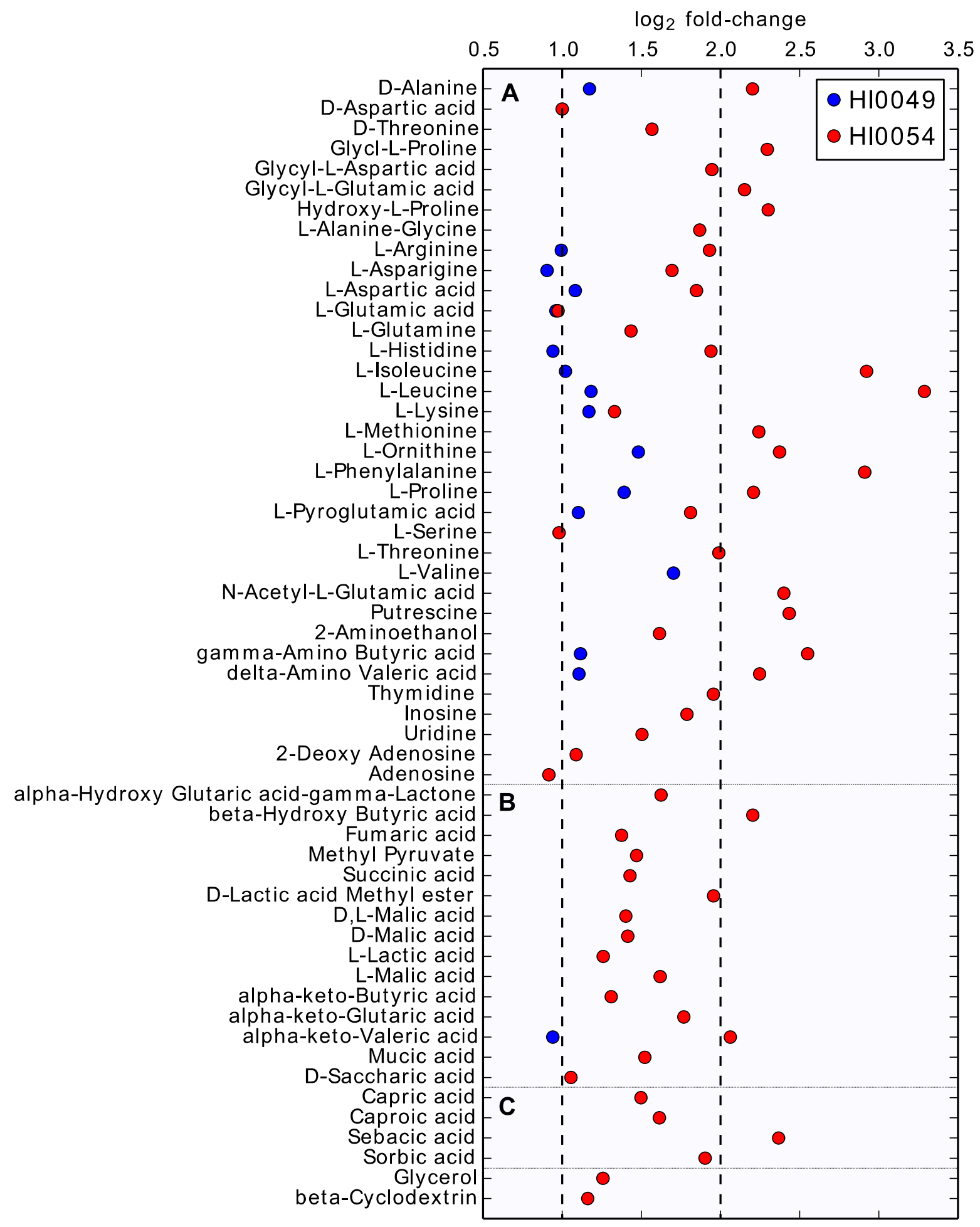




\section{(Opposite page)}

Figure 3.10. The occurrence of predicted CAZy genes in the genomes of Hawaii isolates. Bars indicate the average number of CAZy genes (per enzyme family) identified in each phylogenetic cluster (98\% SSU rRNA sequence similarity) or in DCM and Mesopelagic genomes. The total number of genomes in each group is indicated in parenthesis. Groups with no number indicated consisted of a single representative. CAZy enzyme families: AA, auxiliary activities; CBM, carbohydrate-binding modules; CE, carbohydrate esterases; GH, glycoside hydrolases; GT, glycsyl transferases; PL, polysaccharide lyases. The average number of enzyme families marked with $(*)$ was significantly different between DCM and Mesopelagic genomes (Mann-Whitney U test, P-value $<0.05$ ). A one-way ANOVA was conducted to compare the number of predicted CAZy genes of each class (AA, CBM, CE, GH, GT, and PL) among phylotypes $(\mathrm{P}$-value $<0.05)$. Bars marked with the same letter were not significantly different according to post hoc analysis using Tukey's honest significance difference test (P-value $<0.05)$. Error bars are equal to the SEM of predicted CAZy genes for each phylo-type or isolate. 


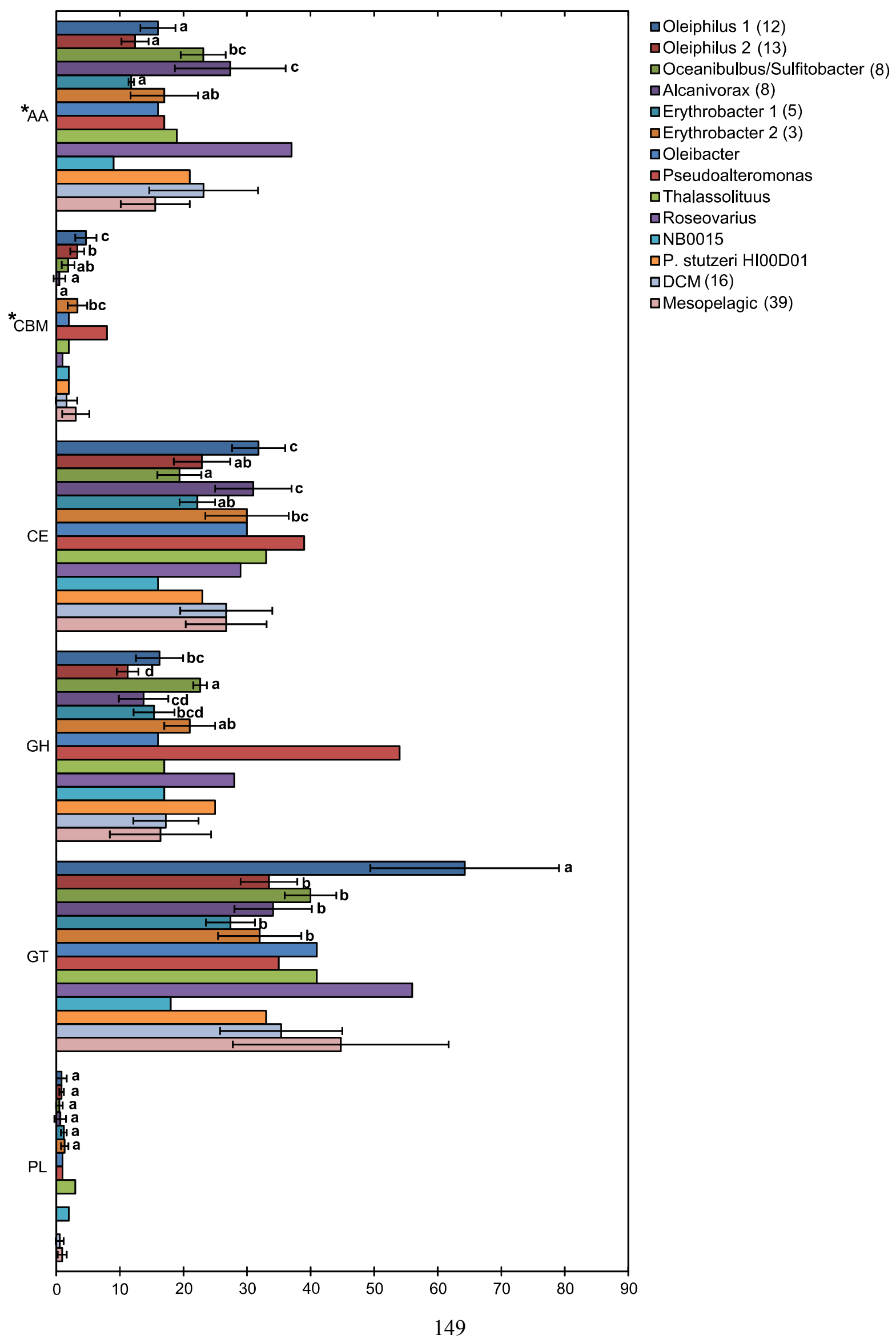




\section{References}

Aluwihare, L. I., Repeta, D. J., \& Chen, R. F. (1997). A major biopolymeric component to dissolved organic carbon in surface sea water. Nature 387, 166-169.

Aluwihare, L. I., Repeta, D. J., Pantoja, S., \& Johnson, C. G. (2005). Two chemically distinct pools of organic nitrogen accumulate in the ocean. Science, 308, 1007-1010. http://doi.org/10.1126/science.1108925

Arístegui, J., Agustí, S., Middelburg, J. J., \& Duarte, C. M. (2005). Respiration in the mesopelagic and bathypelagic zones of the oceans. In del Giorgio P. and Williams P. (Eds.). Respiration in Aquatic Ecosystems, (pp. 181-205). Oxford University Press, New York.

Ausmees, N., Mayer, R., Weinhouse, H., Volman, G., Amikam, D., Benziman, M., \& Lindberg, M. (2001). Genetic data indicate that proteins containing the GGDEF domain possess diguanylate cyclase activity. FEMS Microbiology Letters, 204, 163-167.

Aylward, F. O., Eppley, J. M., Smith, J. M., Chavez, F. P., Scholin, C. a., \& DeLong, E. F. (2015). Microbial community transcriptional networks are conserved in three domains at ocean basin scales. Proceedings of the National Academy of Sciences of the USA, 112(17), 5443-5448.

Azam, F. (1998). Microbial Control of Oceanic Carbon Flux: The Plot Thickens. Science, 280(5364), 694-696.

Azam, F., Fenchel, T., Field, J., Gray, J., Meyer-Reil, L., \& Thingstad, F. (1983). The ecological role of water-column microbes in the sea . Marine Ecology Progress Series, 10, 257-263.

Bankevich, A., Nurk, S., Antipov, D., Gurevich, A. a., Dvorkin, M., Kulikov, A. S., ... Pevzner, P. a. (2012). SPAdes: A New Genome Assembly Algorithm and Its Applications to Single-Cell Sequencing. Journal of Computational Biology, 19(5), 455-477.

Benner, R., Biddanda, B., Black, B., \& McCarthy, M. (1997). Abundance, size distribution, and stable carbon and nitrogen isotopic compositions of marine organic matter isolated by tangential-flow ultrafiltration. Marine Chemistry, 57, 243-263.

Benner, R., Pakulski, J. D., McCarthy, M., Hedges, J. I., \& Hatcher, P. G. (1992). Bulk chemical characteristics of dissolved organic matter in the ocean. Science, 255, 1561-1564.

Bochner, B. R., Gadzinski, P., \& Panomitros, E. (2001). Phenotype Microarrays for highthroughput phenotypic testing and assay of gene function. Genome Research, 11, 12461255. 
Brix, H., Gruber, N., Karl, D. M., \& Bates, N. R. (2006). On the relationships between primary, net community, and export production in subtropical gyres. Deep Sea Research Part II: Topical Studies in Oceanography, 53, 698-717.

Camacho, C., Coulouris, G., Avagyan, V., Ma, N., Papadopoulos, J., Bealer, K., \& Madden, T. L. (2009). BLAST plus: Architecture and applications. BMC Bioinformatics, 10, 421.

Campbell, L., Liu, H., Nolla, H. a., \& Vaulot, D. (1997). Annual variability of phytoplankton and bacteria in the subtropical North Pacific Ocean at Station ALOHA during the 1991-1994 ENSO event. Deep-Sea Research Part I: Oceanographic Research Papers, 44(2), 167192.

Cantarel, B. I., Coutinho, P. M., Rancurel, C., Bernard, T., Lombard, V., \& Henrissat, B. (2009). The Carbohydrate-Active EnZymes database (CAZy): An expert resource for glycogenomics. Nucleic Acids Research, 37, 233-238.

Carini, P., Campbell, E. O., Morré, J., Sañudo-Wilhelmy, S. a, Thrash, J. C., Bennett, S. E., ... Giovannoni, S. J. (2014). Discovery of a SAR11 growth requirement for thiamin's pyrimidine precursor and its distribution in the Sargasso Sea. The ISME Journal, 8, 172738.

Carlson, C. A, Giovannoni, S. J., Hansell, D. a, Goldberg, S. J., Parsons, R., \& Vergin, K. (2004). Interactions among dissolved organic carbon, microbial processes, and community structure in the mesopelagic zone of the northwestern Sargasso Sea. Limnology and Oceanography, 49(4), 1073-1083.

Carlson, C. A., \& Ducklow, H. W. (1996). Growth of bacterioplankton and consumption of dissolved organic carbon in the Sargasso Sea. Aquatic Microbial Ecology, 10, 69-85.

Carlson, C. A., Ducklow, H. W., \& Michaels, A. F. (1994). Annual flux of dissolved organic carbon from the euphotic zone in the northwestern Sargasso Sea. Nature, 371, 405-408.

Carlson, C. A., Hansell, D. a., Nelson, N. B., Siegel, D. a., Smethie, W. M., Khatiwala, S., ... Halewood, E. (2010). Dissolved organic carbon export and subsequent remineralization in the mesopelagic and bathypelagic realms of the North Atlantic basin. Deep-Sea Research Part II: Topical Studies in Oceanography, 57(16), 1433-1445.

Chevreux, B., Wetter, T., \& Suhai, S. (1999). Genome Sequence Assembly Using Trace Signals and Additional Sequence Information. Computer Science and Biology: Proceedings of the German Conference on Bioinformatics (GCB), (1995), 45-56.

Cho, B. C., \& Azam, F. (1988). Major role of bacteria in biogeochemical fluxes in the ocean's interior. Nature, 332, 441-443. 
Cock, P. J. a, Grüning, B. a, Paszkiewicz, K., \& Pritchard, L. (2013). Galaxy tools and workflows for sequence analysis with applications in molecular plant pathology. PeerJ, $1, \mathrm{e} 167$.

Cole, J., Findlay, S., \& Pace, M. (1988). Bacterial production in fresh and saltwater ecosystems: a cross-system overview. Marine Ecology Progress Series, 43, 1-10.

Cuccuru, G., Orsini, M., Pinna, A., Sbardellati, A., Soranzo, N., Travaglione, A., ... Fotia, G. (2014). Orione, a web-based framework for NGS analysis in microbiology. Bioinformatics, 30(13), 1928-1929.

DeBoy, R. T., Mongodin, E. F., Fouts, D. E., Tailford, L. E., Khouri, H., Emerson, J. B., ... Nelson, K. E. (2008). Insights into plant cell wall degradation from the genome Sequence of the soil bacterium Cellvibrio japonicus. Journal of Bacteriology, 190(15), 5455-5463.

Ducklow, H. W., Steinberg, D. K., \& Buesseler, K. O. (2001). Upper ocean carbon export and the biological pump. Oceanography, 14(4), 50-58.

Eddy, S. R. (2009). A new generation of homology search tools based on probabilistic inference. Genome Informatics. International Conference on Genome Informatics, 23, 205-211.

Emerson, S., Quay, P., Karl, D. M., Winn, C., \& Tupas, L. M. (1997). Experimental determination of the organic carbon flux from open-ocean surface waters. Nature, 389, 951-954.

Felsenstein, J. (2010). Confidence limits on phylogenies: an approach using the bootstrap. Evolution, 39(4), 783-791.

Frith, M. C., Hamada, M., \& Horton, P. (2010). Parameters for accurate genome alignment. BMC Bioinformatics, 11, 80 .

Gebhard, S., \& Cook, G. M. (2008). Differential regulation of high-affinity phosphate transport systems of Mycobacterium smegmatis: Identification of PhnF, a repressor of the phnDCE operon. Journal of Bacteriology, 190(4), 1335-1343.

Giovannoni, S. J., Tripp, H. J., Givan, S., Podar, M., Vergin, K. L., Baptista, D., ... Mathur, E. J. (2005). Genome streamlining in a cosmopolitan oceanic bacterium. Science, 309, 12421245.

Hampel, F. R. (1974). The influence curve and its role in robust estimation. Journal of the American Statistical Association, 69(346), 383-393.

Huggett, M. J., Hayakawa, D. H., \& Rappé, M. S. (2012). Genome sequence of strain HIMB624, a cultured representative from the OM43 clade of marine Betaproteobacteria. Standards in Genomic Sciences, 6, 11-20. 
Kanehisa, M., \& Goto, S. (2000). KEGG: Kyoto Encyclopaedia of Genes and Genomes. Nucleic Acids Research, 28(1), 27-30.

Kawasaki, S., Moriguchi, R., Sekiya, K., Nakai, T., Ono, E., Kume, K., \& Kawahara, K. (1994). The cell envelope structure of the lipopolysaccharide-lacking gram- negative bacterium Sphingomonas paucimobilis. Journal of Bacteriology, 176(2), 284-290.

Kiełbasa, S. M., Wan, R., Sato, K., Horton, P., \& Frith, M. C. (2011). Adaptive seeds tame genomic sequence comparison. Genome Research, 21, 487-93.

Kimura, M. (1980). A simple method for estimating evolutionary rates of base substitutions through comparative studies of nucleotide sequences. Journal of Molecular Evolution, 16(1330), 111-120.

Kong, F., Zhang, M., Liao, S., Yu, S., Chi, J., \& Wei, Z. (2010). Antioxidant activity of polysaccharide-enriched fractions extracted from pulp tissue of litchi chinensis sonn. Molecules, 15, 2152-2165.

Kuipers, B., Van Noort, G. J., Vosjan, J., \& Herndl, G. J. (2000). Diel periodicity of bacterioplankton in the euphotic zone of the subtropical Atlantic Ocean. Marine Ecology Progress Series, 201, 13-25.

Lauro, F. M., McDougald, D., Thomas, T., Williams, T. J., Egan, S., Rice, S., ... Cavicchioli, R. (2009). The genomic basis of trophic strategy in marine bacteria. Proceedings of the National Academy of Sciences of the U.S.A, 106, 15527-15533.

Laws, E. a., Letelier, R. M., \& Karl, D. M. (2014). Estimating the compensation irradiance in the ocean: The importance of accounting for non-photosynthetic uptake of inorganic carbon. Deep-Sea Research Part I: Oceanographic Research Papers, 93, 35-40.

Lea-Smith, D. J., Biller, S. J., Davey, M. P., Cotton, C. a. R., Perez Sepulveda, B. M., Turchyn, A. V., ... Howe, C. J. (2015). Contribution of cyanobacterial alkane production to the ocean hydrocarbon cycle. Proceedings of the National Academy of Sciences of the USA, 13591-13596.

Lee, S., \& Fuhrman, J. A. (1987). Relationships between biovolume and biomass of naturally derived marine bacterioplankton. Applied and Environmental Microbiology, 53, 12981303.

Letelier, R. M., Karl, D. M., Abbott, M. R., \& Bidigare, R. R. (2004). Light driven seasonal patterns of chlorophyll and nitrate in the lower euphotic zone of the North Pacific Subtropical Gyre. Limnology and Oceanography, 49(2), 508-519.

Leys, C., Ley, C., Klein, O., Bernard, P., \& Licata, L. (2013). Detecting outliers: Do not use standard deviation around the mean, use absolute deviation around the median. Journal of Experimental Social Psychology, 49, 764-766. 
Ludwig, W. (2004). ARB: a software environment for sequence data. Nucleic Acids Research, 32(4), 1363-1371.

Luo, Y. W., Friedrichs, M. a M., Doney, S. C., Church, M. J., \& Ducklow, H. W. (2010). Oceanic heterotrophic bacterial nutrition by semilabile DOM as revealed by data assimilative modeling. Aquatic Microbial Ecology, 60, 273-287.

Martinez, A., Tyson, G. W., \& Delong, E. F. (2010). Widespread known and novel phosphonate utilization pathways in marine bacteria revealed by functional screening and metagenomic analyses. Environmental Microbiology, 12, 222-238.

Martínez, A., Ventouras, L. A., Wilson, S. T., Karl, D. M., \& DeLong, E. F. (2013). Metatranscriptomic and functional metagenomic analysis of methylphosphonate utilization by marine bacteria. Frontiers in Microbiology, 4, 1-18.

McCarthy, M. D., Hedges, J. I., \& Benner, R. (1993). The chemical composition of dissolved organic matter in seawater. Chemical Geology, 107, 503-507.

McCarthy, M., Hedges, J., \& Benner, R. (1996). Major biochemical composition of dissolved high molecular weight organic matter in seawater. Marine Chemistry, 5, 281-297.

McGrath, J. W., Chin, J. P., \& Quinn, J. P. (2013). Organophosphonates revealed: new insights into the microbial metabolism of ancient molecules. Nature Reviews. Microbiology, 11, $412-419$.

Menzel, D. W., \& Spaeth, J. P. (1962). Occurrence of vitamin B12 in the Sargasso Sea. Limnology and Oceanography, 7, 151-154.

Metcalf, W. W., \& Wanner, B. L. (1993a). Evidence for a fourteen-gene, phnC to phnP locus for phosphonate metabolism in Escherichia coli. Gene, 129, 27-32.

Metcalf, W. W., \& Wanner, B. L. (1993b). Mutational analysis of an Escherichia coli fourteengene operon for phosphonate degradation, using TnphoA' elements. Journal of Bacteriology, 175(11), 3430-3442.

Morton, C. J., \& Campbell, I. D. (1994). SH3 domains. Molecular "Velcro". Current Biology: $C B, 4(7), 615-617$.

Munoz, R., Yarza, P., Ludwig, W., Euzéby, J., Amann, R., Schleifer, K.-H., ... Rosselló-Móra, R. (2011). Release LTPs104 of the All-Species Living Tree. Systematic and Applied Microbiology, 34, 169-70.

Musacchio, A., Gibson, T., Lehto, V.-P., \& Saraste, M. (1992). SH3 - an abundant protein domain in search of a function. FEBS Letters, 307(1), 55-61. 
Ottesen, E. a, Young, C. R., Gifford, S. M., Eppley, J. M., Marin, R., Schuster, S. C., ... DeLong, E. F. (2014). Multispecies diel transcriptional oscillations in open ocean heterotrophic bacterial assemblages. Science, 345, 207-12.

Pruesse, E., Peplies, J., \& Glockner, F. O. (2012). SINA: Accurate high-throughput multiple sequence alignment of ribosomal RNA genes. Bioinformatics, 28(14), 1823-1829.

Repeta, D. J., \& Aluwihare, L. I. (2006). Radiocarbon analysis of neutral sugars in highmolecular-weight dissolved organic carbon: Implications for organic carbon cycling. Limnology and Oceanography, 51(2), 1045-1053.

Saitou, N., \& Nei, M. (1987). The neighbor-joining method: A new method for reconstructing phylogenetic trees. Molecular Biology and Evolution, 4(4), 406-425.

Sarmiento, J. L., \& Gruber, N. (2006). Organic Matter Production. Ocean Biogeochemical Dynamic. Chapter 4 (pp. 102-172). Princeton University Press, Princeton, NJ.

Seemann, T. (2014). Prokka: rapid prokaryotic genome annotation. Bioinformatics, 30(14), 2068-2069.

Singer, E., Webb, E. a., Nelson, W. C., Heidelberg, J. F., Ivanova, N., Pati, A., \& Edwards, K. J. (2011). Genomic potential of Marinobacter aquaeolei, a biogeochemical "Opportunitroph.” Applied and Environmental Microbiology, 77(8), 2763-2771.

Sosa, O. a, Gifford, S. M., Repeta, D. J., \& DeLong, E. F. (2015). High molecular weight dissolved organic matter enrichment selects for methylotrophs in dilution to extinction cultures. The ISME Journal, 9, 2725-2739.

Swartz, T. E., Tseng, T., Frederickson, M. A., Paris, G., Comerci, D. J., Rajashekara, G., ... Bogomolni, R. A. (2005). Science, 317, 1090-1093.

Thingstad, T. F., Hagström, A., \& Rassoulzadegan, F. (1997). Accumulation of degradable DOC in surface waters: Is it caused by a malfunctioning microbialloop? Limnology and Oceanography, 42, 398-404.

Wang, H., Liu, Y. M., Qi, Z. M., Wang, S. Y., Liu, S. X., Li, X., ... Xia, X. C. (2013). An overview on natural polysaccharides with antioxidant properties. Current Medicinal Chemistry, 20, 2899-2913.

Weiner, R. M., Taylor, L. E., Henrissat, B., Hauser, L., Land, M., Coutinho, P. M., ... Hutcheson, S. (2008). Complete genome sequence of the complex carbohydratedegrading marine bacterium, Saccharophagus degradans strain 2-40T. PLoS Genetics, 4(5), e1000087.

White, A. K., \& Metcalf, W. W. (2007). Microbial metabolism of reduced phosphorus compounds. Annual Review of Microbiology, 61, 379-400. 
Williams, K. P., Gillespie, J. J., Sobral, B. W. S., Nordberg, E. K., Snyder, E. E., Shallom, J. M., \& Dickerman, a. W. (2010). Phylogeny of Gammaproteobacteria. Journal of Bacteriology, 192(9), 2305-2314.

Yin, Y., Mao, X., Yang, J., Chen, X., Mao, F., \& Xu, Y. (2012). dbCAN: a web resource for automated carbohydrate-active enzyme annotation. Nucleic Acids Research, 40, W44551. 


\section{CHAPTER FOUR}

Production of hydrocarbon gases during bacterial degradation of covalentlybound phosphonates associated with marine high-molecular-weight dissolved organic matter 


\section{Abstract}

The decomposition of dissolved organic matter (DOM), predominantly a microbialmediated function, is fundamental to the cycling of bio-elements like carbon, nitrogen, and phosphorus and to the sustainability of primary productivity. Yet the underlying mechanisms the microbial taxa and the enzymatic and biochemical reactions carried on by them - driving this important ecological process remain greatly unexplored in the ocean environment. In this chapter I make use of two putative high-molecular-weight (HMW) DOM-degraders, the gammaproteobacterium Pseudomonas stutzeri strain HI00D01 and the alpha-proteobacterium Sulfitobacter strain HI0054 (described in Chapter 3), to investigate the bio-availability of alkylphosphonates - organophosphorus molecules with a direct carbon-phosphorus (C-P) bond associated with marine HMW DOM polysaccharides. In addition to providing a source of phosphorus to microorganisms in the oligotrophic ocean, the degradation of HMW DOM phosphonates like methyl phosphonate may be an important source of methane and other hydrocarbons to the environment. Using batch culture experiments, I demonstrate that both isolates can produce methane and ethylene in the presence of HMW DOM polysaccharides under aerobic conditions. To demonstrate the implication of the phosphonate degradation pathway namely the C-P lyase complex - in the production of hydrocarbons, the same experiment was performed with a mutant strain of $P$. stutzeri HI00D01 unable to metabolize simple phosphonate compounds. As expected, the mutant strain did not produce hydrocarbons when exposed to the HMW polysaccharide amendment. These observations support the hypothesis that HMW DOMbound methyl phosphonates may be a significant source of methane in the water column, and that bacterial degradation of these compounds likely contributes to the subsurface methane maxima observed throughout the world's oceans. 


\section{Introduction}

Phosphorus is often a scarce nutrient in the ocean limiting marine productivity especially in the oligotrophic gyres (Karl et al., 2001; Moore et al., 2013). The organic phosphorus stored in DOM (DOP) dominates the total dissolved phosphorus inventory $(\sim 75-80 \%)$ in subtropical surface waters (Karl et al., 2001) and is of special importance for microbial communities when inorganic phosphorus is scarce or unavailable (Björkman \& Karl, 2003). The high-molecularweight (HMW) fraction of DOM contains two main forms of organic phosphorus: phosphate esters $(75 \%)$ and phosphonates $(25 \%)$, the latter comprising approximately $10 \%$ of total DOP in open-ocean surface waters (Clark, Ingall, \& Benner, 1999; Kolowith et al., 2001). Unlike phosphate esters, phosphonates are often undetectable in particulate organic matter (POM) and plankton biomass (Kolowith et al., 2001; Paytan, Cade-Menun, McLaughlin, \& Faul, 2003) and yet they seem to accumulate in HMW DOP. The mechanism that leads to the prevalence of phosphonates in DOM is unclear, although most likely this occurs because these are more resistant to microbial degradation than the more labile phosphate esters. Nevertheless, both phosphonates and phosphate esters in DOP seem to be utilized by microorganisms at similar rates given that their relative concentrations remain stable as HMW DOP decreases with depth (Clark et al., 1999; Clark \& Ingall, 1998; Kolowith et al., 2001).

This chapter investigates the microbial degradation of phosphonates, molecules that contain a chemically stable C-P bond highly resistant to hydrolysis and bacterial degradation. Several bacterial enzymatic pathways are known to degrade phosphonates including the phosphonopyruvate hydrolase pathway, the phosphonoacetate hydrolase pathway, the phosphonoacetaldehyde hydrolase (phosphonatase) pathway, and the carbon-phosphorus lyase 
(C-P lyase) pathway and are summarized by (White \& Metcalf, 2007). The most widespread is the C-P lyase pathway and is the focus of this chapter.

The C-P lyase is an enzyme complex encoded by a 14-gene operon in Escherichia coli (phnCDEFGHIJKLMNOP) that catalyzes the degradation of a broad range of alkylphosphonates, such as methyl phosphonate and 2-aminoethyl phosphonate, to make the phosphorus available for cell uptake (Metcalf \& Wanner, 1993a, 1993b). Cleavage of the C-P phosphonate bond results in the concomitant release of the alkyl group which may or may not be used as additional carbon source (White \& Metcalf, 2007). Marine metagenomes and sequenced bacterial genomes, mainly of the Proteobacteria lineage, are known to encode several modifications of the C-P lyase gene operon (Martinez, Ventouras, Wilson, Karl, \& Delong, 2013; Villarreal-Chiu, 2012) indicating that phosphonates are bio-available in the ocean. In accordance with these observations, microcosm studies have indicate that bacterioplantkon groups including Rhodobacterales, Vibrio, and Alteromonadales express the C-P lyase pathway under to alleviate phosphorus limitation, in this case induced by the addition of methyl phosphonate and excess glucose (Martínez et al., 2013), producing phosphate for cell uptake and releasing methane into the water column. The microbial degradation of methyl phosphonates has gathered special interest because it has been implicated in the production of the sub-surface methane maxima observed across the ocean (Karl, 2014; Karl et al., 2008). Marine surface waters typically observe methane supersaturation with respect to the atmospheric equilibrium concentration and are considered a source of methane to the atmosphere (Fig. 4.1; Holmes, Sansone, Rust, \& Popp, 2000; Tilbrook \& Karl, 1995). Holmes et al. (2000) calculate a mean flux rate of oceanic methane to the atmosphere of $1.6 \mu \mathrm{mol} \mathrm{m}-2 \mathrm{~d}-1$ for the North Pacific which translates to $0.25 \mathrm{Tg}$ $\mathrm{y}^{-1}$ considering the area encompassed by the North Pacific subtropical gyre, or about $2.5 \%$ of the 
annual natural ocean and freshwater methane emissions (10 $\mathrm{Tg} \mathrm{y}^{-1}$; Reeburgh, 2007), although the latter represents only $2 \%$ of the global methane budget (Reeburgh, 2007). In addition, the methane flux to the atmosphere can increase with the deepening of the mixed layer (high wind speeds and storms) bringing methane up from the sub-surface maxima (Holmes et al., 2000). Neverthelss, in the past the source of this methane remained obscure.

In the North Pacific, surface ocean methane concentrations (upper 300 meters) are consistently $37-67 \%$ (up to $90 \%$ in the North Atlantic) higher than the expected atmospheric equilibrium concentrations over the course of the year (Holmes et al., 2000). In addition, methane sampled in the upper 300 meters is isotopically heavier than the atmospheric methane sampled 5 meters above the surface $(-45.6 \%$ and $-47.35 \%$, respectively). These two pieces of evidence indicate that the methane detected in the water column has an in situ biogenic origin albeit different than the well-known anaerobic methanogenesis which would result in more isotopically depleted methane. The methyl phosphonate associated with HMW DOM ( 10\% of HMW DOP; Daniel Repeta, personal communications) may be sufficient to account for the methane observed in the upper 300 meters of Station ALOHA and in the sub-surface methane maxima concetratios. Assuming a HMW DOC concentration of $24 \mu \mathrm{M}(30 \%$ of total DOC), a C:P atomic ratio of 300:1 (Benner, 2002), and that all methyl phosphonate is bio-available, HMW DOM would produce $8 \mathrm{nM}$ methane, enough to account for the sub-surface methane maxima concentrations. However, the microorganisms and biochemical pathways responsible for HMW DOM phosphonate degradation, and the environmental conditions under which HMW DOM methyl phosphonate degradation can aggravate the greenhouse effect remain to be determined. 
The bacterium Pelagibacterales sp. strain HTCC7211, a representative of the widespread and abundant SAR11 clade, has been shown to produce methane from the degradation of methyl phosphonate and is thought to be an important contributor to oceanic methane (Carini et al., 2014). However, methyl phosphonate has not been reported to exist in free form in marine waters. HMW DOM is most likely the major source of methyl phosphonates and other alkylphosphonates in the water column (Repeta et al., unpublished) though direct evidence of bacterial utilization of HMW DOM-bound phosphonates via the C-P lyase pathway is lacking.

In this work I investigate the bioavailability of HMW DOM phosphonates using batch cultures of the bacteria Pseudomonas stutzeri strain HI00D01 and Sulfitobacter strain HI0054. In addition, I explore inorganic phosphate as a possible regulator of phosphonate degradation and test the direct involvement of the C-P lyase in degradation of HMW DOM phosphonates via a genetic mutagenesis approach. Because both isolates were obtained from HMW DOM-enriched cultures and their genomes encode complete operons of the C-P lyase pathway, I hypothesized that they would be able to degrade alkylphosphonates present in HMW DOM.

\section{Materials and Methods}

\section{Collection of HMW DOM and isolation of neutral polysaccharides}

HMW DOM sampling and isolation of the HMW neutral polysaccharide fraction (F1) by chromatography was done as describes in Chapter 3 Materials and Methods (Ultrafiltration and Isolation of HMW DOM neutral polysaccharides, pp. 98-100).

\section{Culture purity of Pseudomonas and Sulfitobacter isolates}

P. stuzeri isolate HI00D01 was obtained from Hawaii Experiment I dilution-to-extinction samples treated with HMW DOM (7x DOC treatments; see Tables 3.1 and 3.2 in Chapter 3). $P$. 
stutzeri strain HI00D01 was purified by re-streaking single colonies in marine agar plates. Smooth and rough colony morphologies were observed. Sanger sequencing of the SSU rRNA gene indicated $100 \%$ identity between all morphotypes. Cryostocks of smooth and rough colonies were prepared in $20 \%$ glycerol and stored frozen at $-80^{\circ} \mathrm{C}$. A rough clone (RA1) was used for subsequent experiments. Sulfitobacter isolate HI0054 was obtained from Hawaii Experiment II dilution-to-extinction samples treated with HMW DOM (4x DOC; see Tables 3.1 and 3.2 in Chapter 3). HI0054 was also purified on marine agar plates to obtain single colonies for culture-based experiments. The SSU rRNA gene sequence obtained from draft genomes of HI00D01 and HI0054 indicated that both primary cultures consisted of a single taxon (Chapter 3 Table 3.1).

\section{Growth of $P$. stutzeri strain HI00D01 on marine HMW DOM polysaccharides}

P. stutzeri HI00D01 was tested for higher cell yields under increasing concentrations of HMW DOM neutral polysaccharides (F1). HMW DOM was collected by ultrafiltration at Station ALOHA (KM2007). HMW DOM F1 polysaccharides (sample 07182014) consisted of neutral sugars eluted in ultrapure water after anion exchange chromatography of bulk HMW DOM. HMW DOM F1 samples were filter-sterilized through a $0.22 \mu \mathrm{m}$ Supor membrane and stored frozen at $-20^{\circ} \mathrm{C}$ before amending culturing media. The culturing media consisted of MOPS minimal media (Appendix II Table A1) supplemented with $50 \mu \mathrm{M}$ phosphate $\left(\mathrm{K}_{2} \mathrm{HPO}_{4}\right)$. Five DOC treatments were prepared: 1) No DOC, the control treatment consisting of the base media with no HMW DOM added, 2) $\sim 100 \mu \mathrm{M}$ DOC (4 $\mu \mathrm{g} \mathrm{ml}^{-1}$ of HMW DOM F1), 3) $\sim 500 \mu \mathrm{M}$ DOC (20 $\mu \mathrm{g} \mathrm{ml}^{-1}$ of HMW DOM F1), 4) 1 mM DOC (40 $\mu \mathrm{g} \mathrm{ml}^{-1}$ of HMW DOM F1), 5) 2 mM DOC ( $80 \mu \mathrm{g} \mathrm{ml}^{-1}$ of HMW DOM F1). Growth was determined daily from triplicate cultures 
by enumerating DNA-stained cells (SYBR Green I) on an Attune cytometer system (Applied Biosystems, Foster City, CA, USA).

Transposon mutagenesis of $P$. stutzeri H00D01 and identification of strains unable to metabolize phosphonates

Transposon mutagenesis and library preparation

Single colonies of $P$. stutzeri strain HI00D01 clone RA1 were grown on $5 \mathrm{ml}$ of marine broth and incubated at $30^{\circ} \mathrm{C}$ and $255 \mathrm{rpm}$ overnight. Cells were harvested by centrifugation at 2000Xg for $5 \mathrm{~min}$, the supernatant was discarded, and cells were rinsed with $10 \mathrm{~mL}$ of chilled $10 \%$ glycerol solution. Centrifugation and wash steps were repeated after which cells were concentrated in $100 \mu \mathrm{l}$ of $10 \%$ glycerol. The cell suspension was transformed with $2 \mu \mathrm{L}$ of EZTn5 $<$ KAN-2> Tnp Transposome (20 ng $\mu 1^{-1}$ stock, Epicentre Biotechnologies, Madison, WI) by electroporation in a $2 \mathrm{~mm}$ cuvette. Electroporation parameters were $12.5 \mathrm{kV} \mathrm{cm}^{-1}, 200 \Omega$, and 25 $\mu \mathrm{F}$. To facilitate cell outgrowth and expression of the kanamycin antibiotic marker, immediately after electroporation $0.4 \mathrm{ml}$ of marine broth were added to the cuvette to dilute cells and incubated at $30^{\circ} \mathrm{C}$ for 30 minutes. $50 \mu \mathrm{l}$ aliquots of the dilute cell suspension were plated on large square dish plates with marine agar media containing kanamycin $\left(50 \mu \mathrm{g} \mathrm{ml}^{-1}\right)$ to select for transposon insertion mutants. Plates were incubated at $30^{\circ} \mathrm{C}$ overnight. A robot Q-pix Genetix was used to pick colonies from selective media to inoculate a total of sixteen 96 well microtiter plates containing marine broth and kanamycin. Plates were incubated at $30^{\circ} \mathrm{C}$ for 2 days and cryopreserved with $20 \%$ glycerol.

Screening mutants for strains deficient in metabolizing phosphonates

To identify strains that can no longer use phosphonates, the transposon mutant library was screened in media supplemented with 2-aminoethyl phosphonate (99\% purity; Sigma- 
Aldrich 268674) as the sole phosphorus source and $0.2 \%$ glucose. The screening media consisted of Hawaii seawater amended with $1 \mathrm{mM}$ sodium nitrate and ammonium chloride, and kanamycin $\left(50 \mu \mathrm{g} \mathrm{ml}^{-1}\right)$. To assess mutant viability, the library was screened in parallel on marine agar plates with kanamycin $\left(50 \mu \mathrm{g} \mathrm{ml}^{-1}\right)$. A total of 1344 transposon mutants were spotted onto the screening media using a Q-pix Genetix microbial colony picker (Molecular Devices, Sunnyvale, CA). Marine agar plates incubated overnight at $30^{\circ} \mathrm{C}$ while the phosphonate screening media incubated for two days to allow bacterial colonies to grow further. Samples were stored at $4^{\circ} \mathrm{C}$ to halt growth.

\section{Candidate mutants deficient in phosphonate degradation}

To ensure that mutants identified in the screen were not deficient in metabolizing glucose rather than phosphonates, growth was tested in agar media consisting of MOPS minimal media supplemented with glucose $(0.1 \%)$, inorganic phosphate $\left(1 \mathrm{mM} \mathrm{K}_{2} \mathrm{HPO}_{4}\right)$ and kanamycin $(50 \mu \mathrm{g}$

$\left.\mathrm{ml}^{-1}\right)$. To confirm which glucose-viable mutants were deficient in metabolizing phosphonates $\left(\mathrm{phn}^{-}\right)$growth was tested on MOPS agar media with $0.2 \%$ glucose as the sole carbon source and 2-aminoethyl phosphonate $(1 \mathrm{mM})$ or inorganic phosphate $(1.32 \mathrm{mM})$ as the sole phosphorus source. To identify mutation sites, genomic DNA from candidate $\mathrm{phn}^{-}$mutant strains was sequenced on a MiSeq system using a Nextera XT 96 DNA sample preparation kit (Illumina, San Diego, CA, USA) to obtain indexed paired-end libraries and a 2x250 nt paired-end MiSeq run. Paired reads were assembled into contigs using CLC Genomics Workbench (CLC bio, Aarhus, Denmark) de novo assembler with automatic word and bubble sizes, a minimum contig length of 200 , insertion and deletion costs set to 3 , mismatch cost set to 2 , length fraction set to 0.5 and the similarity fraction set to 0.8 . The transposon insertion site in each mutant was located in the assembled contigs using transposon-specific forward and reverse primer sequences as well as the 
mosaic end sequences (5'-AGATGTGTATAAGAGACAG-3') marking the end of the transposon. To identify which genes had been disrupted by the transposon, the sequences flanking the transposon (300 nucleotides upstream and downstream) were compared to PROKKA-predicted genes in the draft genome of HI00D01 using BLASTn.

Evaluation of $P$. stutzeri HI00D01 growth on alkylphosphonates as a source of phosphorus

P. stutzeri HI00D01 and mutant strain 14-E11 (transposon insertion mutant) were tested for growth on several alkylphosphonates as sole phosphorus source in agarose media containing $0.2 \%$ glucose. The media was prepared with MOPS minimal media supplied without inorganic phosphate (M2101; Teknova, Hollister, CA; see Table A1 in Appendix II) in ultrapure water and 1.7\% SeaKem LE agarose (Lonza, Rockland, ME), a high-purity agarose to minimized background growth. Methyl phosphonate (98\%; Sigma-Aldrich 289868), aminomethyl phosphonate (98\%; Sigma-Aldrich 324817), ethyl phosphonate (98\%; Sigma-Aldrich 289876), 2-aminoethyl phosphonate (99\%; Sigma-Aldrich 268674), 2-phosphonopropionate (98\%; VWR AAAL11588-04), 3-phosphonopropionate (94\%; Sigma-Aldrich 228559), 3-aminopropyl phosphonate (99\%; Sigma-Aldrich 268615), and 2-phosphonobutyric acid (97\%; VWR AAAL12036-04) were tested at a concentration of $100 \mathrm{mM}$. The test media for strain 14-E11

was supplemented with kanamycin $\left(50 \mu \mathrm{g} \mathrm{ml}^{-1}\right)$ as selection marker. Phosphonates, glucose, and antibiotic were added to the media after autoclaving. Plates incubated in darkness at $27^{\circ} \mathrm{C}$.

Detection of hydrocarbon gases in batch cultures amended with phosphonates or HMW DOM polysaccharides

Overview

Batch cultures of P. stutzeri HI00D01 and the Sulfitobacter HI0054 were prepared in sealed glass bottles to test for the accumulation of hydrocarbon gases predicted to be released as 
byproducts during phosphonate degradation. To stimulate utilization of phosphonates, the cultures were grown in a phosphorus-limited medium with excess glucose ( $P$. stutzeri HI00D01) or glycerol (Sulfitobacter HI0054). Dissolved methane, ethylene, and ethane concentrations were measured by gas chromatography using a gas stripping and cryo-trap concentration method, described in detail by Tilbrook \& Karl (1995). Dissolved gases were purged by bubbling a known volume of water with ultra high purity helium. The volume of sample purged, determined by weight, was approximately $50 \mathrm{ml}$. During the gas stripping procedure, the gas stream passed through Drierite ${ }^{\circledR}$ and Ascarite ${ }^{\circledR}$ columns to remove water vapor and carbon dioxide, and then the gases were concentrated in a 80-100 mesh Porapack $\mathrm{Q}{ }^{\circledR}$ trap cooled in liquid N2. Once the gas extraction was completed (12 minutes), the trap was heated with boiling water $\left(\sim 90^{\circ} \mathrm{C}\right)$ and the concentrated gases were released and injected into the gas chromatograph (Agilent 7980A). The gases were separated in a capillary column and analyzed with a flame ionization detector (FID). The FID was calibrated by injecting different size loops of a gas mixture standard containing $10 \mathrm{ppm}$ of methane and ethylene in pure $\mathrm{N}_{2}$ (Scott-Marrin). The loops were injected into the purging chamber and concentrated into the Porapack $Q{ }^{\circledR}$ trap following the same procedure as for the water samples. Tilbrook \& Karl (1995) reported a detection limit for methane analysis of approximately $0.05 \mathrm{nM}$ with $\pm 3 \%$ precision of repeated analyses of samples.

\section{Initial screen}

Cutlures of P. stutzeri HI00D01 grown in the presence of phosphonates and excess glucose were screened for production of hydrocarbons. Treatments consisted of MOPS minimal media containing $0.2 \%$ glucose $(11 \mathrm{mM})$ and supplemented with phosphonates [104 $\mu \mathrm{M}$ methyl

phosphonate, aminoethyl phosphonate, 2-aminoethyl phosphonate, or 3-aminopropyl phosphonate], or HMW DOM F1 polysaccharides (40 $\mu \mathrm{g} \mathrm{ml}^{-1}$ or $\sim 1 \mathrm{mM}$ carbon) as phosphorus 
source. Assuming a HMW DOM C:P ratio of 300:1 (Kolowith et al., 2001), the addition of HMW DOM F1 polysaccharides contributed approximately 4-5 $\mu \mathrm{M}$ phosphorus to the media of which $20 \%(0.8-0.9 \mu \mathrm{M})$ is estimated to consist of phosphonates. HMW DOM contains 1 mol of methyl phosphonate per 4000 mols of carbon (HMW DOC:Methyl phosphonate $=4000: 1$; Daniel Repeta, personal communication). Therefore, the addition of HMW DOM polysaccharides (1 $\mathrm{mM}$ DOC) contained $\sim 250 \mathrm{nM}$ methyl phosphonate. Treatments were prepared with an initial inoculum of 4000 cells $\mathrm{ml}^{-1}$ (pre-grown in $0.2 \%$ glucose and no additional phosphorus) in 72-ml glass bottles with no head space and sealed with Teflon-lined butyl septa to collect trace gases. Samples incubated at $26^{\circ} \mathrm{C}$ under a 12 hour diurnal cycle for 3 days. The screen included a culture of the P. stutzeri HI00D01 phn mutant clone 14-E11 as negative control. The media was supplemented with kanamycin $\left(50 \mu \mathrm{g} \mathrm{ml}^{-1}\right.$; Table 4.1$)$ to ensure selection of the transposon insertion mutant. At the end of the incubation period, culture samples were injected and sparged with helium for 12 minutes. Gases were analyzed on a gas chromatograph (Agilent 7890A) to quantify methane, ethylene, and nitrous oxide. Sub-samples from each experiment were also drawn for flow cytometry analysis to determine the final cell yields.

Inhibition of hydrocarbon production from phosphonates by inorganic phosphate additions in batch cultures of $P$. stutzeri strain HI00D01

A second batch culture experiment with P. stutzeri HI00D01 was prepared in which inorganic phosphate was added to determine if phosphonate degradation was inhibited. In addition, the growth conditions were modified to prevent anoxia and ensure phosphorus limitation. To test this hypothesis, cultures of the wildtype and phn ${ }^{-}$mutant strain were pregrown in 0.85 liters of MOPS minimal media supplemented with $100 \mu \mathrm{M}$ carbon (glucose) and 
no additional phosphorus to induce phosphorus starvation. To ensure that cultures were phosphorus-limited, sub-samples of cultures in stationary phase were stimulated with inorganic phosphate and glucose. Addition of $1 \mu \mathrm{M}, 10 \mu \mathrm{M}$ phosphate, or $100 \mu \mathrm{M}$ carbon (glucose) alone did not stimulate growth. The cultures required both phosphate and glucose in order to continue growing. Once such conditions were established, the 0.85 -liter cultures were brought up to 1 liter and were amended with an additional $\sim 100 \mu \mathrm{M}$ carbon in the form of glucose. The resulting media thus contained $100-200 \mu \mathrm{M}$ carbon. In addition, samples were bubbled with filtered air to replenish oxygen. To prepare treatments, phosphorus-limited cultures were aliquoted into $40 \mathrm{ml}$ gas-tight glass bottles sealed with Teflon-lined butyl septa and no head space. Treatments consisted of duplicate samples amended with methyl phosphonate $(1 \mu \mathrm{M}$; Sigma-Aldrich 289868), ethyl phosphonate (1 $\mu \mathrm{M}$; Sigma-Aldrich 289876), or HMW DOM polysaccharides (0.095 mg ml $\mathrm{m}^{-1}$ or $\sim 3.2 \mathrm{mM}$ carbon) with and without additional inorganic phosphate $(1 \mu \mathrm{M})$ to test for inhibition of the phosphonate utilization. Assuming a HMW DOC:Methyl phosphonate ratio of $4000: 1$, the addition of HMW DOM polysaccharides resulted in $\sim 800 \mathrm{nM}$ methyl phosphonate. The control treatment consisted of samples with no added phosphorus source. Samples of the wildtype and mutant cultures were killed with mercuric chloride at the beginning of the incubation to determine the initial concentration of hydrocarbon gases. Additionally, single replicate samples from each treatment were prepared to estimate the total oxygen consumption during batch culture growth from changes in oxygen/argon $\left(\mathrm{O}_{2} / \mathrm{Ar}\right)$ ratios measured by membrane-inlet mass spectrometry (MIMS) as described by Ferrón, Wilson, Martínez-García, Quay, \& Karl (2015) and Kana et al. (1994) using an $\mathrm{O}_{2}$ and Ar solubilities at salinity of 0 ppt and a temperature of $26^{\circ} \mathrm{C}\left(253.55 \mu \mathrm{mol} \mathrm{L} \mathrm{L}^{-1}\right.$ and $12.44 \mu \mathrm{mol} \mathrm{L} \mathrm{L}^{-1}$, respectively). The initial 
oxygen concentration was also determined by MIMS from killed cultures at the beginning of the incubation. The oxygen drawdown was obtained from equation 3.1

$$
\Delta O_{2}=\frac{\frac{O}{2}_{\text {final }}}{\frac{O_{2}}{A r_{\text {initial }}}} \times\left[O_{2}\right]_{\text {initial }}
$$

Treatment samples incubated for 1.75 days at $26^{\circ} \mathrm{C}$ under a diurnal 12 hour cycle. To determine culture growth, total cell counts were obtained by flow cytometry analysis of DNAstained cells (SYBR Green I) at the beginning and end of the incubation period.

\section{Degradation of two representative HMW DOM phosphonates (methyl phosphonate and 2- hydroxyethyl phosphonate) by $P$. stutzeri HI00D01}

Methyl phosphonate and 2-hydroxyethyl phosphonate are the major phosphonate residues indentified in HMW DOM polysaccharides (Repeta et al., unpublished; personal communication). In this experiment, three biological replicates of wildtype and $\mathrm{phn}^{-}$mutant strain 14-E11 P. stutzeri HI00D01 cultures were pre-grown (starting from a single colony) under phosphorus-limited conditions. Cultures were first grown in $200 \mathrm{ml}$ of MOPS minimal media containing $100 \mu \mathrm{M}$ carbon (glucose) with no additional phosphate. Kanamycin $\left(50 \mu \mathrm{g} \mathrm{m}^{-1}\right)$ was added to mutant cultures. The cultures incubated for 5 days at $27^{\circ} \mathrm{C}$ and $200 \mathrm{rpm}$ shaking after which samples were diluted two-fold with sterile medium and supplemented with an additional $200 \mu \mathrm{M}$ carbon (glucose). Samples were bubbled with filtered air to replenish oxygen. The phosphorus-limited cultures were then aliquoted in 72-ml glass bottles containing phosphonates or HMW DOM polysaccharide amendments. Triplicate samples of the wildtype and mutant cultures were killed with mercuric chloride at the beginning of the incubation to obtain the initial gas concentrations. Treatments consisted of triplicate samples amended with methyl phosphonate 
(1 $\mu \mathrm{M}$; Sigma-Aldrich 289868), 2-hydroxyethyl phosphonate (1 $\mu \mathrm{M}$; BOC 22987-21-9), or HMW DOM polysaccharides $\left(0.295 \mathrm{mg} \mathrm{ml}^{-1}\right.$ or $\sim 9.8 \mathrm{mM}$ carbon). Assuming a HMW DOC:Methyl phosphonate ratio of 4000:1 (Daniel Repeta, personal communication), the addition of HMW DOM resulted in $\sim 2.45 \mu \mathrm{M}$ methyl phosphonate. The control treatment consisted of samples with no additional phosphorus source. Samples incubated at $26^{\circ} \mathrm{C}$ in darkness for 3.8 days after which they were killed with mercuric chloride and stored in darkness until analysis.

\section{Test for production of hydrocarbon gases using batch cultures of Sulfitobacter strain HI0054 amended with phosphonates and HMW DOM polysaccharides}

Strain HI0054 was pre-grown under phosphorus-limited conditions. The media consisted of Hawaii seawater sterilized by tangential flow ultrafiltration and amended with $200 \mu \mathrm{M}$ carbon (glycerol), $40 \mu \mathrm{M}$ ammonium chloride, $0.5 \mu \mathrm{M}$ phosphate $\left(\mathrm{K}_{2} \mathrm{HPO}_{4}\right), 1 \mu \mathrm{M}$ ferric chloride, trace metals and vitamins (Appendix table). Upon reaching stationary phase, the culture was supplemented with an additional $20 \mu \mathrm{M}$ ammonium chloride and $100 \mu \mathrm{M}$ carbon (glycerol), and bubbled with filtered air to replenish oxygen. Treatments consisted of dulplicate samples of phosphorus-limited culture amended with inorganic phosphate $(2 \mu \mathrm{M})$, methyl phosphonate $(2$ $\mu \mathrm{M})$, 2-hydroxyethyl phosphonate $(2 \mu \mathrm{M})$, 2-phosphonopropionate $(2 \mu \mathrm{M})$, or HMW DOM polysaccharides (2.6 mM carbon). Assuming a HMW DOC:Methyl phosphonate ratio of 4000:1, the addition of HMW DOM resulted in $\sim 650 \mathrm{nM}$ methyl phosphonate. Samples incubated at $26^{\circ} \mathrm{C}$ under a diurnal 12 hour cycle for 2 days. Total cell counts were obtained at the end of the incubation period by flow cytometry analysis of DNA-stained cells (SYBR Green I).

\section{Metagenomic screening of the C-P lyase pathway genes}

The C-P lyase operon genes (Appendix I Table A8) identified in the draft-genomes of Hawaii open-ocean Rhodobacteraceae, Oceanospirillaceae, and Pseudomonas (strain HI00D01) 
isolates (Chapter 3) and in metagenomes obtained from methyl phosphonate-amended microcosms (Martínez et al., 2013; Appendix I Table A7) were searched by BLAST analysis in the Ocean Microbial Reference Gene Catalogue (OM-RGC) and associated metagenomes obtained during the Tara Oceans Expedition (Sunagawa et al., 2015). OM-RGC hits matching predicted homologs of phosphonate transporter genes $p h n C D E$, the regulatory gene $p h n F$, and the catalytic genes phnGHIJKLM required for phosphonate degradation (Metcalf \& Wanner, $1993 b$ ) were identified with a bitscore $\geq 60$ and percent identity $\geq 60$. Each of these 11 C-P lyase gene homologs was deemed present at a given Tara Ocean metagenome if the OM-RGC hits had

a combined relative coverage $\geq 10^{-6}$. Because the catalogue contains 40 million genes, this cutoff value is $40 \times$ greater than the relative coverage of an individual OM-RGC reference gene ( 1 in 40 million or $2.5 \times 10^{-8}$ ) and thus represents a strict assessment of their occurrence in the metagenome. Presence of the C-P lyase pathway was determined in a given metagenome if at least 7 of the 11 C-P lyase gene homologs surpassed this threshold. The Tara Ocean Expedition station geographic locations and C-P lyase metagenomic screen results were overlaid onto a global map indicating the statistical annual mean of inorganic phosphate concentration in surface waters $(<5$ meters) as obtained from the World Ocean Atlas 2013 available through the NOAA National Oceanographic Data Center (https://www.nodc.noaa.gov/OC5/woa13/woa13data.html). Data downloaded in comma separated values format was visualized using on ArcGIS® $\operatorname{ArcMap}{ }^{\circledR}$ version 10.2.2.

\section{Results and Discussion}

Introduction of Pseudomonas stutzeri HI00D01 and Sulfitobacter HI0054 bacteria as suitable model systems to study the degradation of HMW DOM phosphonates 
The bacterium P. stutzeri strain HI00D01 is a member of the genus Pseudomonas sensu stricto which is often found in terrestrial soils, the rhizosphere, and in groundwater, although several strains have been isolated from marine environments including P. stutzeri, P. balearica, and P. xanthomarina (Lalucat, Bennasar, Bosch, García-Valdés, \& Palleroni, 2006). In many habitats $P$. stutzeri forms part of the community of microbial decomposers and is often actively involved in the cycling of nitrogen (denitrification, nitrogen fixation), phosphorus (phosphite and hypophosphite oxidation) and sulfur (thiosulfate turnover) (Lalucat et al., 2006). P. stutzeri HI00D01 was isolated from a depth of $200 \mathrm{~m}$ in Station ALOHA waters $100 \mathrm{~km}$ north of Hawaii by dilution-to-extinction culturing method, using a seawater based media supplemented with marine HMW DOM (Chapter 3). Strain HI00D01 primarily forms rough colonies on marine agar and can be grown in natural seawater, marine broth (DIFCO 2216), LB broth, and MOPS minimal media. Most importantly, HI00D01 is able to use naturally occurring marine HMW DOM as a growth substrate, as indicated by a small but measureable increase in growth yield with increasing concentrations of HMW DOM polysaccharides (Fig. 4.2). Inspection of the genome draft of P. stutzeri HI00D01 indicated that it contains a complete operon encoding the C-P lyase pathway (Metcalf \& Wanner, 1993a, 1993b). The P. stutzeri HI00D01 operon nucleotide sequence has a $95 \%$ identity to the phnCDEFGHIJKLMNP operon of $P$. stutzeri isolate WM88 (Metcalf and Wolfe, 1998). The C-P lyase pathway has been shown to metabolize several alkylphosphonate compounds including methyl phosphonate and 2-aminoethyl phosphonate (White and Metcalf, 2004). These characteristics make P. stutzeri HI00D01 a suitable model system to study the decomposition of HMW DOM phosphonates.

In contrast to the genus Pseudomonas, the ecology of the genus Sulfitobacter remains largely unexplored. However, several representative members of the Roseobacter clade 
of which the genus Sulfitobacter is part of have been well characterized (reviewd in Buchan, González, \& Moran, 2005). Members of this lineage have developed important physiological adaptations that have enabled its success in the marine environment including the capability for aerobic anoxygenic photosynthesis, dimethyl sulfoniopropionate (DMSP) degradation, carbon monoxide oxidation, diverse photoheterotrophic strategies, as well as apparent association with diverse phytoplankton groups and the organic matter derived from them, such as carbohydrate exudates and glycolate (Luo \& Moran, 2014). Sulfitobacter strain HI0054, along with several closely related isolates ( $>96 \%$ SSU rRNA gene sequence similarity), was obtained from HMW DOM-treated dilution-to-extinction cultures prepared with seawater collected from 250 m-depth at Station ALOHA near Hawaii (Appendix I Fig. A2). Strain HI0054 shares 97.8-98.4\% SSU rRNA gene sequence similarity with Sulfitobacter delicatus strain KMM 3584 (isolated from the starfish Stellaster equestris collected at a depth of $100 \mathrm{~m}$ in the South China Sea; Ivanova et al., 2004), Sulfitobacter dubius strain KMM 3554 (isolated from the sea grass Zostera marina collected from a depth of 5-8 $\mathrm{m}$ in the Sea of Japan; Ivanova et al., 2004), Oceanibulbus indolifex strain HEL-45 (North Sea seawater isolate; Wagner-Döbler et al., 2004) and $\leq 97 \%$ similarity with other Roseobacters. Physiological tests indicate that strain HI0054 seems to preferentially utilize amino acids and organic acids like $\beta$-hydroxybutyrate (Fig. 3.9 in Chapter 3). HI0054 grows robustly on natural seawater media amended with inorganic nutrients and glycerol as the main carbon source and forms well uniformly round, smooth colonies, creamy in color, when grown in marine agar. The observed growth on $\beta$-hydroxybutyrate may be associated with the production of poly- $\beta$-hydroxybutyrate since the three aforementioned reference cultured relatives accumulate this compound intracellularly. Sulfitobacter strain HI0054 may contribute to DMSP turnover as it carries a homolog of DMSP demethylase (dmdA; 
$80.6 \%$ identity with Roseobacter denitrificans OCh 114), the enzyme initiating DMSP breakdown. Most relevant to this work, HI0054 encodes a complete C-P lyase pathway for phosphonate degradation similar in arrangement and amino acid sequence (mean \pm s.d. sequence similarity $=72.2 \pm 9.8 \%$; $\mathrm{n}=15)$ to the operon expressed by a Rhodobacterales population enriched in methylphosphonate-amended microcosms (Martínez et al., 2013; Appendix I Table A7). Using a genetically-modified E. coli strain, Martínez et al. (2013) showed that the Rhdobacterales CP-lyase operon could catalyze the degradation of several alkylphosphonates including methyl phosphonate. These observations along with the growth characteristics of strain HI0054 indicate that it may partially degrade HMW DOM constituents, including alkylphosphonates, making it an appropriate model system for DOM degradation studies.

\section{Growth of $P$. stutzeri HI00D01 on HMW DOM polysaccharides}

In seawater based media, $P$. stutzeri HI00D01 observed increased cell yields concomitantly with HMW DOM polysaccharides concentrations, although the increment was not linear (Fig. 4.2). Cultures reached maximum cell densities after 2 days of incubation. The final cell yields of cultures amended with $<1 \mathrm{mM}$ DOC were not significantly different from control treatments (Student's T-Test; $\mathrm{H}_{0}: \bar{X}_{1}=\bar{X}_{2} ; \mathrm{P}$-value $\left.<0.05\right)$. The observed cell yields $\left(1.5-2 \times 10^{5}\right.$ cells $\mathrm{ml}^{-1}$ ) were similar to yields of cultures grown in the presence of bulk HMW DOM (Fig. 3.5 in Chapter 3). The low cell yields observed compared to the total DOC available indicate that only a limited portion of the HMW DOM F1 polysaccharides is bioavailable for P. stutzeri HI00D01 growth, at least under the conditions and timescale of these experiments.

\section{Growth of $P$. stutzeri strain HI00D01 on alkylphosphonates as phosphorus source}

Strain HI00D01 tested positive for growth on methyl phosphonate, ethyl phosphonate, 2aminoethyl phosphonate, 2-phosphonopropionate, 3-phosphonopropionate, and 3-aminopropyl 
phosphonate as the only available phosphorus source in agarose media containing glucose as sole carbon source (Fig. 4.3). The compounds aminomethyl phosphonate and 2-phosphonobutyric acid did not support growth (Fig. 4.3). The lack of growth on aminomethyl phosphonate is consistent with the absence of phnO in the P. stutzeri operon, which in Escherichia coli is required for catabolism and detoxification of 1-aminoalkylphosphonic acids (Errey \& Blanchard, 2006; Hove-Jensen, McSorley, \& Zechel, 2012; Martínez et al., 2013). On the other hand, 2phsphonobutyric acid may fall outside the substrate range of the C-P lyase or phosphonate transporters and thus cannot support growth.

\section{Identification of $P$. stutzeri HI00D01 transposon mutants deficient in phosphonate utilization}

A transposon mutant library of the phosphonate-degrading P. stutzeri strain HI00D01 (clone RA1) was prepared. The vast majority of the mutants were viable. Only 3 of 1344 mutants obtained failed to grow on marine agar. A total of 28 viable mutants were identified that failed to grow or grew poorly on the phosphonate screening media. Of these 28 viable mutants, only 12 showed clear growth on the glucose medium with inorganic phosphate indicating that the rest seemed to carry mutations that rendered them auxotrophic for other nutrients. Further testing identified 3 strains (14-E11, 15-B9, and 16-A10) that could clearly grow on glucose and inorganic phosphate but failed to metabolize 2-aminoethyl phosphonate. Assembled Illumina reads and BLASTn analysis revealed that strains 14-E11 and 15-B9 had transposon insertions in phnK and strain 16-A10 had an insertion in phnM, both genes required for catalysis of the C-P cleavage reaction (Metcalf and Wanner, 1993b). Mutations in the other phosphonate genes encoding catalytic function were not identified most likely because of the relatively small size of the library screened (1344 mutants compared to the draft genome's 4676 predicted CDS; see 
Appendix I Table A4 and A5). Similarly to the wildtype, these mutants were able to form large colonies when grown in in agarose media containing inorganic phosphate and glucose. Further testing confirmed that $P$. stutzeri HI00D01 mutant strain 14-E11 failed to utilize either of the phosphonate compounds for which the wildtype strain tested positive for growth (Fig. 4.3).

\section{Screening for production of hydrocarbon gases from bacterial phosphonate degradation}

The first screening experiment revealed the ability of $P$. stutzeri HI00D01 of producing hydrocarbons when grown in the presence of several phosphonates and HMW DOM polysaccharides (Table 4.1). However, hydrocarbon gases were not measurable in batch cultures amended with HMW DOM polysaccharides unless glucose was available, most likely because the labile carbon stimulated bacterial growth until trace inorganic phosphorus became limiting (Table 4.1). As expected, methane was not detected in P. stutzeri mutant strain (phn') batch cultures amended with methyl phosphonates or HMW DOM polysaccharides. The wildtype culture's methane yields were lower than the methyl phosphonate available. The culture amended with methyl phosphonate $(104 \mu \mathrm{M})$ only evolved $94.8 \mathrm{nM}(0.09 \%)$ methane (Table 4.1). While the culture amended with HMW DOM F1 polysaccharides (1 mM DOC) and glucose only evolved $4.6 \mathrm{nM}$ (Table 4.1). HMW DOM contains 1 mol of methyl phosphonate per 4000 mols of carbon (C:Methyl phosphonate ratio $=4000: 1$; Daniel Repeta, personal communication). Therefore, the metahane yield in the HMW DOM-amended cultures was approximately $1.84 \%$ of the estimated methyl phosphonate available in HMW DOM polysaccharides $(\sim 250 \mathrm{nM})$. In addition to methane, the wildtype cultures supplemented with HMW DOM polysaccharides and glucose produced comparable amounts of ethylene (Table 4.1) above the background levels of the sterile media. Ethylene gas is most likely produced from the degradation of 2-hydroxyethyl phosphonates, estimated to have comparable abundance as methyl phosphonates in HMW DOM 
polysaccharides (Repeta et al. unpublished). As expected, methane was not produced from aminomethyl phosphonate since this phosphonate could not be used as a phosphorus source by the wildtype strain in agarose plates. Cultures did not produce methane, ethylene, or propylene from 2-aminoethyl phosphonate or 3-aminopropyl phosphonate, compounds that the wildtype strain can utilize as phosphorus source (Table 4.1). It may be necessary to use a medium without nitrogen in order to observe the release of methane and ethylene from to stimulate the utilization of these nitrogen-containing phosphonates as a nitrogen source. Alternatively, the C-P bond cleavage of these phosphonates may produce ethylamine and propylamine that were consumed as carbon and nitrogen sources. Small amounts of methane were detected in the control culture grown with glucose and no phosphorus source; although without replicates this measurement cannot be verified as significantly different from the control sterile media. The high concentration of glucose likely made cultures anoxic as suggested by the observed drawdown of nitrous oxide compared to the initial concentration in the sterile medium. Overall, this production of methane and ethylene from HMW DOM polysaccharides by $P$. stutzeri HI00D01 is consistent with previous observations from microcosm experiments prepared with Hawaii oligotrophic seawater (Repeta et al., unpublished).

\section{Inhibition of phosphonate degradation in $P$. stutzeri HI00D01 with inorganic phosphate}

In Escherichia coli, the C-P lyase pathway is under the control of the phosphorus starvation Pho regulon (Metcalf \& Wanner, 1991, 1993b; Wanner \& Metcalf, 1992). On the other hand, the Pseudomonas sp. 4ASW was observed to utilize a combination of orthophosphate and phenylphosphonate when both phosphorus sources were present in the medium (Kononova \& Nesmeyanova, 2002). In this experiment, inorganic phosphate was added to phosphonate-amended $P$. stutzeri HI00D01 cultures to determine if gas production from 
phosphonate degradation was inhibited. Under phosphate-deficient conditions, approximately $50 \%$ of the methyl phosphonate supplied to cultures $(1 \mu \mathrm{M})$ was accumulated as methane gas over the course of 1.75 days (Table 4.2). Addition of inorganic phosphate $(1 \mu \mathrm{M})$ suppressed methyl phosphonate utilization and methane production to about $5 \%$ of the total methyl phosphonate available most likely because it is a more labile than phosphonates. Similarly, ethane yields were suppressed by an order of magnitude in cultures amended with ethyl phosphonate in the presence of inorganic phosphate $(1 \mu \mathrm{M})$, though ethane gas concentrations could not be quantified in this experiment for lack of an appropriate standard (Table 4.2).

Consistent with the first screening experiment, cultures amended with HMW DOM polysaccharides produced methane and ethylene gas. Methane concentrations [10.3 nM without inorganic phosphate and $6 \mathrm{nM}$ with the addition of inorganic phosphate (Table 4.2)] were similar to the concentrations observed in the first experiment ( $4 \mathrm{nM}$ methane in cultures supplemented with glucose and HMW DOM polysaccharides). These concentrations represent only a small fraction $(1.3 \%$ and $0.75 \%$, respectively) of the methyl phosphonate added as HMW DOM polysaccharides $(800 \mathrm{nM})$. Ethylene concentrations $(17.3 \mathrm{nM})$ in cultures amended with HMW DOM polysaccharides and glucose were slightly higher than methane concentrations $(10.3 \mathrm{nM})$ but again represented a small fraction of the 2-hydroxyethyl phosphonate present in HMW DOM (a similar amount to the methyl phosphonate in HMW DOM). Even though only a small fraction of the HMW DOM phosphonates available were converted to hydrocarbons, the phosphate obtained from these phosphonates may have been sufficient to meet the phosphorus demand of bacteria. The final cell density reached in batch cultures amended with HMW DOM polysaccharides (and glucose) was $\sim 1 \times 10^{6}$ cells $\mathrm{ml}^{-1}$ higher than the cell density in unamended control batch cultures $\left(4.61 \times 10^{6}-3.67 \times 10^{6} \mathrm{cells} \mathrm{m}^{-1}\right.$; Table 4.4). Assuming a cellular carbon 
content of $20 \mathrm{fg}$ cell $^{-1}$ (Lee and Fuhrman, 1987) and a C:P cellular ratio for marine heterotrophic bacteria of $\sim 50$ (Goldman, Caron, \& Dennett, 1987), the phosphorus required to account for this growth is approximately $33.4 \mathrm{nM}$. The evolution of methane $(10.3 \mathrm{nM})$ and ethylene $(17.3 \mathrm{nM})$ totaled $27.6 \mathrm{nM}$ which is equivalent to the concentration of phosphorus released during phosphonate degradation and represents $\sim 82.6 \%$ of the bacterial phosphorus demand. It is possible that once cells meet their phosphorus demand HMW DOM phosphonate degradation stops. This may explain the low methane and ethylene concentrations evolved in the presence of HMW DOM polysaccharides. The higher concentrations of methane ( $448 \mathrm{nM})$ evolved in cultures amended with free methyl phosphonate $(1 \mu \mathrm{M})$ respectively, may be a surplus produced to the continued activity of the C-P lyase. Measurements of inorganic phosphate in the spent media should be included in future experiments to determine if it accumulates once cultures meet their phosphorus quota.

The estimates of bacterial phosphorus demand based on the cellular carbon content of 20


high concentrations of glucose (100-200 $\mu \mathrm{M}$ carbon). Using oxygen consumption measurements (Table 4.3) the carbon consumed by bacteria can be calculated from a theoretical respiratory quotient $\left(\mathrm{CO}_{2}\right.$ evolved per mol of $\mathrm{O}_{2}$ consumed) for carbohydrates consumption of $\sim 1$ and a growth yield constant, (biomass produced per mol of substrate consumed) for glucose, $Y_{\text {glucose }}$ of 0.5 (White, 2007). During the incubation period, $67.7 \mu \mathrm{M} \mathrm{O} \mathrm{O}_{2}$ was consumed in cultures amended with HMW DOM polysaccharides $(237.2 \mu \mathrm{M} \mathrm{O}$ at the beginning of the experiment and $169.5 \mu \mathrm{M} \mathrm{O}_{2}$ when cultures were killed; Table 4.3). Assuming $1 \mathrm{~mol} \mathrm{of} \mathrm{CO}_{2}$ is produced per mol of $\mathrm{O}_{2}$ consumed, $67.7 \mu \mathrm{M} \mathrm{CO}_{2}$ were produced. Given a $Y_{\text {glucose }}$ of 0.5 , the total glucose carbon incorporated into bacterial biomass was also $67.7 \mu \mathrm{M}$. Dividing $67.7 \mu \mathrm{M}$ by the bacterial 
growth in these batch cultures $\left(\sim 3 \times 10^{6}\right.$ cells $\mathrm{ml}^{-1}$ or the difference between the intital and final cell concentrations; Table 4.4) results in a bacterial carbon content of $272 \mathrm{fg} \mathrm{C}$ cell $^{-1}$ (22.6 fmols $\left.\mathrm{C} \mathrm{cell}^{-1}\right)$. This value is 13.6 times greater than the $20 \mathrm{fg} \mathrm{C}^{-1} \mathrm{Cell}^{-1}\left(1.67 \mathrm{fmols}_{\mathrm{C}}\right.$ cell $\left.^{-1}\right)$. Based on this result, and assuming a $\mathrm{C}: \mathrm{P}$ ratio of heterotrophic bacteria of 50 , the bacterial phosphorus demand is of 0.452 fmols $\mathrm{P}$ cell ${ }^{-1}$. Using this phosphorus quota, a culture with $1 \times 10^{6}$ cells ml $^{-1}$ requires $452 \mathrm{nM}$ phosphorus. This value is in closer agreement with the methane concentrations evolved in batch cultures amended with free methyl phosphonate ( 448 nM). If these assumptions are correct, the data indicates that only a small fraction of HMW DOM phosphonates were utilized, most likely because bacteria met their phosphorus demand with additional sources of phosphorus in HMW DOM. It may also be that the majority of HMWDOM phosphonates are simply unaccessible to P. stutzeri.

Inorganic phosphate additions suppressed methane and ethane production ten-fold (relative to cultures with no phosphate added) in cultures amended with methyl phosphonate and ethyl phosphonate (Table 4.2). In contrast, methane and ethylene concentrations were similar in HMW DOM polysaccharide-amended cultures with and without inorganic phosphate additions (Table 4.2). These results indicate that inorganic phosphate does not suppress HMW DOM phosphonate degradation suggesting perhaps a regulation mechanism based on substrate concentration. It is possible though that degradation of HMW DOM phosphonates was suppressed because other forms of organic phosphorus were more readily available in HMW DOM. Phosphate esters and pyrophosphate comprise approximately $80 \%$ of the organic phosphorus in HMW DOM F1 polysaccharides while phosphonates are only 20\% (Daniel Repeta, personal communication). If only a small fraction of these compounds are more readily available than the phosphonates the bacteria may have met their phosphorus quota. Alternatively, 
longer incubation periods may be required to degrade all the available phosphonates in HMW DOM. In the other words, the hydrolysis of phosphonate moieties from HMW DOM polysaccharides is the limiting step in the degradation of phosphonates by the C-P lyase. The incubation period in this experiment was limited to 1.75 days in order to prevent cultures from becoming anoxic. In addition, a large fraction of the HMW DOM phosphonates may be inaccessible to $P$. stutzeri HI00D01 due to molecular size constraints of HMW polysaccharides or the specific linkage of phosphonates and polysaccharides. Another explanation to the low hydrocarbon concentrations observed is that P. stutzeri HI00D01 utilized these as a carbon source. Incubations with ${ }^{14} \mathrm{C}$ radio-labeled phosphonates can be performed to determine if phosphonate carbon is incorporated into bacterial biomass.

Batch cultures of P. stutzeri phn ${ }^{-}$strain 14-E11 amended with phosphonates and HMW DOM polysaccharides did not accumulate hydrocarbon gases as predicted (Table 4.2). Oxygen drawdown measurements (Table 4.3) and total cell counts (Table 4.4) indicated that mutant cultures were as active as the wildtype strain during the incubation period. The mutant strain growth yields were lower than the wildtype strain when phosphonates were the sole source of phosphorus available. This was expected as the mutant strain could not metabolize phosphonates. In addition, the mutant strain seemed to have higher respiration rates than the wild type strain when no phosphorus was available (Table 4.3). Both of these observations suggest that the mutant strain had overall lower growth efficiencies than the wildtype strain most likely due the presence of antiobiotic in the media. Growth yields were similar in both strains when inorganic phosphate was available in the media. These results suggest that the pre-culture conditions were suitable to test utilization of phosphonates and HMW DOM polysaccharides as the source of phosphorus. 
The modifications to the previous experiment, namely adding a lower concentration of glucose (100 $\mu \mathrm{M}$ carbon) and replenishing oxygen in the media at the beginning of the incubation, demonstrated that isolate $P$. stutzeri HI00D01, a phosphonate degrader, is capable of producing methane and ethylene from HMW DOM polysaccharides under aerobic conditions. As expected, methane was produced under aerobic conditions as indicated by the oxygen concentrations present a the end of the incubation (Table 4.3). The disruption of the phosphonate degradation gene phnK in mutant strain 14-E11 clearly disabled the production of trace gases from HMW DOM and model phosphonate compounds.

Methane and ethylene accumulation if $P$. stutzeri HI00D01 cultures amended with methyl phosphonate, 2-hydroxyethyl phosphonate, and HMW DOM polysaccharides

A third experiment was prepared with triplicate batch cultures of P. stutzeri HI00D01 to further verify the production of hydrocarbon gases from HMW DOM phosphonate degradation. Control treatments consisting of phosphorus-deficient cultures of the wildtype strain accumulated a minimal, though significant, amount of methane $(0.5 \mathrm{nM})$ over the initial gas concentration (Table 4.5; T-Test, P-value $<0.001$ ). Consistent with previous observations, gases were not detected in phosphonate-amended cultures of the phn- strain 14-E11 (Table 4.5). The methane concentrations detected in mutant cultures were not significantly different from the gas concentrations at the beginning of the incubation (T-Test, P-value $>0.32$ ). Ethylene was only detected in wildtype cultures supplemented with HMW DOM polysaccharides or 2-hydroxyethyl phosphonate. Approximately $76 \%$ of the methyl phosphonate $(1 \mu \mathrm{M})$ available to cultures accumulated as methane gas over the course of the 3.8 day incubation period. In the previous experiment, the incubation time was limited to 1.75 days to prevent anoxia and the fraction of methyl phosphonate added that was converted to methane was $50 \%$. It is possible that the 
extended incubation period in this experiment allowed further degradation of methyl phosphonate. In contrast, the fraction of 2-hydroxyethylene converted to ethylene was only $6.8 \%$ of the total in wildtype cultures amended with 2-hydroxyethyl phosphonate (Table 4.5). The lower yields of ethylene relative to methane suggest that a fraction of the ethylene was consumed, assuming both phosphonates are used at equal rates. Consistent with this observation, the yields of ethylene from HMW DOM $(2.2 \mathrm{nM})$ were slightly lower than for methane $(7.3 \mathrm{nM})$ (Table 4.5) even though both phosphonates are found at similar concentrations in HMW DOM (Daniel Repeta, personal communication). Alternatively, ethylene can be detrimental to cells or inhibit growth. No ethane or other hydrocarbons were detected in phosphonate-amended cultures. The overall poor yields of methane and ethylene evolved from HWM DOM polysaccharides are consistent with the low yields observed in previous experiments (Table 4.1 and 4.2) and may be an indication of the diagenetic state of HMW DOM. These results confirm the observation that only a small fraction of phosphonates associated with HMW DOM are available to the phosphonate-degrading P. stutzeri isolate HI00D01.

\section{Degradation of HMW DOM phosphonates by Sulfitobacter strain HI0054}

Batch cultures experiments of Sulfitobacter strain HI0054 confirmed that this bacterium is also able to degrade phosphonates associated with HMW DOM. Both methane and ethylene accumulated in the medium amended with HMW DOM polysaccharides (Table 4.6) and yields were similar to those observed in P. stutzeri HI00D01 batch cultures (Table 4.2 and 4.5), albeit ethylene yields were ten times higher. In addition, a small amount of propylene was detected in batch cultures above the background concentration at the beginning of the incubation period. Sulfitobacter HI0054 cultures converted approximately $10 \%$ of methyl phosphonate to methane and $8-35 \%$ of 2 -hydroxyethyl phosphonate to ethylene (Table 4.6). Additionally, ethane was 
released from cultures amended with 2-phosphonopropionate though yields were only $1.1 \%$ of the total. The higher yield of ethylene $(20.6 \mathrm{nM})$ from HMW DOM relative to methane $(7.2 \mathrm{nM})$ may indicate that this isolate cannot consume ethylene. The higher yields of ethylene relative to methane may be due to the use of a different sample of HMW DOM F1 polysaccharides for this experiment which were collected from Station ALOHA rather than in the National Energy Laboratory Hawaii Authority, Kona, Hawaii.

\section{Distribution of the C-P lyase pathway in the global ocean}

The C-P lyase genes identified in the draft genomes of Hawaii open-ocean isolates (Appendix I Table A8) and in phosphonate-amended microcosms experiments (Martinez et al., 2013; Appendix I Table A7) were used to interrogate the OM-RGC, a reference gene database constructed with the metagenomic information of the Tara Oceans Expedition as well as the GOS database and publicly available marine genomes (Sunagawa et al., 2015). The analysis identified Tara Oceans metagenome sampling stations with OM-RGC hits to at least 7 out of 11 C-P lyase genes (phnCDEFGHIJKLM) predicted in the genomes of Hawaii bacterial isolates or in the microcosm metagenomes (Fig. 4.4). OM-RGC hits with a normalized coverage $\geq 10^{-6}$ (that is, with respect to the total coverage of the reference genes from each metagenomic sample) were used to determine presence or absence and thus represents a conservative view of the occurrence of the C-P lyase pathway throughout the ocean. By this metric, the C-P lyase genes were present in 69 out of 243 metagenomes of the Tara Oceans Expedition. Of these 69 metagenomes, 15 occurred in the Mediterranean Sea (or 79\% of Mediterranean Sea metagenomes), 16 in the South Atlantic Ocean (or 30\% of South Atlantic Ocean metagenomes), and 11 in the North Atlantic Ocean (or 52\% North Atlantic Ocean metagenomes) (Fig. 4.4). Of the 243 metagenomes interrogated, a quarter of them (60 total) were obtained from coastal environments, as defined by 
Longhurst (2007). These coastal stations spanned the borders of the Indian Ocean, the North and South Atlantic Ocean, the North and South Pacific Ocean, and the Red Sea. Of these 60 coastal metagenomes, the C-P lyase genes were present in $13(22 \%)$, five of which were located in the Red Sea, three in the Caribbean, two off the Eastern Arica coast, one off the coast of Chile and Peru, and one off the Guianas coast.

The remaining 56 metagenomes where the C-P lyase genes were present were obtained from open sea regions in the Mediterranean Sea (15 metagenomes), the South and North Atlantic Ocean Gyres (11 and 7 metagenomes, respectively), the South Pacific Ocean Gyre (15 metagenomes), and the Indian Ocean (7 metagenomes). In some of these regions planktonic communities are known to be co-limited by phosphorus and another macronutrient, typically nitrogen (Moore et al., 2013). In the Mediterranean Sea for example, bacterioplankton communities are limited by phosphorus especially in the spring and summer months when the water column is more stratified (Pinhassi et al., 2006). Among the bacterioplankton, Pinhassi et al. (2006) found that the Roseobacter and Flavobacteria phylotypes were particularly sensitive to inorganic nitrogen and phosphorus additions. Similarly, in Mediterranean Sea waters Sebastián \& Gasol, (2013) found that the Roseobacter clade was co-limited by nitrogen and phosphorus and the Gammaproteobacteria were the most phosphorus limited, whereas SAR11 bacteria were not sensitive to nutrient levels. In the North Atlantic Ocean, studies in the region of the Bermuda Atlantic Time Series have found that plankton can have a strong deficiency in phosphorus as revealed by measurements of phosphorus availability, phosphorus assimilation rates, and the high N:P ratio of both inorganic and organic nutrient pools (Ammerman, Hood, Case, \& Cotner, 2003 and references therein). There is less information regarding the mechanism of nutrient limitation in the South Atlantic Ocean and Indian Ocean (Moore et al., 2013). 
Additionally, the analysis did not detect the C-P lyase genes in North Pacific Ocean stations representative of the subtropical gyre, a region in which plankton may be under phosphorus control, especially in times of net nitrogen-fixation (Karl et al., 2001).

Based on the depth of the metagenomic samples, the presence of the C-P lyase genes was relatively similar (25-27\% of samples of the same depth category) across surface waters $(5 \mathrm{~m})$, deep chlorophyll maximum waters $(71 \mathrm{~m}$; s.d. $41 \mathrm{~m})$, and mixed layer waters $(120-150 \mathrm{~m})$. Interestingly, half of surface water metagenomes with C-P lyase genes were located in the Mediterranean Sea and North Atlantic Ocean. However, the C-P lyase genes were also present in $42 \%$ of mesopelagic samples $(660 \mathrm{~m}$; s.d. $220 \mathrm{~m})$ suggesting that phosphonate cycling may have special importance even in areas where inorganic phosphorus is not a limiting nutrient.

The analysis presented here is by no means a complete assessment of the distribution of C-P lyase genes across marine regions. It simply corroborates that C-P lyase genes are widespread and begins to explore the hypothesis that phosphonates may be an important source of phosphorus to bacterioplankton especially when inorganic phosphate levels are low such as in oligotrophic stratified systems. The higher percentage of metagenomes with C-P lyase genes presence in open sea regions compared to coastal regions may be an indication of the importance of DOP cycling for the microbial community in waters with low phosphate concentrations. Phosphorus enters the ocean primarily through the riverine flux carrying dissolved and particulate phosphorus derived originally from continental weathering. Most of this phosphorus cycles within the continental shelves and thus other phosphorus inputs like atmospheric deposition (aerosols, volcanic ash, and mineral dust) are more important for open sea regions (Paytan \& Mclaughlin, 2007). As shown in Figure 4.3, the mean annual phosphate concentration in coastal regions $\left(>2 \mu \mathrm{g} \mathrm{L}^{-1}\right)$ is often an order of magnitude higher than in the oligotrophic open 
sea regions $\left(<0.2 \mu \mathrm{g} \mathrm{L}^{-1}\right)$, though not all of the riverine phosphorus is bio-available (Paytan \& Mclaughlin, 2007). Differences in phosphonate gene representation are also evident between two distinct oligotrophic regions. Martinez et al. (2010) explored the prevalence of phosphonate degradation genes, including representative genes of the C-P lyase pathway, in metagenomes from the Sargasso Sea and from Station ALOHA. Based on the abundance metrics used in their bioinformatics analysis, the C-P lyase gene homologues (phnI and $p h n J)$ were present in $1 \%$ or less of the Station ALOHA microbial community in surface waters (upper 100 meters), while in the Sargasso Sea, 5-20\% of the community contained C-P lyase genes. The C-P lyase genes in the Sargasso Sea samples are dominated by the Alphaprotoebacteria SAR11 clade and Rhodobacterales. The prevalence of C-P lyase genes in the Sargasso Sea may be associated with phosphorus availability. In the Sargasso Sea, phosphonates may be more important as an alternative source of phosphorus since the Western North Atlantic is considered phosphoruslimited whereas Station ALOHA waters have higher dissolved inorganic phosphate (DIP) concentrations. However, C-P lyase genes abundance seems to increase at depths below 500 meters where DIP is not limiting (Martinez et al., 2010). As Martinez et al. (2010) discuss, this observation may be related to the use of phosphonates not only as a phosphorus source but as a carbon and nitrogen substrate. In fact, phosphonate utilization is not always controlled by levels of inorganic phosphorus; it can be regulated by substrate concentrations. This seems to be consistent with the observation that phosphate additions did not suppress HMW DOM phosphonate degradation in batch cultures. The C-P lyase genes at depth may thus enable microorganisms to utilize phosphonates produced at those depths or phosphonates exported via sinking particles. Further investigation is needed to determine the sources and sinks driving phosphonate cycling in the ocean. 


\section{Conclusion}

Batch cultures of P. stutzeri HI00D01, P. stutzeri mutant strain 14-E11, and Sulfitobacter HI0054 were prepared to test for production of hydrocarbon gases from the degradation of free phosphonates and HMW DOM-bound phosphonates. The HI00D01 and HI0054 wildtype strains were predicted to release methane and other hydrocarbons as a result of degrading HMW DOM alkylphosphonates while the $P$. stutzeri $\mathrm{phn}^{-}$mutant would have this function inhibited. This potential was also suggested by the presence of C-P lyase genes in the genome of these two wildtype strains. As expected, methane was detectable only in cultures of P. stutzeri HI00D01 and Sulfitaobacter HI0054 wildtype strains when grown with a labile source of organic carbon and methyl phosphonate and HMW DOM polysaccharides as s source of phosphorus (Table 4.1, 4.2, 4.5, and 4.6). Similar tests with a genetic mutant strain of $P$. stutzeri with a disabled phosphonate degradation pathway demonstrated the participation of the C-P lyase pathway in the production of hydrocarbons from HMW DOM phosphonates.

The exact molecular details of the linkage of HMW DOM phosphonates are not clear. NMR spectra of HMW DOM indicates that methyl phosphonate and 2-hydroxyethyl phosphonate account for $>85 \%$ of the phosphonates on HMW DOM polysaccharides (Daniel Repeta, personal communication). The enzymes necessary to cleave HMW DOM-bound phosphonates, however, have not been identified. P. stutzeri strain HI00D01 and other HMW DOM phosphonate-degrading microorganisms may secrete cell-surface enzymes similar to alkaline phosphatase or diphosphoesterases that can cleave phosphonate moieties from polysaccharides to make them available to the C-P lyase pathway. These experiments however, did not aim to identify such enzymes. They solely served to test the potential of HMW DOM phosphonates to serve as a source of phosphorus and to produce environmentally-relevant 
hydrocarbons such as methane. Future work must focus on studying the activity of this pathway under normal environmental conditions (perhaps in situ) rather than under carbon and nutrientreplete conditions (nitrogen and trace elements were supplemented in defined media). Elucidating the genes and enzymes required to cleave HMW DOM-bound phosphonates to make them available for cell uptake will be key in understanding phosphonate and HMW DOM cycling.

One strategy that may prove useful may be to induce the expression of phosphorusacquiring genes of $P$. stutzeri HI00D01 and Sulfitobacter HI0054 cultures grown under phosphorus-limited conditions and in the presence of HMW DOM. However, it may be that HMW DOM phosphonate degradation occurs independently of phosphate starvation as suggested by the relatively low inhibition effect of hydrocarbon production with the addition of inorganic phosphate (Table 4.2) and the alternative regulators (blue-light activated proteins and TetR) clustered with the C-P lyase genes in the isolates studied (Chapter 3). An alternative approach is to target genes in the C-P lyase clusters that are not required for phosphonate catabolism but encode auxiliary functions such as $p h n N$, $p h n O$, and $p h n P$ (Metcalf \& Wanner, 1993b). For example, phnP encodes a phosphodiesterase with high cyclic nucleotide activity (Podzelinska et al., 2009). It is possible that $\mathrm{PhnP}$ also exhibits phosphodiesterase activity towards HMW DOM phosphonates since these are linked to sugar residues by ester bonds (Repeta et al., unpublished).

Event though methyl phosphonate and 2-hydroxyethyl phosphonate account for $>85 \%$ of the phosphonates present in HMW DOM from open ocean surface waters (Daniel Repeta, personal communication), the data gathered in this work suggests that only a small fraction of these HMW DOM-bound phosphonates $(<1 \%$ to $3 \%)$ are bio-available to heterotrophic bacteria. 
It is possible though that the results of batch culture experiments can be interpreted differently assuming that the phosphorus demand of these bacteria is lower than estimated. Representative members of two abundant and widespread lineages of heterotrophic bacteria, the Roseobacter clade and Pseudomonas, were shown to utilize these phosphonates. What limits the degradation of HMW DOM phosphonates, and how prevalent this metabolic property is among heterotrophic microorganisms, remain open questions. The widespread occurrence of the C-P lyase genes in marine bacterial genomes (Fig. 4.4; see also Martinez, Tyson, \& Delong, 2010; Martinez et al., 2013; Villarreal-Chiu, 2012) suggests that many bacterial lineages, at least within the Protoebacteria, may participate in phosphonate cycling. These observations and the accumulation of HMW DOM in the water column support the hypothesis that methyl phosphonate degradation is an important contributor of the observed sub-surface methane maxima across the global ocean and of natural methane emissions (Karl et al., 2008). The methyl phosphonate associated with HMW DOM ( $10 \%$ of HMW DOP; Daniel Repeta, personal communications) is sufficient to account for the methane observed in the upper 300 meters of Station ALOHA and in the sub-surface methane maxima (Fig. 4.1). The sub-surface methane maxima concentrations at Station ALOHA ranged from 2.9-3.5 nM between 100-300 meters (Fig. 4.1; Holmes et al., 2000). Given a HMW DOC concentration of $24 \mu \mathrm{M}(30 \%$ of total DOC) in open ocean surface waters, and assuming a HMW DOC:Methyl phosphonate ratio of 4000:1 and that all methyl phosphonate is bio-available, HMW DOM would produce $6 \mathrm{nM}$ methane, which is enough to account for the sub-surface methane maxima concentrations. Methane evolution in HMW DOM-amended batch cultures was approximately $<1 \%$ to $3 \%$ of the methyl phosphonate available. Thus, not all phosphonates may be bio-available. Based on the methane gas measurements obtained from $P$. stutzeri HI00D01 batch culture experiments, the HMW DOC 
to methane molar yield ratio is ca. $3.1 \times 10^{5}$ to 1 , that is for every $\sim 300,00$ mols of HMW DOC one mol of methane is produced (Table 4.7). Assuming this represents the bio-available fraction of methyl phosphonate, the $24 \mu \mathrm{M}$ HMW DOC normally present in seawater would only produce $0.08 \mathrm{nM}$ methane (Table 4.7), two orders of magnitude lower than the concentrations measured in surface waters (Fig. 4.1). In turn, if the ethylene yields in batch cultures of Sulfitobacter HI0054 (1 mol of ethylene per $\sim 1.26 \times 10^{5}$ mol HMW DOC) are representative of the 2-hydroxyethyl phosphonate fraction available, HMW DOM would account for $0.19 \mathrm{nM}$ concentrations of ethylene, an order of magnitude higher than the 0.01-0.07 nM concentrations detected in open ocean regions (Fig. 4.1). Under these assumptions, HMW DOM (ca. $24 \mu \mathrm{M}$ DOC) can only account for the ethylene levels in the upper water column but not of the methane levels, suggesting that additional methane sources exist. It remains to be tested if methane and ethylene yields are higher when HMW DOM is incubated in the presence of several groups of bacteria. It may be that each bacterial group has the ability to access different phosphonates. Furthermore, the step-wise degradation of HMW DOM by multiple bacterial groups may expose and make bio-available additional phosphonates. Additional information regarding the biological source and bio-availability of of HMW DOM phosphonates may further our understanding of their implication in the marine DOP cycle and the greenhouse climate effect.

Despite the progress made in understanding the role of bacteria in DOP turnover it remains unclear why phosphonates are most prevalent in HMW DOM compared to POM and plankton (Kolowith et al., 2001; Paytan et al., 2003). Diverse organisms have been shown to synthesize or contain phosphonates including Nitrosopumilus maritimus, a representative of Marine Group I Archaea (Metcalf et al., 2012) the cyanobacteria Trichodesmium (Dyhrman, Benitez-Nelson, Orchard, Haley, \& Pellechia, 2009) and various dinoflagellates and 
coccolithophorids (Kittredge, Horiguchi, \& Williams, 1969). In addition, phosphonate biosynthesis genes identified by Metcalf and colleagues have been detected in genomic and metagenomic sequences belonging to two of the most abundant bacteria in marine surface waters, the Alphaproteobacteria SAR11 clade (Metcalf et al., 2012) and the photosynthetic cyanobacteria Prochlorococcus (Yu et al., 2013). In open-ocean waters below depths of $100 \mathrm{~m}$, the Marine Group I Archaea (aka, Thaumarchaeota) rival bacteria in abundance (DeLong, 2003) and may also contribute significantly to the phosphonate content of HMW DOM. Interestingly, the chemical nature of the phosphonates detected in N. maritimus biomass - methyl phosphonate likely associated to exopolysaccharides through an ester bond (Metcalf et al., 2012) - is similar to the phosphonates detected in HMW DOM polysaccharides (Repeta et al., unpublished, personal communication). Perhaps the production of methyl phosphonates by marine Archaea like $N$. maritimus and their high abundance in mesopelagic waters may partly explain the presence of the C-P lyase genes in many of the mesopelagic metagenomes of the Tara Oceans Expedition (Fig. 4.4). However, a mechanistic explanation of why phosphonates accumulate in HMW DOM is needed. It may be that in the environment, secreted exopolysaccharides decorated with phosphonates [as suggested by Metcalf et al. (2012)] dissociate from prokaryotic cells as they are grazed or lysed by viruses thus becoming part of the DOM pool. It may also be that some microorganisms secrete these phosphonated polysaccharides directly into the water column as a way to store phosphorus in a semi-degradable molecule that can be accessed under phosphorus stress, though this strategy seems detrimental to cells as it involves the loss of cellular phosphorus that can be otherwise used for growth. These hypotheses and considering the abundance of these bacterial and archaeal populations in the ocean may explain in part why phosphonates preferentially accumulate in the DOM pool relative to POM. Shedding light on the 
cellular localization and function of phosphonates as well as on the environmental parameters that regulate phosphonate degradation may further our understanding of the implication of these molecules in the carbon and phosphorus cycles of the ocean.

\section{Acknowledgements}

The work accomplished in this chapter would not have been possible without the assistance of the Karl Lab at C-MORE. A big mahalo to Sara Ferron and Abby Bate for their relentless help with gas chromatography and mass spectrometry analysis, and Samuel Wilson and David Karl for providing access to their laboratory equipment. Thanks again to Daniel Repeta for providing samples of dissolved organic matter for batch culture experiments and to Daniel Mende and Frank Aylward for their assistance sampling at the National Energy Laboratory Hawaii Authority facilities. Special thanks to Maia Kapur for assistance with GIS software. Financial support for this work was provided by the National Science Foundation Center for Microbial Oceanography: Research and Education (award \#EF0424599) and the Gordon and Betty Moore Foundation (grant \#492.01, \#3777, and \#3298). 


\section{Tables}

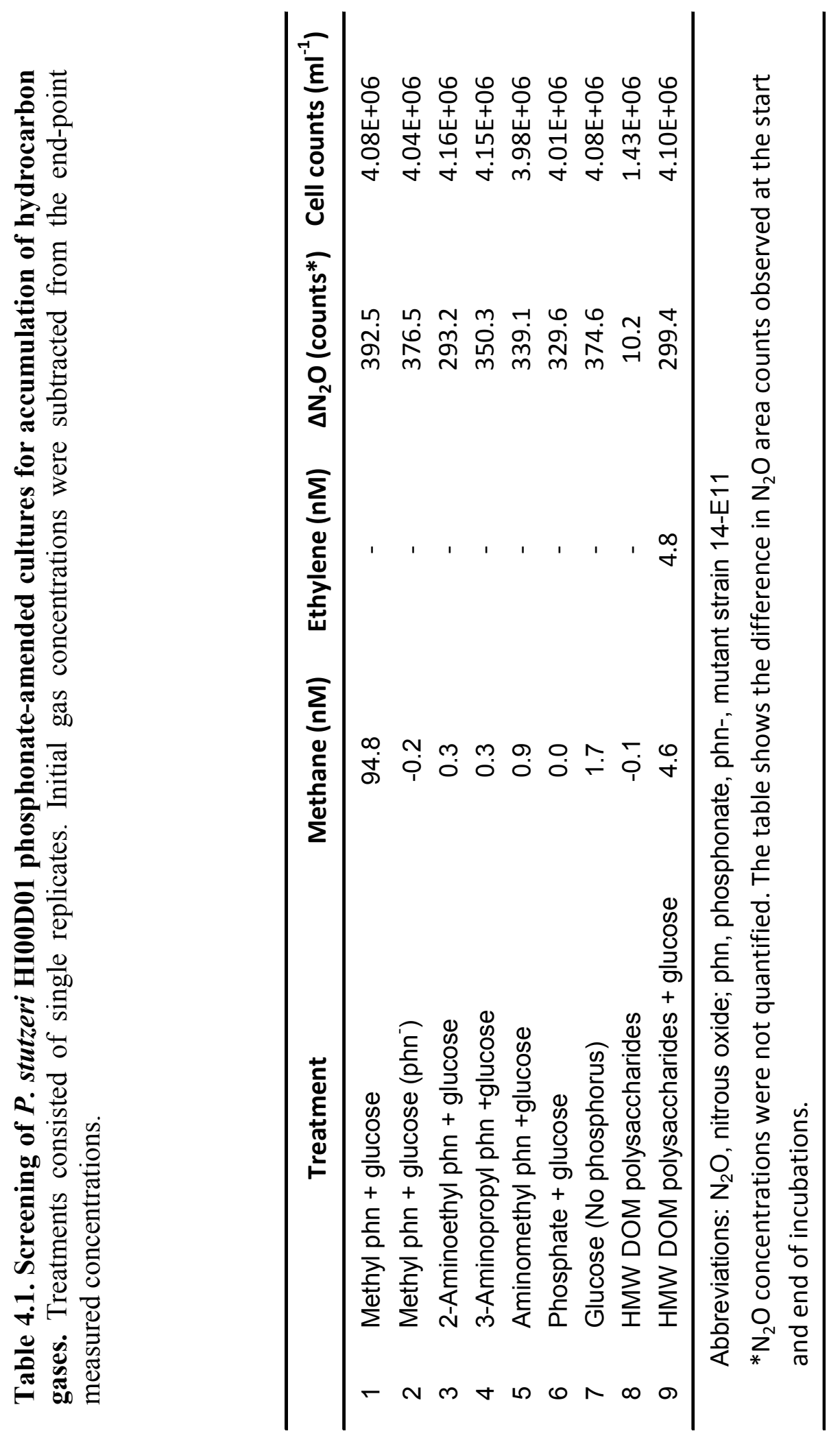




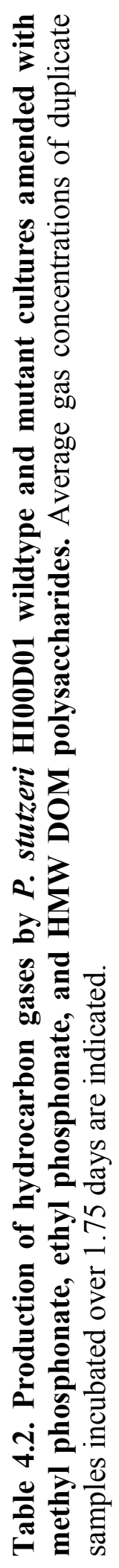






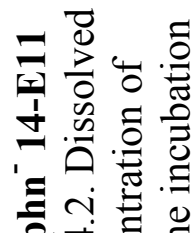

둥 䒕

를 융

능

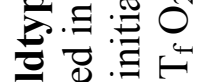

苟

\%

을 웁

을 荌志



:

s

๑ ֻ

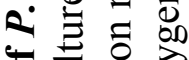

항

률 중

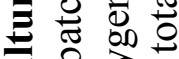

हॉ당

巳

응

유워

i d ฮ

胥

옹 웡

흉 웡

ํํ유

$\Xi$ ठ

용

을 䒕苟

¿ 0

है ठैं

है 氜

ฮ $\sum^{\infty} \cdot \stackrel{0}{0}$

边



ช。

ஸ்

๑

픙 0000

它

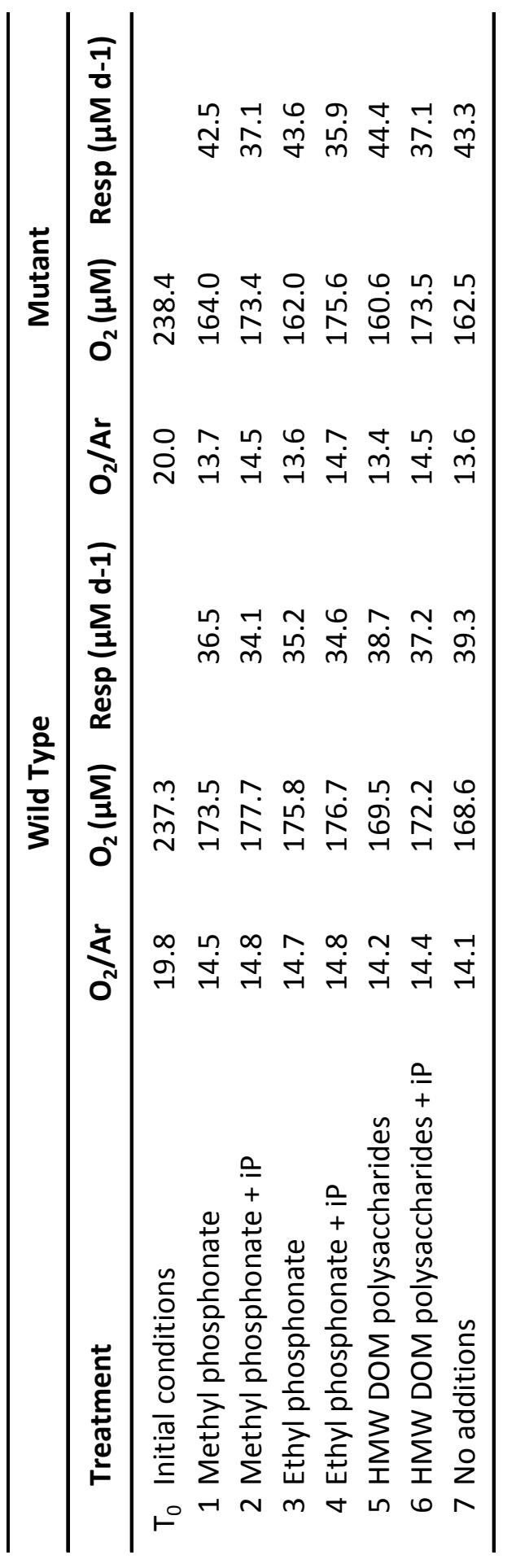



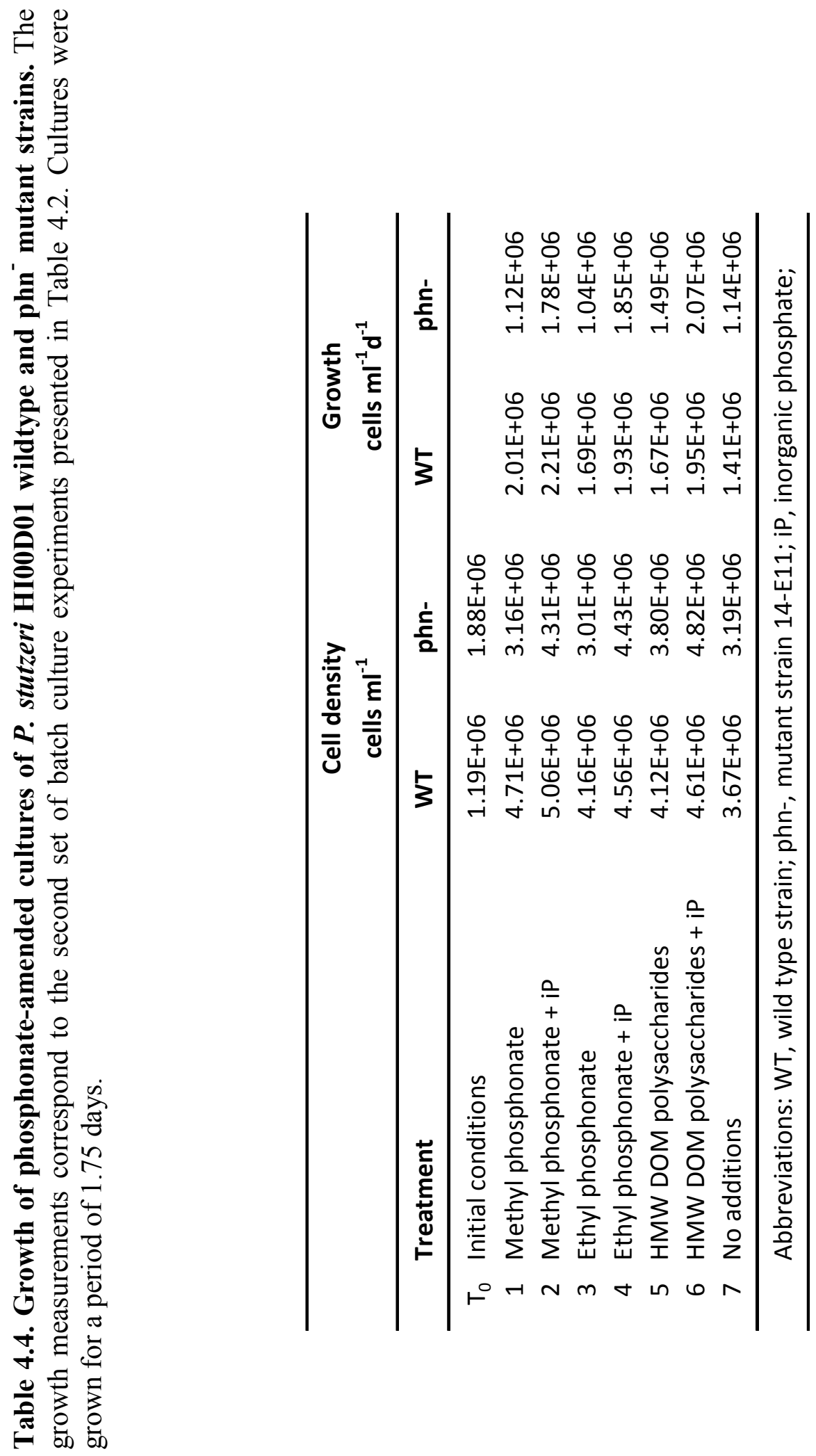


Table 4.6. Degradation of phosphonates by Sulfitobacter strain HI0054. Accumulated hydrocarbon gas concentrations (nM) were measured in duplicate phosphonate-amended cultures after 2 days of growth. The media consisted of Hawaii seawater supplemented with $100 \mu \mathrm{M}$ carbon (glycerol).

\begin{tabular}{llccc}
\hline \multicolumn{1}{c}{ Treatments } & Methane & Ethylene & Ethane \\
\hline 1 & Inorganic phosphate & 0.3 & 0.1 & 0.0 \\
2 & HMW DOM polysaccharides & 7.2 & 20.6 & 0.0 \\
3 & 2-Phosphonopropionate & 0.1 & 0.1 & 11.3 \\
4 & Methyl phosphonate & 100.7 & 0.1 & 0.0 \\
5 & 2-Hydroxyethyl phosphonate & 0.3 & 216.2 & 0.0 \\
\hline
\end{tabular}




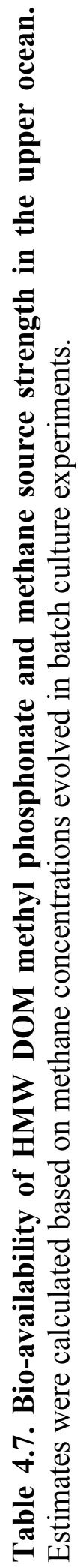

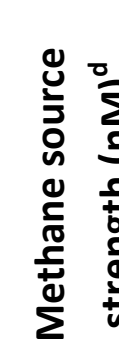

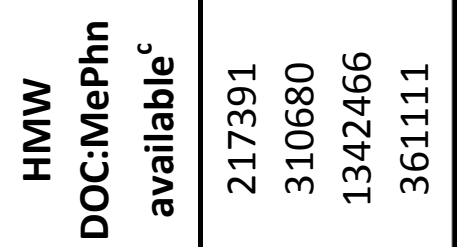





$$
\begin{aligned}
& \text { 은 } \\
& \text { ป ป }
\end{aligned}
$$

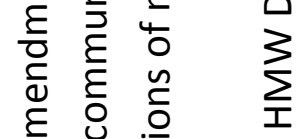

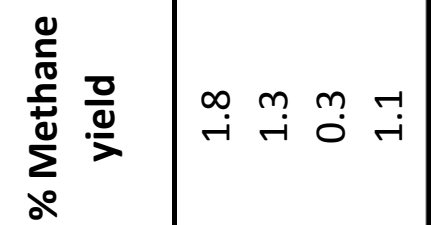

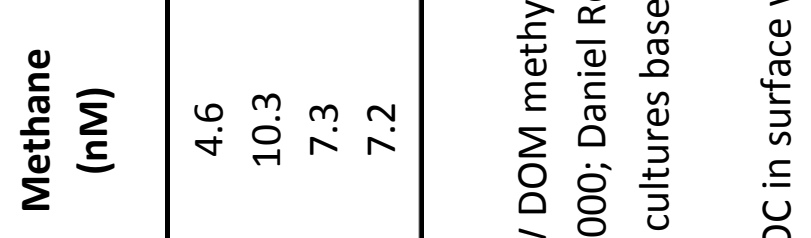

$$
\begin{aligned}
& \text { ¿ }
\end{aligned}
$$

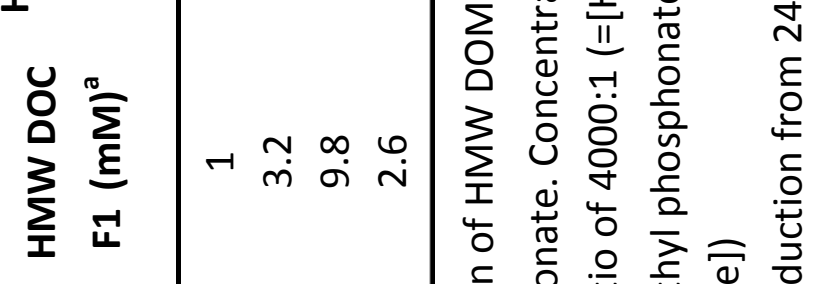

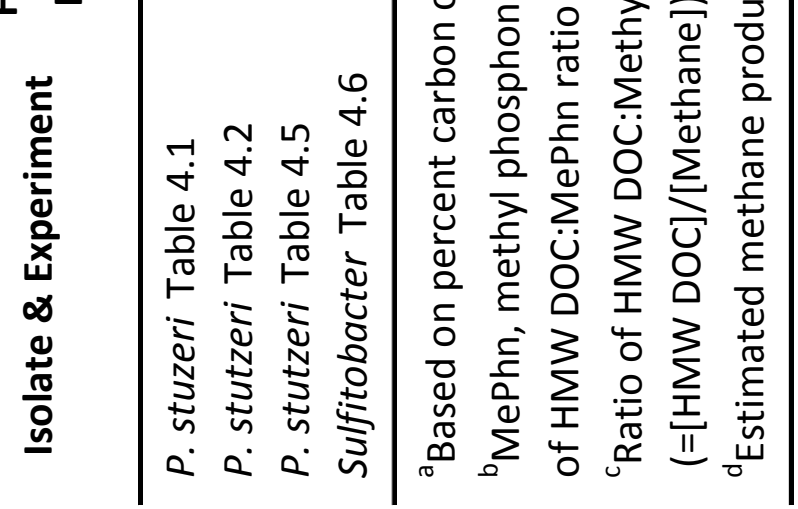




\section{Figures}

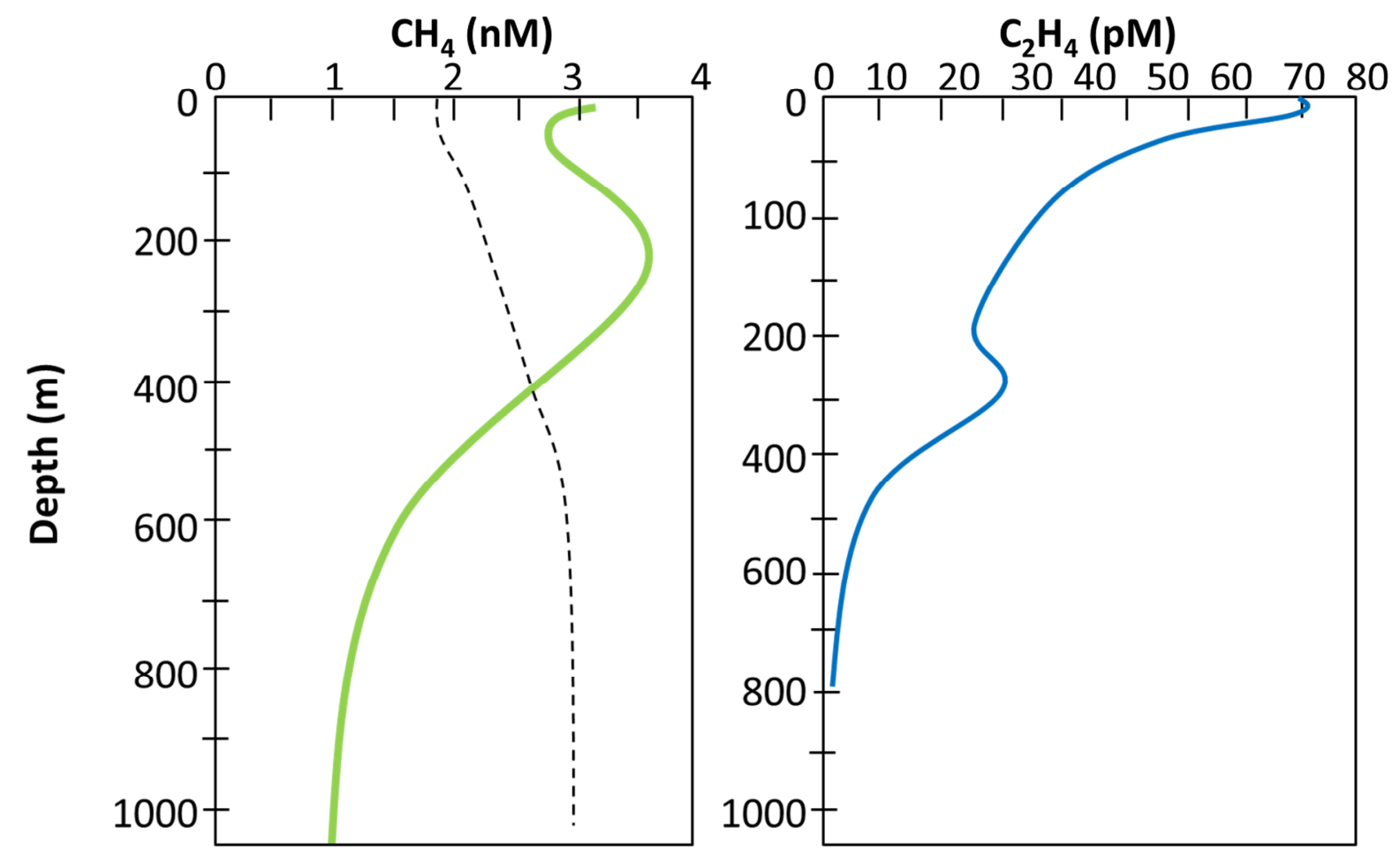

Figure 4.1. Depth profiles of methane $\left(\mathrm{CH}_{4}\right)$ and ethylene $\left(\mathrm{C}_{2} \mathrm{H}_{4}\right)$ gas concentrations characteristic of the oligotrophic ocean. The dotted line in the methane profile indicates the expected atmospheric equilibrium concentrations. In the North Pacific, methane concentrations (green) in the upper 300 meters are consistently 37-67\% (up to 90\% in the North Atlatnic) higher than the expected atmospheric equilibrium concentrations over the course of the year (Holmes, Sansone, Rust, \& Popp, 2000). Ehtylene concentrations (blue) are two orders of magnitude lower than methane. Methane and ethylene profiles are based on measurements in Holmes, Sansone, Rust, \& Popp (2000) and Tsurushima, Watanabe, \& Tsunogai (1999), respectively. 


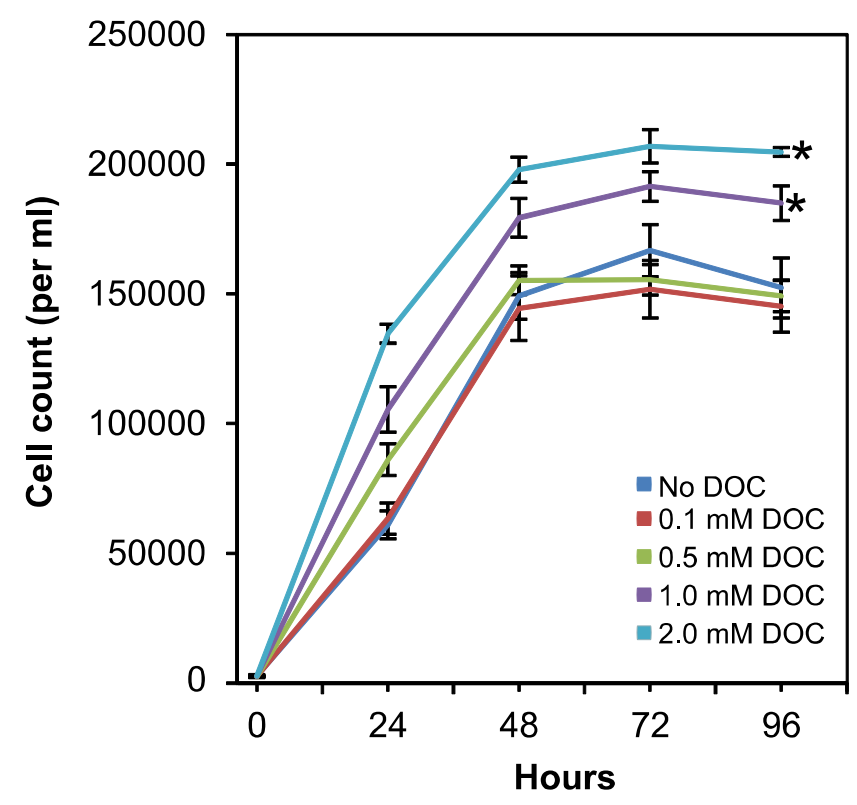

Figure 4.2. Growth of $P$. stutzeri strain HI00D01 on HMW DOM F1 polysaccharides. The growth media consisted of MOPS minimal media amended with $50 \mu \mathrm{M}$ phosphate. DOC amendments were estimated from the carbon content of HMW DOM polysaccharides. Treatment end-point cell yields marked with $\left(^{*}\right)$ were significantly different from the No DOC controls (Student's T-Test; $\mathrm{H}_{0}: \bar{X}_{1}=\bar{X}_{2} ; \mathrm{P}$-value $\left.<0.05\right)$. Error bars indicate one standard deviation $(\mathrm{n}=3)$. 


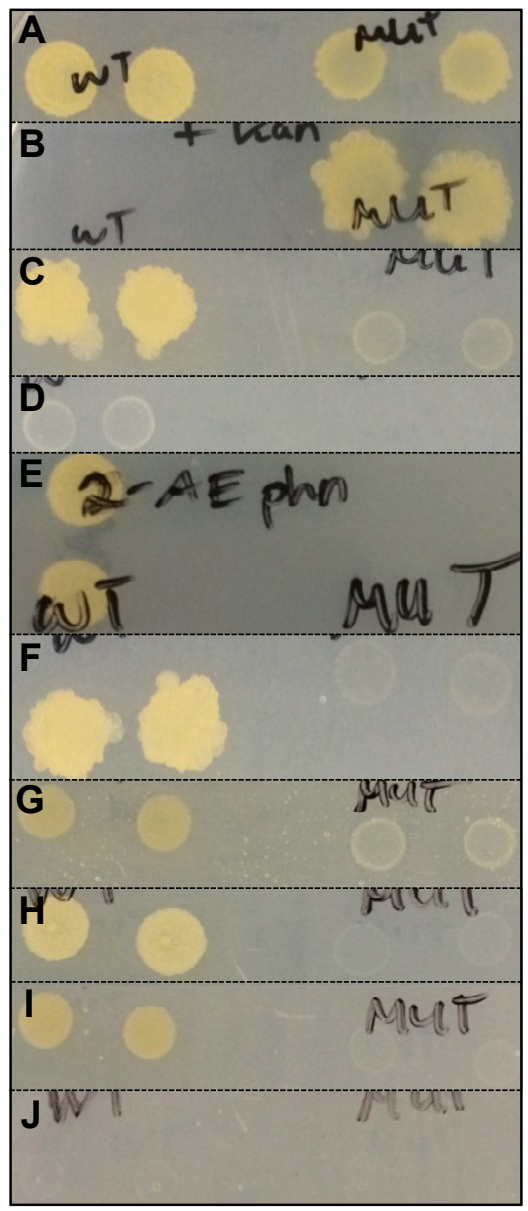

Figure 4.3. Growth of a $P$. stutzeri HI00D01 wildetype strain (WT, left) and phn ${ }^{-}$mutant strain 14-E11 (MUT, right) on phosphonate-amended agarose media. Duplicate samples of each strain were spotted onto the agarose surface and grown in darkness at $26^{\circ} \mathrm{C}$ for 5-7 days. The media consisted of $1 \mathrm{X}$ MOPS buffer in high-purity agarose supplemented with $0.2 \%$ glucose and $100 \mathrm{mM}$ phosphorus. The phosphorus sources tested included: A) inorganic phosphate $\left(\mathrm{K}_{2} \mathrm{HPO}_{4}\right)$ and $\left.\mathrm{B}\right)$ inorganic phosphate $\left(\mathrm{K}_{2} \mathrm{HPO}_{4}\right)$ with kanamycin $\left(50 \mu \mathrm{g} \mathrm{ml} \mathrm{m}^{-1}\right)$ control treatments, C) methyl phosphonate, D) aminomethyl phosphonate, E) 2-aminoethyl phosphonate, F) 3-aminopropyl phosphonate, G) ethyl phosphonate, H) 2-phosphonopropionate, I) 3phosphonopropionate, and J) 2-phosphonobutyrate. 


\section{(Opposite page)}

Figure 4.4. Global ocean distribution of bacterial C-P lyase genes and dissolved inorganic phosphate. The C-P lyase genes identified in open-ocean bacterial isolates (Chapter 3) and metagenomes (Martínez et al., 2013) were searched in the Ocean Microbiome Reference Gene Catalogue (OM-RGC; Sunagawa et al., 2015) by BLAST analysis with a bitscore $\geq 60$ and percent identity $\geq 60$ based on their amino acid sequence. Stations highlighted in color (red, green, or blue) indicate the presence of $\geq 7$ of 11 C-P lyase gene homologs (phnCDEFGHIJKLM) involved in phosphonate degradation. In the map, the circles represent the geographic location of metagenomic samples included in the OM-RGC and the color indicates the sampling depth category: red inner circle, surface waters $(5 \mathrm{~m})$; green middle circle, deep chlorophyll maximum (DCM; $71 \mathrm{~m}$; s.d. $41 \mathrm{~m})$; blue outer circle, mesopelagic waters $(660 \mathrm{~m}$; s.d. $220 \mathrm{~m}$ ). The background color range of global ocean indicates the mean annual dissolved inorganic phosphate concentration in surface waters (depth $<5$ meters; World Ocean Atlas 2013), from high $\left(>2 \mu \mathrm{g} \mathrm{L}^{-1}\right.$, red) to low $\left(<0.2 \mu \mathrm{g} \mathrm{L}^{-1}\right.$, blue) values. Yellow and green represent intermediate values. 


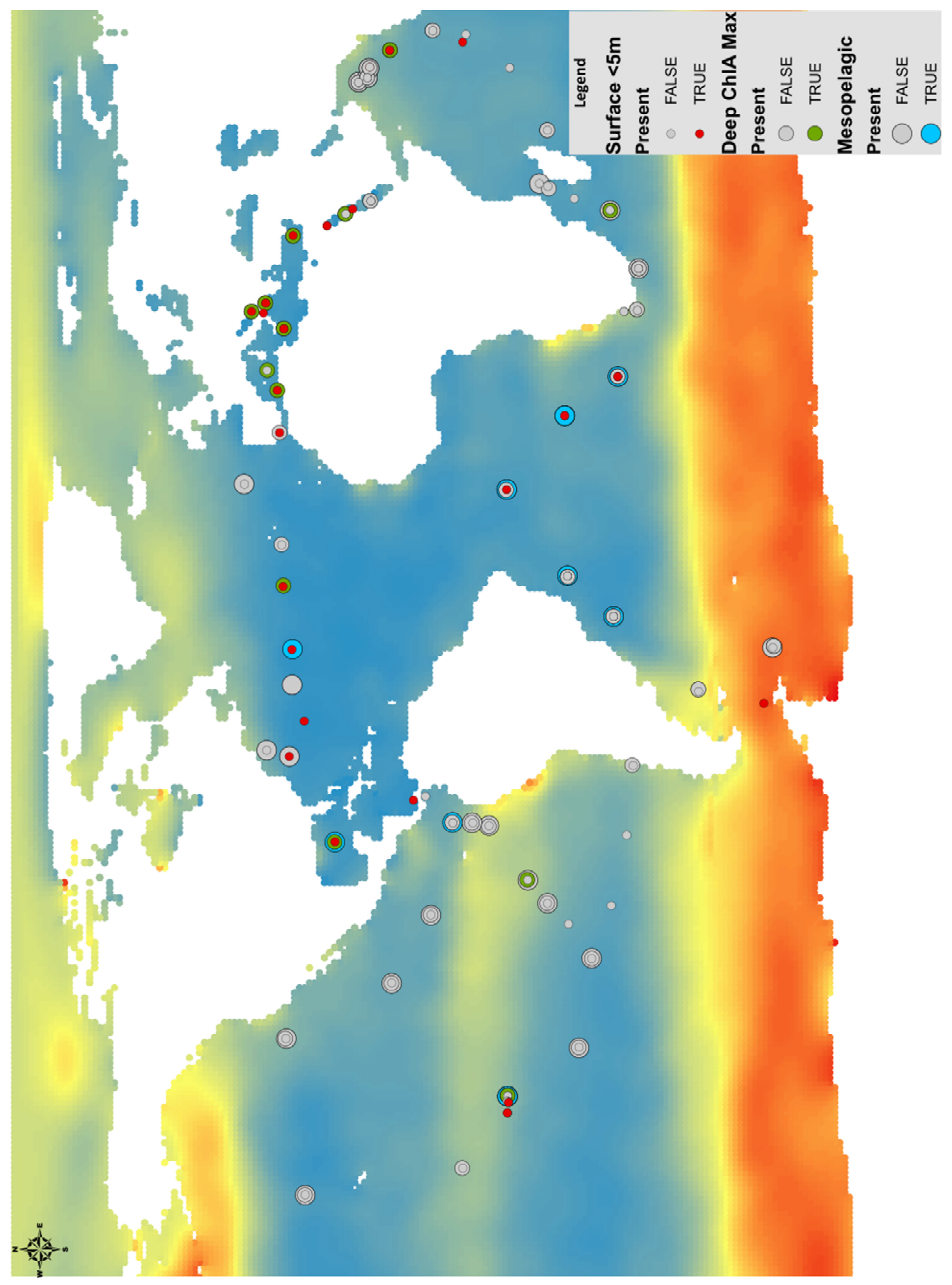




\section{References}

Ammerman, J. W., Hood, R. R., Case, D. a., \& Cotner, J. B. (2003). Phosphorus deficiency in the Atlantic: An emerging paradigm in oceanography. Eos, Transactions American Geophysical Union, 84(18), 165.

Björkman, K., \& Karl, D. (2003). Bioavailability of dissolved organic phosphorus in the euphotic zone at Station ALOHA, North Pacific Subtropical Gyre. Limnology and Oceanography, 48(3), 1049-1057.

Buchan, A., González, J. M., \& Moran, M. A. (2005). Overview of the marine Roseobacter lineage. Applied and Environmental Microbiology, 71(10), 5665-5677.

Clark, L. L., \& Ingall, E. D. (1998). Marine phosphorus is selectively remineralized. Nature, $393,426$.

Clark, L. L., Ingall, E. D., \& Benner, R. (1999). Marine organic phosphorus cycling: Novel insights from nuclear magnetic resonance. American Journal of Science, 29999, 724-737.

DeLong, E. F. (2003). Oceans of Archaea. ASM News, 69(10), 503-511.

Dyhrman, S. T., Benitez-Nelson, C. R., Orchard, E. D., Haley, S. T., \& Pellechia, P. J. (2009). A microbial source of phosphonates in oligotrophic marine systems. Nature Geoscience, 2(10), 696-699.

Ferrón, S., Wilson, S. T., Martínez-García, S., Quay, P. D., \& Karl, D. M. (2015). Metabolic balance in the mixed layer of the oligotrophic North Pacific Ocean from diel changes in O2/Ar saturation ratios. Geophysical Research Letters, 42, 3421-3430.

Goldman, J. C., Caron, D. a., \& Dennett, M. R. (1987). Regulation of gross growth efficiency and ammonium regeneration in bacteria by substrate $\mathrm{C}: \mathrm{N}$ ratio. Limnology and Oceanography, 32(6), 1239-1252.

Holmes, M., Sansone, F., Rust, T., \& Popp, B. N. (2000). Methane production, consumption, and air-sea exchange in the open ocean: An evaluation based on carbon isotopic ratios. Global Biogeochemical Cycles, 14(1), 1-10.

Ivanova, E. P., Gorshkova, N. M., Sawabe, T., Zhukova, N. V., Hayashi, K., Kurinlenko, V., ... Christen, R. (2004). Sulfitobacter delicatus sp. nov. and Sulfitobacter dubius sp. nov., respectively from a starfish (Stellaster equestris) and sea grass (Zostera marina). International Journal of Systematic and Evolutionary Microbiology, 54(2004), 475-480.

Kana, T. M., Darkangelo, C., Hunt, M. D., Oldham, J. B., Bennett, G. E., \& Cornwell, J. C. (1994). Membrane inlet mass spectrometer for rapid high-precision setermination of $\mathrm{N}_{2}$, $\mathrm{O}_{2}$, and Ar in environmental water samples. Analytical Chemistry, 66(23), 4166-4170. 
Karl, D. M. (2014). Microbially mediated transformations of phosphorus in the sea: New views of an old cycle. Annual Review of Marine Science, 6, 279-337.

Karl, D. M., Beversdorf, L., Björkman, K. M., Church, M. J., Martinez, A., \& Delong, E. F. (2008). Aerobic production of methane in the sea. Nature Geoscience, 1, 473-478.

Karl, D. M., Björkman, K. M., Dore, J. E., Fujieki, L., Hebel, D. V., Houlihan, T., ... Tupas, L. M. (2001). Ecological nitrogen-to-phosphorus stoichiometry at station ALOHA. DeepSea Research Part II, 48, 1529-1566.

Kittredge, J. S., Horiguchi, M., \& Williams, P. M. (1969). Aminophosphonic acids: Biosynthesis by marine phytoplankton. Comparative Biochemistry and Physiology, 29, 859-863.

Kolowith, L. C., Ingall, E. D., \& Benner, R. (2001). Composition and cycling of marine organic phosphorus. Limnology and Oceanography, 46(2), 309-320.

Kononova, S. V, \& Nesmeyanova, M. a. (2002). Phosphonates and their degradation by microorganisms. Biochemistry. Biokhimiia, 67(2), 184-195.

Lalucat, J., Bennasar, A., Bosch, R., García-Valdés, E., \& Palleroni, N. J. (2006). Biology of Pseudomonas stutzeri. Microbiology and Molecular Biology Reviews : MMBR, 70(2), 510-547.

Longhurst, A. R. (2007). Ecological Geography of the Sea. (pp. 327-441). Academic Press, San Diego.

Luo, H., \& Moran, M. A. (2014). Evolutionary ecology of the marine Roseobacter clade. Microbiology and Molecular Biology Reviews, 78(4), 573-587.

Martinez, A., Tyson, G. W., \& Delong, E. F. (2010). Widespread known and novel phosphonate utilization pathways in marine bacteria revealed by functional screening and metagenomic analyses. Environmental Microbiology, 12, 222-238.

Martínez, A., Ventouras, L. A., Wilson, S. T., Karl, D. M., \& DeLong, E. F. (2013). Metatranscriptomic and functional metagenomic analysis of methylphosphonate utilization by marine bacteria. Frontiers in Microbiology, 4, 340.

Metcalf, W. W., Griffin, B. M., Cicchillo, R. M., Gao, J., Janga, S. C., Cooke, H. A, ... Donk, W. a Van Der. (2012). Synthesis of methylphosphonic acid by marine microbes: A source for methane in the aerobic ocea. Science, 337(6098), 1104-1107.

Metcalf, W. W., \& Wanner, B. L. (1991). Involvement of the Escherichia coli phn (psiD) gene cluster in assimilation of phosphorus in the form of phosphonates, phosphite, P(i) esters, and P(i). Journal of Bacteriology, 173(2), 587-600. 
Metcalf, W. W., \& Wanner, B. L. (1993a). Evidence for a fourteen-gene, phnC to phnP locus for phosphonate metabolism in Escherichia coli. Gene, 129, 27-32.

Metcalf, W. W., \& Wanner, B. L. (1993b). Mutational analysis of an Escherichia coli fourteengene operon for phosphonate degradation, using TnphoA' elements. Journal of Bacteriology, 175(11), 3430-3442.

Moore, C. M., Mills, M. M., Arrigo, K. R., Berman-Frank, I., Bopp, L., Boyd, P. W., ... Ulloa, O. (2013). Processes and patterns of oceanic nutrient limitation. Nature Geoscience, 6(9), $701-710$.

Paytan, A., Cade-Menun, B. J., McLaughlin, K., \& Faul, K. L. (2003). Selective phosphorus regeneration of sinking marine particles: evidence from ${ }^{31} \mathrm{P}-\mathrm{NMR}$. Marine Chemistry, 82, $55-70$.

Paytan, A., \& Mclaughlin, K. (2007). The Oceanic Phosphorus Cycle. Chemical Reviews, 107(2), 563-576.

Pinhassi, J., Gómez-Consarnau, L., Alonso-Sáez, L., Sala, M., Vidal, M., Pedrós-Alió, C., \& Gasol, J. (2006). Seasonal changes in bacterioplankton nutrient limitation and their effects on bacterial community composition in the NW Mediterranean Sea. Aquatic Microbial Ecology, 44, 241-252.

Podzelinska, K., He, S.-M., Wathier, M., Yakunin, a., Proudfoot, M., Hove-Jensen, B., ... Jia, Z. (2009). Structure of PhnP, a phosphodiesterase of the carbon-phosphorusl lyase pathway for phosphonate degradation. Journal of Biological Chemistry, 284(25), 17216-17226.

Repeta, D. J., Ferron, S., Sosa, O. A., DeLong, E. F., \& Karl, D. M. (2016). Title of paper. Unpublished manuscript.

Sebastián, M., \& Gasol, J. M. (2013). Heterogeneity in the nutrient limitation of different bacterioplankton groups in the Eastern Mediterranean Sea. The ISME Journal, 7, 16651668.

Sunagawa, S., Coelho, L. P., Chaffron, S., Kultima, J. R., Labadie, K., Salazar, G., ... Lepoivre, C. (2015). Structure and function of the global ocean microbiome. Science, 348(6237), 110.

Tilbrook, B. D., \& Karl, D. M. (1995). Methane sources, distributions and sinks from California coastal waters to the oligotrophic North Pacific gyre. Marine Chemistry, 49, 51-64.

Villarreal-Chiu, J. F. (2012). The genes and enzymes of phosphonate metabolism by bacteria, and their distribution in the marine environment. Frontiers in Microbiology, 3, 1-13.

Wagner-Döbler, I., Rheims, H., Felske, A., El-Ghezal, A., Flade-Schröder, D., Laatsch, H., ... Tindall, B. J. (2004). Oceanibulbus indolifex gen. nov., sp. nov., a North Sea 
alphaproteobacterium that produces bioactive metabolites. International Journal of Systematic and Evolutionary Microbiology, 54(2004), 1177-1184.

Wanner, B. L., \& Metcalf, W. W. (1992). Molecular genetic studies of a 10.9-kb operon in Escherichia coli for phosphonate uptake and biodegradation. FEMS Microbiology Letters, 79, 133-9.

White, D. (2007). The physiology and biochemistry of prokaryotes (3rd ed., pp. 70-71). New York: Oxford University Press.

White, A. K., \& Metcalf, W. W. (2007). Microbial metabolism of reduced phosphorus compounds. Annual Review of Microbiology, 61, 379-400.

Yu, X., Doroghazi, J. R., Janga, S. C., Zhang, J. K., Circello, B., Griffin, B. M., ... Metcalf, W. W. (2013). Diversity and abundance of phosphonate biosynthetic genes in nature. Proceedings of the National Academy of Sciences of the USA, 110(51), 20759-20764.

Zhang, Q., \& van der Donk, W. (2012). Answers to the carbon-phosphorus lyase conundrum. Chembiochem, 13(5), 627-629. 


\section{CHAPTER FIVE}

\section{Summary and future directions}

Modeling studies of the marine carbon cycle often exclude or sparingly mention the role of microorganisms, specifically of heterotrophic bacteria which live through the oxidation or organic substrates, because the net carbon fluxes they mediate are negligible on the timescales relevant to the ocean-atmosphere $\mathrm{CO}_{2}$ equilibrium, i.e., thousands of years (Sarmiento \& Gruber, 2006). The biological pump - the biological and physical processes that transport inorganic carbon fixed into organic matter to the interior of the deep blue ocean - for example, is left out of the equation because it is assumed to operate in steady-state with the upward transport of dissolved inorganic carbon and because phytoplankton, a major component of the sinking export flux, are primarily controlled by nutrients and light, not by $\mathrm{CO}_{2}$ levels, and therefore does not contribute to anthropogenic $\mathrm{CO}_{2}$ sequestration (Sarmiento \& Gruber, 2006). These assumptions however are prone to fail with the onset of feedback mechanisms that result from a changing climate influencing both food web structure and dynamics and the capacity of the ocean to take up $\mathrm{CO}_{2}$. For example, the domain shift hypothesis - the alteration of the native phytoplankton community composition from eukaryotic and bacterial to bacterial-dominated assemblages (primarily Prochlorococcus) as a result of ecosystem changes driven by climate change predicts consequent changes in the efficiency of the biological pump - the fraction of photosynthetically-fixed carbon exported from the surface layer (Karl, Bidigare, \& Letelier, 2001). Moreover, the possible impact of ocean warming on the marine oxygen cycle can have future implications on the metabolic state of the ocean - the balance between gross primary production and community respiration - a topic that has remained controversial over a decade (Ducklow \& Doney, 2011). These examples warrant the need not only to include biology in 
current models (Reid, 2011) but to expand our understanding of the functions performed by microorganisms in the carbon cycle.

The role of heterotrophic bacteria in regulating the biological pump as well as the contribution of dissolved organic carbon (DOC) to the export flux are now well recognized (Ducklow, Steinberg, \& Buesseler, 2001). New insights from cultivation-independent techniques in oxygenated marine waters have gained insight into the aerobic microbial loop (McCarren et al., 2010a; Ottesen et al., 2013, 2014; Rinta-Kanto, Sun, Sharma, Kiene, \& Moran, 2012; Sharma et al., 2014; Teeling et al., 2012), wherein heterotrophic bacterioplankton play a central role in the turnover of dissolved organic matter (DOM) and serve as a link to higher trophic levels (Azam et al., 1983). These studies are extremely valuable because they provide information about the microbial taxa, biochemical pathways, and temporal and spatial scales that are relevant to DOM turnover, albeit they lack details illustrating the exact molecular transformations underlying the bacterial degradation of DOM substrates. Even though thousands of microbial isolates (including marine bacteria) have been tested to determine the types of organic substrates they can degrade or use for growth, only a few model microorganisms exist today that have enabled detailed studies of the exact transformations of organic substrates in the marine environment. An important example is that of cultured members of the Roseobacter lineage which have been used to describe the degradation of organic sulfur compounds such as the phytoplankton-derived osmolyte dimethyl sulfoniopropionate into the greenhouse gas dimethyl sulfide and other byproducts (Gonzalez, Kiene, \& Moran, 1999). Another case is that of cultured strains of the ubiquitous SAR11 clade which have been used to investigate the degradation of one-carbon compounds (Sun et al., 2011) including methyl phosphonate which releases methane, another greenhouse gas (Carini, White, Campbell, \& Giovannoni, 2014). However, detailed 
information regarding the microorganisms relevant to the slower decomposition cycles of less labile pools of DOM are lacking.

A primary objective of this work was to identify appropriate model systems, e.i., marine heterotrophic microorganisms, with which to study DOM decomposition under laboratory conditions. To attain this goal, an ecologically relevant organic carbon substrate, namely the high-molecular-weight fraction (HMW) of marine DOM obtained by tangential flow ultrafiltration (Aluwihare et al., 1997; Mccarthy et al., 1996) was selected to grow and isolate suitable model microorganisms. HMW DOM is of special interest to microbial oceanographers and biogeochemists because its proton NMR-based molecular signature and predominant carbohydrate constitution is highly conserved throughout the global ocean (Aluwihare et al., 1997; Mccarthy et al., 1996) indicating that similar food web processes, if not the same organisms, produce this material. HMW DOM is also thought to be representative of the semilabile reservoir of DOM due its periodic accumulation in surface waters and its particular nutrient-deplete elemental stoichiometry. Thus, understanding the molecular details of HMW DOM degradation has the potential of shedding light on the cycling of one of the largest organic carbon reservoirs of the planet.

In Chapter 2, I tested the hypothesis that HMW DOM isolated from marine surface waters contains bio-available carbon substrates that can stimulate the growth of bacteria. The enrichment of dilution-to-extinction cultures prepared with coastal seawater with HMW DOM resulted in the isolation of several clades of Beta- and Gammaproteobacteria that could support higher cell yields with increasing concentrations of HMW DOM. The dominant bacterial group isolated was a member of the methylotrophic Betaproteobacteria OM43 clade (Giovannoni et al., 2008) with a metabolism geared towards the oxidation of $\mathrm{C} 1$ compounds like methanol and 
formaldehyde. This result was unexpected given that the major bioreactive constituents of HMW DOM are thought to be carbohydrates (Benner et al., 1992; Mccarthy et al., 1996). However, previous open-ocean microcosm experiments amended with HMW DOM also resulted in the enrichment of methylotrophic Gammaproteobacteria (McCarren et al., 2010a) suggesting the presence of a common degradation pathway supporting $\mathrm{C} 1$ metabolism in both microbial communities. Thus a logical next step was to reproduce this experimental framework in an openocean environment.

In Chapter 3, a series of similar cultivation experiments conducted at Station ALOHA near Hawaii resulted in the enrichment of several Alpha- and Gammaproteobacteria strains with putative HMW DOM-degrading capabilities, though none of the cultures identified matched known methylotrophic strains. Even though HMW DOM clearly stimulated the recovery of open-ocean dilution-to-extinction cultures, further experiments indicated that the majority of isolates did not exhibit significant increases in cell yields in response to HMW DOM additions, a result that contrasted with the more robust growth response of the coastal methylotrophs described in Chapter 2. The Station ALOHA isolate Pseudomonas stutzeri strain HI00D01, however, was studied further and was shown to increase its growth concomitantly with HMW DOM additions (Fig. 4.2 in Chapter 4) though maximum cell yields were an order of magnitude lower than the Nahant Bay OM43 clade isolate NB0046 (described in Chapter 2) suggesting that a limited fraction of HMW DOM is available to this bacterium.

A factor that may have contributed to the differences in growth yields observed between the coastal methylotrophs identified in Chpater 2 and open-ocean isolates explored in Chapter 3 is their specific bacterial carbon demand (BCD). $\mathrm{BCD}$ is equal to the gross bacterial production expressed in carbon units and includes the carbon incorporated into biomass and the carbon used 
for respiration (Ducklow, 2000). Even though estimates of BCD were not obtained from cultures grown on HMW DOM, the cell size of these isolates may provide an indirect assessment of their carbon quota. NB0046 is similar to other cultured members of the oligotrophic OM43 clade in having a small genome ( $<1400$ genes) and relatively small cell size $(0.1-0.3 \mu \mathrm{m}$ wide and 0.6-1.8 $\mu \mathrm{m}$ long) (Huggett et al., 2012). These small cells were in fact often difficult to enumerate by flow cytometry due their low scattering signal and small genome. Thus, one can speculate that NB0046 was likely able to achieve the highest cell yields with HMW DOM additions due to its relatively low BCD. In turn, other Hawaii isolates like P. stutzeri strain HI00D01 (5 Mbps genome) and Sulfitobacter strain HI0054 (4.2 Mbps genome) are more representative of the socalled "high-DNA" bacteria (Gasol, Giorgio, \& del Giorgio, 2000) and of copiotrophic bacteria. Pedler, Aluwihare, \& Azam (2014) large bacterial cells $\left(\sim 0.3355 \mu \mathrm{m}^{3}\right.$ and $>40 \mathrm{fg}$ carbon cell $\left.{ }^{-1}\right)$ from the Alteromonas clade that can rapidly consume most of the labile DOC pool indicating that these bacteria may require high levels of carbon to sustain their populations. Consistent with this observation, several bacterial production studies indicate that high-DNA cells are responsible for incorporating most of the radio-labeled thymidine and leucine (Gasol et al., 2000). To test this hypothesis the carbon content of OM43 clade and Pseudomonas stutzeri bacteria were estimated based on their theoretical cell volumes. Based on the cell dimensions measured by Huggett et al. (2012), the OM43 clade bacterial cells have a theoretical maximum volume of $0.162 \mu \mathrm{m} 3$. Applying the allometric relationship between cell volume and bacterial cellular carbon of Loferer-Krößbacher, Klima, \& Psenner (1998), the carbon content of the OM43 clade bacteria is of $45.5 \mathrm{fg} \mathrm{C}^{-1}{ }^{-1}$. Using this carbon conversion factor and assuming a bacterial growth efficiency of $20 \%$, cells may require up to $227.5 \mathrm{fg} \mathrm{C}$ cell $^{-1}$ to grow. Considering the ca. $5 \times 10^{6}$ cells ml $^{-1}$ cell yields observed in $10 \mathrm{X}$ and 50X DOC treatments (700- 
$3500 \mu \mathrm{M}$ DOC; Fig. 2.5A), the maximum carbon required to account for this bacterial biomass is estimated to be $0.095 \mu \mathrm{mol} \mathrm{C} \mathrm{ml}{ }^{-1}$, or 2.7 to $13.6 \%$ of the carbon in $50 \mathrm{X}$ and $10 \mathrm{X} \mathrm{DOC}$ treatments, respectively. A more conservative estimate, based on the mean cellular carbon content of 20 fg per cell $^{-1}$ for a natural bacterial assemblage (Lee and Fuhrman, 1987; LofererKrößbacher, Klima, \& Psenner, 1998) and a growth efficiency of 50\%, results in carbon utilization fractions of 0.04 to $2.4 \%$, in $50 \mathrm{X}$ and $10 \mathrm{X}$ DOC treatments, respectively. With respect to Pseudomonas stutzeri, in the DOM growth response experiment (Fig. 4.2) cultures reached cell concentrations of $2 \times 10^{5}$ cells $\mathrm{ml}^{-1}$ in $2 \mathrm{mM} \mathrm{DOC} \mathrm{(ca.} \mathrm{25X} \mathrm{DOC)} \mathrm{treatments,} 25$ times less than the OM43 clade bacteria grown under similar DOC concentrations. Assuming $P$. stutzeri cells are in the large part of size spectrum of natural bacterial samples $(\sim 0.3355 \mu \mathrm{m} 3$; Pedler, Aluwihare, \& Azam, 2014), the carbon to volume conversion results in a cell carbon content of $85 \mathrm{fg} \mathrm{C}$ cell $^{-1}$. Applying again a growth efficiency of $20 \%$, P. stutzeri cells would require approximately $425 \mathrm{fg} \mathrm{C}$ cell $^{-1}$ to grow. Therefore, the maximum carbon utilized by these cultures is estimated to be $0.007 \mu \mathrm{mol} \mathrm{C} \mathrm{ml}^{-1}$, or $0.35 \%$ of the $2 \mathrm{mM} \mathrm{DOC}$ in the media. Despite having similar BCD, OM43 clade and P. stutzeri bacteria cell yields (per DOC) differed by an order of magnitude $\left(1.42 \times 10^{6}\right.$ cells $\mu \mathrm{mol}^{-1}$ and $1 \times 10^{5}$ cells $\mu \mathrm{mol}^{-1}$, respectively), indicating that less DOC was available to the $P$. stutzeri cells. Incorporating measurements of respiration and carbon consumption in future studies will help tease apart these growth differences and improve the detection of HMW DOM-degrading bacteria.

The non-linear growth response observed in DOM dose experiments remains unclear. In the case of the OM43 clade NB0046 strain, the 50X DOC treatment did not yield a corresponding five-fold increase in cell yields with respect to the 10X DOC treatment (Fig. 2.5). There are several explanations to this behavior. For example, nutrients such as vitamins may be limiting 
growth. This is possible considering that the cultivation media was prepared with UV-oxidzed seawater to lower the total DOC content. Another explanation for the DOM dose response observed is that the methylorophs' growth is inhibited at high DOC concentrations. This could occur because at high DOC concentrations the probability of intermolecular interactions is increased and molecules tend to form aggregates (Zsolnay, 2003) that reduce the available substrate concentration. Another possibility is that the non-linear growth observed is related to the abiotic release of methanol; if a fraction of abiotically-produced methanol escapes from the medium a smaller amount of methanol would be available for bacterial consumption. The abiotic production of methanol from HMW DOM most likely did not influence the isolation of methylotrophs from dilution-to-extinction cultures nor their growth response in DOM dose experiments considering that neither of the cultivation experiments performed with samples from Hawaii resulted in the isolation of methylotrophic strains like the ones observed before in microcosm experiments (McCarren et al., 2010). Transcriptome analysis of methylotrophs and other bacterial isolates grown in HMW DOM-amended media may shed light on the biochemical pathways and HMW substrates these bacteria degrade and metabolize.

In contrast to other dilution-to-extinction cultivation studies, the experiments conducted in this work did not identify cultures related to the abundant Alphaproteobacteria SAR11 clade (Giovannoni et al., 2005). Members of the SAR11 clade are among the most common, though difficult to culture, bacterial isolates in high throughput dilution-to-extinction experiments because of their dominance in bacterioplankton communities (Connon \& Giovannoni, 2002; Rappé et al., 2002; Song et al., 2009). However, neither the coastal or open-ocean cultivation experiments performed in this work were able to isolate members of this clade. This result is not unexpected given the sensitivity and recalcitrance of oligotrophic clades to grow under 
laboratory conditions. Additionally, SAR11 clade strains seem to be streamlined to consume low-molecular-weight organic compounds to support their metabolism (Grote et al., 2012; Sun et al., 2011a) rather than HMW DOM. Interestingly, members of the OM43 clade share similar characteristics with the SAR11 clade; yet NB0046 cultures were able to reach high cell yields in the presence of HMW DOM. It may well be that only a few genes are required to confer HMW DOM-degradation properties to these oligotrophic isolates. Future genomic studies and gene expression experiments will be necessary to identify the enzymes encoded by NB0046 that degrade HMW DOM substrates.

Physiological parameters and genome content are both implicated in the ability of bacteria to degrade HMW DOM. In these studies, despite supplementing cultures with high concentrations of DOC and sufficient nutrients (nitrogen and phosphorus) to induce carbon consumption, cell yields were usually low and the fraction of DOC consumed was estimated to be $>1 \%$ (up to $13 \%$ in non-conservative estimates) of the total organic carbon available. These results indicate that in its native form HMW DOM offers a limited supply of labile carbon to monocultures. Whether inherent physicochemical properties of HMW DOM (e.g., formation of nanogels, intermolecular interactions, or steric hindrance; see Verdugo et al., 2008) or the genomic potential of isolates are the main restriction to HMW DOM degradation remains to be determined. In addition to the apparent difference in the fraction of HMW DOM substrates available to the bacterial groups tested, the freeze-drying process used to preserve HMW DOM for analysis and culturing expriments may have affected its physicochemical properties and influenced the degree to which it is labile to bacterial degradation. Even though freeze-drying is the best method available to preserve organic matter, as it minimizes physicochemical changes and microbial degradation, the possibility that the procedure results in, for example, the 
dehydration of HMW DOM moieties, cannot be neglected. Such reactions may or may not be reversible and therefore ultimately affect the way natural bacterial assemblages interact and breakdown HMW DOM. However, freeze-drying is unlikely to exert physicochemical alterations on HMW DOM given that the powder extract readily dissovles in water wherase air-drying or heat-drying of other forms of organic matter are much harder to dissolve (Malcolm, 1968).

The genomic analysis performed in Chapter 3 suggests that the bacterioplankton clades identified may provide complementary functions in the aerobic decomposition of HMW DOM involving the degradation of different moieties from HMW polysaccharides like acetyl, amino, and phosphonate residues, and methyl or methoxy groups in the case of methylotrophs (Fig. 5.1). It is hypothesized that OM43 clade bacteria encode enzymes that cleave single carbon atom moiteties from HMW DOM such as methyl and methoxy groups, as these are enriched in the sugars making up HMW polysaccharides (Panagiotopoulos, Repeta, \& Johnson, 2007; Quan \& Repeta, 2007).The role of OM43 clade methylotrophs in HMW DOM cycling is intriguing. Methylotrophic bacteria are widespread in the marine environment and are thought to be an important sink of atmospheric methanol as it enters the ocean (Dixon, Beale, \& Nightingale, 2011; Dixon, Sargeant, Nightingale, \& Colin Murrell, 2013). The OM43 clade is characteristic of bacterioplankton communities in coastal waters (Giovannoni et al., 2008; Rappe, Kemp, \& Giovannoni, 1997) and has been observed to increase significantly in abundance during phytoplankton blooms (Morris, Longnecker, \& Giovannoni, 20006; Rich, Pham, Eppley, Shi, \& DeLong, 2011) presumably due to the production of one-carbon compounds like methanol, though the exact nature of this association is not well constrained. Even though both the atmosphere and phytoplankton supply methanol to mehtylotrophic bacteria in the ocean, the OM43 clade isolates described in Chapter 2 may gain a competitive advantage over other 
methylotrophs by obtaining one-carbon compounds from the degradation of HMW DOM, especially during non-bloom conditions. Furthermore, by contributing to the aerobic decomposition chain of HMW DOM (Fig 5.1), methylotrophs like the OM43 clade bacteria may gain access to additional carbon sources as well as to organic forms of nitrogen and phosphorus. Future work focused on co-culture experiments and artificial (chemical) alteration of HMW DOM polymers may shed some light as to why HMW DOM seems inaccessible to monocultures.

In Chapter 4, two microbial isolates were explored further: the alpha-proteobacterium Sulfitobacter HI0054 and the gamma-proteobacterium P. stutzeri HI00D01. These HMW DOM isolates were selected as candidate model systems to study HMW DOM metabolism due to their ease of growth under laboratory conditions, including robust growth on defined agar-based, nutrient-rich media, and the potential to modify them genetically. Strain HI00D01, a member of the genus Pseudomonas sensu stricto, was particularly amenable to genetic manipulation. In Chapter 4, I used genomic information gathered in Chapter 3 and previous chemical information derived from HMW DOM NMR spectra to test the hypothesis that bacteria carrying a known phosphonate degradation pathway were capable of utilizing alkylphosphonates associated to HMW DOM polysaccharides. Both isolates tested were capable of using phosphonates in HMW DOM as shown by the accumulation of methane and other hydrocarbons expected to be released as byproducts in batch cultures grown under phosphorus-limited conditions. The methane concentrations evolved during HMW DOM phosphonate degradation were considerably lower than expected considering the methyl phosphonate content of HMW DOM and than the total phosphorus required to account for the cell growth observed. However, it is possible that the bacterial phosphorus demand was met and bacteria down-regulated the degradation of additional 
phosphonates. It is also possible that alternative sources of organic phosphorus in HMW DOM, such as phosphate esters, were more readily accessible to these bacteria and suppressed utilization of phosphonates. HMW DOM contains four times more phosphate esters and pyrophosphate than phosphonates (Daniel Repeta, personal communication). Given that HMW DOM methyl phosphonate additions were estimated to be $0.25-2.5 \mu \mathrm{M}$, an additional 1-10 $\mu \mathrm{M}$ organic phosphorus was available to bacteria and could have been sufficient to suppress phosphonate degradation (only $1 \mu \mathrm{M}$ inorganic phosphate was required to considerably reduce methane evolution; Table 4.2). Alternatively, only a limited fraction of phosphonates in HMW DOM polysaccharides may be accessible to bacteria, a pattern that is consistent with the apparent low availability of HMW DOM carbon substrates to monocultures as indicated by their poor DOM dose responses (Figures 3.4, 3.5, and 3.6).

Additionally, using a genetic mutant of strain HI00D01 deficient in phosphonate catabolism, I demonstrated the involvement of a well described phosphonate-degrading enzyme complex, the C-P lyase pathway (Metcalf \& Wanner, 1993), in the production of methane gas from the degradation of HMW DOM phosphonates. The C-P lyase pathway is present in the genomes of diverse Proteobacteria lineages (Martínez et al., 2013) and may be a primary mechanism controlling the sub-surface methane maxima observed across ocean basins (Holmes et al., 2000). Like other potent greenhouse gases, methane absorbs terrestrial radiation in wavelengths outside the spectrum already absorbed by $\mathrm{CO}_{2}$ meaning that small increases in the concentration of this trace gases in the atmosphere can have profound effects on climate change. Therefore, confirming the involvement of the bacterial C-P lyase pathway and HMW DOM phosphobates in aerobic methanogenesis represents an important step in understanding the potential of the ocean's DOM cycle as a natural source of methane. The experiments conducted 
as part of this study however, focused on assessing the potential of bacterial methane production from HMW DOM phosphonates under conditions not characteristic of the environment (e.g., glucose- and nutrient-replete cultures) and thus do not provide a thorough assessment of its ecological and climatic implications. Future work must focus on identifying additional sources and sinks of marine phosphonates and methane, as well as characterizing this methanogenic pathway under relevant environmental conditions so that such processes can be appropriately parameterized and evaluated in climate and ecosystem models.

Investigating the role of HMW DOM in the environment remains difficult in great part because its exact source is not well constrained. However, the presence of phosphonates in HMW DOM may be evidence of its microbial origin and provide clues reagarding its function. The fact that at least a small fraction of HMW DOM phosphonates were readily used by heterotrophic bacteria like P. stutzeri HI00D01 and Sulfitobacter HI0054 suggst that production of phosphonates may be a mechanism by which microorganisms lock away phosphorus for later use. This strategy seems to be contradicted by the observation that POM does not usually contain phosphonates as it would be expected if these served as a cellular phosphorus bank. In a more complex scenario, however, HMW DOM phosphonates may be produced or exported extracellularly as semi-labile forms (e.g., phosphono-sugars) that cannot be easily degraded. This strategy would benefit the microbial community by alleviating phosphorus limitation for example, under periods of net nitrogen fixation and by maintaining phosphorus levels in the upper ocean that would otherwise be exported via sinking particular organic matter. Hypothetically, during these stress periods, heterotrophic microorganisms capable of degrading phosphonates like $P$. stutzeri and other bacteria encoding the C-P lyase pathway, regenerate phosphorus from this HMW DOM phosphonate reservoir for their direct benefit and indirectly 
for the original producer of phosphonates. Expanding this scenario, HMW DOM nitrogen may serve a similar function as phosphorus. HMW DOM polysaccharides contain semi-labile amino sugars that may serve as a source of nitrogen to microbial communities when inorganic forms are scarce. Using measurements of stable nitrogen isotope in HMW DOM, Benner, Biddanda, Black, \& McCarthy (1997) estimated turnover times of HMW dissolved organic nitrogen (DON) of 4-6 $n \mathrm{nd}^{-1}$, a rate that can support a large fraction of the phytoplankton nitrogen demand if is representative of the total DON pool, suggesting that DON is an important part of the upper ocean nitrogen cycle. If this is the case, heterotrophic bacteria capable or remineralizing phosphorus and nitrogen from HMW DOM may be vital to maintain productivity in marine surface waters.

In this thesis, the model system-based approach proved useful in identifying a microbial HMW DOM decomposition pathway that can have significant implications on climate. Additionally, several candidate model microorganisms were identified such as the methylotrophic betaproteobacterium strain NB0046, the oligotrophic SAR92 clade strain NB0015, several Oceanospirillacea hydrocarbon degraders, and the aforementioned phosphonate-degrading bacteria which can be used to explore further the role of bacteria in the aerobic decomposition of semi-labile DOM. Continuation of the development of microbial model systems identified in HMW DOM enrichment experiments may prove useful in identifying novel pathways and carbon transformations that may have important implications on the ecology of the sea. 


\section{Figures}

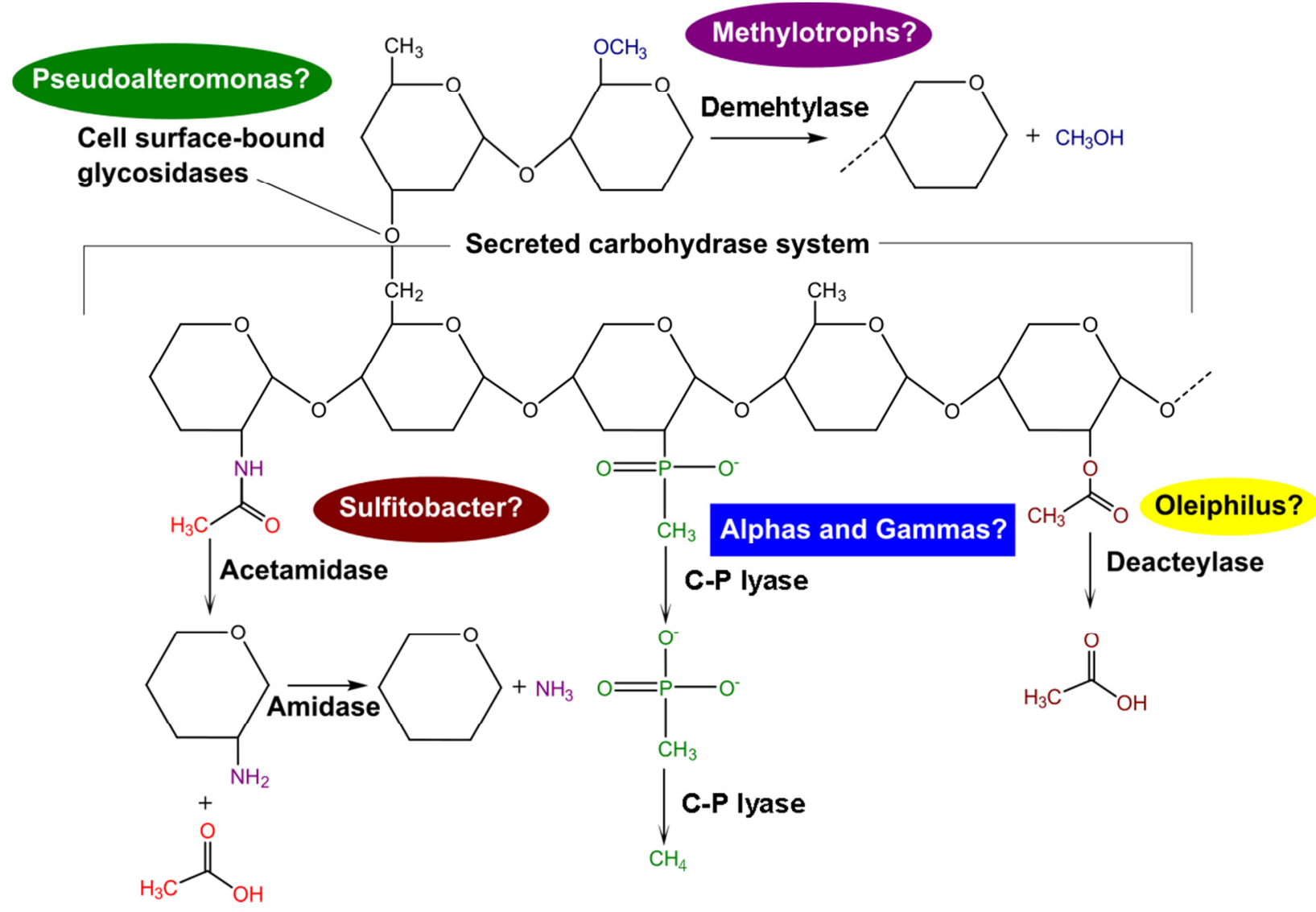

Figure 5.1. Hypothetical model of the microbial decomposition of high-molecular-weight (HMW) marine dissolved organic matter (DOM). HMW DOM is enriched in acylpolysaccharides (Aluwihare et al., 1997) and amino (Aluwihare et al., 2005), deoxy, methyl, and phosphono sugars (Panagiotopoulos, Repeta, \& Johnson, 2007; Quan \& Repeta, 2007, Repeta et al., unpublished, personal communication) with moderate branching. A suite of diverse bacterial groups is hypothesized to participate in the partial degradation of HMW DOM. The cleavage of the organic moieties decorating HMW polysaccharides serves as carbon and nutrient sources to heterotrophic bacteria (e.g., methanol, acetate, and the phosphate group from phosphonates) and enables larger enzyme complexes such as secreted carbohydrases to bind and breakdown the backbone polysaccharides. In addition, the degradation of alkylphosphonates results in the release of methane and other hydrocarbons, that may or may not be consumed by bacteria. 


\section{References}

Aluwihare, L. I., Repeta, D. J., \& Chen, R. F. (1997). A major biopolymeric component to dissolved organic carbon in surface sea water. Nature 387, 166-169.

Aluwihare, L. I., Repeta, D. J., Pantoja, S., \& Johnson, C. G. (2005). Two chemically distinct pools of organic nitrogen accumulate in the ocean. Science, 308(May), 1007-1010.

Azam, F., Fenchel, T., Field, J., Gray, J., Meyer-Reil, L., \& Thingstad, F. (1983). The ecological role of water-column microbes in the sea. Marine Ecology Progress Series, 10, 257-263.

Benner, R., Pakulski, J. D., McCarthy, M., Hedges, J. I., \& Hatcher, P. G. (1992). Bulk chemical characteristics of dissolved organic matter in the ocean. Science, 255, 1561-1564.

Carini, P., White, A. E., Campbell, E. O., \& Giovannoni, S. J. (2014). Methane production by phosphate-starved SAR11 chemoheterotrophic marine bacteria. Nature Communications, $5,1-8$.

Connon, S. A, \& Giovannoni, S. J. (2002). High-throughput methods for culturing microorganisms in very-low-nutrient media yield diverse new marine isolates. Applied and Environmental Microbiology, 68(8), 3878-3885.

Dixon, J. L., Beale, R., \& Nightingale, P. D. (2011). Microbial methanol uptake in northeast Atlantic waters. The ISME Journal, 5(4), 704-16.

Dixon, J. L., Sargeant, S., Nightingale, P. D., \& Colin Murrell, J. (2013). Gradients in microbial methanol uptake: productive coastal upwelling waters to oligotrophic gyres in the Atlantic Ocean. The ISME Journal, 7(3), 568-80.

Ducklow, H. (2000). Bacterial production and biomass in the oceans. Microbial Ecology of the Oceans, 85-120.

Ducklow, H. W., \& Doney, S. C. (2013). What Is the metabolic state of the oligotrophic ocean? A debate. Annual Review of Marine Science, 5, 525-33.

Ducklow, H. W., Steinberg, D. K., \& Buesseler, K. O. (2001). Upper ocean carbon export and the biological pump. Oceanography, 14(4), 50-58.

Gasol, J. M., Giorgio, P. a D. E. L., \& del Giorgio, P. a. (2000). Using flow cytometry for counting natural planktonic bacteria and understanding the structure of planktonic bacterial communities. Scientia Marina, 64(2), 197-224.

Giovannoni, S. J., Hayakawa, D. H., Tripp, H. J., Stingl, U., Givan, S. a., Cho, J. C., .. Rappé, M. S. (2008). The small genome of an abundant coastal ocean methylotroph. Environmental Microbiology, 10, 1771-1782. 
Giovannoni, S. J., Tripp, H. J., Givan, S., Podar, M., Vergin, K. L., Baptista, D., ... Mathur, E. J. (2005). Genome streamlining in a cosmopolitan oceanic bacterium. Science, 309, 1242 1245.

Gonzalez, J. M., Kiene, R. P., \& Moran, M. A. (1999). Tranformation of sulfur compounds by an abundant lineage of marine bacteria in the $\alpha$-aubclass of the class Proteobacteria. Applied and Environmental Microbiology, 65(9), 3810-3819.

Grote, J., Cameron Thrash, J., Huggett, M. J., Landry, Z. C., Carini, P., Giovannoni, S. J., \& Rappé, M. S. (2012). Streamlining and core genome conservation among highly divergent members of the SAR11 clade. mBio, 3, e00252-12.

Holmes, M., Sansone, F., Rust, T., \& Popp, B. N. (2000). Methane production, consumption, and air-sea exchange in the open ocean: An evaluation based on carbon isotopic ratios. Global Biogeochemical Cycles, 14(1), 1-10.

Huggett, M. J., Hayakawa, D. H., \& Rappé, M. S. (2012). Genome sequence of strain HIMB624, a cultured representative from the OM43 clade of marine Betaproteobacteria. Standards in Genomic Sciences, 6, 11-20.

Karl, D. M., Bidigare, R. R., \& Letelier, R. M. (2001). Long-term changes in plankton community structure and productivity in the North Pacific Subtropical Gyre: The domain shift hypothesis. Deep Sea Research Part II: Topical Studies in Oceanography, 48, 1449-1470.

Loferer-Krößbacher, M., Klima, J., \& Psenner, R. (1998). Determination of bacterial cell dry mass by transmission electron microscopy and densitometric image analysis, 64(2), 688694.

Malcolm, R. L. (1968). Freeze-drying of organic matter, clays, and other earth materials. U. S. Geological Survey Research - Professional Paper 600-C, C211-C216.

Martínez, A., Ventouras, L. A., Wilson, S. T., Karl, D. M., \& DeLong, E. F. (2013). Metatranscriptomic and functional metagenomic analysis of methylphosphonate utilization by marine bacteria. Frontiers in Microbiology, 4, 1-18.

McCarren, J., Becker, J. W., Repeta, D. J., Shi, Y., Young, C. R., Malmstrom, R. R., ... DeLong, E. F. (2010). Microbial community transcriptomes reveal microbes and metabolic pathways associated with dissolved organic matter turnover in the sea. Proceedings of the National Academy of Sciences of the USA, 107, 16420-16427.

Mccarthy, M., Hedges, J., \& Benner, R. (1996). Major biochemical composition of dissolved high molecular weight organic matter in seawater. Marine Chemistry, 55, 281-297. 
Metcalf, W. W., \& Wanner, B. L. (1993). Mutational analysis of an Escherichia coli fourteengene operon for phosphonate degradation, using TnphoA' elements. Journal of Bacteriology, 175(11), 3430-3442.

Morris, R. M., Longnecker, K., \& Giovannoni, S. J. (2006). Pirellula and OM43 are among the dominant lineages identified in an Oregon coast diatom bloom. Environmental Microbiology, 8, 1361-1370.

Ottesen, E. A, Young, C. R., Eppley, J. M., Ryan, J. P., Chavez, F. P., Scholin, C.A, \& DeLong, E. F. (2013). Pattern and synchrony of gene expression among sympatric marine microbial populations. Proceedings of the National Academy of Sciences of the USA, 110, E488-97.

Ottesen, E. a, Young, C. R., Gifford, S. M., Eppley, J. M., Marin, R., Schuster, S. C., ... DeLong, E. F. (2014). Multispecies diel transcriptional oscillations in open ocean heterotrophic bacterial assemblages. Science, 345, 207-12.

Panagiotopoulos, C., Repeta, D. J., \& Johnson, C. G. (2007). Characterization of methyl sugars, 3-deoxysugars and methyl deoxysugars in marine high molecular weight dissolved organic matter. Organic Geochemistry, 38, 884-896.

Pedler, B. E., Aluwihare, L. I., \& Azam, F. (2014). Single bacterial strain capable of significant contribution to carbon cycling in the surface ocean. Proceedings of the National Academy of Sciences of the USA, 111(20), 7202-7207.

Quan, T. M., \& Repeta, D. J. (2007). Periodate oxidation of marine high molecular weight dissolved organic matter: Evidence for a major contribution from 6-deoxy- and methyl sugars. Marine Chemistry, 105, 183-193.

Rappé, M. S., Connon, S. a, Vergin, K. L., \& Giovannoni, S. J. (2002). Cultivation of the ubiquitous SAR11 marine bacterioplankton clade. Nature, 418, 630-633.

Reid, A. (2011). Incorporating microbial processes into climate models. A Report from the American Academy of Microbiology (p. 16). Dallas, TX. Retrieved from http://academy.asm.org/images/stories/documents/Incorporating_Microbial_Processes_In to_Climate_Models.pdf

Repeta, D. J., Ferron, S., Sosa, O. A., DeLong, E. F., \& Karl, D. M. (2016). Title of paper. Unpublished manuscript.

Rich, V. I., Pham, V. D., Eppley, J., Shi, Y., \& DeLong, E. F. (2011). Time-series analyses of Monterey Bay coastal microbial picoplankton using a "genome proxy" microarray. Environmental Microbiology, 13, 116-134. 
Rinta-Kanto, J. M., Sun, S., Sharma, S., Kiene, R. P., \& Moran, M. A. (2012). Bacterial community transcription patterns during a marine phytoplankton bloom. Environmental Microbiology, 14, 228-239.

Sarmiento, J. L., \& Gruber, N. (2006). Oceanic carbon cycle, atmospheric CO2, and climate. Ocean Biogeochemical Dynamics. Chapter 10 (pp. 1-99). Princeton University Press, Princeton, NJ.

Sharma, A. K., Becker, J. W., Ottesen, E. a, Bryant, J. a, Duhamel, S., Karl, D. M., ... DeLong, E. F. (2014). Distinct dissolved organic matter sources induce rapid transcriptional responses in coexisting populations of Prochlorococcus, Pelagibacter and the OM60 clade. Environmental Microbiology, 16, 2815-30.

Song, J., Oh, H. M., \& Cho, J. C. (2009). Improved culturability of SAR11 strains in dilution-toextinction culturing from the East Sea, West Pacific Ocean. FEMS Microbiology Letters, $295,141-147$.

Sun, J., Steindler, L., Thrash, J. C., Halsey, K. H., Smith, D. P., Carter, A. E., ... Giovannoni, S. J. (2011). One carbon metabolism in SAR11 pelagic marine bacteria. PLoS ONE, 6(8), e23973.

Teeling, H., Fuchs, B. M., Becher, D., Klockow, C., Gardebrecht, a., Bennke, C. M., ... Amann, R. (2012). Substrate-controlled succession of marine bacterioplankton populations induced by a phytoplankton bloom. Science, 336, 608-611.

Verdugo, P., Orellana, M. V, Chin, W.-C., Petersen, T. W., van den Eng, G., Benner, R., \& Hedges, J. I. (2008). Marine biopolymer self-assembly: implications for carbon cycling in the ocean. Faraday Discussions, 139, 393-398. 


\begin{abstract}
APPENDIX I
This section presents supplementary data for Chapter 3 which includes the complete flow cytometry growth screen results for open-ocean dilution-to-extinction cultivation experiments I and II (Tables A1 and A2, respectively). The tables indicate the total number of wells screened for each DOC treatment in DCM and Mesopelagic samples. The phylogeny of SSU rRNA gene sequences of open-ocean isolates is presented in Figures A1 and A2.
\end{abstract}




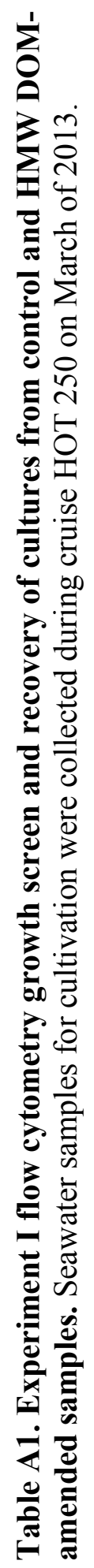

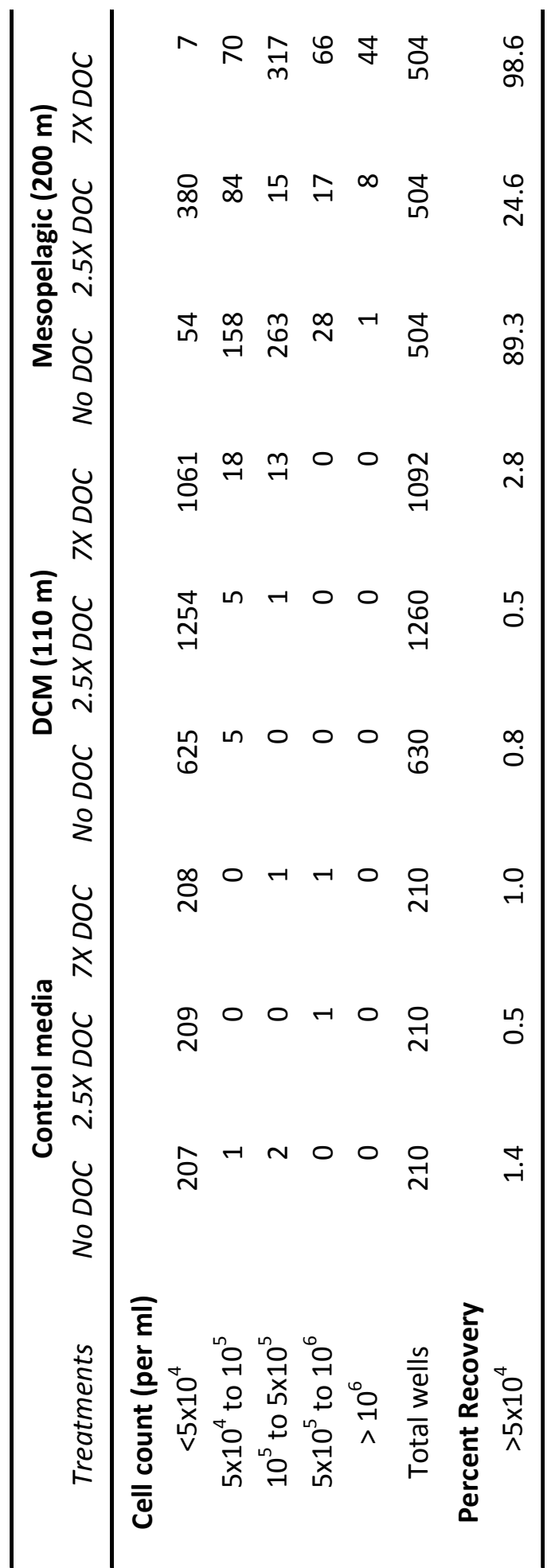




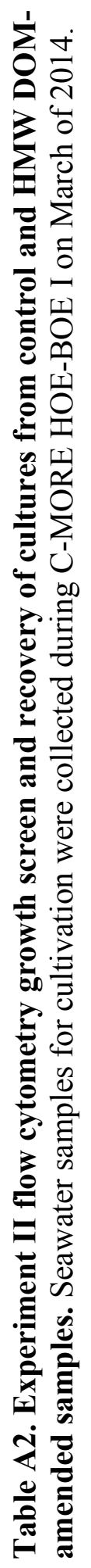

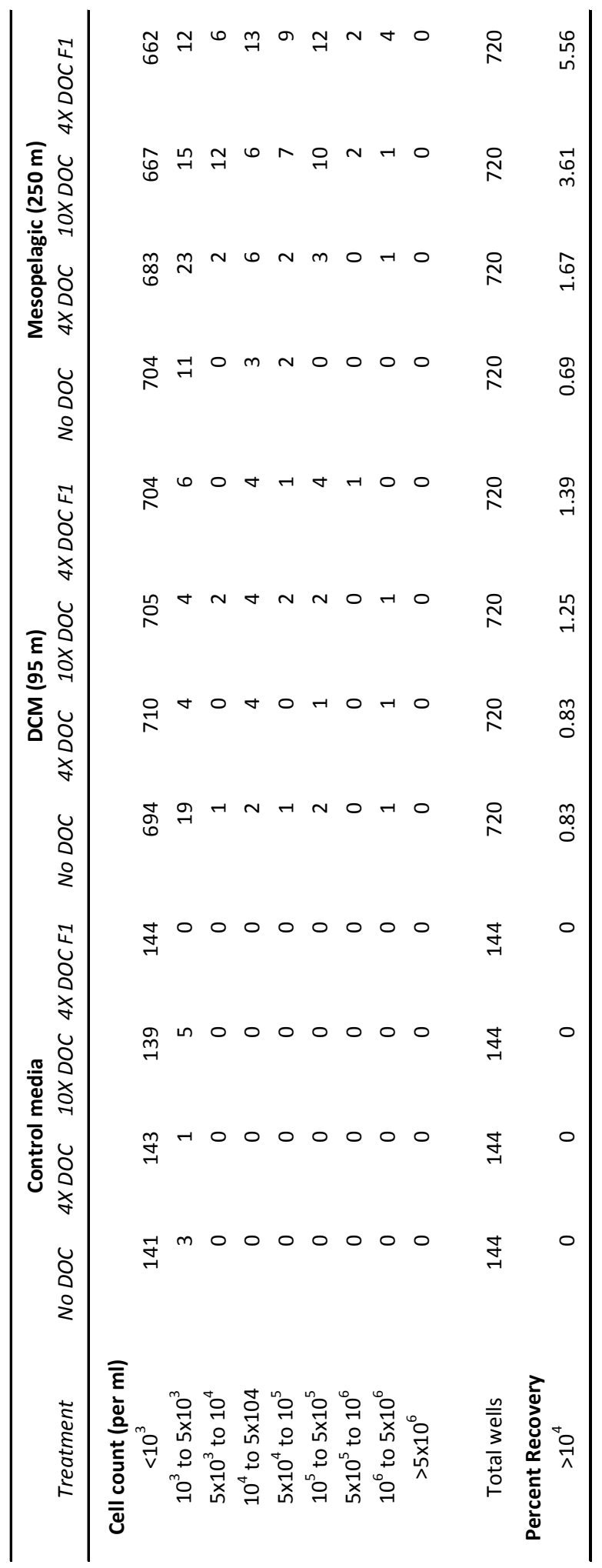


Table A3. Vitamin and trace metal supplements for Hawaii seawater cultivation media.

\begin{tabular}{ll}
\hline Vitamins & Final concentration (nM) \\
\hline Pyrodxine-HCl & 243 \\
Clacium pantothenate & 420 \\
PABA-paraaminobenzoic acid & 36 \\
Folic acid & 2 \\
Vitamin B12 & 0 \\
Biotin & 2 \\
Thiamine & 297 \\
& \\
\hline Tracel metals & Final concentration (nM) \\
\hline Manganese sulfate (monohydrate) & 179 \\
Zinc chloride & 20 \\
Cobalt chloride (hexahydrate) & 2 \\
Sodium molybdate (dihydrate) & 20 \\
Nickel chloride (hexahydrate) & 2 \\
Sodium selenite (pentahydrate) & 1 \\
\hline
\end{tabular}

\section{(Opposite page)}

Table A4. Genome draft assembly summary of 59 representative open-ocean isolates of cultivation Experiments I and II, as well as of the coastal SAR92 clade isolate NB0015. Assembled genomes were deposited in NCBI as Bioproject PRJNA305749. 


\begin{tabular}{|c|c|c|c|c|c|c|c|c|c|}
\hline Isolate ID & Phylogenetic Id ${ }^{a}$ & Reads assembled & $\% G C$ & Coverage $^{b}$ & Total contigs & Largest contig & N50 & Total consensus ${ }^{c}$ & Quality $^{d}$ \\
\hline NB0015 & SAR92 clade & 222378 & 50 & 15 & 470 & 49503 & 11234 & 2630413 & 83 \\
\hline HIOOS01-18 & Halioglobus & 8224731 & 57 & 330 & 834 & 460777 & 342731 & 4643869 & 72 \\
\hline HIOOD01-58 & Pseudomonas & 7574112 & 63 & 257 & 699 & 564926 & 231407 & 5056098 & 74 \\
\hline HI00D59-64 & Erythrobacter & 3326750 & 63 & 172 & 151 & 623674 & 306780 & 3352205 & 75 \\
\hline HIOOD65-71 ${ }^{\mathrm{e}}$ & Vibrio & 3168151 & 44 & 95 & 748 & 361131 & 195360 & 5339401 & 73 \\
\hline HI00O3 & Alcanivorax & 552606 & 59 & 27 & 510 & 89908 & 25632 & 3656522 & 81 \\
\hline HI0007 & Alcanivorax & 716839 & 59 & 35 & 528 & 124870 & 46304 & 3656241 & 81 \\
\hline HI0009 & Oleiphilus & 723138 & 44 & 30 & 2693 & 241593 & 16347 & 6322614 & 55 \\
\hline HI0011 & Alcanivorax & 627875 & 59 & 26 & 2529 & 156362 & 21670 & 5638842 & 58 \\
\hline HI0013 & Alcanivorax & 850375 & 59 & 36 & 3241 & 163490 & 18494 & 6614072 & 60 \\
\hline HI0019 & Erythrobacter & 320380 & 64 & 18 & 984 & 28738 & 8598 & 3360862 & 81 \\
\hline HI0020 & Erythrobacter & 586146 & 63 & 32 & 461 & 146840 & 41339 & 3217465 & 81 \\
\hline HI0021 & Oceanibulbus & 631044 & 61 & 24 & 928 & 92580 & 18120 & 4494867 & 81 \\
\hline HI0023 & Oceanibulbus & 596480 & 63 & 26 & 857 & 67329 & 18387 & 4335530 & 81 \\
\hline HI0027 & Oceanibulbus & 1124339 & 61 & 45 & 732 & 134133 & 46668 & 4482328 & 81 \\
\hline HI0028 & Erythrobacter & 324735 & 64 & 19 & 668 & 40850 & 12736 & 3317849 & 44 \\
\hline HI0033 & Alcanivorax & 488095 & 59 & 25 & 708 & 94967 & 20152 & 3690776 & 81 \\
\hline HI0035 & Alcanivorax & 822176 & 59 & 35 & 3156 & 205575 & 17383 & 6694373 & 59 \\
\hline HI0037 & Erythrobacter & 774140 & 63 & 37 & 3032 & 143343 & 21899 & 5774452 & 62 \\
\hline HI0038 & Erythrobacter & 475039 & 63 & 22 & 2043 & 87689 & 14945 & 4662640 & 58 \\
\hline HI0040 & Oceanibulbus & 646904 & 63 & 27 & 932 & 90981 & 20339 & 4230235 & 81 \\
\hline HI0043 & Oleiphilus & 707561 & 44 & 26 & 2044 & 143440 & 25101 & 5481930 & 54 \\
\hline HI0044 & Alcanivorax & 488420 & 58 & 19 & 2059 & 48075 & 10187 & 5164445 & 60 \\
\hline HI0049 & Roseovarius & 567627 & 64 & 16 & 3524 & 57962 & 4960 & 7104809 & 66 \\
\hline HI0050 & Oleiphilus & 344906 & 44 & 14 & 2072 & 28608 & 4972 & 4825708 & 71 \\
\hline HI0053 & Pseudoalteromonas & 695383 & 42 & 19 & 3130 & 40367 & 5334 & 6742281 & 70 \\
\hline HI0054 & Sulfitobacter & 731891 & 62 & 31 & 777 & 91112 & 23268 & 4207901 & 81 \\
\hline HI0061 & Oleiphilus & 434002 & 44 & 18 & 1925 & 62339 & 8507 & 5100920 & 60 \\
\hline HI0063 & Erythrobacter & 630550 & 63 & 33 & 586 & 161626 & 41202 & 3293092 & 81 \\
\hline HI0065 & Oleiphilus & 818810 & 48 & 35 & 2711 & 336635 & 28355 & 6401110 & 56 \\
\hline HI0066 & Oleiphilus & 560893 & 44 & 25 & 1926 & 150802 & 22410 & 5050227 & 54 \\
\hline HI0067 & Oleiphilus & 503329 & 44 & 22 & 1789 & 119737 & 20427 & 4845662 & 55 \\
\hline HI0068 & Oleiphilus & 365219 & 44 & 14 & 2039 & 21553 & 5157 & 4848124 & 71 \\
\hline HI0069 & Oleiphilus & 590352 & 44 & 22 & 2264 & 96705 & 14127 & 5905670 & 53 \\
\hline HI0071 & Oleiphilus & 601234 & 48 & 26 & 2311 & 143853 & 24676 & 5701391 & 53 \\
\hline HI0072 & Oleiphilus & 337845 & 44 & 14 & 2241 & 25254 & 4687 & 4928926 & 71 \\
\hline HI0073 & Oleiphilus & 784137 & 48 & 34 & 2660 & 418796 & 56040 & 6107507 & 55 \\
\hline HI0074 & Erythrobacter & 379698 & 64 & 22 & 747 & 48613 & 12515 & 3174080 & 81 \\
\hline HI0075 & Oceanobacter & 535677 & 51 & 22 & 2622 & 98856 & 12664 & 6125644 & 56 \\
\hline HI0076 & Oceanibulbus & 574934 & 61 & 23 & 1070 & 47234 & 13536 & 4400770 & 81 \\
\hline HI0077 & Erythrobacter & 365940 & 64 & 21 & 667 & 74328 & 13723 & 3173227 & 81 \\
\hline HI0078 & Oleiphilus & 303674 & 44 & 12 & 2589 & 16558 & 2900 & 4440923 & 78 \\
\hline HI0079 & Oleiphilus & 426827 & 47 & 19 & 1492 & 48425 & 13007 & 4413786 & 58 \\
\hline HI0080 & Oleiphilus & 377861 & 47 & 16 & 1308 & 33760 & 8068 & 3946656 & 72 \\
\hline HI0081 & Oleiphilus & 298111 & 44 & 12 & 2517 & 15225 & 3026 & 4411065 & 78 \\
\hline HI0082 & Oceanibulbus & 616668 & 61 & 21 & 2364 & 49576 & 9483 & 5450880 & 62 \\
\hline HI0083 & Alcanivorax & 345236 & 58 & 14 & 1829 & 29024 & 5595 & 4452193 & 73 \\
\hline HI0085 & Oleiphilus & 253579 & 44 & 11 & 3293 & 15089 & 2070 & 4492359 & 78 \\
\hline HI0086 & Oleiphilus & 506633 & 44 & 20 & 1604 & 52346 & 10771 & 4764100 & 63 \\
\hline HI0117 & Oleiphilus & 546950 & 44 & 19 & 1632 & 35441 & 7173 & 4636056 & 75 \\
\hline HI0118 & Oleiphilus & 1204101 & 48 & 49 & 2842 & 443600 & 15926 & 6562827 & 55 \\
\hline HI0120 & Oceanospirillaceae & 766145 & 49 & 27 & 2130 & 225416 & 35705 & 5682561 & 55 \\
\hline HI0122 & Oleiphilus & 743601 & 48 & 32 & 2536 & 358202 & 37188 & 6045884 & 55 \\
\hline HI0123 & Oleiphilus & 545524 & 44 & 17 & 2100 & 21032 & 4967 & 4493975 & 79 \\
\hline HI0125 & Oleiphilus & 605193 & 44 & 25 & 1616 & 109922 & 19459 & 4565113 & 55 \\
\hline HI0128 & Oleiphilus & 568083 & 44 & 20 & 1725 & 98189 & 11624 & 4898028 & 59 \\
\hline HI0129 & Oceanibulbus & 395966 & 63 & 17 & 1228 & 81523 & 8497 & 4223361 & 81 \\
\hline HI0130 & Oleiphilus & 433776 & 48 & 18 & 2114 & 62064 & 10256 & 5203078 & 57 \\
\hline HI0132 & Oleiphilus & 501301 & 44 & 20 & 1963 & 51478 & 9469 & 5179518 & 61 \\
\hline HI0133 & Oleiphilus & 869569 & 48 & 36 & 2428 & 329080 & 47727 & 5733204 & 55 \\
\hline \multicolumn{10}{|c|}{ a Genus of most closely realted sequence based on LAST analysis against SILVA 119} \\
\hline \multicolumn{10}{|c|}{${ }^{b}$ Average total coverage assessment calculated from contigs $>=5000$ with uniform coverage } \\
\hline \multicolumn{10}{|c|}{${ }^{c}$ Contig size $>=500$} \\
\hline \multicolumn{10}{|c|}{${ }^{d}$ Average concensus quality } \\
\hline
\end{tabular}


(Opposite page)

Table A5. PROKKA annotation summary of the draft genomes of 59 representative openocean isolates and the SAR92 clade isolate NB0015. The number of PROKKA-predicted CDSs matching known and hypothetical proteins in the RefSeq and KEGG databases are also indicated. Draft annotations of genomes are available under NCBI BioProject PRJNA305749. 


\begin{tabular}{|c|c|c|c|c|c|c|c|c|c|c|c|c|}
\hline \multirow[b]{2}{*}{ Isolate ID } & \multirow[b]{2}{*}{ Phylogenetic ID ${ }^{a}$} & \multirow[b]{2}{*}{ Conitgs $^{b}$} & \multirow[b]{2}{*}{ Bases $^{\mathrm{b}}$} & \multirow[b]{2}{*}{ rRNAs } & \multirow[b]{2}{*}{ ssu } & \multirow[b]{2}{*}{ LSU } & \multirow[b]{2}{*}{ tRNAs } & \multirow[b]{2}{*}{ CDS } & Ref & & KE & \\
\hline & & & & & & & & & Annot. $^{c}$ & Hyp. $^{d}$ & Annot. $^{c}$ & Hyp. $^{d}$ \\
\hline NB0015 & SAR92 clade & 467 & 2629892 & 3 & 1 & 1 & 29 & 2401 & 1466 & 672 & 1478 & 636 \\
\hline HI00S01-18e & Halioglobus & 415 & 4588515 & 6 & 1 & 1 & 57 & 4293 & 4236 & 1266 & 2006 & 1248 \\
\hline HIOOD01-58e & Pseudomonas & 607 & 5044166 & 10 & 1 & 1 & 77 & 4676 & 2749 & 1851 & 2700 & 1871 \\
\hline HI00D59-64e & Erythrobacter & 121 & 3347358 & 4 & 1 & 1 & 48 & 3217 & 3169 & 1218 & 1641 & 1245 \\
\hline HI00D65-71e & Vibrio & 614 & 5319010 & 21 & 2 & 1 & 187 & 4707 & 4520 & 2146 & 2133 & 2320 \\
\hline HI0003 & Alcanivorax & 378 & 3635468 & 38 & 1 & 1 & 38 & 3338 & 1709 & 1389 & 1717 & 1364 \\
\hline HI0007 & Alcanivorax & 286 & 3620498 & 5 & 1 & 1 & 45 & 3303 & 1699 & 1369 & 1703 & 1350 \\
\hline HI0009 & Oleiphilus & 2650 & 6316839 & 9 & 2 & 1 & 90 & 5721 & 2716 & 1682 & 2696 & 1636 \\
\hline HI0011 & Alcanivorax & 2482 & 5632014 & 5 & 1 & 0 & 65 & 5387 & 2797 & 2143 & 2812 & 2102 \\
\hline HI0013 & Alcanivorax & 3199 & 6607668 & 7 & 2 & 1 & 72 & 6449 & 3444 & 2511 & 3471 & 2456 \\
\hline HI0019 & Erythrobacter & 880 & 3344147 & 3 & 1 & 1 & 41 & 3290 & 1672 & 1249 & 1658 & 1240 \\
\hline HI0020 & Erythrobacter & 275 & 3189298 & 4 & 1 & 1 & 45 & 3091 & 1580 & 1186 & 1565 & 1187 \\
\hline HI0021 & Oceanibulbus & 717 & 4462052 & 6 & 1 & 1 & 46 & 4403 & 2481 & 1542 & 2405 & 1575 \\
\hline HI0023 & Oceanibulbus & 652 & 4303630 & 3 & 1 & 1 & 46 & 4219 & 2377 & 1534 & 2308 & 1560 \\
\hline HI0027 & Oceanibulbus & 458 & 4441089 & 6 & 1 & 1 & 48 & 4343 & 2428 & 1542 & 2351 & 1575 \\
\hline HI0028 & Erythrobacter & 610 & 3308918 & 3 & 1 & 1 & 44 & 3239 & 1637 & 1234 & 1620 & 1230 \\
\hline HI0033 & Alcanivorax & 509 & 3659598 & 5 & 1 & 1 & 34 & 3355 & 1729 & 1379 & 1735 & 1358 \\
\hline HI0035 & Alcanivorax & 3128 & 6690527 & 7 & 2 & 2 & 68 & 6566 & 3471 & 2558 & 3486 & 2513 \\
\hline HI0037 & Erythrobacter & 2993 & 5769061 & 7 & 2 & 2 & 77 & 5795 & 3060 & 2036 & 3030 & 2039 \\
\hline HI0038 & Erythrobacter & 2004 & 4656539 & 5 & 1 & 2 & 70 & 4641 & 2405 & 1688 & 2383 & 1686 \\
\hline HI0040 & Oceanibulbus & 611 & 4181428 & 2 & 1 & 0 & 42 & 4079 & 2310 & 1475 & 2240 & 1505 \\
\hline HI0043 & Oleiphilus & 1975 & 5472755 & 10 & 2 & 2 & 49 & 4693 & 2396 & 1515 & 2378 & 1500 \\
\hline HIOO44 & Alcanivorax & 1990 & 5153888 & 7 & 2 & 1 & 7 & 5021 & 2572 & 2072 & 2599 & 2032 \\
\hline HI0049 & Roseovarius & 3470 & 7096493 & 4 & 2 & 0 & 45 & 7101 & 3883 & 2403 & 3822 & 2358 \\
\hline HI0050 & Oleiphilus & 2036 & 4819895 & 9 & 1 & 2 & 38 & 4043 & 2022 & 1286 & 2020 & 1269 \\
\hline HI0053 & Pseudoalteromonas & 2964 & 6718721 & 6 & 2 & 3 & 117 & 5484 & 2939 & 2055 & 2860 & 2039 \\
\hline HI0054 & Sulfitobacter & 555 & 4174729 & 6 & 1 & 1 & 47 & 4099 & 2304 & 1427 & 2217 & 1465 \\
\hline HI0061 & Oleiphilus & 1885 & 5095272 & 8 & 1 & 2 & 57 & 4352 & 2186 & 1439 & 2167 & 1433 \\
\hline HI0063 & Erythrobacter & 356 & 3258146 & 4 & 1 & 1 & 48 & 3059 & 1559 & 1126 & 1546 & 1132 \\
\hline HI0065 & Oleiphilus & 2693 & 6398614 & 10 & 2 & 2 & 67 & 5497 & 2868 & 1800 & 2880 & 1719 \\
\hline HI0066 & Oleiphilus & 1887 & 5044867 & 10 & 2 & 2 & 52 & 4447 & 2341 & 1428 & 2350 & 1370 \\
\hline HI0067 & Oleiphilus & 1752 & 4840075 & 9 & 2 & 2 & 53 & 4291 & 2245 & 1369 & 2246 & 1323 \\
\hline HI0068 & Oleiphilus & 2001 & 4842151 & 9 & 2 & 2 & 46 & 4173 & 2083 & 1338 & 2047 & 1348 \\
\hline HI0069 & Oleiphilus & 2238 & 5901752 & 10 & 2 & 2 & 57 & 5080 & 2540 & 1634 & 2517 & 1623 \\
\hline HI0071 & Oleiphilus & 2289 & 5698317 & 10 & 2 & 2 & 63 & 4940 & 2570 & 1620 & 2569 & 1568 \\
\hline HI0072 & Oleiphilus & 2192 & 4921543 & 7 & 2 & 1 & 38 & 4140 & 2087 & 1321 & 2069 & 1303 \\
\hline HI0073 & Oleiphilus & 2628 & 6103244 & 12 & 2 & 2 & 73 & 5230 & 2706 & 1736 & 2702 & 1676 \\
\hline HI0074 & Erythrobacter & 583 & 3148101 & 4 & 1 & 1 & 42 & 3112 & 1585 & 1151 & 1573 & 1146 \\
\hline HI0075 & Oceanobacter & 2573 & 6118559 & 9 & 2 & 2 & & 5706 & 2772 & 2367 & 2803 & 2306 \\
\hline HI0076 & Oceanibulbus & 875 & 4370296 & 5 & 1 & 1 & 46 & 4312 & 2423 & 1507 & 2358 & 1528 \\
\hline HI0077 & Erythrobacter & 592 & 3161113 & 5 & 1 & 1 & 45 & 3091 & 1568 & 1152 & 1556 & 1146 \\
\hline HI0078 & Oleiphilus & 2530 & 4431832 & 9 & 1 & 1 & 22 & 3679 & 1839 & 1163 & 1807 & 1166 \\
\hline HI0079 & Oleiphilus & 1448 & 4407017 & 9 & 2 & 2 & 43 & 3867 & 2011 & 1257 & 2009 & 1214 \\
\hline HI0080 & Oleiphilus & 1249 & 3938001 & 7 & 1 & 1 & 43 & 3439 & 1803 & 1143 & 1810 & 1101 \\
\hline HI0081 & Oleiphilus & 2463 & 4402732 & 9 & 2 & 1 & 30 & 3655 & 1839 & 1159 & 1837 & 1131 \\
\hline HI0082 & Oceanibulbus & 2310 & 5443144 & 8 & 2 & 1 & 68 & 5472 & 3165 & 1788 & 3065 & 1825 \\
\hline HI0083 & Alcanivorax & 1795 & 4446909 & 7 & 2 & 2 & 50 & 4404 & 2293 & 1811 & 2312 & 1782 \\
\hline HI0085 & Oleiphilus & 3230 & 4482542 & 8 & 1 & 1 & 40 & 3669 & 1831 & 1115 & 1824 & 1093 \\
\hline HI0086 & Oleiphilus & 1534 & 4753747 & 10 & 2 & 2 & 41 & 4080 & 2063 & 1351 & 2035 & 1349 \\
\hline HI0117 & Oleiphilus & 1521 & 4620570 & 9 & 2 & 2 & 37 & 3984 & 1959 & 1287 & 1947 & 1277 \\
\hline HI0118 & Oleiphilus & 2826 & 6560891 & 11 & 2 & 2 & 77 & 5687 & 2946 & 1819 & 2945 & 1754 \\
\hline HI0120 & Thalassolituus & 2071 & 5674715 & 11 & 2 & 2 & 73 & 4960 & 2430 & 1876 & 2422 & 1843 \\
\hline HI0122 & Oleiphilus & 2490 & 6039240 & 11 & 2 & 2 & 61 & 5133 & 2681 & 1677 & 2673 & 1623 \\
\hline HI0123 & Oleiphilus & 1909 & 4468126 & 8 & 2 & 1 & 41 & 3752 & 1846 & 1203 & 1829 & 1198 \\
\hline HI0125 & Oleiphilus & 1531 & 4553828 & 8 & 2 & 2 & 41 & 4033 & 2148 & 1286 & 2147 & 1247 \\
\hline HI0128 & Oleiphilus & 1636 & 4885910 & 7 & 1 & 1 & 46 & 4166 & 2114 & 1354 & 2128 & 1312 \\
\hline HI0129 & Oceanibulbus & 1145 & 4210493 & 3 & 1 & 1 & 36 & 4170 & 2358 & 1488 & 2285 & 1522 \\
\hline HI0130 & Oleiphilus & 2071 & 5196716 & 9 & 2 & 2 & 65 & 4544 & 2313 & 1455 & 2278 & 1433 \\
\hline HI0132 & Oleiphilus & 1901 & 5170237 & 8 & 2 & 1 & 48 & 4436 & 2215 & 1441 & 2195 & 1436 \\
\hline HI0133 & Oleiphilus & 2393 & 5728633 & 10 & 2 & 2 & 68 & 4947 & 2587 & 1604 & 2569 & 1556 \\
\hline${ }^{\mathrm{a}}$ Genus of most & realted sequence $b$ & n LAST & is against & VA 119 & & & & & & & & \\
\hline${ }^{\mathrm{b}}$ The contigs ann & d by PROKKA and th & nucleot & comprising & ose cor & & & & & & & & \\
\hline${ }^{\mathrm{C}} \mathrm{CDSs}$ matching & wn function & & & & & & & & & & & \\
\hline${ }^{d} \mathrm{CDSs}$ matching & othetical function & & & & & & & & & & & \\
\hline${ }^{\mathrm{e}}$ Assemblies for $\mathrm{v}$ & the raw reads of sev & tion- & no & es that & & & & & & & & \\
\hline
\end{tabular}


Table A6. One-way ANOVA comparisons of the mean number of CAZy-predicted genes for each CAZy class (AA, CBM, CE, GH, GT, and PL). Hawaii isolate phylot-ypes Oleiphilus 1, Oleiphilus 2, Alcanivorax, Erythrobacter 1, Erythrobacter 2, and Sulfitobacter/Oceanibulbus were compared.

\begin{tabular}{cccccc}
\hline & DF & Sum Square & Mean Square & F-value & P-value \\
\hline AA & 5 & 1561.8 & 312.36 & 16.49 & $4.54 \mathrm{E}-09$ \\
Residuals & 43 & 814.6 & 18.94 & & \\
CBM & 5 & 132.66 & 26.531 & 18.11 & $1.23 \mathrm{E}-09$ \\
Residuals & 43 & 62.98 & 1.465 & & \\
CE & 5 & 1200.7 & 240.14 & 11.69 & $3.62 \mathrm{E}-07$ \\
Residuals & 43 & 883.3 & 20.54 & & \\
GH & 5 & 761.9 & 152.39 & 17.66 & \\
Residuals & 43 & 371.1 & 8.63 & & $2.33 \mathrm{E}-11$ \\
GT & 5 & 8769 & 1754 & 23.69 & \\
Residuals & 43 & 3184 & 74 & & 0.318 \\
PL & 5 & 2.646 & 0.5293 & 1.217 & \\
Residuals & 43 & 18.701 & 0.4349 & & \\
\hline Abbreviations: DF, degrees of freedom; AA, auxilary activities; CBM, carbohydrate binding \\
modules; CE, carbohydrate esterases; GH, glycoside hydrolases; GT, glycosyl transferases; \\
\begin{tabular}{c} 
PL, plysaccharide lyases \\
\hline
\end{tabular}
\end{tabular}




(Opposite page)

Table A8. The predicted C-P lyase genes in Hawaii isolate genomes and their PROKKA CDS identification number. The phylogeny and isolate ID are indicated for each gene cluster. PROKKA CDSs are available under NCBI BioProject PRJNA305749. 


\begin{tabular}{|c|c|c|c|c|c|c|c|c|}
\hline Isolate ID & PROKKA CDS & C-P lyase gene & Isolate ID & PROKKA CDS & C-P lyase gene & Isolate ID & PROKKA CDS & C-P lyase gene \\
\hline \multicolumn{3}{|c|}{ Pseudomonas stutzeri } & \multicolumn{3}{|c|}{ Rhodobacteraceae } & \multicolumn{3}{|c|}{ Oceanospirillaceae } \\
\hline \multirow[t]{12}{*}{ HIOOD01 } & 874 & phnc & HI0021 & 574 & phnC & HI0009 & 4933 & phnC \\
\hline & 875 & phnD & & 573 & $p h n D$ & & 4932 & phnD \\
\hline & 876 & phnE & & 571 & phnE & & 4934 & phnE \\
\hline & 877 & phnF & & 572 & phnE & & 4931 & phnF \\
\hline & 878 & phnG & & 570 & phnF & & 4935 & phnG \\
\hline & 879 & phnH & & 569 & phnG & & 4936 & phnH \\
\hline & 880 & phnl & & 568 & phnH & & 4937 & phnl \\
\hline & 881 & phnJ & & 567 & phnl & & 4938 & phnJ \\
\hline & 882 & phnK & & 566 & phnJ & & 4939 & phnK \\
\hline & 883 & phnL & & 565 & phnK & & 4940 & phnL \\
\hline & 884 & phnM & & 564 & phnL & & 4941 & phnM \\
\hline & & & & 561 & phnM & & & \\
\hline \multicolumn{3}{|c|}{ Rhodobacteraceae } & & & & HI0066 & 2175 & phnc \\
\hline \multirow{15}{*}{ HI0049 } & & & HI0027 & 2282 & phnC & & 2176 & phnD \\
\hline & 5135 & phnc & & 2283 & $p h n D$ & & 2174 & phnE \\
\hline & 5136 & $p h n D$ & & 2284 & phnE & & 2177 & phnF \\
\hline & 5137 & phnE & & 2285 & phnE & & 2173 & phnG \\
\hline & 5138 & phnE & & 2286 & phnF & & 2172 & phnH \\
\hline & 3370 & phnF & & 2287 & phnG & & 2171 & phnl \\
\hline & 3371 & phnG & & 2288 & phnH & & 2170 & phnJ \\
\hline & 3372 & phnH & & 2289 & phnl & & 2169 & phnK \\
\hline & 3373 & phnl & & 2290 & phns & & 2168 & phnL \\
\hline & 3375 & phnJ & & 2291 & phnK & & 2167 & phnM \\
\hline & 3376 & phnK & & 2292 & phnL & & & \\
\hline & 4894 & phnL & & 2295 & phnM & HI0067 & 2616 & phnc \\
\hline & 5140 & phnM & & & & & 2617 & phnE \\
\hline & 4891 & phnM & HI0076 & 3373 & phnc & & 2618 & phnG \\
\hline & & & & 3374 & $p h n D$ & & 2619 & phnH \\
\hline \multirow[t]{23}{*}{ HI0054 } & 442 & phnc & & 3375 & phnE & & 2620 & phnl \\
\hline & 441 & PhnD & & 3376 & phnE & & 2621 & phnJ \\
\hline & 439 & PhnE & & 3377 & phnF & & 2622 & phnK \\
\hline & 440 & phnE & & 3378 & phnG & & 2623 & phnL \\
\hline & 437 & phnF & & 3379 & phnH & & 2624 & phnM \\
\hline & 436 & phnG & & 3380 & phnl & & & \\
\hline & 435 & phnH & & 3381 & phnJ & HI0125 & 1618 & phnc \\
\hline & 434 & phnl & & 3382 & phnK & & 1619 & $p h n D$ \\
\hline & 433 & phnJ & & 3383 & phnL & & 1617 & phnE \\
\hline & 432 & phnK & & 3386 & phnM & & 1620 & phnF \\
\hline & 431 & phnL & & & & & 616 & phnG \\
\hline & 428 & phnM & HI0082 & 428 & phnc & & 1616 & phnG \\
\hline & & & & 429 & $p h n D$ & & 617 & phnH \\
\hline & & & & 430 & phnE & & 618 & phnl \\
\hline & & & & 431 & phnE & & 619 & phnJ \\
\hline & & & & 432 & phnF & & 3860 & phnK \\
\hline & & & & 433 & phnG & & 3861 & phnL \\
\hline & & & & 434 & phnH & & 3862 & phnM \\
\hline & & & & 435 & phnl & & & \\
\hline & & & & 436 & phnJ & & & \\
\hline & & & & 437 & phnK & & & \\
\hline & & & & 438 & phnL & & & \\
\hline & & & & 441 & phnM & & & \\
\hline
\end{tabular}


(Opposite page)

Table A9. SSU rRNA genes of 59 Hawaii isolates and coastal isolate NB0015 identitied in PROKKA draft genome assemblies. Sequences are available in the draft genome assemblies deposited in NCBI as BioProject PRJNA305749. The draft assemblies contained one or two copies of the SSU rRNA gene and belonged to the same phylogenetic group. 


\begin{tabular}{|c|c|c|c|c|c|}
\hline Isolate ID & PROKKA ID & Length (bps) & Isolate ID & PROKKA ID & Length (bps) \\
\hline$N B 0015^{a}$ & 763 & 1506 & HI0068 & 4113 & 1379 \\
\hline HIOOS01-18 & 4326 & 1492 & HI0069 & 5063 & 1530 \\
\hline HIOOD01-58 & 4617 & 1533 & HI0069 & 5123 & 1530 \\
\hline HIOOD59-64 & 3259 & 1481 & HI0071 & 4986 & 1530 \\
\hline HI00D65-71 & 4734 & 1545 & HI0071 & 4994 & 1515 \\
\hline HI00D65-71 & 4752 & 1551 & HI0072 & 4043 & 1530 \\
\hline HI0003 & 3376 & 1537 & HI0072 & 4172 & 1239 \\
\hline HI0007 & 3348 & 1537 & HI0073 & 5290 & 1530 \\
\hline HI0009 & 5772 & 1530 & HI0073 & 5291 & 1530 \\
\hline HI0009 & 5788 & 1530 & HI0074 & 3138 & 1486 \\
\hline HI0011 & 5370 & 1537 & HI0075 & 5700 & 1529 \\
\hline HI0013 & 6467 & 1537 & HI0075 & 5707 & 1340 \\
\hline HI0013 & 6518 & 1405 & HI0076 & 4259 & 1461 \\
\hline HI0019 & 3309 & 1486 & HI0077 & 3117 & 1486 \\
\hline HI0020 & 3121 & 1484 & HI0078 & 3567 & 1530 \\
\hline HI0021 & 4354 & 1461 & HI0079 & 3841 & 1530 \\
\hline HI0023 & 2280 & 1457 & HI0079 & 3850 & 1530 \\
\hline $\mathrm{HI0027}$ & 4296 & 1461 & HI0080 & 3472 & 1530 \\
\hline HI0028 & 3264 & 1486 & HI0081 & 3547 & 1530 \\
\hline HI0033 & 3383 & 1537 & HI0081 & 3558 & 1024 \\
\hline HI0035 & 6594 & 1537 & HI0082 & 5253 & 1461 \\
\hline HI0035 & 6629 & 1537 & HI0082 & 5469 & 1461 \\
\hline HI0037 & 5825 & 1484 & HI0085 & 3515 & 1530 \\
\hline HI0037 & 5839 & 1484 & HI0086 & 4018 & 1530 \\
\hline HI0038 & 4638 & 1484 & HI0086 & 4124 & 1530 \\
\hline HI0040 & 1485 & 1457 & HI0117 & 3928 & 1530 \\
\hline HI0043 & 4662 & 1530 & HI0117 & 4019 & 1495 \\
\hline HI0043 & 4737 & 1530 & HI0118 & 5741 & 1530 \\
\hline HI0044 & 4931 & 1537 & HI0118 & 5750 & 1530 \\
\hline HI0044 & 5064 & 1537 & HI0120 & 5003 & 1535 \\
\hline HI0049 & 1640 & 1329 & HI0120 & 5004 & 1535 \\
\hline HI0049 & 6443 & 1379 & HI0122 & 5178 & 1530 \\
\hline HI0050 & 3958 & 1530 & HI0122 & 5188 & 1530 \\
\hline HI0053 & 5419 & 1538 & HI0123 & 3677 & 1530 \\
\hline HI0053 & 5431 & 1538 & HI0123 & 3794 & 1463 \\
\hline HI0054 & 4070 & 1459 & HI0125 & 4036 & 1530 \\
\hline HI0061 & 4312 & 1530 & HI0125 & 4043 & 1530 \\
\hline HI0063 & 972 & 1063 & HI0128 & 4137 & 1530 \\
\hline HI0065 & 5547 & 1530 & HI0129 & 3432 & 1295 \\
\hline HI0065 & 5555 & 1530 & HI0130 & 4507 & 1530 \\
\hline HI0066 & 4459 & 1530 & HI0130 & 4542 & 1530 \\
\hline HI0066 & 4460 & 1467 & HI0132 & 4394 & 1530 \\
\hline HI0067 & 4307 & 1530 & HI0132 & 4476 & 1125 \\
\hline HI0067 & 4350 & 1530 & HI0133 & 4995 & 1530 \\
\hline HI0068 & 4099 & 1530 & HI0133 & 5001 & 1530 \\
\hline
\end{tabular}




\section{(Opposite page)}

Figure A1. SSU rRNA gene phylogeny of Hawaii open-ocean isolates belonging to the Gammaproteobacteria orders Oceanospirillales and Cellvibrionales. Nodes with $>70 \%$ agreement (1000 replicates) are shown. The scale bar indicates substitutions per site. Marked in green are sequences identified from Experiment I samples and in green, sequences from Experiment II. ${ }^{\mathrm{a}}$ Grouping of HI0065 and 14 closely related sequences. ${ }^{\mathrm{b}}$ Grouping of HI0043 and 17 closely related sequences. ${ }^{\mathrm{c}}$ Grouping of $\mathrm{HI} 0003$ and 5 closely related sequences from the DCM. ${ }^{\mathrm{d}}$ Grouping of 41 P. stutzeri sequences. 


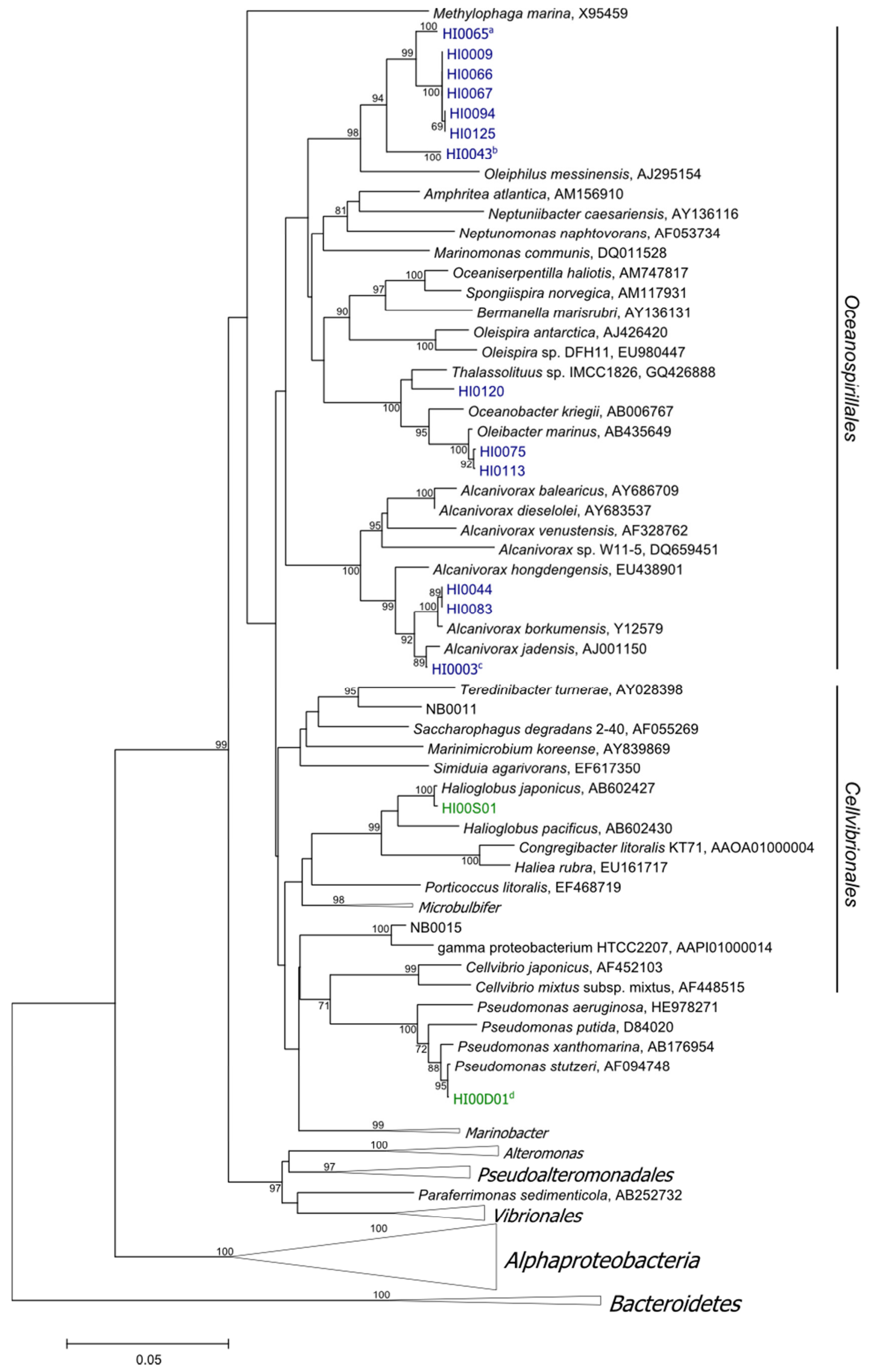




\section{(Opposite page)}

Figure A2. The SSU rRNA gene phylogeny of Hawaii open-ocean isolates belonging to the Alphaproteobacteria orders Rhodobacterales and Sphingomonadales. Nodes with $>70 \%$ agreement (1000 replicates) are shown. The scale bar indicates substitutions per site. Only sequences $>1400$ bps long were included. Marked in green are sequences identified from Experiment I samples and in green, sequences from Experiment II. 


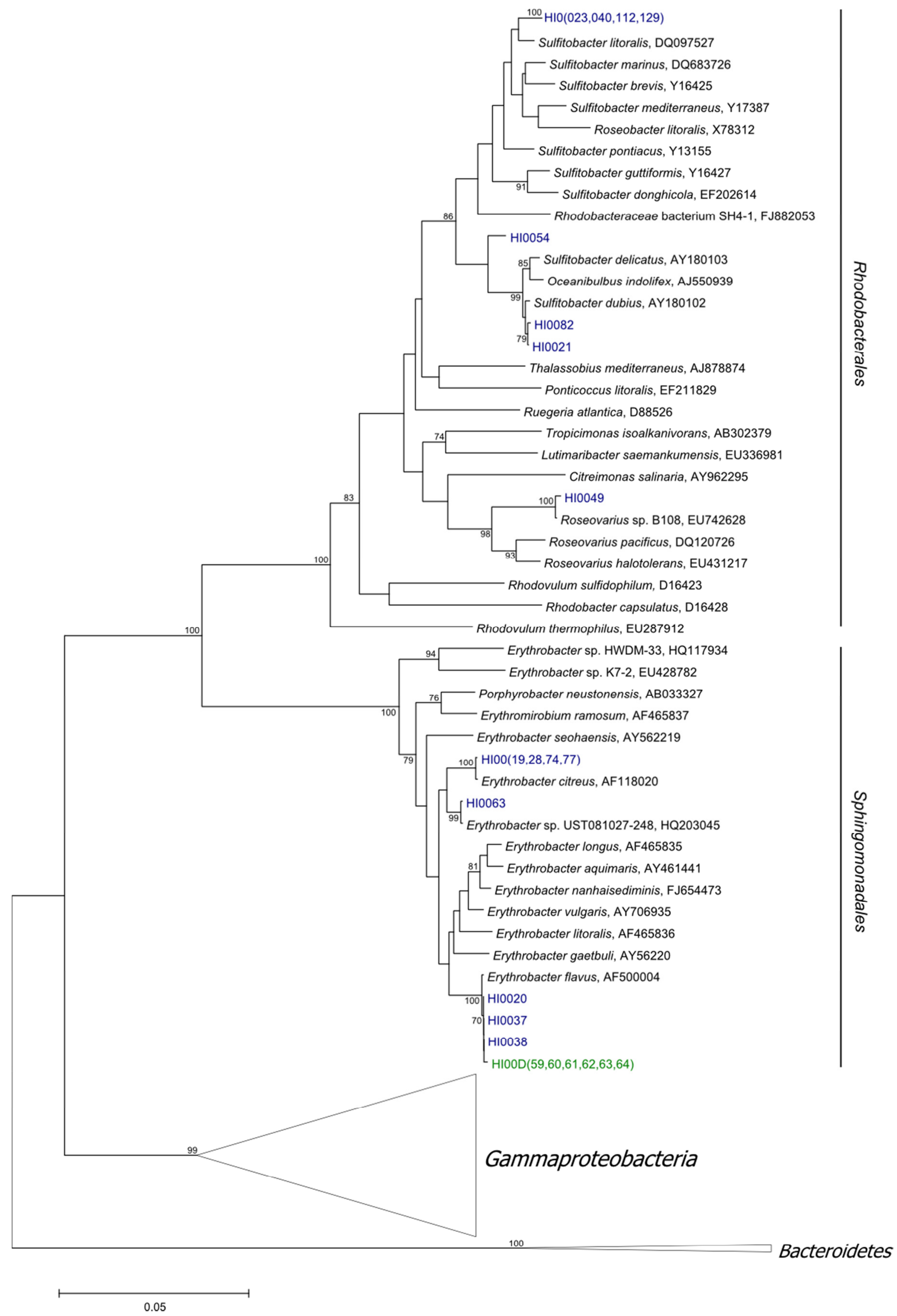




\section{APPENDIX II}

This section describes the defined media formulation for growth of Pseudomonas stutzeri HI00D01 (Table A1).

Table A1. MOPS minimal formulations (http://www.teknova.com/category-s/519.htm) used for the growth of $P$. stutzeri strain H00D01.

\begin{tabular}{|l|c|c|}
\hline M2101 MOPS Modified Rich Buffer & $\begin{array}{c}\text { 10X } \\
\text { Concentration }\end{array}$ & $\begin{array}{c}\text { M2105/M2106 } \\
\text { 1X Concntration }\end{array}$ \\
\hline MOPS (MW 209.3) & $400 \mathrm{mM}$ & $40 \mathrm{mM}$ \\
\hline Tricine (MW 179.2) & $40 \mathrm{mM}$ & $4.0 \mathrm{mM}$ \\
\hline Iron Sulfate Stock & $0.1 \mathrm{mM}$ & $0.01 \mathrm{mM}$ \\
\hline Ammonium Chloride & $95 \mathrm{mM}$ & $9.5 \mathrm{mM}$ \\
\hline Potassium Sulfate & $2.76 \mathrm{mM}$ & $0.276 \mathrm{mM}$ \\
\hline Calcium Chloride & $0.005 \mathrm{mM}$ & $0.0005 \mathrm{mM}$ \\
\hline Magnesium Chloride & $5.25 \mathrm{mM}$ & $0.525 \mathrm{mM}$ \\
\hline Sodium Chloride & $500 \mathrm{mM}$ & $50 \mathrm{mM}$ \\
\hline Ammonium Molybdate & $3 \times 10^{\wedge}-8 \mathrm{M}$ & $3 \times 10^{\wedge}-9 \mathrm{M}$ \\
\hline Boric Acid & $4 \times 10^{\wedge}-6 \mathrm{M}$ & $4 \times 10^{\wedge}-7 \mathrm{M}$ \\
\hline Cobalt Chloride & $3 \times 10^{\wedge}-7 \mathrm{M}$ & $3 \times 10^{\wedge}-8 \mathrm{M}$ \\
\hline Cupric Sulfate & $10^{\wedge}-7 \mathrm{M}$ & $10^{\wedge}-8 \mathrm{M}$ \\
\hline Manganese Chloride & $8 \times 10^{\wedge}-7 \mathrm{M}$ & $8 \times 10-8 \mathrm{M}$ \\
\hline Zinc Sulfate & $10^{\wedge}-7 \mathrm{M}$ & $10^{\wedge}-8 \mathrm{M}$ \\
\hline
\end{tabular}

